\title{
Optimization of Infill Drilling in Naturally-Fractured Tight-Gas Reservoirs Phase II
}

\author{
Final Report
}

Lawrence W. Teufel, Her-Yuan Chen, Thomas W. Engler, and Bruce Hart

May 2004

U.S. Department of Energy and Industry Cooperative Agreement DE-FC26-98FT40486

New Mexico Institute of Mining and Technology

Socorro, NM 87801

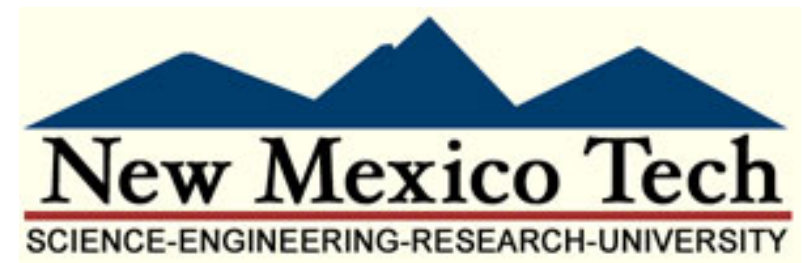




\section{DISCLAMER}

This report was prepared as an account of work sponsored by an agency of the United States Government. Neither the United States Government nor any agency thereof, nor any of their employees, makes any warranty, express or implied, or assumes any legal liability or responsibility for the accuracy, completeness, or usefulness of any information, apparatus, product, or process disclosed, or represents that its use would not infringe privately owned rights. References herein to any specific commercial product, process, or service by trade name, trademark, manufacturer, or otherwise does not necessarily constitute or imply its endorsement, recommendation, or favoring by the United States Government or any agency thereof. The views and opinions of the authors expressed herein do not necessarily state or reflect those of the United States Government or any agency thereof. 


\begin{abstract}
A major goal of industry and the U.S. Department of Energy (DOE) fossil energy program is to increase gas reserves in tight-gas reservoirs. Infill drilling and hydraulic fracture stimulation in these reservoirs are important reservoir management strategies to increase production and reserves. Phase II of this DOE/cooperative industry project focused on optimization of infill drilling and evaluation of hydraulic fracturing in naturally-fractured tight-gas reservoirs. The cooperative project involved multidisciplinary reservoir characterization and simulation studies to determine infill well potential in the Mesaverde and Dakota sandstone formations at selected areas in the San Juan Basin of northwestern New Mexico. This work used the methodology and approach developed in Phase I. Integrated reservoir description and hydraulic fracture treatment analyses were also conducted in the Pecos Slope Abo tight-gas reservoir in southeastern New Mexico and the Lewis Shale in the San Juan Basin. This study has demonstrated a methodology to (1) describe reservoir heterogeneities and natural fracture systems, (2) determine reservoir permeability and permeability anisotropy, (3) define the elliptical drainage area and recoverable gas for existing wells, (4) determine the optimal location and number of new in-fill wells to maximize economic recovery, (5) forecast the increase in total cumulative gas production from infill drilling, and (6) evaluate hydraulic fracture simulation treatments and their impact on well drainage area and infill well potential. Industry partners during the course of this five-year project included BP, Burlington Resources, ConocoPhillips, and Williams.
\end{abstract}




\section{TABLE OF CONTENTS}

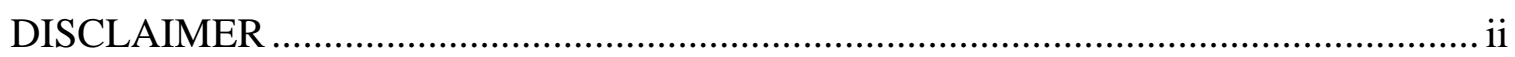

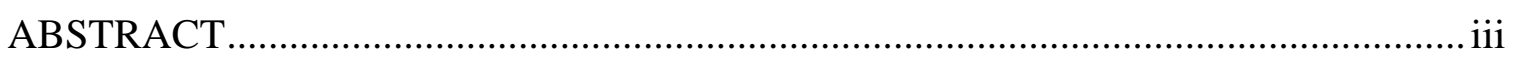

TABLE OF CONTENTS ............................................................................................ iv

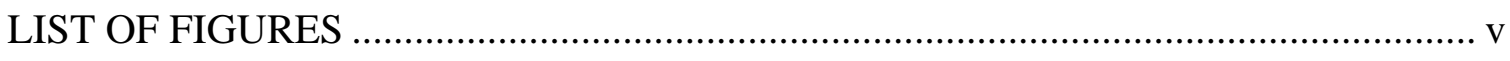

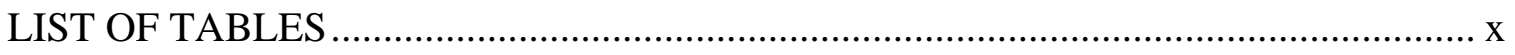

EXECUTIVE SUMMARY …………………………..........................................

CHAPTER 1

Introduction and Overview ............................................................................... 1

\section{CHAPTER 2}

3-D Seismic-Based Geoscience Characterization of Dakota Formation, Mesaverde Group, and Fruitland Coal, San Juan Basin, New Mexico................... 18

\section{CHAPTER 3}

Evaluation of the Infill Well Potential of the Blanco Mesaverde Rosa

Unit in the San Juan Basin, New Mexico

\section{CHAPTER 4}

Simulation Study of the Feasibility of 80-Acre Infill Well Development in the Dakota Formation, Culpepper Martin Unit

\section{CHAPTER 5}

Evaluation of Fracture Stimulation Treatments in Tight-Gas Reservoirs with Application to Infill Drilling Potential

\section{CHAPTER 6}

Analytical and Numerical Procedures and Tools Developed for Production and Well Testing Analysis of Tight-Gas Reservoirs

CHAPTER 7

Technology Transfer and Industry Impact. 


\section{LIST OF FIGURES}

Figure 1.1. Shape of drainage area for isotropic and anisotropic permeability

(from Harstad, 1998)

Figure 1.2. Rotation of well alignment (from Harstad, 1998)

Figure 1.3. New infill well relative to elongated drainage from an existing well

(from Harstad, 1998)

Figure 1.4. Plot showing initial shut-in pressure versus angular deviation from north

of new well alignment relative to an existing well (from Harstad, 1998).

Figure 1.5. Comparison of cumulative gas production forecasts for infill wells

(from Al-Hadrami, 2000)

Figure 1.6. Comparison of cumulative gas production forecasts

(from Al-Hadrami, 2000)

Figure 1.7. Comparison of infill drilling cases with the base case in the west area (from Medford, 2000).

Figure 2.1. Map showing database for Dakota sub-project. Colored background shows time-structure (TWT) of Dakota top from 3-D seismic data

Figure 2.2. Location of Rosa study area (lower left) and 3-D seismic and log database for the Fruitland sub-project

Figure 2.3. Strike curvature of the Dakota Formation calculated with an aperture of 3 .. 45

Figure 2.4. NW (left) to SE (right) log cross-section through the Dakota Formation in the Rosa 3-D seismic study area

Figure 2.5. Validation error (red curve) and prediction error (black curve) against the number of attributes used in the stepwise linear regression

Figure 2.6. Top - predicted versus measured net sand using the multivariate linear regression technique (correlation coefficient $=0.88$ ).

Figure 2.7. Top - predicted versus measured net sand using the probabilistic neural network technique (correlation coefficient $=0.86$ )

Figure 2.8. Top - predicted versus measured net sand using the multi-layer feedforward neural network technique (correlation coefficient $=0.89$ ) 
Figure 2.9. Comparison of MLR (upper left), PNN (lower right) and MLFN

(upper right) predictions of net sand

Figure 2.10. Log-based prediction of net sand thickness for the upper parasequence

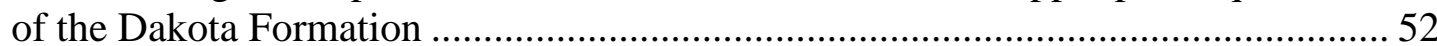

Figure 2.11. Seismic facies classification of reflection corresponding to the top of the Dakota Formation

Figure 2.12. Comparison of seismic facies analysis (left) with seismic attribute analysis (right)

Figure 2.13. Wireline log cross-section (gamma ray on left, density log on right) showing stratigraphic units studied in this report .............................................. 55

Figure 2.14. Thickness of basal coal layer based on kriging of well log data ................. 56

Figure 2.15. Log-based seismic model showing expected character of principal

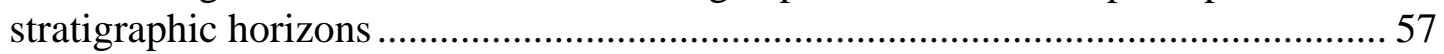

Figure 2.16. Sample seismic transect showing picks............................................ 58

Figure 2.17. Validation (top) and prediction (below) error ......................................... 59

Figure 2.18. Predicted versus measured thickness for lower coal layer at well locations 60

Figure 2.19. Seismic attribute-based prediction of coal thickness

Figure 2.20. Depth-converted structure map of the top of the thick coal layer

(TopTC seismic horizon)

Figure 2.21. Maximum curvature map of the TopTC seismic pick.............................. 63

Figure 2.22. Strike curvature map of the TopTC seismic horizon................................. 64

Figure 2.23. Dip curvature map of the TopTC seismic horizon .................................. 65

Figure 2.24. Synthetic traces and corresponding wedge model................................... 66

Figure 2.25. Crossplots of the (a) maximum absolute amplitude, (b) integrated trace, and (c) total energy against wedge thickness or coal seam thickness.

Figure 2.26. 3-D crossplots of thickness versus maximum absolute amplitude and combination of inverse transform attributes 
Figure 2.27. Bubble plot of cumulative production normalized by number of years of production and curvature lineaments superimposed over predicted thickness map

Figure 2.28. Sample logs (gamma ray and caliper on left, density on right) through parts of the Dakota Formation from the Phase I (right) and Phase II (left) study areas

Figure 2.29. Two wells net (colors) and gross (contours) thickness and cumulative gas production (bubbles)

Figure 2.30. Schematic illustration of fracture swarms associated with subtle structural features, in this case a flexure

Figure 2.31. Part of the Curvz website

Figure 2.32. Location of two "sweet-spot" wells (i.e., cumulative production 10 BCF greater than neighboring wells) along a structural feature (small graben, green in top image) defined by strike curvature.

Figure 2.33. Schematic representation of the effect of changing the aperture over which curvature attributes is derived

Figure 2.34. Schematic representation of map showing geological controls on fracture density 76

Figure 2.35. Schematic representation of an infill-drilling situation in a tight-gas reservoir.....

Figure 3.1. Location of Rosa Unit relative to Blanco Mesaverde Pool limits.....

Figure 3.2. Gamma Ray, Porosity and Resistivity readings vs CDF for Cliffhouse, Menefee and Point Lookout in Well No. 9A

Figure 3.3. GR, Resistivity, and Porosity logs for Well 9A 88

Figure 3.4. CDF of normalized gamma ray for Cliffhouse.

Figure 3.5. CDF of normalized gamma ray for Menefee 90

Figure 3.6. CDF of normalized gamma ray for Point Lookout 91

Figure 3.7. Porosity log availability in study area. (blue squares - density logs only, green circles - density/neutron logs, red circles - no porosity logs.

Figure 3.8. EUR and PF trends for the four groups identified. 100 
Figure 3.9. Relative bubble map of productivity factor, PF 101

Figure 3.10. Relative bubble map of flow capacity, kf..... 101

Figure 3.11. Relative bubble map of initial gas in place, IGIP.

Figure 3.12. Relative bubble map of estimate ultimate recovery, EUR 102

Figure 3.13. Relative bubble map of drainage area, A) net-to-gross thickness ratio $=1, \mathrm{~B}$ ) net-to-gross thickness ratio $=0.75$.

Figure 3.14. Relative bubble map of drainage area, A) net-to-gross thickness ratio $=0.50, \mathrm{~B}$ ) net-to-gross thickness ratio $=0.25$.

Figure 3.15. Well location map of Section 14 of the Rosa Unit. (Infill 80-acre wells are denoted by large circles)

Figure 3.16. Anisotropy ratio predicted by the IWLC for different orientations of maximum permeability

Figure 3.17. Pressure difference ( $\left.\mathrm{P}_{\text {measured }}-\mathrm{P}_{\text {predicted }}\right)$ for different orientations of permeability anisotropy....

Figure 3.18. Locations of wells that were used to build the reservoir model.

Figure 3.19. Isopach map of the Point Lookout net thickness for the 9-section simulation area

Figure 3.20. Pressure distribution map (a) prior to infill well development and (b) after 10 years of forecasting. (Isotropic case)

Figure 3.21. Pressure distribution map (a) prior to infill well development and (b) after 10 years of forecasting. (Anisotropic case)

Figure 3.22. Comparison of 10 -year total cumulative production forecast of all 8 wells in Section 14 between the actual drilled infill well locations and the proposed new infill well locations

Figure 4.1. Formation layer grid structure for simulation 119

Figure 4.2. Top of Dakota Formation 120

Figure 5.1. Histogram of the fluid types used for Lewis Shale only completions. 131

Figure 5.2. Histogram of the number of stages used for Lewis Shale only completions 
Figure 5.3. Histogram of the proppant volumes used for Lewis Shale only completions

Figure 5.4. Histogram of the gross perforation thickness used for Lewis Shale only completions

Figure 5.5. Cross-sectional and map views of a hypothetical Lewis Shale well and natural fracture network showing the reservoir (a) before stimulation, (b) after stimulation, and (c) after cleanup (maximum permeability direction, maximum stress direction and compass shown on map view)

Figure 5.6. Sample well showing Lewis Shale only production 134

Figure 5.7. Sample well showing Mesaverde Group and commingled production

Figure 5.8. Sample well showing Mesaverde Group, Lewis Shale only, and commingled production

Figure 5.9. Average difference in incremental production for wells with similar stimulations within a given radius

Figure 5.10a. Incremental production range for various fluids including failed and unusually productive wells (tick marks indicate mean production)

Figure 5.10b. Incremental production values for various fluids including failed and unusually productive wells (ellipses show discarded values; numbers on x-axis correspond to fluid types in figure 5.10a)

Figure 5.11. Incremental production range for various fluids excluding rejected wells (tick marks indicate mean production; values indicate number of wells) ..... 138

Figure 5.12. Incremental production range for various proppant volumes excluding rejected wells (tick marks indicate mean production; values indicate number of wells; curve shows apparent trend)

Figure 5.13. Incremental production range for various number of stages excluding rejected wells (tick marks indicate mean production; values indicate number of wells)

Figure 5.14. Incremental production range for various gross perforation thicknesses excluding rejected wells (tick marks indicate mean production; values indicate number of wells; line shows apparent trend) 


\section{LIST OF TABLES}

Table 2.1. Log picks and derived thickness and net sand for the Dakota Formation ...... 41

Table 2.2. Spearman's rank correlation coefficient between seismic amplitude

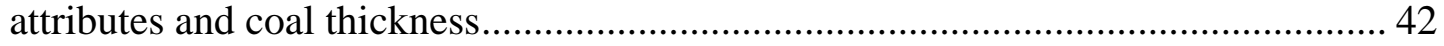

Table 3.1. Vshale cut off and net thickness for each formation and well........................ 84 1

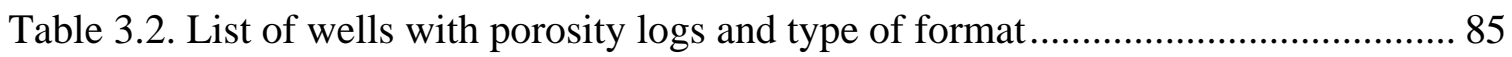

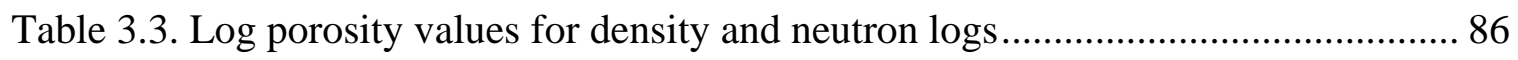

Table 3.4. Input data for analysis of individual well gas production data ...................... 97

Table 3.5 Main properties from example wells .................................................... 98

Table 3.6 Average productivity and flow per-well characteristics, San Juan Basin,

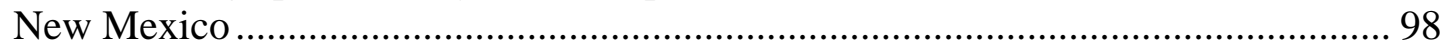

Table 3.7. Average drainage per-well characteristics, San Juan Basin, New Mexico...... 99

Table 3.8. Total values, Rosa Unit, San Juan Basin, New Mexico ................................ 99

Table 3.9. Output permeability ratio utilized by the IWLC for different orientations

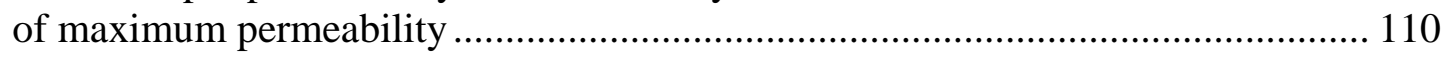

Table 3.10. Measured shut-in pressure for the infill well at actual drilled location, and the predicted reservoir pressure by the IWLC at the same location, including the difference between these for different orientation of maximum permeability for infill well 20C.

Table 3.11. Measured shut-in pressure for the infill well at actual drilled location, and the predicted reservoir pressure by the IWLC at the same location, including the difference between these for different orientation of maximum permeability for infill wells $16 \mathrm{C}$ and 20B

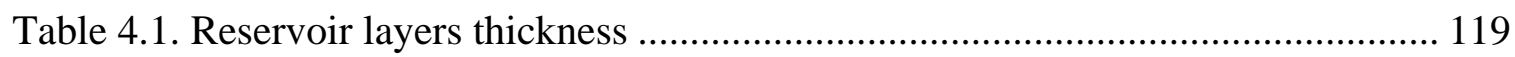

Table 4.2. Comparison of reservoir input data for both models ................................ 121 


\section{EXECUTIVE SUMMARY}

Natural fractures are important in the economical production of low-permeability (tight) gas reservoirs throughout the Rocky Mountain region. Previous studies have shown that fractures not only enhance the overall permeability of these reservoirs, they can also create significant permeability anisotropy. Permeability anisotropy causes the drainage area around the wells to be elliptical. Elongated drainage can create more production interference and drainage overlap between adjacent wells and may leave large areas of the reservoir undrained. Evaluation of infill well potential in these reservoirs requires knowledge of the magnitude and orientation of reservoir permeability anisotropy to determine the optimal number and location of new wells and assess their impact on drainage efficiency.

A major goal of industry and the U.S. Department of Energy (DOE) fossil energy program is to increase gas reserves in tight-gas reservoirs. Infill drilling and hydraulic fracture stimulation in these reservoirs are important reservoir management strategies to increase production and reserves. Phase II of this DOE/cooperative industry project focused on optimization of infill drilling and evaluation of hydraulic fracturing in naturally-fractured tight-gas reservoirs. The cooperative project involved multidisciplinary reservoir characterization and simulation studies to determine infill well potential in the Mesaverde and Dakota sandstone formations at selected areas in the San Juan Basin of northwestern New Mexico. This work used the methodology and approach developed in Phase I. Integrated reservoir description and hydraulic fracture treatment analyses were also conducted in the Pecos Slope Abo tight-gas reservoir in southeastern New Mexico and the Lewis Shale in the San Juan Basin. Industry partners during the course of this five-year project included BP, Burlington Resources, ConocoPhillips, and Williams.

Phase I reservoir studies on the Mesaverde examined the infill well potential in two areas of low and moderate well/reservoir productivity that were near the northwest-southeast trending fairway of high productivity. The 30-year production forecast of the reservoir models predicted a total net increase in recoverable gas for the two pilot areas of 26 percent and 44 percent over the predicted gas recovery of existing wells on 160-acre spacing. The largest potential increase in recoverable gas was in the area with lower well/reservoir productivity. In Phase II, these studies were extended to two new areas: (1) an area of high reservoir permeability and well/reservoir productivity in the fairway and (2) the Mesaverde Rosa Unit, which is an area of very low well/reservoir productivity on the northeast margin of the basin. In contrast to the two pilot areas with much lower equivalent permeability, the area of high permeability has the potential of widespread drainage to occur. Existing wells exhibit an average drainage of about 160 acres and only limited infill drilling was identified on the drainage maps. Simulation results estimate that the potential recovery for 80 -acre infill wells at selected locations is $800 \mathrm{MMscf} /$ well. This study demonstrated that although limited infill drilling exists, proper evaluation methods might be useful in identifying the best locations. In the Rosa Unit, the well production history and lack of any reported measured pressure interference 
between wells indicates little or no influence of natural fractures on reservoir permeability or permeability anisotropy. The potential for 80 -acre infill drilling exists, but limited knowledge of permeability and the distribution of permeability within the modeled area increase the uncertainty in the evaluation of infill well locations and the quality of the production forecasts in this simulation study. Reservoir studies of the four study areas have significantly different well/reservoir productivity, and demonstrate the range of importance that natural fractures and the associated reservoir permeability and permeability anisotropy have on drainage efficiency and infill well potential.

The Dakota Formation infill well study in Phase I focused on two selected areas in northwestern portion of the basin. The infill well potential in these two areas is significantly different. The east area, defined as a shore parallel facies, has no potential for further drilling. Inversely, the west area is a channel-type deposit with significant potential for infill drilling. Optimization of infill drilling in the Dakota relies upon two inter-related features: (1) the degree of natural fracturing and (2) the depositional facies. In Phase II, the Dakota Formation study was extended to an 80-acre well spacing pilot area in the Culpepper Martin Unit. This unit is located in the northeastern part of the basin. A single phase, multilayer simulation model was constructed. The model was rateconstrained, using the output flowing pressures from the simulator as the matching variable to the limited, observed flowing pressure data set. Preliminary simulation cases resulted in excellent rate matches, but with inconsistent flowing pressure matches. Investigations revealed significant GIP difference between various models and is suspected to be the primary reason for the difficulty in obtaining pressure matches. This conclusion emphasizes the importance of proper reservoir characterization in lowpermeability, naturally-fractured reservoirs.

Vertical wells in tight gas reservoirs are always stimulated to increase production. Hydraulic fracturing is the most common stimulation treatment. In Phase II, evaluation of fracture stimulation treatments and their impact on infill drilling was accomplished by integrated reservoir description and fracture treatment analysis in the Pecos Slope Abo tight-gas reservoir in southeastern New Mexico and the Lewis Shale in the San Juan Basin. The integration of decline curve analysis and fracture analysis in the Abo Formation provides better descriptions of reservoir properties and more accurate designs of fracture propagation models. The combined approached also improves evaluation of infill drilling potential by evaluating reservoir properties and stimulation. The Lewis Shale study summarizes relevant geological and engineering data, analyzes current stimulation procedures, and makes recommendations for improving the efficiency of hydraulic fractures.

In Phase II, new analytical and numerical procedures and tools were also developed for production and well testing analysis of tight-gas reservoirs and applied to the field studies. These procedures and tools address issues related to estimation of reservoir production/flow characteristics, determination of reservoir permeability anisotropy and well interference, delineation of the drainage volume/area, and evaluation of infill well potential. 


\title{
CHAPTER 1
}

\section{Introduction and Overview}

\author{
Lawrence W. Teufel \\ Petroleum and Natural Gas Engineering Department \\ New Mexico Institute of Mining and Technology \\ Socorro, New Mexico
}

\section{Introduction}

Natural fractures are important in the economical production of low-permeability (tight) gas reservoirs throughout the Rocky Mountain region. Fractures not only enhance the overall permeability of these reservoirs, they can also create significant permeability anisotropy. Permeability anisotropy causes the drainage area around the wells to be elliptical. Elongated drainage can create more production interference and drainage overlap between adjacent wells and may leave large areas of the reservoir undrained. Evaluation of infill well potential in these reservoirs requires knowledge of the magnitude and orientation of reservoir permeability anisotropy to determine the optimal number and location of new wells and assess their impact on drainage efficiency.

A major goal of industry and the U.S. Department of Energy (DOE) fossil energy program is to increase gas reserves in tight-gas reservoirs. Infill drilling and hydraulic fracture stimulation in these reservoirs are important reservoir management strategies to increase production and reserves. Phase II of this DOE/cooperative industry project focused on optimization of infill drilling and evaluation of hydraulic fracturing in naturally-fractured tight-gas reservoirs. The cooperative project involved multidisciplinary reservoir characterization and simulation studies of the Mesaverde and Dakota sandstone formations in selected areas of the San Juan Basin in northwestern New Mexico. These studies have (1) described reservoir heterogeneities and natural fracture systems, (2) determined reservoir permeability and permeability anisotropy, (3) defined the elliptical drainage area and recoverable gas for existing wells, (4) determined the optimal location and number of new in-fill wells to maximize economic recovery, (5) forecasted the increase in total cumulative gas production from infill drilling, and (6) evaluated hydraulic fracture simulation treatments and their impact on well drainage area and infill well potential. Industry partners during the course of this five-year project included BP, Burlington Resources, ConocoPhillips, and Williams.

This chapter will first briefly review the results of Phase I and summarize the results of the Phase II study. Methodology and approach used to characterize and analyze reservoir performance and evaluate infill-drilling potential in Phase I was applied to new areas in the San Juan Basin for the Mesaverde Group and Dakota Formation.

Phase I reservoir studies on the Mesaverde examined the infill well potential in two areas of low and moderate well/reservoir productivity that were near the northwest-southeast 
trending fairway of high productivity. In Phase II, these studies were extended to two new areas: (1) an area of high well/reservoir productivity in the fairway and (2) the Mesaverde Rosa unit, which is an area of very low well/reservoir productivity on the northeast margin of the basin. Reservoir studies of the four study areas have significantly different well/reservoir productivity, and demonstrate the range of importance that natural fractures and the associated reservoir permeability and permeability anisotropy have on drainage efficiency and infill well potential.

The Dakota formation study in Phase I was extended to an 80-acre well spacing pilot area in the Culpepper Martin Unit. This unit is located in the northeastern part of the basin. To enhance the productivity of this unit, three infill well locations were drilled on 80 -acre well spacing as a pilot test to determine the feasibility to infill drill. Previous methodologies, such as decline curve analysis and integrated simulation were utilized in this study.

Vertical wells in tight gas reservoirs are always stimulated to increase production. Hydraulic fracturing is the most common stimulation treatment. In Phase II, evaluation of fracture stimulation treatments and their impact on infill drilling was accomplished by integrated reservoir description and fracture treatment analysis in the Pecos Slope Abo tight-gas reservoir in southeastern New Mexico and the Lewis Shale in the San Juan Basin.

In Phase II, new analytical and numerical procedures and tools were developed for production and well testing analysis of tight-gas reservoirs and applied to field studies. These procedures and tools address issues related to estimation of reservoir production/flow characteristics, determination of reservoir permeability anisotropy and well interference, delineation of the drainage volume/area, and evaluation of infill well potential.

\section{Background}

The importance of natural fractures on reservoir permeability and productivity in tight gas sandstone reservoirs is well documented in an extensive series of papers and reports on the U.S. Department of Energy's Multi-Well Experiment (MWX) that was conducted from 1980 to 1988 (see Northrop and Frohne, 1990). This field project was designed to characterize low-permeability (tight) gas reservoirs and assess stimulation technology. It consisted of three closely spaced wells located in the Piceance basin of northwestern Colorado. The three wells are arranged in a triangle with interwell spacing varying from about 150-250 ft, depending on depth. The reservoirs of interest were sandstones of the Mesaverde Formation, which occur between the depths of 4,000 ft and 8,350 $\mathrm{ft}$ at this site. Different depositional zones within the formation contain reservoirs of different character, varying from blanket-shaped marine sandstones to narrow, lenticular sandstones. All of the sandstone reservoirs have low matrix permeability (usually less than a microdarcy), are enclosed in shale or mudstone, and are naturally fractured. 
A total of 4,200 ft of core was taken from the three wells for extensive rock property testing and reservoir characterization. During the eight-year program, six individual reservoir zones were isolated one at a time, and each tested and characterized with extensive reservoir draw-down, build-up, and interference tests, in situ stress measurements, and stimulation experiments. Complimentary geologic studies of the core and nearby outcrops helped to characterize reservoir shapes, sizes, and lithologic heterogeneity, and the distribution, intensity, and orientation of natural fractures.

Natural fractures in these Mesaverde sandstone reservoirs are primarily vertical regional extension fractures. They occur in essentially flat lying strata and in the absence of major structural deformation of the local strata. Regional fractures form a systematic set of unidirectional fractures that are present over large areas of a sedimentary basin. Their distribution and intensity is a function of bed thickness and lithology. In general, fracture intensity decreases with increasing bed thickness and fractures tend to be longer and further apart. Fracture intensity is higher in clean sandstone and the intensity decreases with increasing shale content as the rock becomes softer and less brittle. At the MWX site, fractures occur only in sandstones and terminate at shale boundaries. The regional fracture trend is about $\mathrm{N} 70^{\circ} \mathrm{W}$ and is aligned with the maximum horizontal in situ stress direction and the direction of hydraulic fracture propagation.

Well tests indicated that the equivalent reservoir permeability was one to three orders of magnitude greater than laboratory-derived matrix-rock permeability of one microdarcy. Documented permeability anisotropy at the MWX site, due to the unidirectional fractures, ranges from 8:1 to 100:1 for the ratio of the maximum to minimum horizontal reservoir permeability. Permeability anisotropy creates elongated drainage area along the fracture trend. Moreover, permeability anisotropy limits lateral communication between closely spaced wells in the direction orthogonal to the fracture trend in these reservoirs with very low matrix permeability.

Subsequent to the MWX program, the Slant Hole Completion Test (SCHT) was conducted at the same site and was designed based on the MWX findings. This Gas Technology Institute sponsored project consisted of a deviated well, locally cored, through the Mesaverde reservoirs. The hole azimuth was normal to the trend of the subsurface regional fracture trend. This well and core confirmed that vertical regional natural fractures are pervasive through out the sandstone reservoirs and that these fractures constitute the primary permeability system in the reservoirs.

\section{Permeability Anisotropy and Well Drainage Area}

The size and shape of well drainage areas in naturally fractured reservoirs that have strong permeability anisotropy are not represented by radial flow. Instead of being circular, the drainage area is better described as being elliptical (Figure 1.1). The aspect ratio of the elliptical drainage area is given by the square root of the permeability ratio of the maximum to minimum horizontal reservoir permeability. For a 9:1 permeability ratio, the aspect ratio of the drainage ellipse is 3:1.

Conceptual simulation models by Harstad (1998) demonstrated that knowledge of the orientation and magnitude of horizontal permeability anisotropy and the size and shape 
well drainage area of a producing well has significant economic importance in optimizing the number and location of infill wells. Locating the infill well away from the maximum permeability direction reduces production interference and drainage overlap between adjacent wells, increases reservoir drainage efficiency and decreases the potential for leaving parts of the reservoir undrained (Figure 1.2). An example calculation of the models show that a 20-degree angular rotation in well alignment away from maximum permeability direction increased cumulative gas production by more than 20 percent for a tight-gas reservoir with a permeability anisotropy ratio of 10:1

\section{Mesaverde Group Study}

The Mesaverde Group play in the San Juan Basin is a basin-centered gas accumulation. Cumulative gas production in these tight-gas reservoirs shows a northwestsoutheast trend coincident with the depositional strike of the formations. The Mesaverde Group comprises, in ascending stratigraphic order, three commingled sandstone formations: the Point Lookout Sandstone, Menefee Formation, and Cliff House Sandstone. The Cliffhouse and Point Lookout are massive shoreline sand deposits that span most of the basin. The Menefee consists of discontinuous channel sands that result from estuarine, deltaic and fluvial geologic environments. Well performance in these formations varies throughout the basin due to net thickness differences, reservoir heterogeneity, and natural-fracture-dependent reservoir permeability. The actual contributions from each formation throughout the basin are unknown because the production is commingled.

Production from low-permeability gas sandstones of the Mesaverde Group is highly dependent on natural fractures. Natural fractures not only enhance the overall permeability, they can also create significant permeability anisotropy. Although natural fractures exist throughout the basin, their type, distribution, intensity, interconnectivity, and orientations within the basin is not well known. In general, vertical regional extension fractures tend to have a north-south to northeast-southwest orientation within the basin. Fracture swarms, associated with local faulting or geologic structure that have higher rates of bed curvature, are also present in the basin. They are relatively narrow, linear zones of high-density interconnected fracturing that create "sweet spots" of much higher reservoir permeability, permeability anisotropy and productivity. Fracture swarms have been identified from 3-D seismic analysis of horizon curvature attributes and confirmed by production decline analysis (Hart, et al., 2002).

The Blanco Mesaverde reservoir was discovered in 1927. Extensive development took place on 320 acre spacing during the 1950's and defined areas of high initial gas potential and thick net pay. The time required to reach pressure stabilization in long term shut-in pressure buildup tests conducted by El Paso Natural Gas Company in the late 1950's and early 1960's indicated low permeabilities and low drainage efficiency at 320 acre spacing (Maldonado, et al., 1983). These observations prompted the request for 160-acre infill well development, which was approved in 1974 (Whitehead, 1993).

Recent work has lead to the conclusion that 160-acre infill well spacing is not sufficient to efficiently drain the Mesaverde, and further infill drilling to 80-acre spacing is 
warranted. Pressure plots generated from the initial pressure of wells drilled in the 1950's compared to wells drilled in the 1970's indicate that some areas had almost initial reservoir pressure even after 20 years of production. Sinha (1981) also found that pressures from infill wells were considerable higher than those obtained from 7-day shutin pressures of the original wells. Remaining gas reserves are based on the performance of existing wells. If these wells have high interference and low drainage efficiency, then the remaining reserves will be underestimated.

In 1997, pilot studies were conducted to determine the feasibility of reducing spacing to 80 acres. Harstad (1998) analyzed well tests and production data and performed conceptual reservoir simulation studies on two pilot areas to quantify the infill drilling potential. The results of this study demonstrated the importance of reservoir permeability anisotropy on drainage area and shape, and in determining the optimal location and number of infill wells in a given area.

The two pilot areas are located adjacent the northwest-southeast trending Mesaverde fairway that has good producing wells. The reservoir net thickness, permeability and production characteristics are different for the two pilots. The first pilot is adjacent to the fairway and has moderate well/reservoir productivity in comparison to the fairway. The second pilot is farther away from the fairway and has lower well/reservoir productivity. Pressure interference tests in the Cliffhouse formation in the first pilot indicate isotropic reservoir permeability with a maximum and minimum horizontal permeability of 0.348 and $0.035 \mathrm{md}$, respectively (Harstad, 1998). The observed horizontal permeability anisotropy ratio is $10: 1$, with the maximum horizontal permeability direction trending north-south. The calculated equivalent reservoir permeability (geometric average of the maximum and minimum permeability) from these tests is $0.110 \mathrm{md}$, which is more than an order of magnitude of greater than matrix permeability, which is less than $0.01 \mathrm{md}$. Analysis of production data from wells in both pilots indicates equivalent reservoir permeabilities that are one to two orders greater than matrix permeability. Fractures have been found in core and are believed to control reservoir permeability, production and drainage.

The effect of permeability anisotropy on drainage is illustrated in Figure 1.3. Wells drilled on 160-acres spacing have a typical distance of about 2,500 feet between an old well and a new well. Initial pressure in the new well is a function of where the new well intersected the elongated drainage from the existing well. An increase in initial pressure in the new wells is observed with increasing angular deviation from north and the maximum permeability direction (Figure 1.4). Knowledge of the magnitude and orientation of reservoir permeability anisotropy a priori can clearly optimize the location of new infill wells in areas of higher-pressure potential and increase drainage efficiency.

Reservoir simulation models were developed from geologic models and production data to history match the performance of existing wells on 160-acre spacing. Conceptual reservoir simulation models were then run to determine the number of infill wells that were required to effectively drain the reservoir and forecast the contribution of each well to the increased cumulative gas recovery. The infill evaluation involved using the output 
pressure-distribution map from the simulation to determine areas of higher pressure. Areas of higher pressure are an indication that the reservoir the reservoir is not sufficiently drained by the current well spacing and additional reserves can be recovered if 80-acre infill wells are drilled.

Results of the simulation models predicted that 80 -acre infill wells would increase recoverable gas by 23 to 46 percent for the four section pilot areas. The largest potential increase in recoverable gas was in the area with lower well/reservoir productivity. The models predicted that 80-acre infill wells would recover at least one Bscf/infill well. Results of the pilot tests coupled with the reservoir simulation study prompted the approval of 80-acre spacing for the Mesaverde in 1998. Extrapolation of the results from these two pilots across the Mesaverde producing area provides a preliminary estimate of an additional 7.8 Tscf that could be recovered by optimal infill drilling.

Performance of 80-acre infill wells that were drilled in the two pilot areas was evaluated by Al-Hadrami (2000). Infill wells were drilled based on knowledge of the reservoir pressure, direction and magnitude of the reservoir permeability anisotropy, reservoir net thickness and heterogeneity, drainage areas of existing wells, and feasibility of surface locations. Al-Hadrami developed geologic models from well logs of existing and infill wells and available petrophysical data using geostatistical methods. The geologic model of each pilot was incorporated into a reservoir simulation model that included the observed permeability anisotropy ratio of 10:1 with the maximum horizontal permeability direction of north-south. The simulation models were verified through pressure and production history matching of the 160-acre well spacing development. Further verification was achieved by history matching the 80 -acre well spacing development without adjusting any of the model parameters. The 30-year production forecast of the reservoir model predicted a total net increase in recoverable gas for the two pilot areas of 26 percent to 44 percent over the predicted gas recovery of existing wells on 160 -acre spacing.

The importance of considering permeability anisotropy was clearly demonstrated in this study by comparing the performance of the actual infill wells that were drilled off the north-south trend of maximum horizontal reservoir permeability to hypothetical wells that had locations north-south of existing wells. The hypothetical infill well locations were the worst-case scenarios that created more drainage overlap and pressure interference between wells because of the reservoir permeability anisotropy, and thus significantly reduced the potential increase in gas recovery. Figure 1.5 shows a comparison of the predicted cumulative gas for individual 80-acre infill wells to the lower gas recovery predicted at the hypothetical well locations in one of the pilots. Simulation results for all the wells in the pilot area show that the predicted total cumulative gas production is reduced by 7.4 Bscf or 17 percent if the wells had been drilled along the north-south trend of maximum horizontal permeability anisotropy (Figure 1.6).

In Phase II the methodology and approach used to characterize and analyze reservoir performance and evaluate infill-drilling potential was applied to an area of high 
well/reservoir productivity in the fairway and very low well/reservoir productivity on the northeast margin of the basin. The results of these studies combined with the Phase I studies show the range of reservoir behavior in the basin and the influence of natural fractures on reservoir permeability, permeability anisotropy, and drainage efficiency. Robinson and Engler (2002) presented an integrated geologic and reservoir engineering study of a highly fractured and high equivalent permeability area within the Mesaverde fairway. In the study area, the dominant fracture trend was $\mathrm{N} 30^{\circ} \mathrm{E}$ as identified by seismic bed curvature analysis and confirmed by production decline analysis. Type-curve analysis resulted in an average well permeability from $0.10 \mathrm{md}$ to $7.75 \mathrm{md}$. Simulations demonstrated that a minimum permeability anisotropy of 13.7:1 was sufficient to match the interfering production response between wells. In contrast to the two pilot areas with much lower equivalent permeability, this area of high permeability has the potential of widespread drainage to occur. Existing wells exhibit an average drainage of about 160 acres and only limited infill drilling was identified on the drainage maps. Simulation results estimate that the potential recovery for 80 -acre infill wells at selected locations is $800 \mathrm{MMscf} /$ well. This study demonstrated that although limited infill drilling exists, proper evaluation methods might be useful in identifying the best locations.

The potential for infill drilling was also evaluated in the Blanco Mesaverde Rosa Unit, which is located along the northeast basin margin of the basin. The Mesaverde formations in this area of the basin have poorer reservoir quality and much lower well productivity than the other study areas that were located in and adjacent to the main fairway, where natural fractures have been observed and anisotropic permeability has been documented. Since an 80-acre pilot program already existed, efforts were directed towards developing models to predict well performance and subsequently compare with the actual values. The comprehensive analysis included reservoir characterization techniques, decline curve analysis, and flow simulation. Hart and others conducted a 3-D seismic-based geoscience characterization of the Mesaverde Group, Dakota Formation and Fruitland Coal in the Rosa Unit.

Results of production analysis (Munoz, 2001) show that the estimated ultimate recovery of Rosa Unit wells has decreased with the initial production date from a high of 1.46 Bscf/well for 320-acre well spacing to a low of $0.40 \mathrm{Bscf} /$ well for the new 80-acre infill wells drilled in 1999. This implies that new well locations are partially drained by older, existing wells. Reservoir simulation modeling of the pilot area (Iden, 2001) shows no significant effects of permeability anisotropy on infill well locations, and suggests isotropic reservoir permeability is probably a good assumption for this reservoir. Moreover, the well production history and lack of any reported measured pressure interference between wells indicates little or no influence of natural fractures on reservoir permeability or permeability anisotropy. The potential for 80 -acre infill drilling exists, but limited knowledge of permeability and the distribution of permeability within the modeled area increase the uncertainty in the evaluation of infill well locations and the quality of the production forecasts in this simulation study.

Natural fractures appear to exist in the Mesaverde sandstones of the San Juan Basin, but their distribution, intensity and orientation varies within the basin. Thus, there are areas 
of high and lower gas productivity depending on the degree of fracturing. Natural fracture systems also have varying effects on reservoir permeability, permeability anisotropy, and the drainage shape and area of individual wells. Reservoir studies of the four study areas discussed in this article have significantly different well/reservoir productivity. These studies demonstrate the range of importance that natural fractures and the associated reservoir permeability and permeability anisotropy have on drainage efficiency and infill well potential.

The 3-D seismic study used in reservoir characterization of the Rosa Unit is presented in Chapter 2. The reservoir engineering and simulation studies of the Rosa Unit are presented in Chapters 3.

\section{Dakota Formation Study}

The Dakota Formation is a basin-centered low-permeability stratigraphic gas reservoir flanked by shallower fractured oil reservoirs on and outside the basin margins. In petroleum system terms, the Dakota is closely linked to the Mancos Shale, the primary source frock for the Dakota hydrocarbons. The variety of depositional environments and stratigraphic units included in the Basin Dakota pool add complexity to the reservoir. The most important Dakota reservoir rocks, Dakota marine sandstone beds, tend to be quartz rich and silica cemented. In general, these very low permeability marine sandstone units are reliably gas charged, where as the better reservoir-potential facies tend to have higher water saturation and are often avoided in well completions. Permeability of the reservoir varies with depth, but is typically in the range of $10^{-2}$ to $10^{-4} \mathrm{md}$. Porosity is similarly variable but usually $4 \%$ to $8 \%$. As with other major San Juan Basin reservoirs, natural fracture networks enhance the effective permeability of the reservoir and cause permeability anisotropy. Dakota sandstone reservoir pressure is generally near normal pressure in contrast to the underpressured Mesaverde Group.

The Basin Dakota Pool was created in 1960 by consolidating numerous small Dakota reservoirs. Original well spacing was 320 acres. In the late 1970's, long term, shut-in buildup tests conducted by El Paso Natural Gas Company demonstrated the low permeability of the Basin Dakota reservoir (Maldonado, et al., 1983). Subsequently, the company applied for and was granted a reduction in well spacing to 160 acres in 1979. Average shut-in pressure of the first 750 infill wells was greater than 800 psi, which was greater than the current pressure for the original wells in the spacing unit. This success has been attributed to the reservoir heterogeneity or improved fracture stimulation techniques or a combination of the two.

Phase I of this project attempted to define the drainage area and hence the infill well potential for the Dakota reservoir. These studies involved production decline analysis to estimate gas in place and reservoir characterization and simulation to estimate multi-well drainage patterns.

Sunde and others (2000) used production decline analysis of 500 random wells within the San Juan Basin to estimate gas-in-place. They found a general decreasing trend in the 
IGIP with time, but substantial scatter in the data exists, and therefore precluded any specific observations about drainage.

Jaramillo and Medford both applied reservoir characterization and simulation to two designated areas producing from the Dakota. These areas are located on the margin of Dakota producing area and do not represent the fairway. The west area was selected based on the northeast - southwest production trend coinciding with the direction of channel sand deposits. The east-area production trend is northwest - southeast and is parallel to the barrier island-type depositional facies. The objective was to estimate multiwell drainage patterns and infill drilling potential.

The results of the infill well study for the two selected areas are significantly different. The east area, defined as a shore parallel facies, has no potential for further drilling. Inversely, the west area is a channel-type deposit with significant potential for infill drilling. Optimization of infill drilling in the Dakota relies upon two inter-related features: (1) the degree of natural fracturing and (2) the depositional facies. After history matching, the model predicted 80-acre infill well potential in the west area of 410 MMscf/well, but no infill well potential was discovered in the east area, with the best locations resulting in only $250 \mathrm{MMscf} /$ well. The results of the west study area are shown in Figure 1.7.

The Dakota formation studies in Phase I were extended to include an 80-acre well spacing pilot area in the Culpepper Martin Unit. This unit is located in the northeastern part of the basin. It is comprised of 12 sections that include 42 producing gas wells on 160-acre spacing. The Dakota sandstones in this area range in depths of 950 to $1200 \mathrm{ft}$ below sea level. To enhance the productivity of this unit, three infill well locations were drilled on 80-acre well spacing as a pilot test to determine the feasibility to infill drill.

A single phase, multilayer simulation model was constructed for the Dakota Formation in the Culpepper Martin Unit. The model was rate-constrained, using the output flowing pressures from the simulator as the matching variable to the limited, observed flowing pressure data set. Previous methodologies, such as decline curve analysis and integrated simulation proposed earlier, were utilized in this study.

Preliminary simulation cases resulted in excellent rate matches, but with inconsistent flowing pressure matches. Investigations revealed significant GIP difference between various models and is suspected to be the primary reason for the difficulty in obtaining pressure matches. This conclusion emphasizes the importance of proper reservoir characterization in low-permeability, naturally-fractured reservoirs. For the storage capacity, the net pay thickness, porosity model (single versus dual) and cutoff criteria are the key parameters. For flow capacity, the magnitude, orientation, permeability model and the net pay thickness are critical. Finally, the interaction between stimulation and the reservoir cannot be overemphasized. It is well known that these types of reservoirs require stimulation and the response is typically favorable. However, few simulation cases attempt to incorporate the complete details of stimulation and therefore fall short of accurately depicting the true reservoir behavior. 
The reservoir characterization and simulation study of Dakota Formation in the Culpepper Martin Unit are summarized in Chapter 4.

\section{Fracture Stimulation Treatments}

Vertical wells in tight gas reservoirs are always stimulated to increase production. Hydraulic fracturing is the most common stimulation treatment. In Phase II, evaluation of fracture stimulation treatments was accomplished by integrated reservoir description and fracture treatment analysis in the Pecos Slope Abo tight-gas reservoir in southeastern New Mexico and the Lewis Shale in the San Juan Basin. The primary goal of these studies was to couple reservoir characterization with hydraulic fracture analysis and subsequently, to infer infill drilling potential.

Sanchez, Engler and Kelly (2001) conducted two detailed case studies of the Pecos Slope Abo Field to reevaluate original hydraulic fracture treatment designs, to compare and evaluate fracture parameters, and to determine if the fracture treatments were providing sufficient reservoir stimulation. The field was originally discovered in June of 1977, but development did not escalate until the early 1980's. In May of 1981 the Abo Formation was designated a tight gas sandstone formation. Currently over 800 wells have been drilled in the field on160-acre well spacing.

Approximately 80 wells were studied in the southern part of the Pecos Slope Abo Field. Decline curve analysis was performed on all wells by a modified set of Fetkovich type curves. Analysis of this work show linear to near-linear flow in most cases with permeability values less than $0.1 \mathrm{md}$ and variations in reservoir properties as typically observed in low permeability reservoirs. These variations resulted in difficulty in evaluating infill-drilling potential.

In their study, evaluation of fracture stimulation treatments was accomplished by matching recorded surface treating pressure with a fracture propagation model. Unusually high initiation pressures were found in the case study wells. Initial stress state, vertical fracture growth, perforation restrictions, and the development of multiple fractures in a single, bounded layer were evaluated as possible causes for the high initiation pressures. Results form this work showed the multiple fractures model providing the best match. Fracture length varied from approximately $1150 \mathrm{ft}$ to $750 \mathrm{ft}$ with a single fracture model, and was reduced by approximately 10 to $30 \%$ for additional fracture added. The fracture data was input into a fractured well performance model, which was used to match the production rate and therefore verified the process.

The integration of decline curve analysis and fracture analysis provided better descriptions of reservoir properties and more accurate designs of fracture propagation models. The combined approached also improved evaluation of infill drilling potential by evaluating reservoir properties and stimulation. Current infill development on 160 acres could be reduced to 80 -acre well spacing and improve drainage. However, this study indicated that about 50 to 60 percent of the wells were draining more than 100 acres. Therefore, some 80 -acre wells could encounter drainage from offset wells and result in 
poor well productivity. If stimulation treatments are performed properly, infill well development at reduced spacing would not be necessary.

Sande (2002) conducted an analysis of the fracture stimulation treatments of the Lewis Shale. The Lewis Shale reservoir is undeveloped in over 2000 wells producing from the Mesaverde Group and deeper reservoirs in the San Juan Basin. The Lewis Shale is considered to be part of the Mesaverde Group statutorily, although it is geologically separate. This means, in most cases, that completing the Lewis Shale reservoir is simply a process of perforating the casing, hydraulically fracturing the Lewis, and commingling Lewis production with existing Mesaverde production. Improving the hydraulic fracture design used to complete the Lewis Shale reservoir offers significant economic benefits in terms of increased production and decreased costs. This study summarizes relevant geological and engineering data, analyzes current stimulation procedures, and makes recommendations for improving the efficiency of hydraulic fractures.

A variety of hydraulic fracture designs have been used to complete the Lewis in many of these wells. The production data from 313 Lewis wells was analyzed to determine what design parameters should be used to (1) maximize the fracture surface area, (2) minimize damage, and (3) minimize stimulation costs. This analysis was conducted by analyzing production decline curves and determining whether changing a certain parameter (e.g. fluid type) had an effect on the one-year incremental production from the Lewis. An estimate of the economic value of adding Lewis production was made using forecasted rates and gas prices for a one-year breakeven comparison. Based on the available data and the methods used, the optimum stimulation procedure for the Lewis Shale, throughout the San Juan Basin, is a single-stage, 150,000 lb foamed linear gel, hydraulic fracture treatment. However, based on preliminary results from a small number of completions, it is recommended that slickwater designs be analyzed further to determine whether they would have better results

A summary of the analysis of hydraulic fracture stimulation treatments in the Lewis Shale is presented in Chapter 5.

\section{Production and Well Testing Analysis of Tight-Gas Reservoirs}

In Phase II, analytical and numerical procedures and tools were developed for production and well testing analysis of tight-gas reservoirs and applied to field studies. These procedures and tools address issues related to estimation of reservoir production/flow characteristics, determination of reservoir permeability anisotropy and well interference, delineation of the drainage volume/area, and evaluation of infill well potential. These procedures and tools are documented in a series of papers presented and published in proceedings of Society of Petroleum Engineers conferences. These papers are briefly summarized in Chapter 6.

\section{Technology Transfer}

Results of the studies conducted in Phase II of this project have been presented and published in 11 papers at Society of Petroleum Engineering conferences. 
The U. S. Bureau of Land Management (BLM) recognized the importance and impact of the project on resource development and management of oil and gas in the San Juan Basin. New Mexico Tech conducted a study and completed a report for the BLM entitled "Oil and Gas Resource Development for the San Juan Basin, New Mexico: 20 year, Reasonable Foreseeable Development (RFD) Scenario Supporting the Resource Management Plan for the Farmington Field Office, Bureau of Land Management.” The report was published in July 2001. The objective of this study was to determine the subsurface development supported by geological and engineering evidence, and to further estimate the associated surface impact of this development in terms of actual wells drilled. For the major existing producing reservoirs, two approaches were used to predict development potential. The first approach was a survey of operating companies in the San Juan Basin, obtaining their perspective of future development based on current reservoir management practices. The second approach applied engineering techniques developed in this project to optimize infill drilling in naturally fractured, tight-gas reservoirs in the basin.

Burlington Resources and BP were granted permission to site new well locations based on the concept of elliptical drainage area and drainage pattern of previously drilled wells. Typically, wells are drilled on a given well spacing and pattern (usually square) that is specified by the New Mexico Oil and Gas Conservation Commission. For certain formations, gas operators have been able to convince the commission to reduce well spacing so that additional reserves could be produced. This was the first approved deviation in the Mesaverde tight gas sandstone reservoirs based on elliptical drainage patterns to prevent well interference and increase recoverable gas reserves in the San Juan Basin, and the approval was a direct result of this project.

\section{References}

Al-Hadrami, H.: "Influence of Permeability Anisotropy and Reservoir Heterogeneity on Optimization of Infill Drilling In Naturally Fractured Tight-Gas Mesaverde Sandstone Reservoirs, San Juan Basin,” Ph.D. Dissertation, New Mexico Institute of Mining and Technology, Socorro, NM, 2000.

Harstad, H.: "Drainage Patterns in Fractured Tight Gas Reservoirs," Ph.D. Dissertation, New Mexico Institute of Mining and Technology, Socorro, NM, 1998.

Hart, B. S., Pearson, R., Reawling, G. C., 2002: "3-D seismic horizon-based approaches to fracture-swarm sweet spot definition in tight-gas reservoirs," Geophysics, v. 66, p. $220-236$.

Iden, K: "Evaluation of Infill Drilling in Blanco Mesaverde Rosa Unit, San Juan Basin, New Mexico Using a Commercial Reservoir Simulator,” M.S. Thesis, New Mexico Institute of Mining and Technology, Socorro, NM, 2001.

Maldonado, N., Peace, J.H., and Lippman, G.A., 1983: "Case History: Infill Drilling Increases Reserves in Blanco Mesaverde and Basin Dakota Reservoirs, San Juan 
Basin, New Mexico,” SPE paper 11642, presented at the 1983 Symposium on Low Permeability, Denver, CO.

Munoz, J.: "Delineation of Drainage Area and Flow Characteristics of Rosa Unit (Mesaverde), San Juan Basin, New Mexico,” M.S. Thesis, New Mexico Institute of Mining and Technology, Socorro, NM, 1998.

Northrop, D.A. and Frohne, K.H., 1991: Insights and contributions from the Multiwell Experiment: a field laboratory in tight sandstone reservoirs: Journal of Petroleum Technology, v. 42, p. 772-779.

Robinson, R.L. and Engler, T.W.: “An Effective Technique of Estimating Drainage Shape, Magnitude, and Orientation in a Low-Permeability Gas Sand," SPE Paper 77742, presented at the SPE Annual Technical Conference and Exhibition, San Antonio, Texas, 29 September - 2 October 2002.

Sanchez, S., Engler, T., and Kelly, M.: "Evaluation of Fracture Stimulation Treatments by Integrated Reservoir Description and Fracture Treatment Analysis in the Pecos Slope Abo Tight-Gas Reservoir, Southeastern New Mexico,” SPE paper 70005 presented at Permian Basin Oil and Gas Recovery Conference, Midland, Texas, 1516 May 2001.

Sande, T.: “An Investigation into the Effectiveness of Simulations in the Lewis Shale, San Juan Basin,” M.S. Thesis, New Mexico Institute of Mining and Technology, Socorro, NM, 2002.

Sinha, M.K., 1981: "How to check reserve estimates in tight, transmissible reservoirs," Petroleum Engineering International, v.53, p. 348-362.

Whitehead, N.H.: Atlas of Major Rocky Mountain Gas Reservoirs, New Mexico Bureau of Mines and Mineral Resources, Socorro, NM, 1993. 

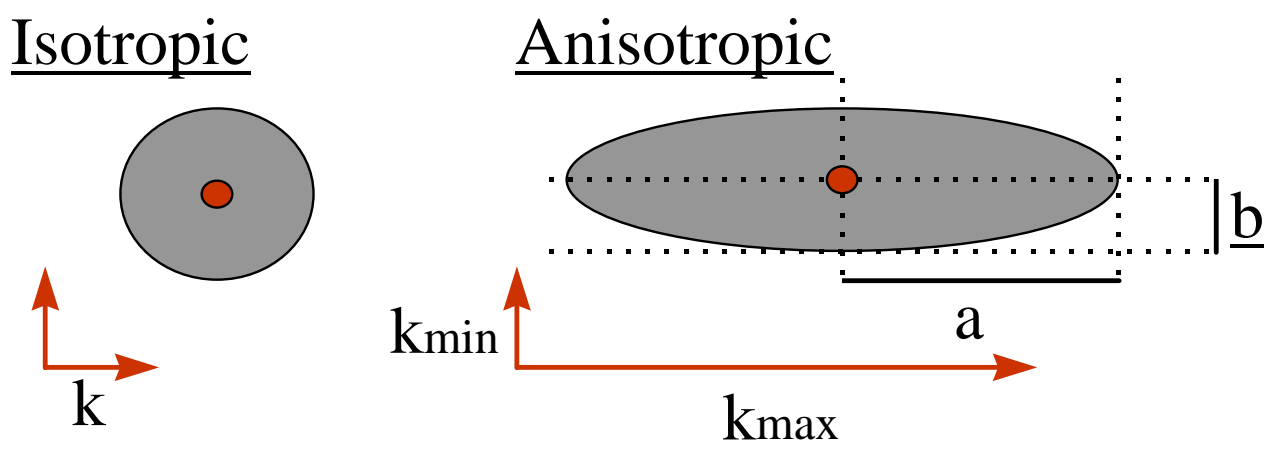

Figure 1.1. Shape of drainage area for isotropic and anisotropic permeability from Harstad, 1998). Knowledge of the shape and size of the elliptical drainage area of wells can be used to determine well spacing, location and number of infill wells needed to effectively drain a reservoir with permeability anisotropy.

a)
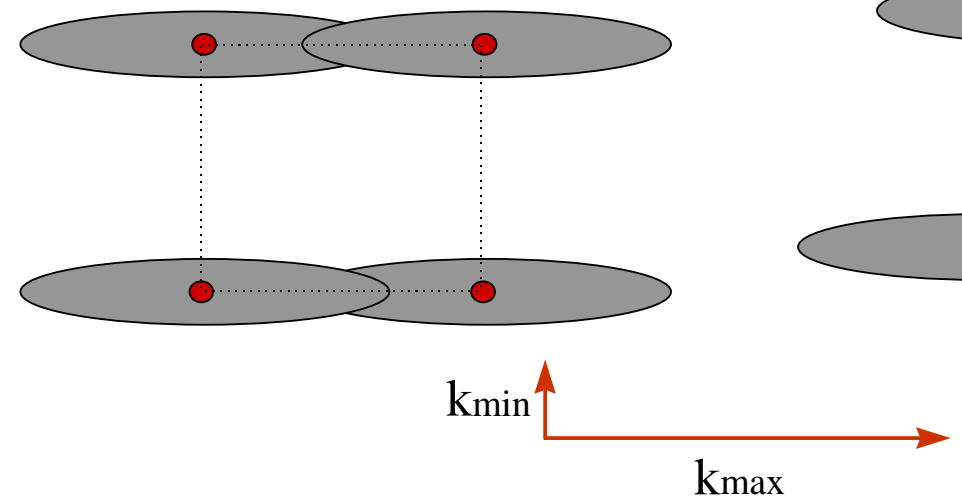

b)

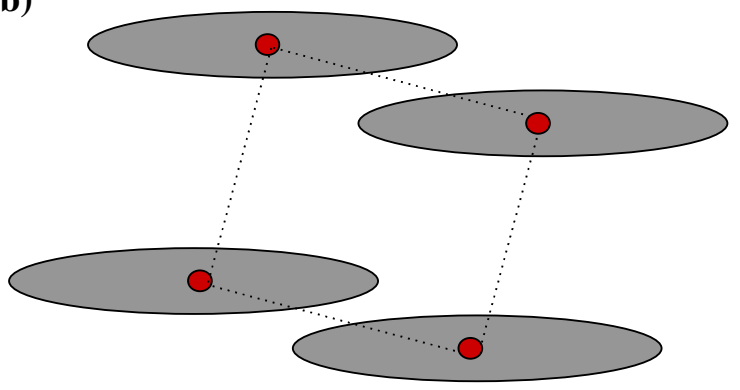

Figure 1.2. Rotation of well alignment (from Harstad, 1998). A) Square well pattern aligned with maximum permeability direction, B) Square well pattern shifted 10 degrees from maximum permeability axis. 


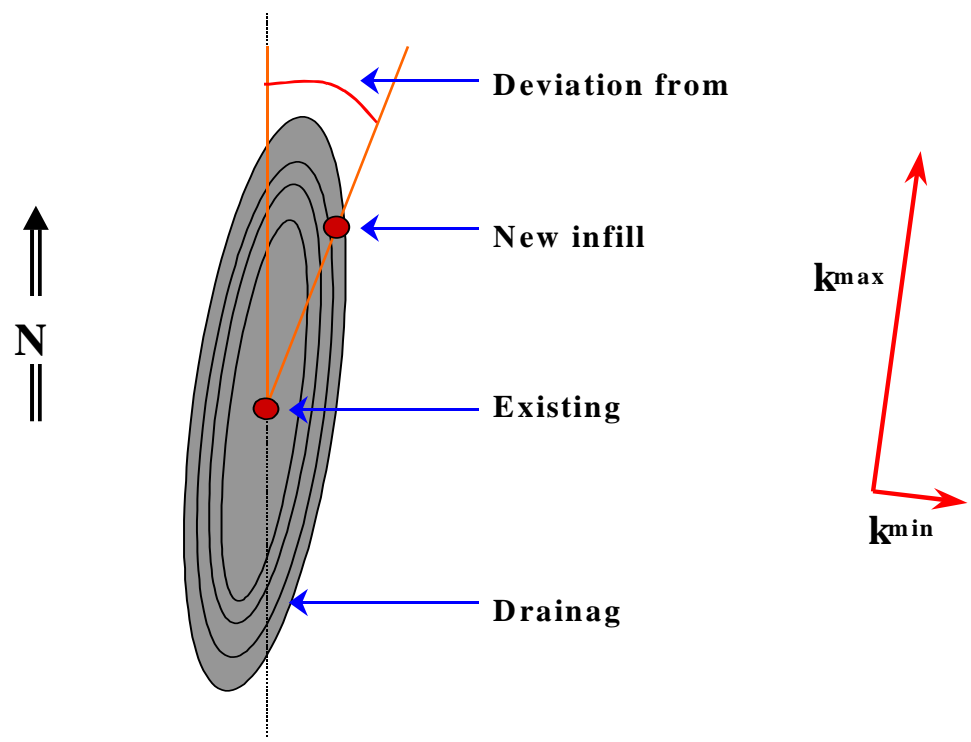

Figure 1.3. New infill well relative to elongated drainage from an existing well (from Harstad, 1998)

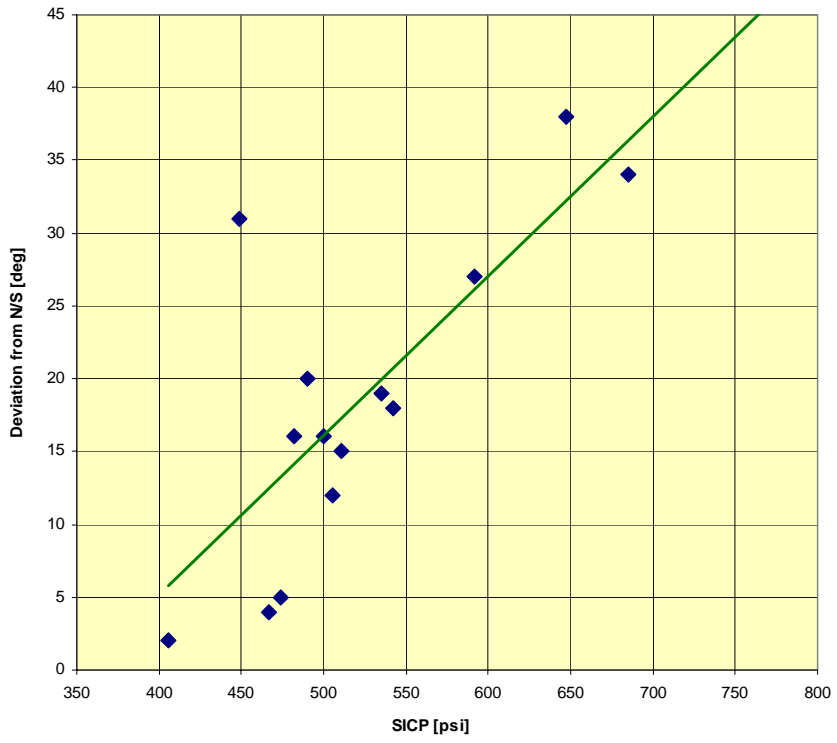

Figure 1.4. Plot showing initial shut-in pressure versus angular deviation from north of new well alignment relative to an existing well (from Harstad, 1998). Maximum permeability and elongated drainage direction is approximately north-south. 


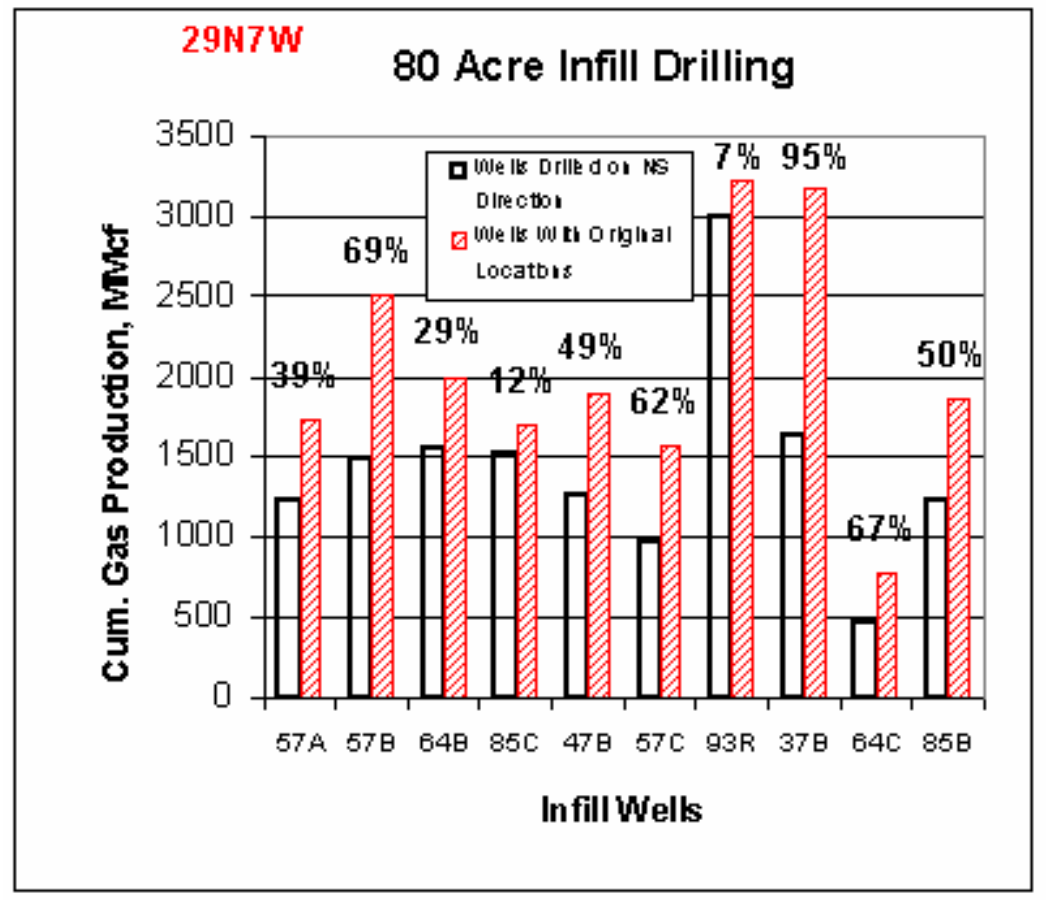

Figure 1.5. Comparison of cumulative gas production forecasts for infill wells (from AlHadrami, 2000).

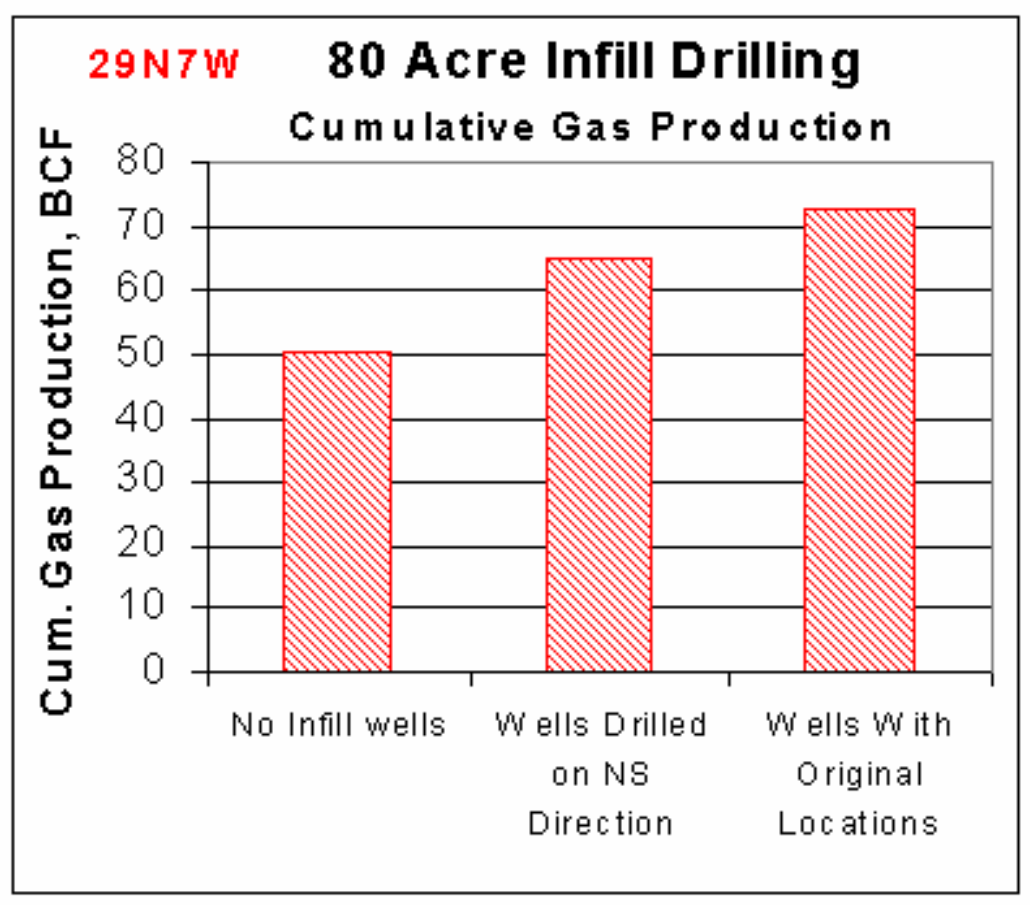

Figure 1.6. Comparison of cumulative gas production forecasts (from Al-Hadrami, 2000). 


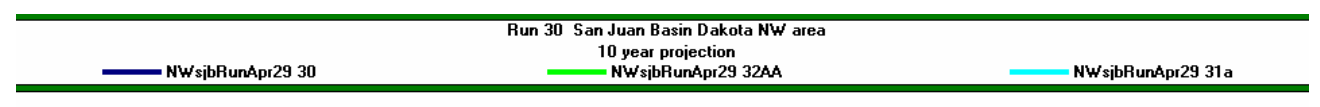

Cum Gas (MMM ft³) vs. Time (yrs)

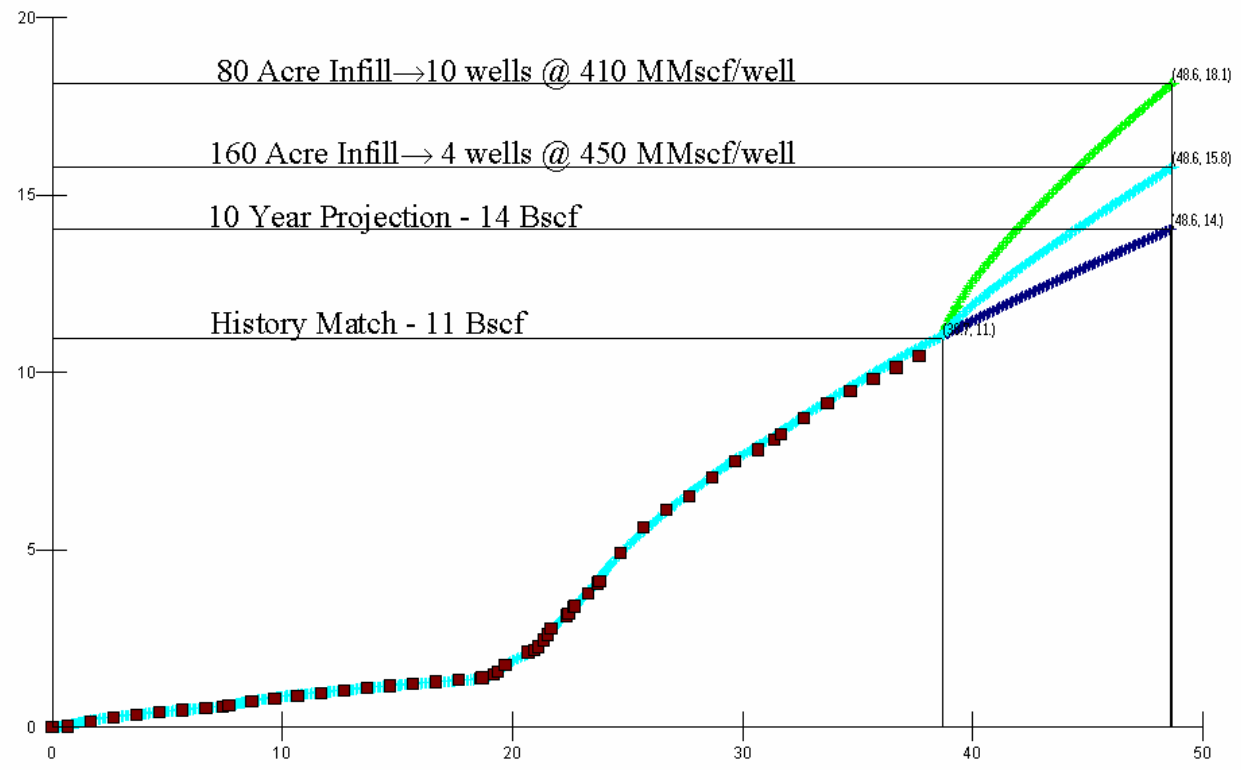

Figure 1.7. Comparison of infill drilling cases with the base case in the west area (from Medford, 2000). 


\title{
CHAPTER 2
}

\section{3-D Seismic-Based Geoscience Characterization of Dakota Formation, Mesaverde Group, and Fruitland Coal, San Juan Basin, New Mexico}

\author{
Bruce Hart, Robin Pearson, Ivan Marroquin, Marc-André Chen \\ Earth and Planetary Sciences \\ McGill University \\ Montréal, QC, CANADA
}

\section{Introduction}

The objectives of the 3-D seismic-based geoscience characterization were to identify structural and/or stratigraphic controls on production from tight-gas sandstones of the Dakota Formation and the Mesaverde Group in and around the area of two conventional (p-wave) 3-D seismic data volumes. The goal was to identify stratigraphic and structural controls on production from these two stratigraphic units, and thereby identify potential infill drilling targets.

In Phase I of the project, conducted while Hart and Pearson were at New Mexico Tech, $\log , 3-\mathrm{D}$ seismic and production data were integrated to identify the controls on gas production from a $\sim 100$ square mile area northeast of Farmington (Hart and Pearson, 2000). Horizon attribute (dip, azimuth, curvature) analyses of both the Mesaverde Group and the Dakota Formation allowed identification of wells that were in direct pressure communication along fracture swarms. Furthermore, at the Mesaverde level, links were established between regional production trends and depositional trends (derived from log analyses) that strongly suggested that the thickness of clean sandstones (a function of depositional processes) has a direct control on production. Similar results were had from the Dakota Formation. Wells that penetrate thick clean sandstones generally produce better than wells that penetrate thinner or shalier sandstones. Clean sandstones generally have higher porosity, and therefore gas storage potential, than shaly sandstones. Based on outcrop observations of the Mesaverde, Dakota and similar units, it is believed that the clean sandstones will have higher fracture density than shalier sandstones. These fractures enhance bulk permeability. At the Dakota level, seismic attributes were used to predict net sand, and thereby produce maps that, again, seem to indicate a strong depositional control on production from these tight-gas sandstones. Some of the results from the geoscience characterization of the Dakota, some of which were based on seismic attribute studies, were used as input for reservoir simulations.

Phase II of the project was conducted by Hart, Pearson, Marroquin and Chen at McGill University. In this Phase, the methodology developed in Phase I was applied and tested in a new study area centered on a 3-D seismic survey in the Rosa Unit (Figs. 2.1 and 2.3), south and east of the study area for Phase I. 
The results of the Rosa Unit Mesaverde Group study are largely negative. Clear relationships could not be established between production and seismically detectable stratigraphic and/or structural features in the Rosa Unit area. This lack of success is attributed to the following problems:

1. Data quality - the quality of the 3-D seismic data volume was poor, making it hard to consistently map horizons, especially at the Mesaverde level.

2. Data availability - our digital wireline log database for this project was much smaller than that for Phase I. For example, as discussed below, only three logs were available through the Dakota Formation in the area of the 3-D seismic survey. There were no time-depth ("checkshot") surveys with which to calibrate $\log$ and seismic data. As such, some of the picks (i.e., at the Mesaverde level) are essentially guesses.

3. Stratigraphic factors - the Mesaverde Group is shalier and thinner in this area as compared to the study area of Phase I. Accordingly, average gas production per well is less at the Rosa Unit.

4. Structural factors - no flexures at the Mesaverde level were found that could correspond to fracture-swarm sweet spots such as those identified in the Mesaverde Group during Phase I. There are some structures in the Paleozoic section and in the Fruitland Coal that appear to show a spatial correspondence with the best-producing well in the Dakota, but unequivocal relationships could not be established.

There are no suggestions of "sweet spot" wells in the study area and the formation is thinner and shalier in the Rosa Unit area than further west (in the "fairway"). This makes production per well lower in the Rosa area, and the lack of pronounced lithology contrast (compounded by the lack of checkshot surveys) makes seismic stratigraphic analyses difficult. Perhaps, if fracture density is related to lithology and clean sandstones generally have higher fracture density, the lack of sweet spots is attributable to the relative shaliness of the Mesaverde in this area.

For the final year of the project the geoscience characterization study, in consultation with project co-participants at New Mexico Tech, Williams Petroleum and BP, focused on the following aspects of the Rosa Survey area:

1. Stratigraphic characterization of the Dakota Formation was studied using new digital logs for the Dakota in the Rosa area in order to determine whether they could be integrated with the seismic data to provide new insights into the stratigraphy of the Dakota in this area.

2. Structural and stratigraphic controls on coalbed methane production from the Fruitland Coal was studied through integration of seismic, log, and production data to investigate the relationships between coal thickness, subtle structures and gas production. 


\section{Database}

The database for this study consisted of an irregularly shaped 3-D seismic survey and well information from the Rosa Unit area. Most of these data were supplied by Williams Petroleum, and this data transfer was facilitated because both our group and Williams use GeoGraphix software. Our group was new to the software however, and so learning how to use the applications slowed our work somewhat.

The 3-D seismic data volume covers approximately 15 square miles. Bin size is 150'x150', the sampling rate is $4 \mathrm{~ms}$, and the record length is three seconds. As described below, the data have a relatively low signal-to-noise ratio, thus making interpretation difficult at some levels. We had no details about the acquisition or processing parameters for the 3-D survey. Because of the noisiness of the data, especially near the Mesaverde level, we attempted to use different post-stack processing flows to improve the interpretability of the data. To this end, we experimented with both GeoGraphix' PStax application (which became available to us in the Spring of 2001) and various processing algorithms in Hampson-Russell's Strata application. Results of this post-stack processing are discussed subsequently in the section on the Mesaverde Group. We also generated "coherency" volumes using the SCAN algorithm in PStax (the SCAN algorithms are based on coherency processing algorithms in Landmark).

We received well information (location, name, API number, etc.) for 65 wells from Williams Petroleum. We had some digital logs (typically gamma ray with a resistivity and/or density log) for all of these wells although we only had digital logs through the Mesaverde interval for 54 of these wells, and only six of the wells had digital log information for the Dakota Formation. Of these wells, only 31 of the 54 Mesaverde wells with logs were in the area of the 3-D seismic survey, and only three of the six Dakota wells with logs were in the area of the $3-\mathrm{D}$ survey.

We had no checkshot data for any wells in the survey area. Only one of the wells, the Rosa 99 well had a sonic log with which to generate a synthetic seismogram. This well is located on the southwest margin of the 3-D survey in an area of high seismic noise. To generate a synthetic, we used a checkshot survey from the Carson \#1 well, located a couple of miles southwest of the survey area. Accordingly, we were not able to generate synthetic seismograms that had a high correlation to the seismic data. Our horizon picks were therefore based on: a) experience gained from Phase I of the project, and b) information provided by Williams.

\section{Dakota Interval}

In the first year of Phase II, we focused on structural aspects of the Dakota in the Rosa 3-D survey. This was primarily because we only had digital logs for three wells in the 3-D survey area at that time. Our results suggested that curvature attributes could be used to define structural features in the Dakota. In particular, we found that the strike curvature attribute, calculated with an aperture of 3 , indicated the presence of a NE-SW trending structural feature that was penetrated by the best-producing well in the survey area (Fig. 2.3). 
In the past year we have focused on stratigraphic aspects of the Dakota Formation. We began by working with the digital logs to identify mappable stratigraphic subdivisions of the formation. These subdivisions loosely correspond to the various members of the Dakota (e.g., Paguate, Cubero) although we have not assigned such names to them. We used high gamma ray kicks interpretable as marine flooding surfaces to define stratigraphic packages, and then transferred those horizons from well to well. Three such surfaces were defined: a) the top of the Dakota, b) a surface approximately $40-50$ ' below the top of the Dakota, and c) a third surface approximately $60-80$ ' below the second flooding surface. Table 2.1 lists these picks, and Figure 2.4 shows a log crosssection through the 3-D seismic study area that illustrates the locations of the picks.

The interval between the top of the Dakota (Dakota MD pick) and the Dakota 2 pick consists of a single sandier-upward parasequence that is typically about $45^{\prime}$ thick. This interval, henceforth termed the "uppermost parasequence" may be interpreted as the product of progradation of a single clastic strandplain/shoreface. The interval between the Dakota 2 and Dakota 3 picks is thicker (approximately 75') and shows much more lateral lithological heterogeneity. Sandier-upward packages suggestive of shoreface progradation are present in this interval, as are (in some wells) shalier-upward packages (channels), blocky log responses (channels or shorefaces) and serrated log responses (?floodplain). We interpret this second interval to represent sedimentation in a lobate deltaic setting. The interval below the Dakota 3 pick shares many similarities with the overlying interval and may too have been deposited in a deltaic/floodplain environment. Because we were unable to tie the logs to the seismic data in detail, we cannot be confident about the locations in the seismic data of any package below the uppermost parasequence. A similar problem was encountered during Phase I of this project in the 3D seismic dataset to the Northeast of Farmington.

Because of the limitations on our ability to tie the seismic and log data lower down in the Dakota, we sought to predict lithological factors from the 3-D seismic data for the uppermost parasequence. This same rationale was employed in Phase I of the project. In that study area, Pearson used seismic attribute-based prediction of lithology in the Twowells Member of the Dakota to demonstrate the existence of NW-SE trending (i.e., shore-parallel) thicks, and her predictions were used by Jaramillo (2000) for simulation purposes. For this study, we sought to predict net sand for the uppermost parasequence. The methodology (Hampson-Russell software) is similar to that employed by Pearson in Phase I of the project.

We used a horizon-based attribute approach. Thirty-four attributes were generated in SeisVision and Hampson-Russell. The best attributes were ranked according to their correlation to net sand and weighted by stepwise linear regression (Russell et al., 1997; Hampson et al., 2001). The number of attributes retained by this predictive model was determined by crossvalidation. Following the methodology proposed by Russell et al. (1997), and Hampson et al. (2001), wells are systematically hidden one at a time, while the remaining wells were used to predict the excluded one. This technique seeks to eliminate the problem of overfitting the data when a large number of attributes are used (e.g., Kalkomey, 1997). Consequently, the point at which adding a new attribute 
increases the validation error determines the optimal number of attributes to be used (see Hampson et al., 2001, for a full discussion of the methodology). In our analyses, we investigated non-linear transforms (e.g, $\left.1 / \mathrm{x}, \mathrm{x}^{2}\right)$ of both the target variable (net sand) and the attributes.

Our results suggest that four attributes: a) integrated trace, b) 1/(instantaneous phase), c) $1 /$ (total absolute amplitude), and d) $1 /$ (instantaneous phase $6 \mathrm{~ms}$ below the Dakota seismic pick) provided the best solution (Fig. 2.5) when correlated against the square root of net sand. We then used three different methods to predict the distribution of net sand: multivariate linear regression (MLR), a probabilistic neural network (PNN) and a multilayer feed-forward neural network (MLFN). When predicted net sand is cross-plotted against measured net sand for each of these three methods, the respective correlation coefficients are: 0.88 (MLR), 0.86 (PNN) and 0.89 (MLFN). Cross-plots of predicted versus measured net sand and maps of predicted net sand for each of the three methods are presented in Figures 2.6-2.8.

Figure 2.9 shows a comparison of the three results. We note the following characteristics:

- The MLR attribute analysis yields the estimate of net sand thickness with the greatest variance. This is due to the fact that the neural networks never estimate the thickness outside the thickness range of the wells. The range of net sand thickness in the wells was from 6 to $19.25 \mathrm{ft}$, which is the range of the estimates of both neural networks. Within that range, the picks of the MLFN have a greater variance than the picks of the PNN. It seems unlikely, however, that at all points in the survey area have a net sand thickness within the range of the two most extreme wells.

- Although the nominal values of each different attribute analysis are quite different, all models tend to agree on the areas of the Dakota MD formation which have highest and lowest net sand. A NW-SE trend in net sand values, interpretable as a shoreline orientation, is observable in all cases.

- The trend for higher net sand values to be present in the SE part of the 3-D survey area is supported by a computer-contoured log-based map of net sand (Fig. 2.10). However, the seismic-based maps show more heterogeneity and more geologically reasonable trends (i.e., NW-SE - shore-parallel - trending variations).

We sought to use Paradigm Geophysical's Stratimagic application to see whether seismic facies classification could be used to define stratigraphic variability in the upper parasequence. The Stratimagic application uses a self-organizing neural network to map seismic character and assess the variation in signal shape over an interval of interest (e.g., reservoir). The result is a series of color classified model facies traces (neurons) that represent seismic data heterogeneity. Classification maps are then computed to show the distribution of seismic facies.

Figure 2.11 shows the distribution of the three seismic facies we chose to define. We selected three facies because our qualitative analyses of gamma ray logs suggested three 
different types of log characters in the upper parasequence: 1) thin interval and relatively low net sand, 2) thick interval and relatively low net sand, and 3) thick interval and relatively high net sand. In the seismic facies map, we note that the red facies is predominant in the SE part of the survey, the green facies is predominant in the NW part of the survey, and the yellow facies is an intermediate facies between the red and green. Unfortunately, the geological significance of the facies is not readily apparent.

In Figure 2.12 we compare the results of the seismic facies analyses (i.e., Fig. 2.11) with the results of discriminant analysis of the results of the MLFN result (Fig. 2.8). The discriminant analysis allows us to simplify the MLFN result into three categories according to the predicted net sand thickness ("high", "medium" and "low"). When plotted side-by-side, it becomes clear that the seismic facies analysis has identified changes in reflection character that are primarily due to changes in net sand in the upper parasequence of the Dakota. We interpret the convergence of these two different approaches to seismic analysis (seismic attribute analysis and seismic facies analysis) to indicate that they are identifying meaningful stratigraphic variations in the upper parasequence of the Dakota Formation.

We found no correlation between net sand of the upper parasequence and production from the Dakota, although the best producing well from this area (Rosa 66) is located at the intersection of a curvature-delineated structure (Hart and Pearson, 2001) and a continuation of the NW-SE striking thick zone shown in Figure 2.9. We note that perforations in the Dakota are located in several intervals (e.g., Rosa UN 9A well, Fig. 2.4), not just the upper parasequence, making the lack of correlation not surprising. We suggest however, that if appropriate data were available, seismic attribute-based lithology prediction for all intervals of the Dakota could make an attractive product for identifying areas that are more and less attractive from a stratigraphic perspective.

\section{Fruitland Interval}

Due to the increasing importance of coal seams as sources of methane gas, knowledge of the controls acting on these reservoirs is essential for successful exploration and production. The San Juan Basin is the world's largest producer of coalbed methane (Dugan, 2000). In this basin, methane is produced from coal seams within the Cretaceous Fruitland Formation. Production began in 1951 with the Ignacio Blanco-Fruitland gas field at Ignacio, Colorado. Today Fruitland coal seams have a cumulative production of $9 \mathrm{Tcf}$, an annual production of $0.9 \mathrm{Tcf}$, and contain in-situ gas resources estimated at $55 \mathrm{Tcf}$ (Dugan, 2002).

Production patterns vary on a basin-wide and local scale across the basin reflecting differences in geologic factors and, undoubtedly, engineering factors (completion techniques, etc.). Geologic factors affecting the capacity of coal seams to store and produce coalbed methane include reservoir pressure, composition and rank of the coal, gas composition, water production, thickness, and degree of fracturing (e.g., Kaiser and Ayers, 1994). In this study, we examine a thick, continuous coal seam in the lower part of the Fruitland Formation, Rosa Unit at the north-central part of the San Juan Basin (Fig. 2.2), using well logs and p-wave 3-D seismic data. We then used 3-D seismic data to 
predict coalbed thickness, as well as the distribution and orientation of subtle structures that may be associated with enhanced permeability zones. We conclude that high coalbed methane production is generally associated with thick coal accumulations and curvature lineaments, both of which may be detected seismically.

The depositional history of the Fruitland Formation was summarized by Ayers et al. (1994). Intermittent transgressive-regressive shifts of the shoreline, during larger scale Late Cretaceous regression, resulted in the intertonguing of the Pictured Cliffs Sandstone and the overlying Fruitland Formation. The Fruitland Formation is the primary coalbearing formation in San Juan Basin and is considered as continental facies deposited landward of the Pictured Cliffs Sandstone (Ayers et al., 1994).

No sonic (DT) well logs were available for modeling studies. We therefore generated these logs from density logs (RHOB) using the Gardner equation (Gardner et al., 1974):

$$
\mathrm{DT}=(\mathrm{RHOB} / 0.23)^{4}
$$

However, this equation provided unreasonably low velocities values for coal. To overcome this problem, we assigned a velocity of $8695 \mathrm{ft} / \mathrm{s}(2650 \mathrm{~m} / \mathrm{s})$ to intervals possessing density values $<2 \mathrm{~g} / \mathrm{cm}^{3}$.

We delineated the occurrence of coal seams and established the vertical and lateral extents of Pictured Cliffs Sandstone and Fruitland Formation primarily with gamma ray and density logs. Figure 2.13 shows a sample log cross-section through the Fruitland Formation in the seismic area. The top of the Pictured Cliffs Sandstone was identified by a combination of high gamma ray and low-density log values. This signature is thought to be associated with a marine flooding surface. The upper Pictured Cliffs tongues have a blocky well log response and are considered to be stratigraphically located between the Picture Cliffs Sandstone and lowermost Fruitland coal seam. These strata were found to have an average thickness of $135 \mathrm{ft}$. Coal, on geophysical well logs, is identified on the basis of the presence of both low density $\left(<2 \mathrm{~g} / \mathrm{cm}^{3}\right)$ and low gamma ray values.

Two intervals of coal were delineated in the Fruitland (Fig. 2.13), a thick, continuous coal seam in the lower part of the formation (with an average thickness of $26 \mathrm{ft}$ ), overlain by a succession of thin, laterally less continuous coal seams interbedded with clastic sediments. The thick, lower Fruitland coal seam is believed to have been deposited during periods of shoreline stillstands (Ayers et al., 1994) and is thought to be the main productive interval for coalbed methane (Engler, pers. comm., 2002). Whereas the succession of thin, discontinuous coal seams are interpreted to be deposited in unstable floodplain settings related to renewed shoreline progradation. An unusually low thickness value $(2.89 \mathrm{ft})$ was observed for the lower, thick coal seam in one well on the west margin of the seismic area. We were not able to determine the cause of this anomalous value and so it was disregarded in further analyses.

We used a kriging technique to produce an isopach map of coal thickness from well control alone (Fig. 2.14). This technique estimates values using a linear weighted average of the values measured at existing wells. The resulting map is consistent with the spatial trends and honors the values at the control points. From this map, we noted that coal was 
thicker in the southeastern part of the seismic area, with NW-SE contour lines approximately parallel to the inferred shoreline orientation. This trend of thicker coal may indicate the development of a local depocenter, which coincides with major northwest trending belts of thicker coal found in the northeastern part of the San Juan Basin (Ayers et al., 1994). This is the same area that has the higher net sand content in the upper parasequence of the Dakota Formation (Figs. 2.9, 2.10, 2.12), suggesting tectonic control (local subsidence) on coal thickness. Toward the north part of the seismic area, a gradual thickness decrease is observed, which in turn is cut by a NE-SW trending of thin coal at the north of the seismic area. The pattern of the contour lines may indicate that this thin trend may be the result of erosion caused by a Fruitland river, which supplied sediments to the Pictured Cliffs shoreline.

\section{Methodology}

We used density and sonic logs to construct a seismic model that predicts the seismic character of coal seams and related strata and then used the model result to tie the well logs with the seismic data. This allowed log-based stratigraphic horizons to be mapped, using auto-tracking wherever possible, through the volume data. We then used a seismic attribute analysis (see Dakota study for methodology) in order to estimate coal thickness in Rosa Unit. Finally, we employed structural curvature analysis to delineate subtle structural features that might be associated with areas of increased permeability in coal seams.

\section{Seismic Character of Coal Seams and Related Rocks}

We generated seismic models by convolving a Butterworth zero-phase wavelet of bandwidth 5-65 Hz with cross-sections based on bulk density and sonic logs from wells within the seismic area. An example of a seismic model is shown in Figure 2.15. This work allowed us to identify and map five horizons in the 3-D seismic data. The seismic character for each interpreted horizon is summarized as follows:

- FRLD: a continuous peak of moderate amplitude corresponding to the top of the Fruitland Formation.

- Upper Coal: a relatively continuous and moderate to weak amplitude trough. This reflection is caused by the succession of thin coal seams, from which their individual reflections are not clearly visible because of interference effects. Interference results from short path multiples such that their overlapping waveforms superpose and outweigh the amplitude of the initial primary reflection (Gochioco, 1991, 1992).

- TopTC and BottomTC: robust, continuous, high amplitude trough and peak respectively. They define the upper and lower limits of the thick coal seam found in the geophysical well logs. The BottomTC corresponds to the top of the upper Pictured Cliffs tongues.

- MainPC: a fairly constant trough of poor quality that corresponds to the top of the Pictured Cliffs Sandstone.

In Figure 2.16 we show an arbitrary line through the 3-D seismic volume that illustrates the seismic response of these horizons. 
We observed a predominant peak frequency $\left(f_{p}\right)$ of $40 \mathrm{~Hz}$ for the seismic data in the Fruitland interval. By assuming an interval velocity (V) of $8695 \mathrm{ft} / \mathrm{sec}$ for coal seams, the predominant wavelength $(\lambda)$ was:

$$
\lambda=\mathrm{V} / \mathrm{f}_{\mathrm{p}}=8695 \mathrm{ft} / \mathrm{sec} / 40 \mathrm{~Hz} \approx 217 \mathrm{ft}
$$

yielding a tuning thickness $(\lambda / 4)$ of $54 \mathrm{ft}$. This value is at least twice the average thickness of the lower Fruitland coal seam in our study area. Therefore, we conclude that this coal seam is a seismic thin bed, for which the composite amplitude has previously been used to estimate the true bed thickness (Gochioco, 1991; Brown, 1996).

\section{Seismic Attribute Analysis}

Coal thickness is a critical factor that determines gas resources, and is considered to be an indicator of productivity (Kaiser and Ayers, 1994). We used a window-based approach (Chen and Sidney, 1997) to derive a statistical relationship between coal thickness and seismic attributes (Taner et al., 1979; Brown, 1996; Chen and Sidney, 1997). The time window for seismic attribute extraction was defined by the TopTC and BottomTC horizons. Thickness of the coal seam was determined using bulk density log at values less than $2.0 \mathrm{~g} / \mathrm{cm}^{3}$. The multiattribute analysis was based on 27 geophysical well logs within the 3-D seismic survey, and 35 amplitude, frequency, and phase attributes. This number was further increased by applying non-linear transforms to each attribute (natural log, exponential, square, inverse, and square root).

The best attributes were ranked according to their correlation to the coal thickness and weighted by stepwise linear regression (Russell et al., 1997; Hampson et al., 2001). The number of attributes retained by this predictive model was determined by cross-validation (Hampson et al., 2001). This technique seeks to eliminate the problem of overfitting the data when a large number of attributes are used (Kalkomey, 1997; Hirsche et al., 1998; Hart, 1999). Consequently, the point at which adding a new attribute increases the validation error determines the optimal number of attributes to be used (Hampson et al., 2001).

Figure 2.17 shows the total validation error and prediction error against the number of attributes used in the stepwise linear regression. We note that the validation error curve stops declining monotonically at the third attribute, determining the optimal number of attributes to be used. The following linear relationship was obtained:

Thickness $=3.922+2.005 \mathrm{e}-8 \mathrm{X}_{1}+3.183 \mathrm{e} 9\left(1 / \mathrm{X}_{2}\right)+6.812 \mathrm{e} 18\left(1 / \mathrm{X}_{3}\right)$ where:

$\mathrm{X}_{1}$ : Maximum absolute amplitude

$\mathrm{X}_{2}$ : Integrated trace

$\mathrm{X}_{3}$ : Total energy

with a correlation coefficient of $\mathrm{R}^{2}=0.87$ and average error of $3.2 \%$. Figure 18 shows a crossplot of the predicted thickness versus the actual thickness values.

Following Brown (1996), Chen and Sidney (1997), and Partyka (2000), we interpret these attributes as follows: 
- The maximum absolute amplitude is the maximum value within the window interval, and shows how the reflection energy is influenced by the interference from the top and base of the reservoir.

- The integrated trace is the averaged sum of trace amplitudes in the window analysis. This attribute indicates subtle amplitude variations caused by thickness changes of the reservoir.

- The total energy is the sum of all squared trace amplitudes within the window interval, and measures lateral trace energy variations, which can quantify variations in bed thickness.

Figure 2.19 shows the thickness of the lower coal seam as predicted by Equation 3. We note that the coal is predicted to be thickest (up to approximately 40') in the southeastern part of the survey area with a general thinning to the northwest. There is some indication of NW-SE trending thickness variations.

\section{Curvature Attribute Analysis}

For development of coalbed methane, important opening-mode fractures contribute to permeability pathways for gas. Additionally, strata that have been faulted or folded may also influence gas production (Pashin, 1998). As Kaiser and Ayers (1994) pointed out, the presence of minor folds and faults, in the San Juan Basin, may be more important to the production of coalbed methane because these structures may form sites of fracture/cleat-enhanced permeability and conventional trapping.

Horizon attributes, such as various curvature types have been successfully used to detect subtle faults in reservoirs (e.g., Steen et al., 1998). Hart et al. (2002), using results that were in part derived from Phase I of this project, showed that horizon attributes might also be used to detect highly productive fracture swarms in tight-gas reservoirs. We sought to investigate whether curvature maps could be used to predict the location and orientation of low amplitude structural features too small to be detected on vertical transects or horizon slides. The best results were obtained with maximum-, strike-, and dip-curvature maps from the TopTC seismic horizon. We also show the depth-structure map of TopTC horizon to assist in the interpretation of minor structural features.

The depth-structure map of TopTC seismic horizon is shown in Figure 20. The seismic area is cut by a structural low access oriented NW-SE. The local depocenter observed from the log-based isopach map (Fig. 2.14) coincides with this low structural relief. Toward the northwest of the seismic area, the progressive coal thinning does not appear to be influenced by the structural relief variations of TopTC.

The maximum-curvature map (Fig. 2.21) displays the shape surface in terms of symmetric (e.g., valleys, ridges) or asymmetric features (e.g., faults). In the first case, lineaments are represented by an isolated color; by contrast, asymmetric lineaments are represented by a juxtaposition of two colors (Roberts, 2001). On this display, small, lowangle structures appear as yellow curvature lineaments. We note that new structural features, probably hidden by the background trend on the depth-structure map (Fig. 2.20), are evident on this display. In the north part of the seismic area, lineaments tend to be more curved giving a sharper appearance to this region. While in the southeast, we 
observed an apparent decrease in the abundance of subtle structures, except for the presence of a major feature trending NW-SE.

The strike-curvature map (Fig. 2.22) describes the shape of the surface into areas of syncline shapes having negative curvature values, and anticline shapes having positive curvature values (Roberts, 2001). From this display, two principal trending lineaments of high curvature values are delineated by the yellow color (e.g., NW-SE and NE-SW). These ridges mostly correspond with high curvature lineaments on the maximum curvature display (Fig. 2.21).

The dip-curvature map (Fig. 2.23) shows relief variations within the surface, and is a measure of the rate of change of dip in the maximum dip direction (Roberts, 2001). We interpret this curvature attribute as an indicator of orientation of curvature lineaments. As previously observed on the strike-curvature display (Fig. 2.22), two principal trending lineaments are also observed.

\section{Discussion}

A key factor for the incorporation of multi-attribute-based analysis and sparse well control relies on the recognition of a significant relationship (Schultz et al.,1994; Gorell, 1995; Hirsche et al., 1997, 1998; Hart, 1999). It is very important that basic criteria must be considered in building a realistic model of the reservoir (Kalkomey, 1997; Hart, 1999; Leiphart and Hart, 2001). The multi-attribute-based study must thus meet the following criteria:

- the model must be statistically significant,

- a reasonable relationship between attributes and physical properties of the reservoir must exist,

- the result must be geological plausible, and

- the result must conform to available engineering data.

In order to assess the statistical significance of the predicted model, we measured the Spearman's rank correlation coefficient between attributes composing the predicted model plus amplitude attributes and coal thickness. This correlation is a measure of the monotonic association between two variables (Lehmann and D'Abrera, 1998). Unlike the correlation coefficient, Spearman's rank correlation coefficient works on ranked data and measures both linear and non-linear relationships between variables. Table 2 shows that the seismic attributes from the model have a high-ranking correlation with coal thickness, but for integrated trace which has a moderate correlation (e.g., -0.619). We also note that composite amplitude, as well as some other attributes, have a strong correlation with coal thickness. According to Russell et al. (1997) and Hampson et al. (2001), the stepwise linear regression methodology will not select attributes providing essentially the same information to the predicted model. Accordingly, we conclude that the attributes composing our predicted model must be providing different information related to the thickness of the lower Fruitland coal seam.

The Hampson-Russell methodology does not, however, guard against spurious correlations. We thus used a tuning curve approach to evaluate the geophysical reliability of the predicted model, and assign a physical meaning to the correlated seismic attributes 
(equation 3). The estimation of thickness of a seismically thin bed is commonly done by analyzing tuning effects from an isolated thinning bed (Gochioco, 1991; Brown, 1996). For beds thinner than one-fourth of the predominant wavelength $(\lambda / 4)$, thickness has sometimes been resolved by measuring variations in the composite amplitude, which is the sum of the amplitudes of reflections identified at the top and base of the reservoir (Brown, 1996).

The Butterwoth zero-phase wavelet used to generate synthetic trace models was reemployed to be convolved with a wedge model (Fig. 2.24). We estimated the P-wave velocity of coal and sandstones to be $8695 \mathrm{ft} / \mathrm{sec}$ and $12666 \mathrm{ft} / \mathrm{sec}$, and their respective densities to be $2.0 \mathrm{~g} / \mathrm{cm}^{3}$ and $2.5 \mathrm{~g} / \mathrm{cm}^{3}$. Note that the reflections picked at the top and base of the wedge model do not correspond to the actual seismic horizons delimiting the lower Fruitland coal. That is because below $\lambda / 4$ the trough-peak separation (top and base of coal, respectively) is invariant and no longer tracks the changing thickness of the coal layer itself.

From the seismic response of the wedge model, we extracted the maximum absolute amplitude, integrated trace, and total energy attributes. Figure 2.25 shows the crossplots of these attributes against wedge thickness for values below tuning thickness (53 ft). We also crossplotted the attribute values at well locations with coal thickness. Besides the step-shaped curve of integrated trace and total energy attributes, these crossplots readily show that the same attributes extracted from the wedge model responded in a similar fashion to that of the seismic data. To understand how the predicted model operates, we separately analyzed the linear attribute and the inverse transform attributes. The observed decrease in amplitude in all attributes, in concordance with the decrease in thickness on both wedge model and coal seam, reflects the tuning effect. Partyka (2001) used a wedge model to show that amplitude attributes are sensitive to lateral energy variations, which in turn can quantify bed thickness. We interpret the maximum absolute amplitude attribute as related to the behavior of the composite amplitude attribute in seismically thin beds. For thin beds the composite reflection is approximately proportional to thickness of the bed (Widess, 1973). This relation requires that the acoustic impedances of the layers above and below the thin bed be the same, yielding reflection coefficients at the top and base of the layer that have the same magnitude but different polarity. In our case, the higher-ranking correlation of the maximum absolute amplitude, with respect to the composite amplitude, could be due to differences in acoustic impedance between the layers above and below the lower Fruitland coal seam (reflection coefficients at the top and base of the coal will not be of equal magnitude). Therefore, the maximum absolute amplitude perhaps better accentuates the interplay between the reflections from the top and base of the coal seam.

By contrast, the inverse transforms of integrated trace and total energy attributes no longer depict amplitude variations; instead they must provide a further insight into the subtle variations in the waveform shape. According to our model, inverse transform attributes become predominant in areas where the coal is thin. Figure 2.26 shows 3-D crossplots of thickness with seismic attributes. We note that for relative high thickness values, the maximum absolute amplitude will carry most of the prediction. However, as 
soon as lower thickness values are reached, the thickness prediction will be done by the combination of inverse transform attributes.

Our wedge model analyses neglected attenuation effects within coal seams. Hughes and Kennett (1983) studied attenuation in coals using synthetic seismograms. They conclude that loss of seismic energy is small because coal seams are thin in comparison to the predominant wavelength. Hence, the variations in the waveform are due to the interference from the top and base of the lower Fruitland coal seam. Consequently, by using a multi-attribute approach, we show that these subtle variations in the seismic response are good indicators of coal thickness.

Another way to analyze the reliability of the predicted model was to evaluate its geological significance through curvature attribute analysis and production data. We first carefully assessed from maximum-, strike-, and dip-curvature maps, we then sought to reduce the problem of discerning real structural features from noise. To do this, we used a juxtaposition analysis was used to identify linked curvature lineaments, which may indicate changes in horizon shape produced by low amplitude structural features, from unlinked curvature lineaments. The latter were considered to be the result of map generation or processing artifacts (Hesthammer and Fossen, 1997). To interpret linked curvature lineaments, we inferred empirical relationships between maximum-, strike-, and dip-curvature attributes. While the curvature lineaments in the maximum-curvature map would indicate the distribution of structural features, the curvature lineaments in the strike- and/or dip-curvature maps would describe their orientation. Although the maximum-curvature attribute did not discriminate between minor folds and faults, the combined results of these curvature attributes suggest a higher structural deformation in the north part of the seismic area.

To examine the net effect of structural controls and coal thickness on coalbed methane production, we superimposed a bubble plot of cumulative gas production normalized by years of production and result of curvature lineaments analysis over the predicted thickness map (Fig. 2.27). Before mapping the predicted thickness values, we obtained some negative values, and because the statistical nature of our model these were set to zero. These values, as well as some exceptionally high thickness values, are due to poor input data quality close to the margins of the 3-D seismic area. We note that coal is uniformly thicker in the southeast portion of the seismic area with a northwest-southeast trend. This belt of thicker coal coincides with the local depocenter observed from the logbased isopach map (Fig. 2.14) and structural low access from the depth-structure display (Fig. 2.20). This result is consistent with the idea that a constant shoreline trend, uniform sediment supply, and relative stable climate produced thicker coal seam with $\mathrm{NW}$ depositional strike (e.g., Ayers et al., 1994). However to the north, patches of thick coal are found toward the margins of the 3-D seismic survey. The discontinuity in coal thickness probably indicates syn-depositional structural activity (e.g., compaction slumping), slight differences in clastic sediment supply, or a combination of both.

Coalification in the Fruitland Formation occurred while the compressive forces of the Laramide orogeny episode were active in the San Juan Basin area. The 3-D seismic 
survey was collected from a region presenting both northwest and northeast tectonic compressive principal stress (Tremain et al, 1994). These stress orientations are probably at the origin of the structural features observed from the curvature maps (Figs. 2.21-2.23). In order to distinguish between syn- and post-depositional tectonic activities, we need to consider the development of thick coal accumulation and cause of structural deformation. If syn-depositional tectonic activity indirectly controlled the occurrence of thick Fruitland coal seams (e.g., Ayers et al., 1994), then curvature lineaments are probably showing the evidence of post-depositional deformation.

Dominant production trends (with wells producing gas exceeding 80,000 Bcf/year are concentrated in areas of thicker coal and in the vicinity of curvature lineaments. Another area of exceptional gas production is in the western margin of the seismic area. However the poor quality of seismic data in the margins makes the interpretation uncertain. Generally, wells with lower production are located in areas of thinner coal in the north part of the seismic area, except for one well in the west margin of the southeast part. Despite the exceptions, dominant production patterns indicate that coalbed methane production is related to both the presence of subtle structures and coal thickness. According to Fassett (2002), structural evolution of the San Juan Basin clearly influenced the ability of the basin for trapping hydrocarbons. Therefore, the combination of thick coal and subtle structures may serve as good targets for increased coalbed methane production areas.

We have shown the potential application of using 3-D seismic attributes and structural curvature attributes in predicting the thickness and fracture/cleat-enhanced permeability zones of a coal seam in the lower part of the Fruitland Formation, Rosa Unit, northcentral part of the San Juan Basin. We used a multi-attribute approach to generate an empirical relationship that predicts coal thickness as a function of 3 attributes (e.g., maximum absolute amplitude, integrated trace, and total energy). Then we sought to determine the reliability of the predicted model, with the aim of reducing the uncertainty of the prediction in areas without well control. The reliability of the model was confirmed from: i) the statistical significance of the correlation between seismic attributes and coal thickness; ii) the physical relevance of the correlation (confirmed through seismic modeling); and iii) the significant association between curvature lineaments, coal thickness, and coalbed methane production data. We have also demonstrated the advantage of using multi-attribute approach over a single-base attribute analysis (e.g., composite amplitude). In fact, for a coal seam thinner than tuning thickness, the energy loss is small; and so, the waveform changes in the seismic response are due to interference between the reflections from the top and the bottom of the coal seam. These patterns of the waveform are a good indicator of changes in the coal seam thickness.

The predicted model suggests a more complex depositional setting in contrast to the logbased isopach map. Knowing that the structural behavior of lower Fruitland coal seam was controlled by Laramide tectonic activity, the use of structural curvature attributes improved the detailed interpretation of structural features that were otherwise difficult to define from conventional seismic transects. By superimposing interpreted curvature lineaments over our predicted coal thickness map, we were able to infer how different 
tectonic activities may influenced the occurrence of thick coal accumulation, as well as the development of sites of enhanced fracture/cleat permeability. Structural features having two principal trends (e.g., NW and NE) were observed, these orientations are consistent with the complex stress pattern suggested in the surroundings of the seismic area. Furthermore, the subsequent analysis of dominant production trends indicated that in areas where thick coal accumulation and curvature lineaments are present might form sites of increased coalbed methane production. Therefore, the characterization of both dominant production trends and curvature lineaments with predicted thickness map added robustness to our attribute-based interpretation.

\section{Synthesis: Phase I and Phase II}

The results obtained from Phase I and Phase II of this project show both similarities and differences that are related to geoscience factors (stratigraphy, structure, etc.), data quality and availability issues (logs, seismic, production) and (perhaps) engineering factors (completion techniques, etc.). In general, we were better able to characterize Dakota and Mesaverde reservoirs in the Phase I study area because we had more and better data from that area. Results of the Fruitland characterization project undertaken in the Rosa area (Phase II) suggest that similar results could be obtained in the Phase I study area, although we did not explore that possibility.

Our results point to two fundamental geoscience controls on production from tight-gas sandstones: a) stratigraphic factors, and b) structural features.

\section{Stratigraphic Controls}

There are at least two ways that stratigraphy exerts an influence on production from tight-gas sandstones. First, the shaliness of an interval has an important impact because: a) reservoir quality (porosity, permeability) is typically diminished as shale content increases, and b) fracture density is typically higher in cleaner sandstones because they are more brittle.

The effect of shale content of reservoir quality are well documented and will not be discussed here. The effect of shaliness on fracture density is observed in outcrops of the Dakota and can be inferred from logs in our study areas. Sample well logs from both Phase I and Phase II study areas are shown in Figure 2.28. In both cases, logs show indications of preferential fracture development in the cleanest sandstones. From both outcrop and $\log$ data, we conclude that clean sandstones are more brittle and, all else being equal, will have higher fracture density than neighboring shalier rocks.

The second way in which stratigraphy exerts an influence is through net thickness. Thicker sandstones will, all else being equal, produce more gas than thinner sandstones. Since sandstone thickness is a function of depositional environment and sequence stratigraphic development, stratigraphic mapping may be used to identify more productive areas.

The net impact of stratigraphic features on gas production was illustrated by the Dakota Formation in Phase I of the project. Using well logs (because seismic data quality was 
poor in some parts of the 3-D survey area) we established net and gross thickness maps for the Twowells Member of the Dakota (Fig. 2.29). The best production is clearly from areas of high gross thickness and net sandstone. We were not able to establish similar relationships for the other units we studied mostly, we believe, because the number and stratigraphic location of perforations varies considerably from well to well. (This implies that the Twowells Member of the Dakota is responsible for most of the gas production in the Phase I study area.) This is particularly true for the Mesaverde Group, which can be perforated in any or all of the Point Lookout, Menefee or Cliff House formations. As such, it is not possible to make simple correlations between net sandstone of one part of the Mesaverde and gas production. On a broad scale however, we note that production from the Mesaverde is higher in the Phase I area than in the Phase II area, and attribute this difference to the cleaner nature of the sandstones in the former.

Although data quality and data availability issues prevented us from using seismic attributes and wireline logs to generate pseudo-lithology logs for the intervals we studied, we were able to integrate logs and seismic data to produce maps of net sandstone (upper part of the Dakota) and coal thickness (Fruitland). These results lead us to suggest that, in areas of good-quality 3-D seismic and log data, it should be possible to predict lithology, perhaps through the generation of pseudo-gamma ray log (or volume of shale) volumes.

\section{Structural Controls}

The presence of a "regional" fracture set (i.e., fractures approximately equally spaced and with the same orientation) is well-established for the San Juan Basin and elsewhere. Our analyses suggest that, in addition to regional fractures, highly productive fracture swarms are associated with subtle structures that may be defined with 3-D seismic data (Fig. 2.30). In our approach, we first tie logs to seismic data, then map horizons throughout the seismic data volume. The horizons are then analyzed using curvature analysis. For this purpose, we developed a Windows-compatible software application called "Curvz" that may be freely downloaded from our website (Fig. 2.31). This application may be used to derive various curvature measures, including dip curvature, strike curvature, contour curvature, etc. (see Roberts, 2001, for a description of these attributes). Figure 2.32 shows the use of curvature to identify a subtle structural feature in the Phase I study area that appears to be associated with a productive fracture swarm. Earlier (e.g., Fig. 2.27) we demonstrated the use of curvature to identify important structural features at the Fruitland Coal level. In Curvz, we added the capability of deriving curvature with various apertures (Fig. 2.33). This allows the user to identify structural features of different scales. The utility of this capability was illustrated in Year I of Phase II, when calculating strike curvature with an aperture of 3 allowed an important subtle structural feature to be identified at the Dakota level (Fig. 2.3).

\section{Integrated Model}

Our analyses lead us to propose the following conceptual model for naturally fractured tight-gas sandstones (Fig. 2.34). Regional fractures are present throughout an area, but are more densely spaced in areas of clean sandstones. The location of these 
clean sandstones is determined by depositional factors. As such, these stratigraphically defined areas are associated with relatively high permeability. Within the area, structural features may be associated with highly productive fracture swarms, that may or may not have the same orientation as the regional fractures. In this scenario, the two best locations for drilling are either the high-permeability clean sandstones or the fracture swarm. We emphasize that both lithology and subtle structural features may be defined using conventional (i.e., p-wave) 3-D seismic data.

In an infill drilling situation, it becomes important to understand whether the fracture swarms have already been penetrated by drilling or not (Fig. 2.35). Undrilled fracture swarms should be preferred drilling targets, whereas operators should avoid locating infill wells on fracture swarms that have already been drilled.

We note that it is important to understand whether the curvature-defined structures are associated with higher or lower permeability. In this project, subtle curvature-defined structures are associated with above-average gas production. In other cases however, similar structures might be associated with lower permeability (and hence lower production) if the associated fractures have been mineralized. Such zones are known to exist in the Rocky Mountain region. This dichotomy illustrates the need to integrate seismic, geological and engineering data into a curvature study. This work may be undertaken in development settings, but the requisite data may not be available in an exploration setting.

\section{Data Quality and Availability}

We terminate this section with a brief discussion on the importance of data quality and availability to geoscience characterization of tight-gas sandstones. Typically a modern, integrated seismic interpretation begins by tying borehole geology to seismic data via the generation of synthetic seismograms. Sonic logs and velocity information (e.g., checkshot surveys) are both needed for this enterprise. Once the wells have been tied to the seismic data, high seismic data quality helps the interpretation team to extract subtle stratigraphic and structural features that can be of importance during field development.

There were no sonic logs available to us in either the Phase I or Phase II study areas. Because the rocks are underpressured, operators typically drill with air, and this practice precludes the collection of velocity logs. Although understandable from an operational perspective, the lack of sonic logs prevented us from generating synthetic seismograms and so adequately tying the borehole geology and seismic data. We were unable to achieve satisfactory results in our attempts to generate synthetic seismograms using pseudo-sonic logs derived from density logs (using the Gardner equation) or from resistivity logs (using the Faust equation).

In the absence of sonic logs, checkshot data could be collected to help tie borehole and seismic data. Reliable time-depth information, such as obtained through good-quality checkshot surveys, may be used to help tie $\log$ and seismic data in the absence of synthetics. Unfortunately only one checkshot survey was available to us, and it only 
extended from the Dakota down to the Paleozoic interval. Accordingly, our ability to tie the $\operatorname{logs}$ and seismic data was impaired, particularly at the Mesaverde level (the distinctive succession of lithologies in the Fruitland/Picture Cliffs interval and at the top of the Dakota interval allowed us to make reasonable seismic ties). We could therefore not undertake advanced seismic stratigraphic analyses that might have allowed us to better characterize our target reservoirs.

From a data quality perspective, we note that the 3-D seismic data volumes used in this study are, for a variety of reasons (mostly related to original data acquisition), of relatively poor quality. We were therefore unable in some places to make reasonable seismic picks (especially at the Mesaverde level) and therefore could not effectively use curvature or other analyses to look for subtle structural features that might be associated with sweet spots. At the Dakota level, although we were able to use seismic attributes to predict lithology in one part of the survey area, data quality in another part of the survey area was too poor for us to successfully predict lithology from seismic attributes.

The net effect of these shortcomings is that multi-million dollar 3-D seismic data sets cannot be adequately exploited. If proper data integration could lead to the identification and drilling of only one additional "sweet spot" well (e.g., cumulative production $\sim 10$ $\mathrm{BCF}$ greater than neighboring wells), then the cost (for example) of acquiring a single detailed checkshot survey would be handsomely rewarded. Our understanding is that the economics of each well in the infill drilling program needs to be justified, and on a wellby-well basis, the cost of running checkshot surveys or sonic logs cannot be justified. In that this approach never permits data to be collected that will allow full exploitation of the 3-D seismic data, we consider it to be "penny wise, pound foolish".

\section{Conclusions}

The major conclusions of both Phase I and Phase II are:

1. Two primary geoscience factors exert a major control on gas production from tight Mesaverde Group and Dakota Formation reservoirs of the San Juan Basin. These are: a) lithology, as defined by the relative thickness of "clean" sandstone, and b) density of natural fractures.

2. Coalbed methane production from the Fruitland Formation is strongly influenced by two geologic variables: a) coal thickness, and b) density of natural fractures (cleats).

3. Lithologic variations (thickness, net sand, etc.) may be defined through the integration of 3-D seismic data and wireline logs. We used seismic attributebased approaches to predict lithologic variability for some of the stratigraphic units in some areas. In Phase I, we demonstrated that these results could be supplied to engineers for direct input into reservoir simulations. Our ability to undertake similar analyses for all units being studied was compromised by data quality and availability constraints (see below). 
4. We employed curvature attributes to define subtle structural elements that appear to be associated with above-average fracture density and above-average gas production ("sweet spot" wells, with cumulative production about 10 BCF greater than neighboring wells. We generated the curvature attributes using Curvz, a freeware package we developed during the course of this project and are making freely available through the following website: http://eps.mcgill.ca/ hart/CURVZ website.htm. At present we cannot predict which type of curvature will best indicate the location and orientation of productive fracture swarms (if any). This should be an avenue of future research.

5. Different apertures of curvature should be computed during structural analyses to examine curvatures of different scales. At present we cannot predict which aperture/scale of curvature will best indicate the location and orientation of productive fracture swarms (if any). This should be an avenue of future research.

6. Stratigraphic complexity (i.e., non-curviplanar seismic picks) and poor quality seismic data both make horizon-based definition of subtle structures difficult.

7. NE-SW striking curvature-defined structures appear to be associated with the most productive fracture swarms. The orientation of these features is: a) typically somewhat different from the $\mathrm{N} 10^{\circ} \mathrm{E}$ orientation commonly assumed for the orientation of natural fractures in tight gas sandstones of the San Juan Basin, b) broadly consistent with NE-SW compression of the basin during the Laramide Orogeny. Although some of these structures may be related to reactivation of structures lower in the section, generally they do not correspond to basement or near-basement structures.

8. The stratigraphic complexity of the constituent formations of the Mesaverde Group, combined with poor data quality and lack of sonic logs and checkshot surveys prevented us from undertaking advanced seismic stratigraphic analyses of that interval. Log-based interpretations from the Phase I study area illustrate depositional trends that are consistent with a NW-SE oriented shoreline. These results are consistent with results of other, previous workers.

9. The Rosa area is nearer to the progradational limit of the Mesaverde Group, and so that interval is shalier at Rosa than the Phase I study area. The lack of "sweet spot" wells in the Mesaverde in the Rosa area could be because of the relative lack of clean sandstones in that part of the San Juan Basin.

10. The uppermost part of the Dakota in both the Phase I and Phase II (Rosa) study areas consists of progradational marine deposits (i.e., shoaling-upward parasequence), although it is not clear that the two progradational packages are stratigraphically equivalent. Log- and 3-D seismic-based maps of these intervals show NW-SE trends that suggest a NW-SE oriented shoreline. These results are consistent with results of other, previous workers. 
11. The current practice of not collecting checkshot or sonic log data is economically counterproductive. Although collecting these data will add to the cost of any one well, without them the logs cannot be adequately tied to the 3-D seismic data. As such, the multi-million dollar investment represented by the seismic data cannot be adequately exploited and potentially attractive drilling targets cannot be identified.

12. Seismic data acquisition parameters for the two 3-D seismic surveys used in this project were not optimal. The data are excessively noisy, especially in the upper part of the section (e.g., Mesaverde). Post-stack processing helps to reduce the noise, but cannot eliminate it. This processing probably also attenuates subtle structures that may be sites of potentially productive fracture swarms.

13. Conventional (p-wave) 3-D seismic data, integrated with borehole data and engineering data, may be used to provide important information that can be exploited during infill-drilling activities.

\section{References}

Ayers, W. B., Jr., Ambrose, W. A. and Yeh, J. S. (1994), Coalbed methane in the Fruitland Formation, San Juan Basin - depositional and structural controls on occurrence and resources, in Coalbed methane in the Upper Cretaceous Fruitland Formation, San Juan Basin, New Mexico and Colorado, Ayers, W. B., Jr. and Kaiser, W. R., eds. Bureau of Economic Geology. Bulletin 146, 13 - 40.

Brown, A. R. (1996), Interpretation of three-dimensional seismic data, Fourth Edition. AAPG Memoir 42. Tulsa, Oklahoma, 179 - 190, 223 - 259.

Chen, Q. and Sidney, S. (1997), Seismic attribute technology for reservoir forecasting and monitoring. The Leading Edge, 16, no. 5, $445-456$.

Condon, S. M. and Huffman, A. C., Jr. (1989), Mesozoic and Cenozoic structure and stratigraphy of the San Juan Basin: an overview, in Coal, Uranium, an Oil and Gas in Mesozoic Roks of the San Juan Basin: Anatomy of a Giant Energy-rich Basin, Finch, W. I., Huffman, A. C., Jr. and Fassett, J. E. eds. $28^{\text {th }}$ International Geological Congress, Field Trip Guidebook T120. $13-18$.

Dugan, T., (2002), A History of Fruitland Formation Coal-Bed Methane Development in the San Juan Basin, New Mexico and Colorado. Abstract. AAPG Conference.

Fasset, J. E. (2002), Laramide Structural Evolution of the San Juan Basin, New Mexico and Colorado. Abstract. AAPG Conference.

Gardner, G. H. F., Gardner, L. W., and Gregory, A. R. (1974), Formation velocity and density - the diagnostic basics for stratigraphic traps. Geophysics, 36, $770-780$. 
Gochioco, L. M. (1991), Tuning effect and interference reflections from thin beds and coal seams. Geophysics, 56, $1288-1295$.

Gochioco, L. M. (1992), Modeling studies of interference reflections in thin-layered media bounded by coal seams. Geophysics, 57, $1209-1216$.

Gorell, S. B. (1995), Using geostatistics to aid in reservoir characterization. The Leading Edge, 14, no. 9, $967-974$.

Hamilton, W. (1987), Plate-tectonic evolution of the western U.S.A. Episodes, 10, no. 4, $271-276$.

Hampson, D. P., Schuelke, J. S., James, S., and Quirein, J. A. (2001), Use of multiattribute transforms to predict log properties from seismic data. Geophysics, 66, $220-236$.

Hart, B. S. (1999), Geology plays key role in seismic attribute studies. Oil and Gas Journal, 97, no. 7, $76-80$.

Hart, B.S., and Pearson, R.A. (2000), Geological and geophysical characterization of Mesaverde and Dakota Formations. Final Report, Phase 1, US Department of Energy and Industry Cooperative Agreement DE-FC26-98FT40486, Chapter 3, 80p.

Hart, B.S., Pearson, R.A., Herrin, J.M., Engler, T., and Robinson, R.L. (2000), Horizon attributes and fracture-swarm sweet spots in low-permeability gas reservoirs. SPE 63207, presented at the 2000 SPE Annual Technical Conference and Exhibition, Dallas, CD-ROM, $7 \mathrm{p}$.

Hart, B. S., Pearson, R., Reawling, G. C. (2002), 3-D seismic horizon-based approaches to fracture-swarm sweet spot definition in tight-gas reservoirs. Geophysics, 66, $220-$ 236.

Heller, P. L., Bowdler, S. S., Chambers, H. P., Coogan, J. C., Hagen, E. S., Shuster, M. W. and Winslow, N. S. (1986), Time of initial thrusting in the Sevier orogenic belt, Idaho-Wyoming and Utah. Geology, 14, 388 - 391.

Hesthammer, J. and Fossen, H. (1997), The influence of seismic noise in structural interpretation of seismic attribute maps. First Break, 15, no. 6, $209-219$.

Hirsche, K., Porter-Hirsche, J., Mewhort, L., and Davis, R. (1997), The use and abuse of geostatistics. The Leading Edge, 16, no. 3, $247-251$.

Hirsche, K., Kalkomey, C., Boerner, S., and Gastaldi, C. (1998), Avoiding pitfalls in geostatistical reservoir characterization: A survival guide. The Leading Edge, 17, no. $4,493-504$. 
Hughes, V. J. and Kennett, B. L. N. (1983), The nature of seismic reflections from coal seams. First Break, 1, no. 2, $9-18$.

Kaiser, W. R. and Ayers, W. B., Jr. (1994), Coalbed methane production, Fruitland Formation, San Juan Basin: geologic and hydrologic controls. in Coalbed methane in the Upper Cretaceous Fruitland Formation, San Juan Basin, New Mexico and Colorado, Ayers, W. B., Jr and Kaiser, W. R., Eds.: Bureau of Economic Geology. Bulletin 146, $187-207$.

Kalkomey, C. T. (1997), Potential risks when using seismic attributes as predictors of reservoir properties. The Leading Edge, 16, no. 13, 247 - 251.

Laubach, S. E. and Tremian, C. M. (1994), Tectonic setting of the San Juan Basin, in Coalbed methane in the Upper Cretaceous Fruitland Formation, San Juan Basin, New Mexico and Colorado, Ayers, W. B., Jr and Kaiser, W. R., Eds.: Bureau of Economic Geology. Bulletin 146, $9-11$.

Kalkomey, C. T. (1997), Potential risks when using seismic attributes as predictors of reservoir properties. The Leading Edge, 16, $247-251$.

Lehman, E. L. and D’Abrera, H. J. M. (1998), Nonparametrics: Statistical methods based on ranks. Upper Saddle River, NJ. Prentice-Hall, 292, 303 and 323.

Leiphart, D. J. and Hart, B. S. (2001), Comparison of linear regression and a probabilistic neural network to predict porosity from 3-D seismic attribute in lower Brushy Canyon channeled sandstones, southeast New Mexico. Geophysics, 66, 1349 - 1358.

Partyka, G. A. (2000), Seismic attribute sensitivity to energy, bandwidth, phase and thickness, 70 ${ }^{\text {th }}$ Ann. Internat. Mtg.: Soc. of Expl. Geophysics, $2405-2048$.

Pashin, J. C. (1998), Stratigraphy and structure of coalbed methane reservoirs in the United States: An overview. International Journal of Coal Geology, 35, $209-240$.

Ridgley, J. L. (1989), Introduction to the geology and geography of the San Juan Basin, in Coal, Uranium, an Oil and Gas in Mesozoic Roks of the San Juan Basin: Anatomy of a Giant Energy-rich Basin, Finch, W. I., Huffman, A. C., Jr. and Fassett, J. E. eds. $28^{\text {th }}$ International Geological Congress, Field Trip Guidebook T120. $9-12$.

Roberts, A. (2001), Curvature attributes and their application to 3-D interpreted horizons. First Break, 19, no. 2, $85-99$.

Robinson, R.L. (2001), Estimation of drainage from production analysis of the MesaVerde Field, San Juan Basin, New Mexico. Unpublished M.S. thesis, New Mexico Tech, Socorro, NM, 116 p. 
Russell, B., Hampson, D., Schuelke, J. and Quirein, J. (1997), Multiattribute seismic analysis. The Leading Edge, 16, 1439-1443.

Schultz, P. S., Ronen, S., Hattori, M., Mantran, P. and Corbett, C. (1994), Seismic guided estimation of log properties. Part 3: A controlled study. The Leading Edge, 13, no. 7, $770-776$.

Steen, Ø., Sverdrup, E., and Hansson, T. H. (1998), Predicting the distribution of small faults in a hydrocarbon reservoir by combining outcrop, seismic and well data. in Faulting, Fault Sealing and Fluid Flow in Hydrocarbon Reservoirs, Jones, G., Fisher, Q. J., and Knipe, R. J.: Geologic Society, London, Special Publication, 147, 27 - 50.

Stewart, S.A. and Wynn, T.J., 2000, Mapping spatial variation in rock properties in relationship to scale-dependent structure using spectral curvature. Geology, 28, 691694.

Taner, M. T., Koehler, F., and Sheriff, R. E. (1979), Complex seismic trace analysis. Geophysics, 44, $1041-1063$.

Teldford, W. M., Geldart, L. P. and Sheriff, R. E. (1990), Applied Geophysics, $2^{\text {nd }}$ Edition. Cambridge University Press, New York, 147, 669.

Tremain, C. M., Laubach, S. E., and Whitehead, N. H., III (1994), Fracture (cleat) patterns in Upper Cretaceous Fruitland Formation coal seams, San Juan Basin. in Coalbed methane in the Upper Cretaceous Fruitland Formation, San Juan Basin, New Mexico and Colorado, Ayers, W. B., Jr and Kaiser, W. R., Eds.: Bureau of Economic Geology. Bulletin 146, $87-102$.

Widess, M. B. (1973), How thin is a thin bed?. Geophysics, 38, no. 6, $1176-1180$. 
Table 2.1. Log picks and derived thickness and net sand for the Dakota Formation.

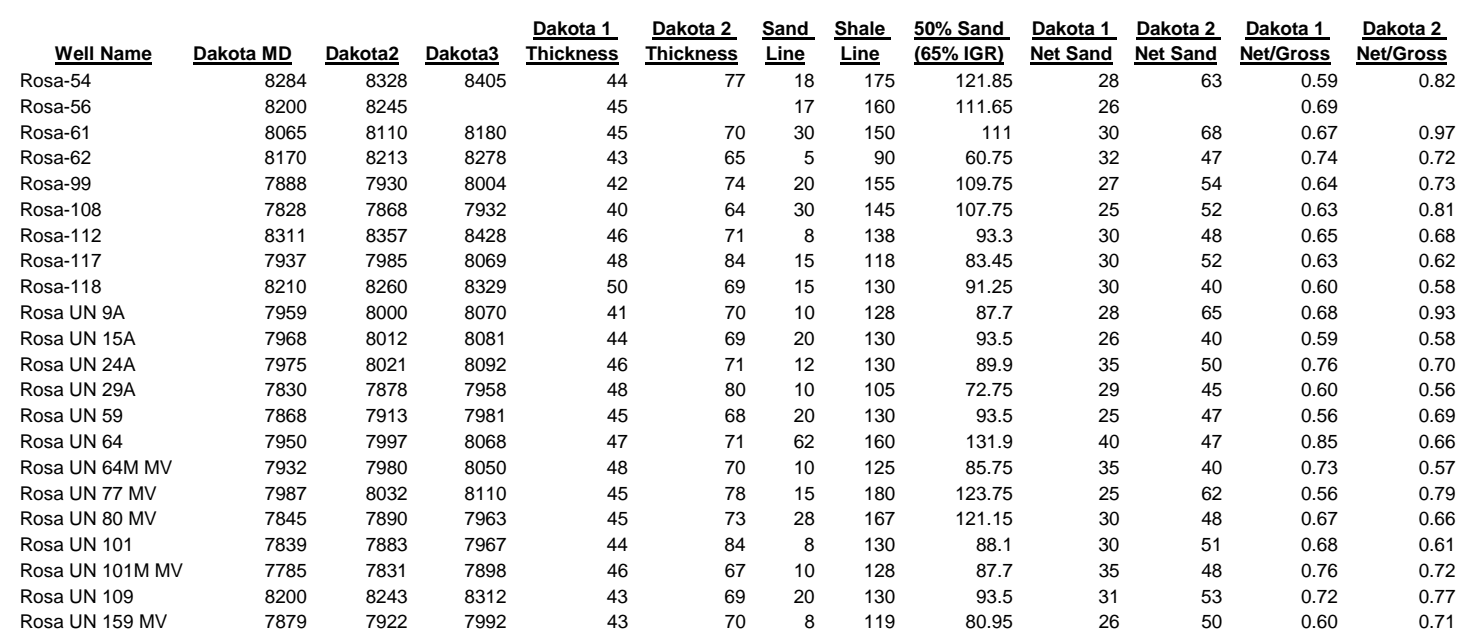


Table 2.2. Spearman's rank correlation coefficient between seismic amplitude attributes and coal thickness.

\begin{tabular}{|l|c|}
\hline Amplitude Attribute & Spearman's rank correlation \\
\hline Maximum absolute amplitude & 0.737 \\
\hline Total energy & 0.723 \\
\hline Variance in amplitude & 0.720 \\
\hline Kurtosis amplitude & 0.698 \\
\hline Average energy & 0.686 \\
\hline Root mean square amplitude & 0.686 \\
\hline Composite amplitude & 0.676 \\
\hline Average reflection strength & 0.658 \\
\hline Average absolute amplitude & 0.630 \\
\hline Total absolute amplitude & 0.620 \\
\hline Integrated trace & -0.619 \\
\hline Trace length & 0.581 \\
\hline Amplitude envelope & 0.576 \\
\hline Total amplitude & -0.516 \\
\hline Reflection strength slope & -0.495 \\
\hline Integrate absolute amplitude & 0.485 \\
\hline Mean amplitude & -0.474 \\
\hline Amplitude & -0.411 \\
\hline Skew amplitude & 0.235 \\
\hline
\end{tabular}




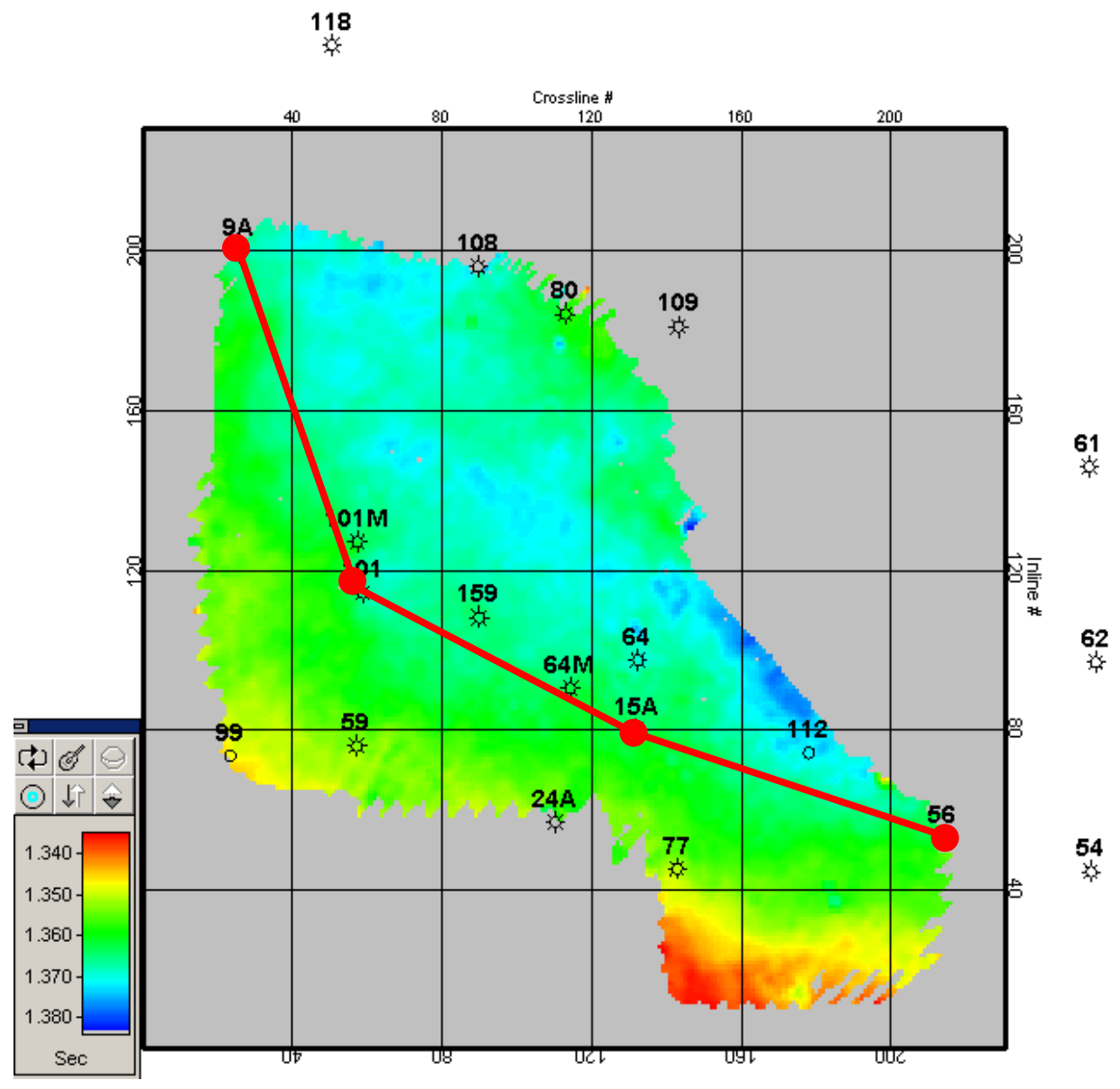

Figure 2.1. Map showing database for Dakota sub-project. Colored background shows time-structure (TWT) of Dakota top from 3-D seismic data. Circles show locations of wells with digital logs through the Dakota. Red line shows location of log cross-section shown in Figure 2.4. 


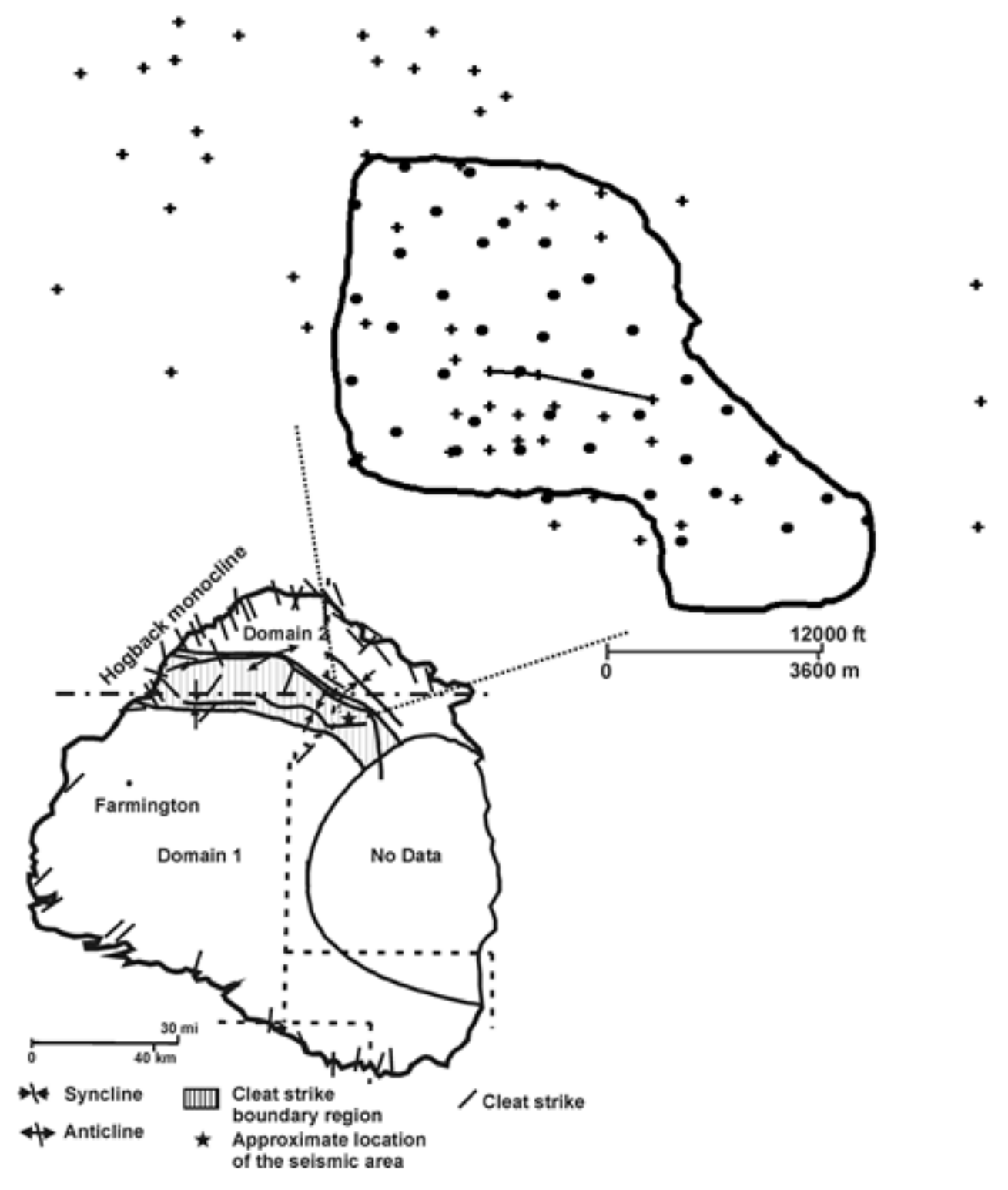

Figure 2.2. Location of Rosa study area (lower left) and 3-D seismic and log database for the Fruitland sub-project. 


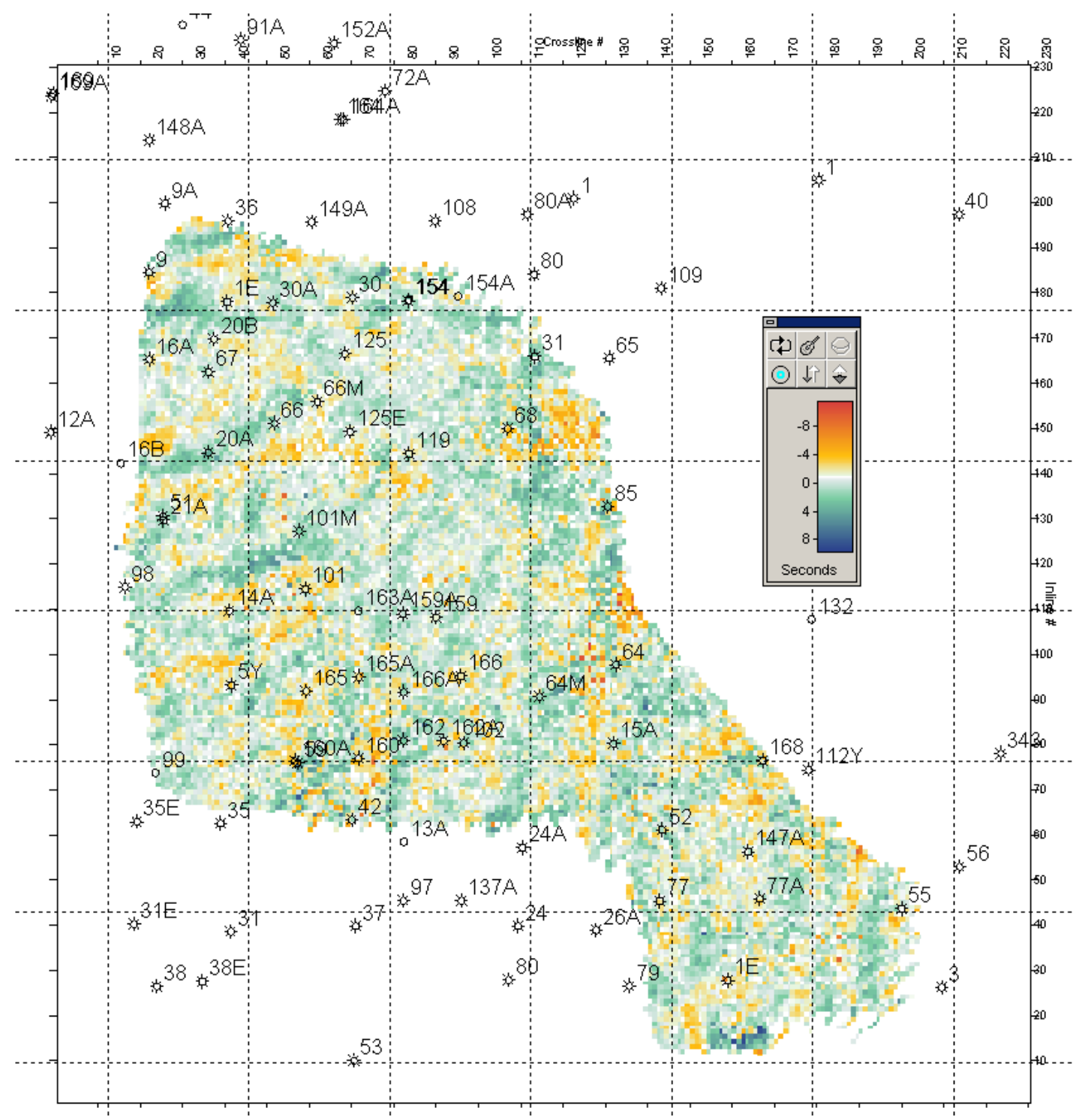

Figure 2.3. Strike curvature of the Dakota Formation calculated with an aperture of 3. Note the SW-NE lineation (turquoise trend) through the \#66 well (the best-producing well from the Dakota) in the upper left (red circle). Not all wells shown produce from the Dakota. This structural feature was probably produced by reactivation of a NE-SW striking Paleozoic normal fault during Laramide compression (from Hart and Pearson, 2001). 


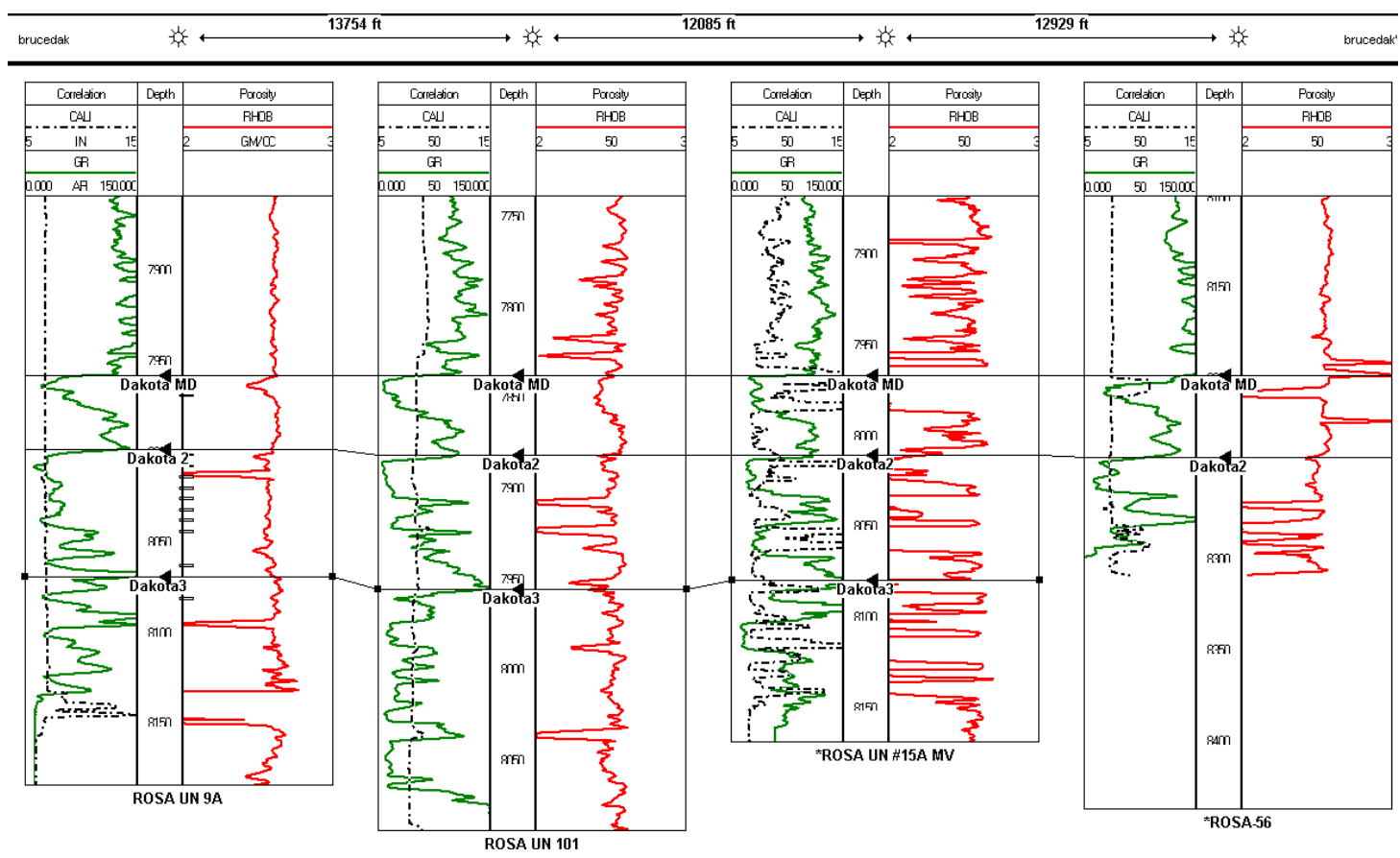

Figure 2.4. NW (left) to SE (right) log cross-section through the Dakota Formation in the Rosa 3-D seismic study area (see Figure 1 for location). Gamma ray (green) and caliper (black) curves on track 1, density (red) in track 3. Rosa UN 9A well shows location of perforations. Note variations of borehole washouts from well to well and up/down section within a well. Washouts often associated with density spikes (anomalously low values). Notice variability in thickness and lithology (net sand) within the interval ("uppermost parasequence") between the Dakota MD and Dakota 2 picks. The Dakota 3 pick could not be picked in all wells, because some were not drilled deeply enough (e.g., Rosa 56). 


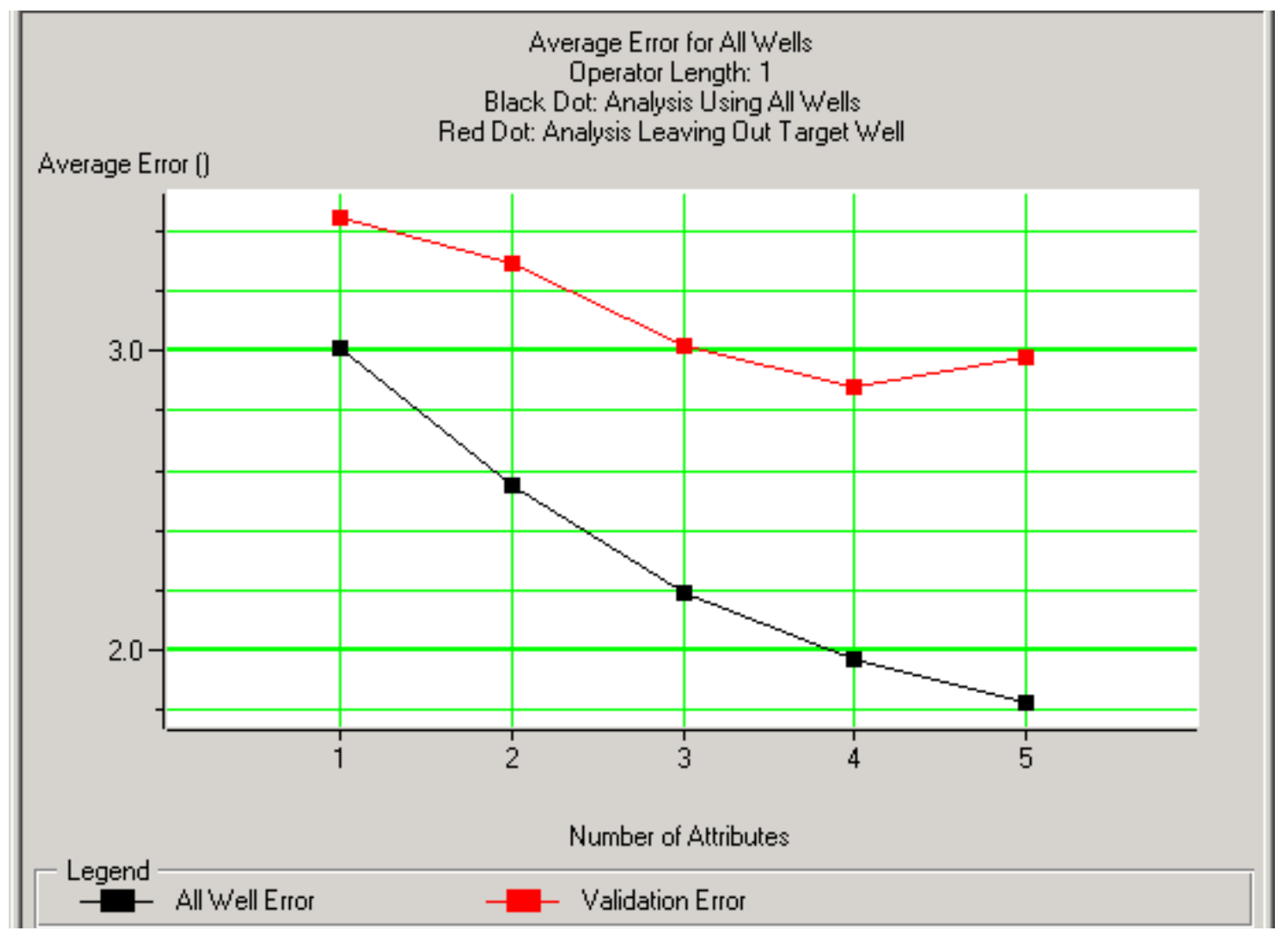

Figure 2.5. Validation error (red curve) and prediction error (black curve) against the number of attributes used in the stepwise linear regression. The validation error curve indicates that the optimal number of attributes to predict net sandstone in the upper Dakota parasequence is four (see text). 

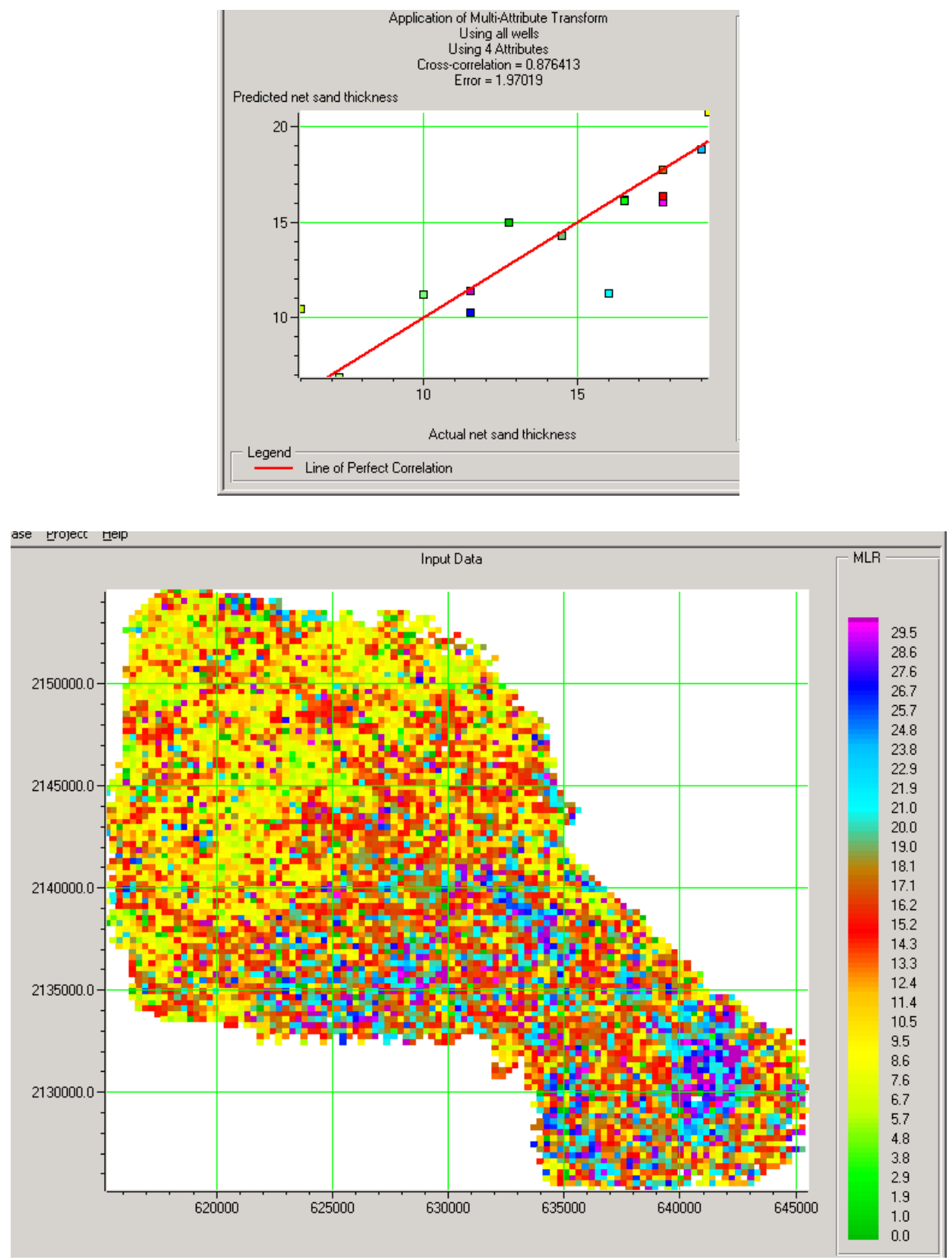

Figure 2.6. Top - predicted versus measured net sand using the multivariate linear regression technique (correlation coefficient $=0.88$ ). Below - map showing predicted net sand within the 3-D seismic study area. Highest values (blue) are predicted for the SE part of the survey area. 

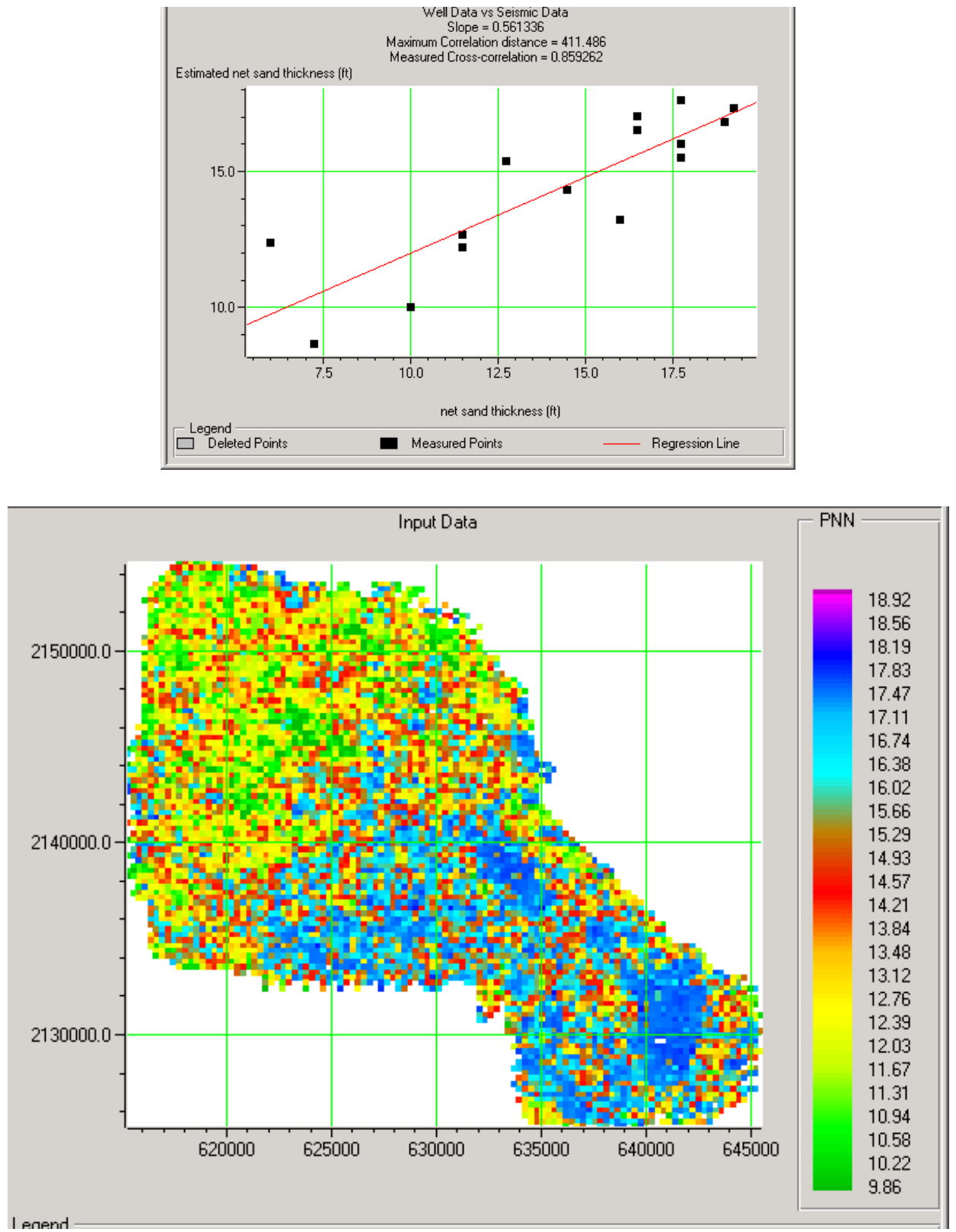

Figure 2.7. Top - predicted versus measured net sand using the probabilistic neural network technique (correlation coefficient $=0.86$ ). Below - map showing predicted net sand within the 3-D seismic study area. Highest values (blue) are predicted for the SE part of the survey area. 

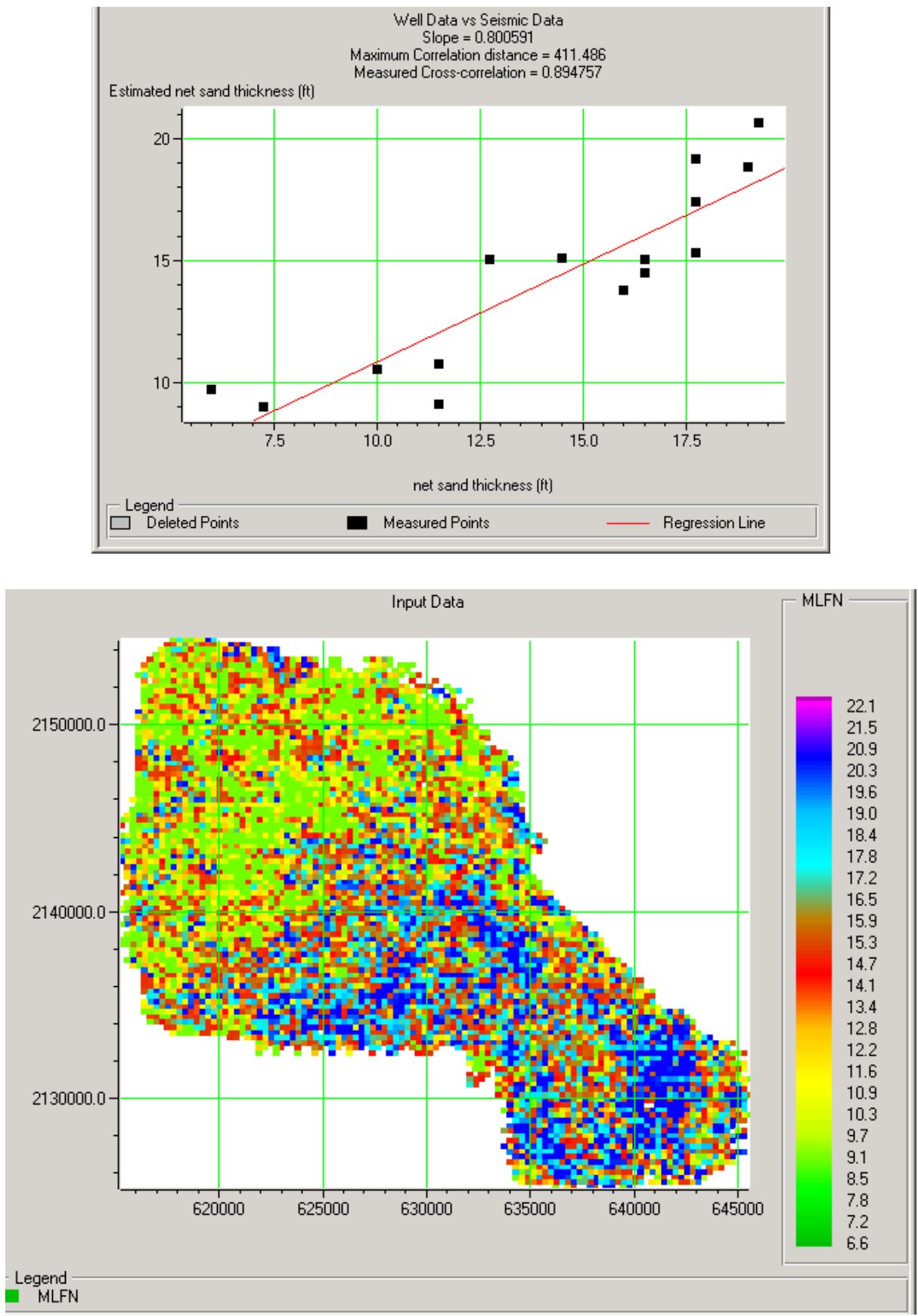

Figure 2.8. Top - predicted versus measured net sand using the multi-layer feed-forward neural network technique (correlation coefficient $=0.89$ ). Below - map showing predicted net sand within the 3-D seismic study area. Highest values (blue) are predicted for the SE part of the survey area. 

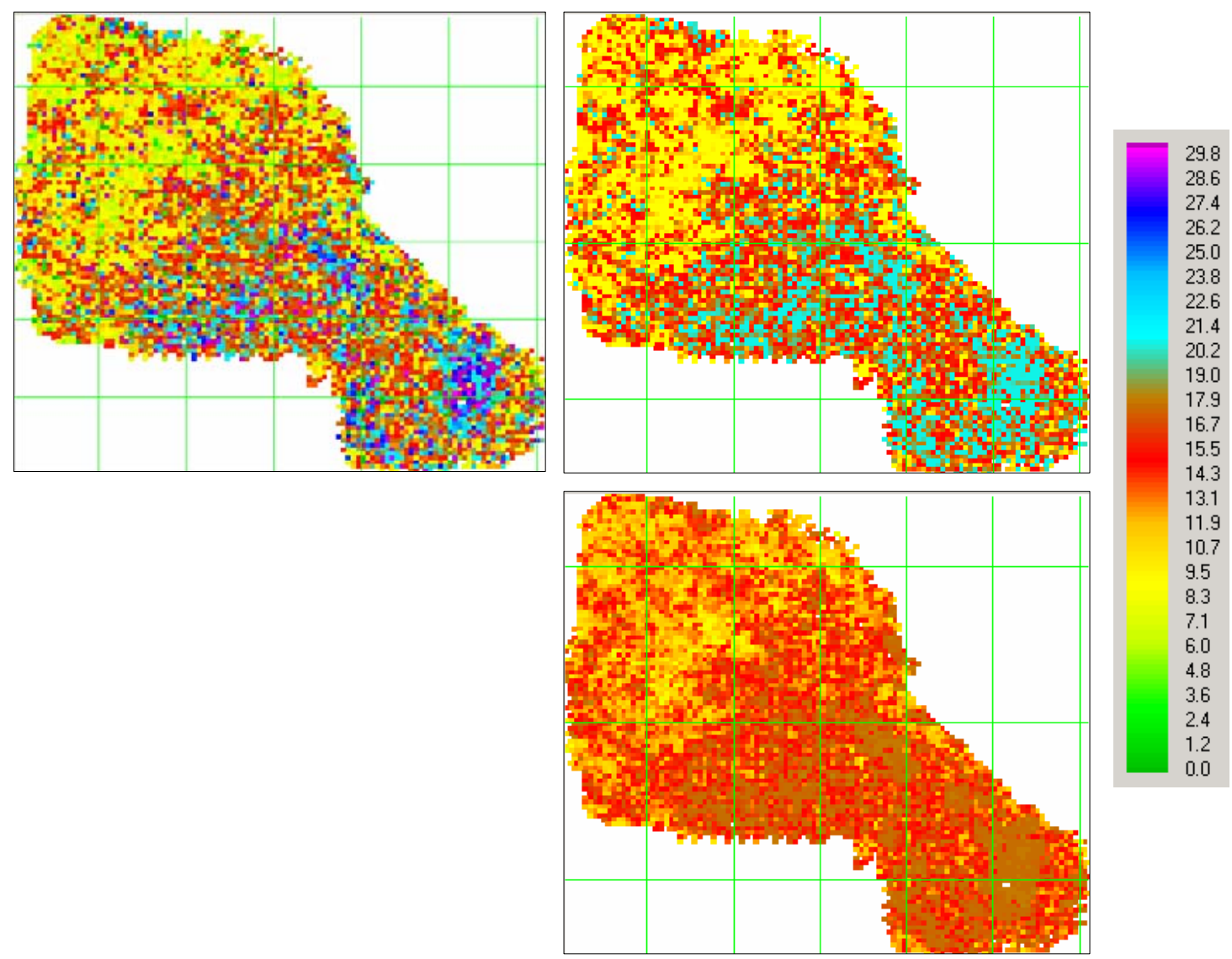

Figure 2.9. Comparison of MLR (upper left), PNN (lower right) and MLFN (upper right) predictions of net sand. The same scale is used in each case. The MLR map has higher variance and predicts higher values than the other two approaches. All results show increase in net sand to the southeast and NW-SE trends ( $\sim$ shore parallel) in net sand. 


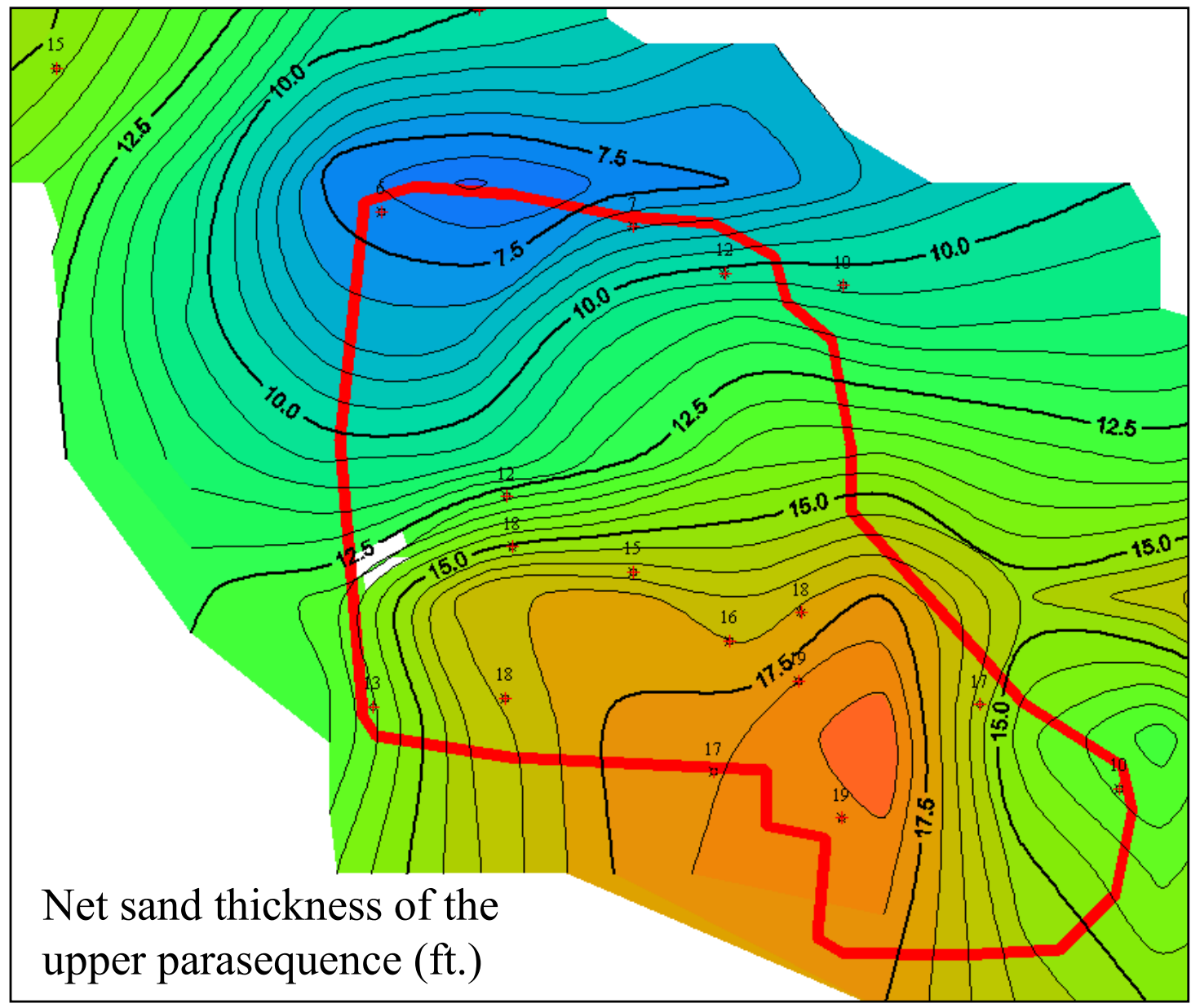

Figure 2.10. Log-based prediction of net sand thickness for the upper parasequence of the Dakota Formation. This map, in agreement with the seismic-based predictions (Fig. 2.9) suggests highest net sand values in the southeastern part of the 3-D survey area. However, the seismic-based predictions show much more heterogeneity and more geologically plausible trends. 


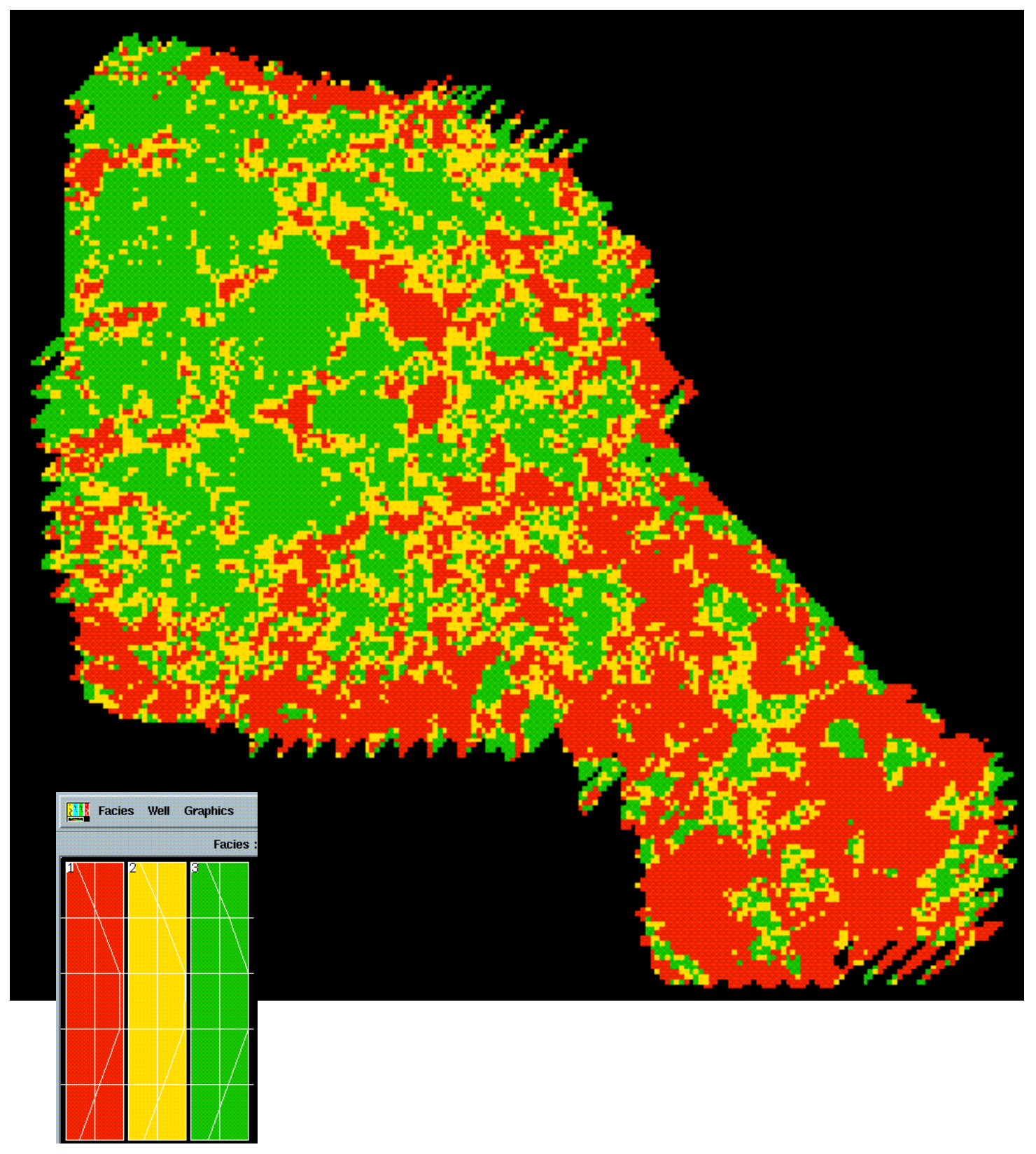

Figure 2.11. Seismic facies classification of reflection corresponding to the top of the Dakota Formation. Three facies were selected. Inset shows color-coded "end member" waveform types. 


\section{Seismic Trace Groupings}

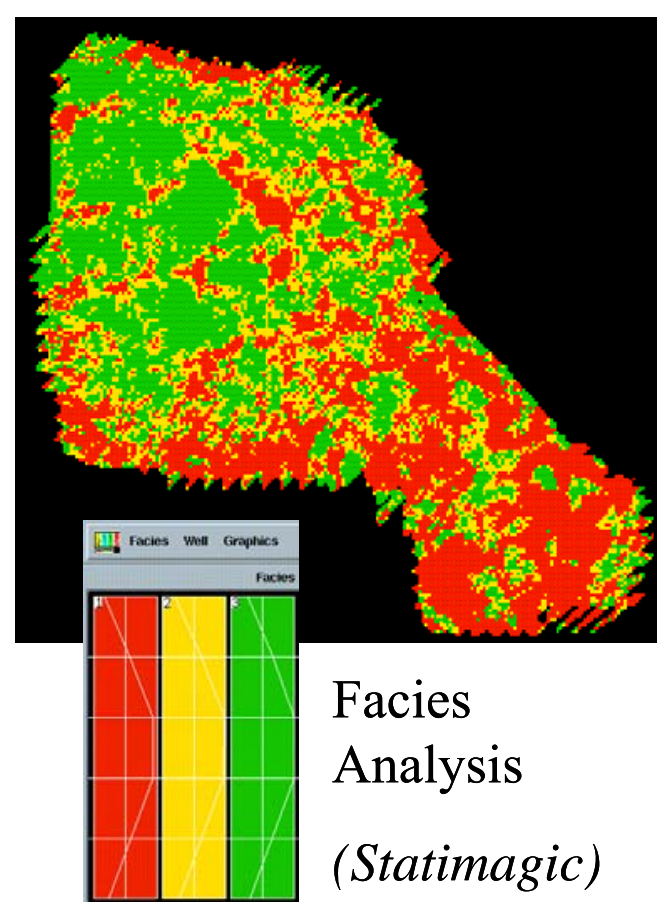

\section{Attribute Based Thickness Groupings}

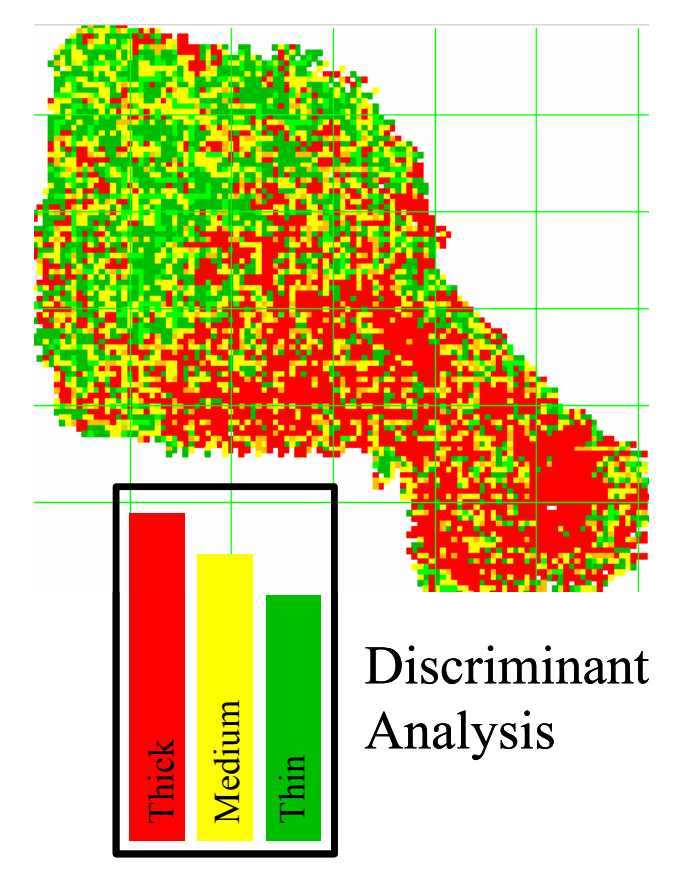

Figure 2.12. Comparison of seismic facies analysis (left) with seismic attribute analysis (right). Areas of thick, medium and thin net sand (red, yellow and green, respectively) identified from the seismic attribute analysis are strikingly similar to the different types of seismic facies identified on the left. 


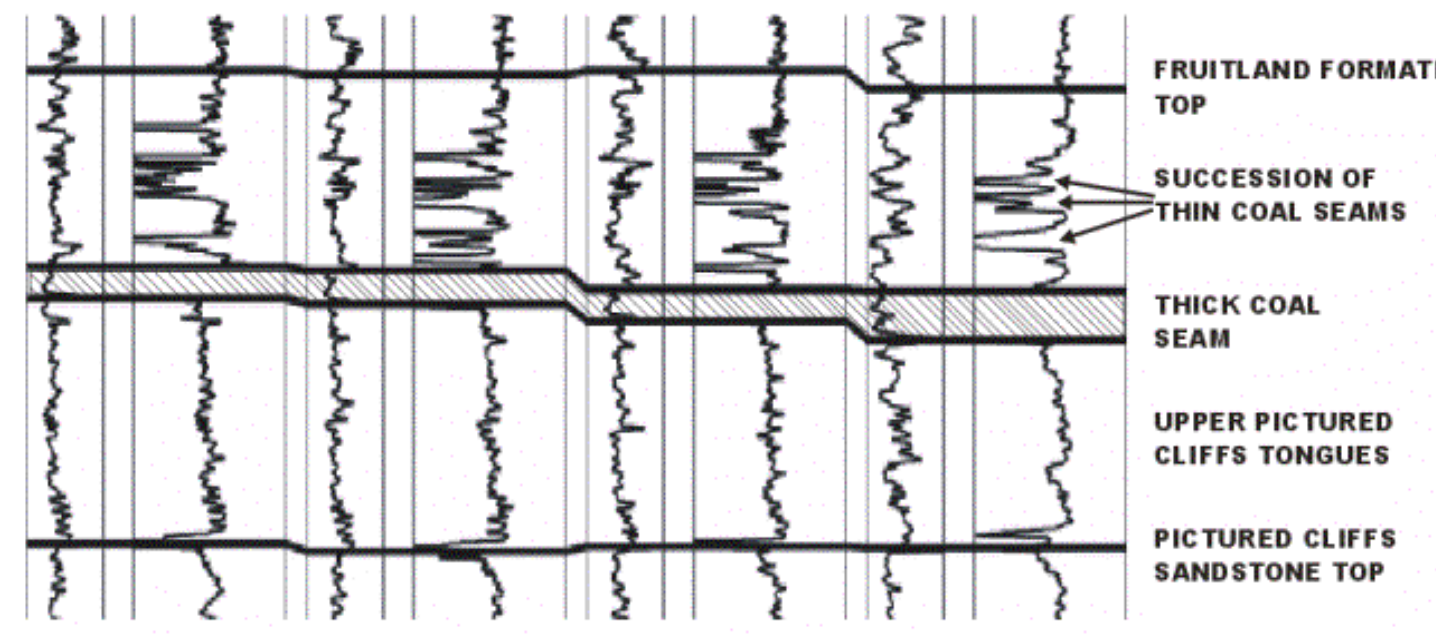

Figure 2.13. Wireline log cross-section (gamma ray on left, density log on right) showing stratigraphic units studied in this report. 


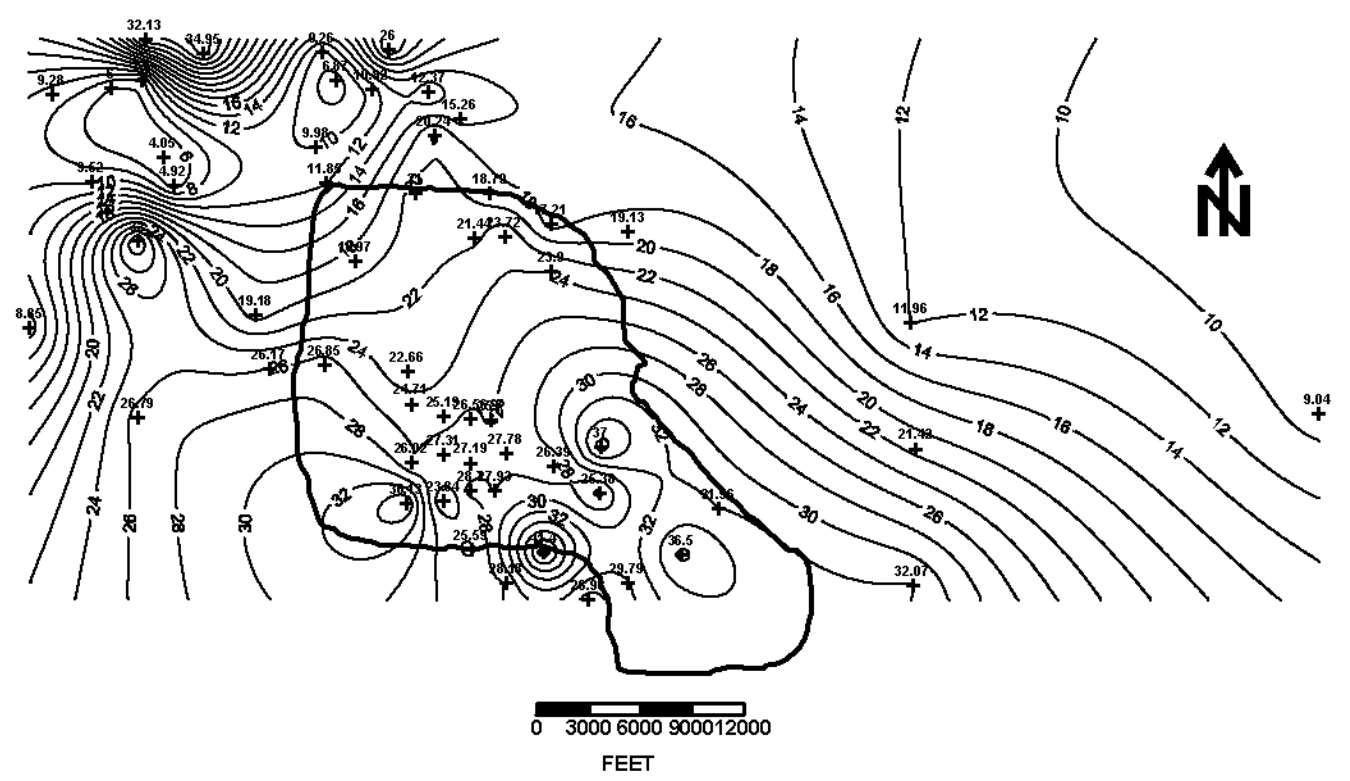

Figure 2.14. Thickness of basal coal layer based on kriging of well log data. Note outline of 3-D seismic survey area. 


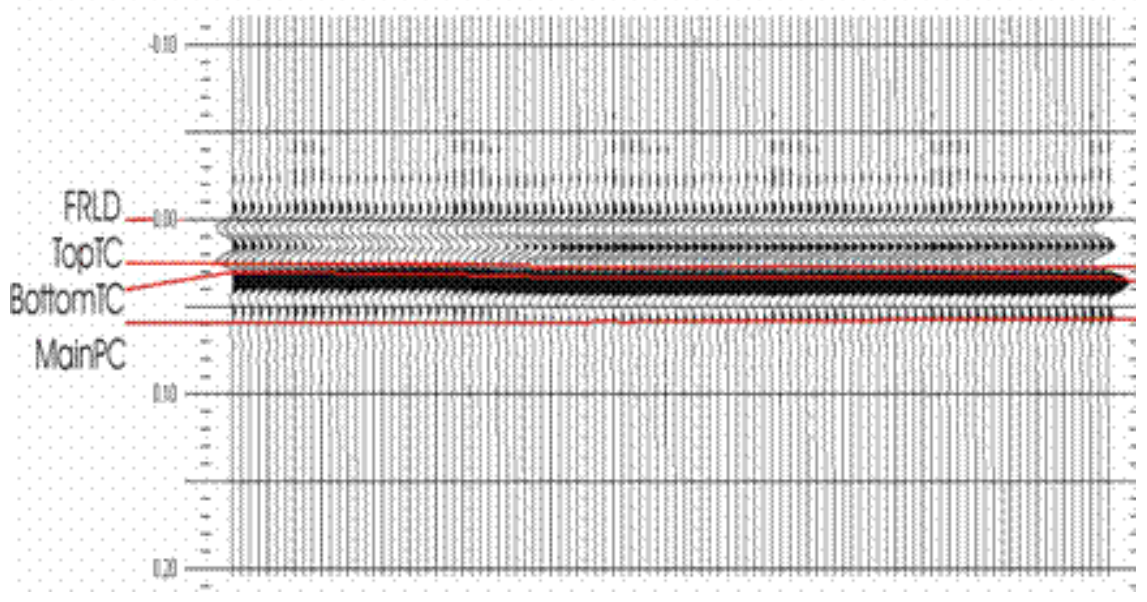

Figure 2.15. Log-based seismic model showing expected character of principal stratigraphic horizons. 


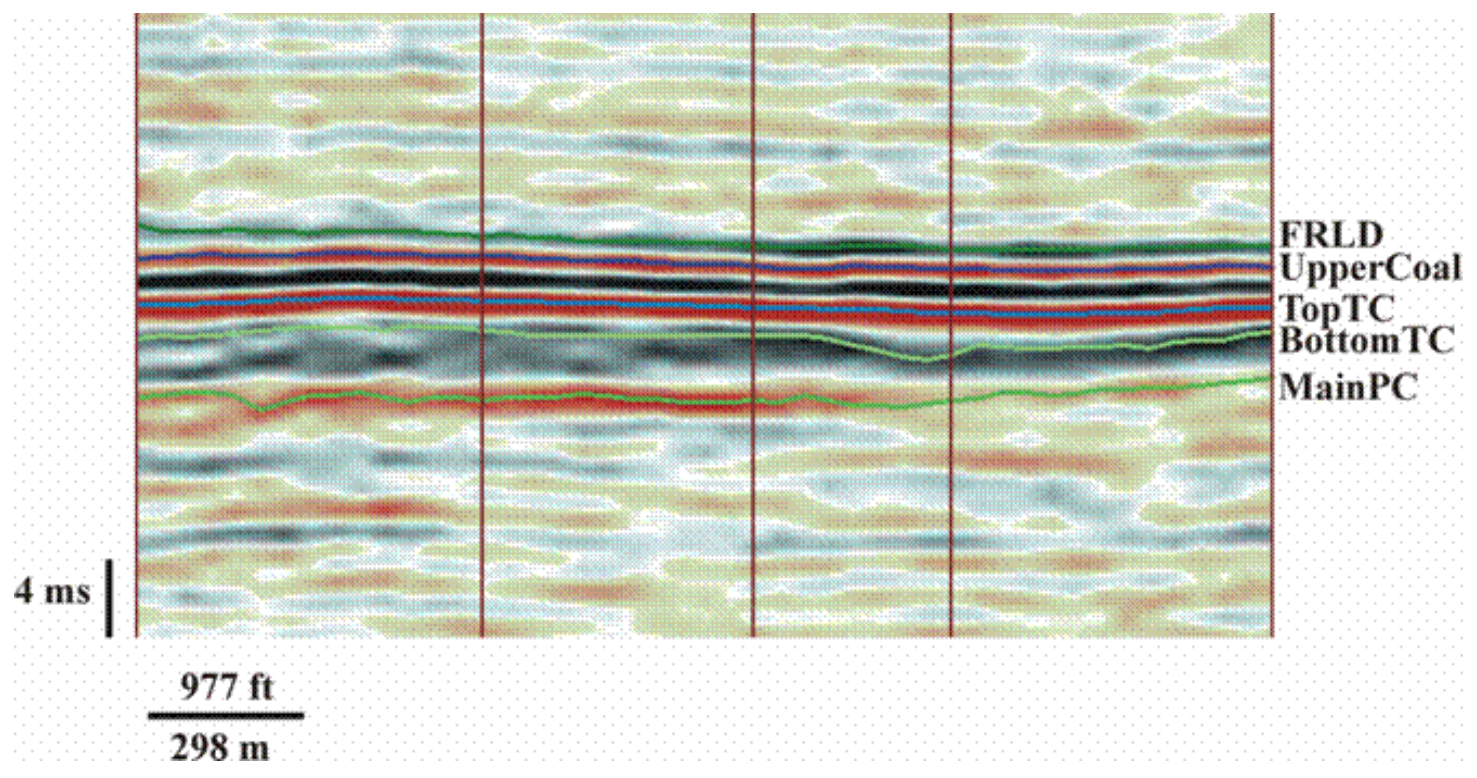

Figure 2.16. Sample seismic transect showing picks. 


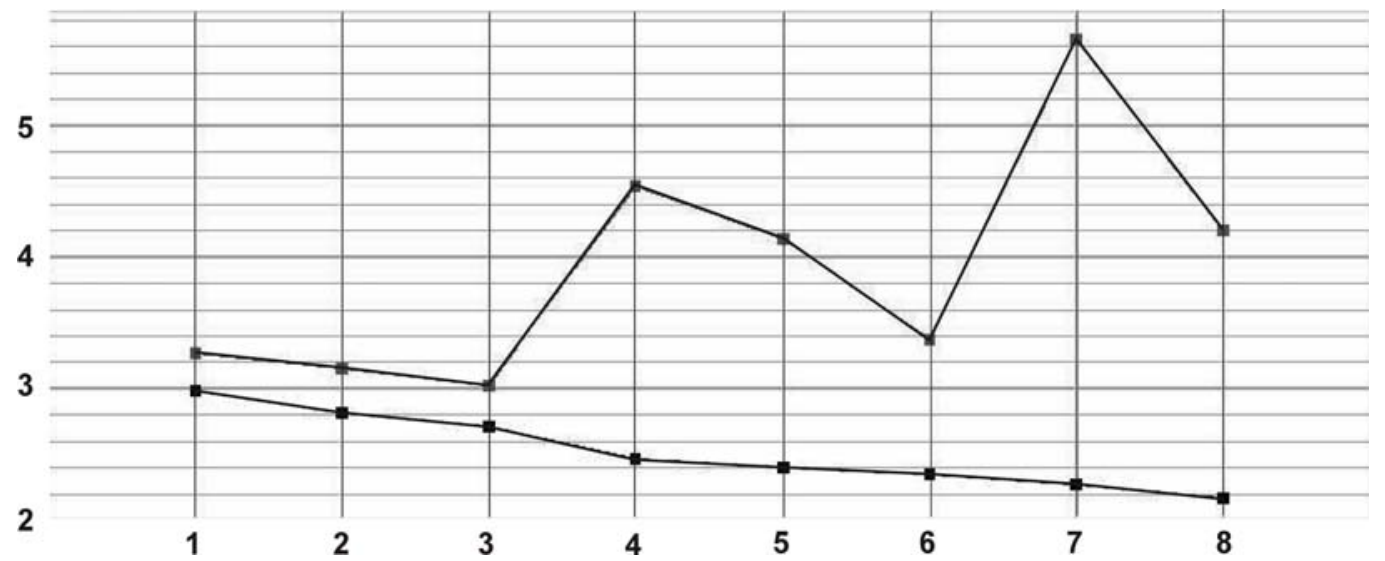

Figure 2.17 - Validation (top) and prediction (below) error. The optimum number of attributes used to predict coal thickness is three. 


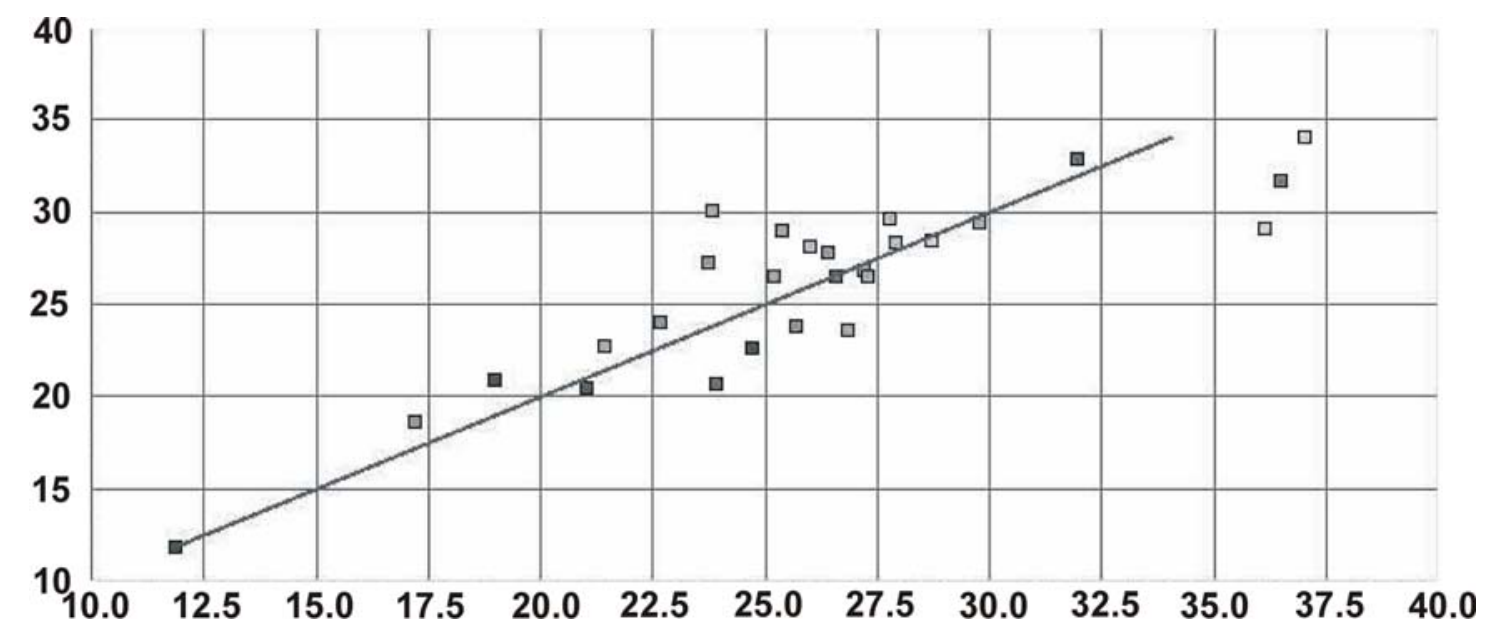

Figure 2.18. Predicted versus measured thickness for lower coal layer at well locations. 


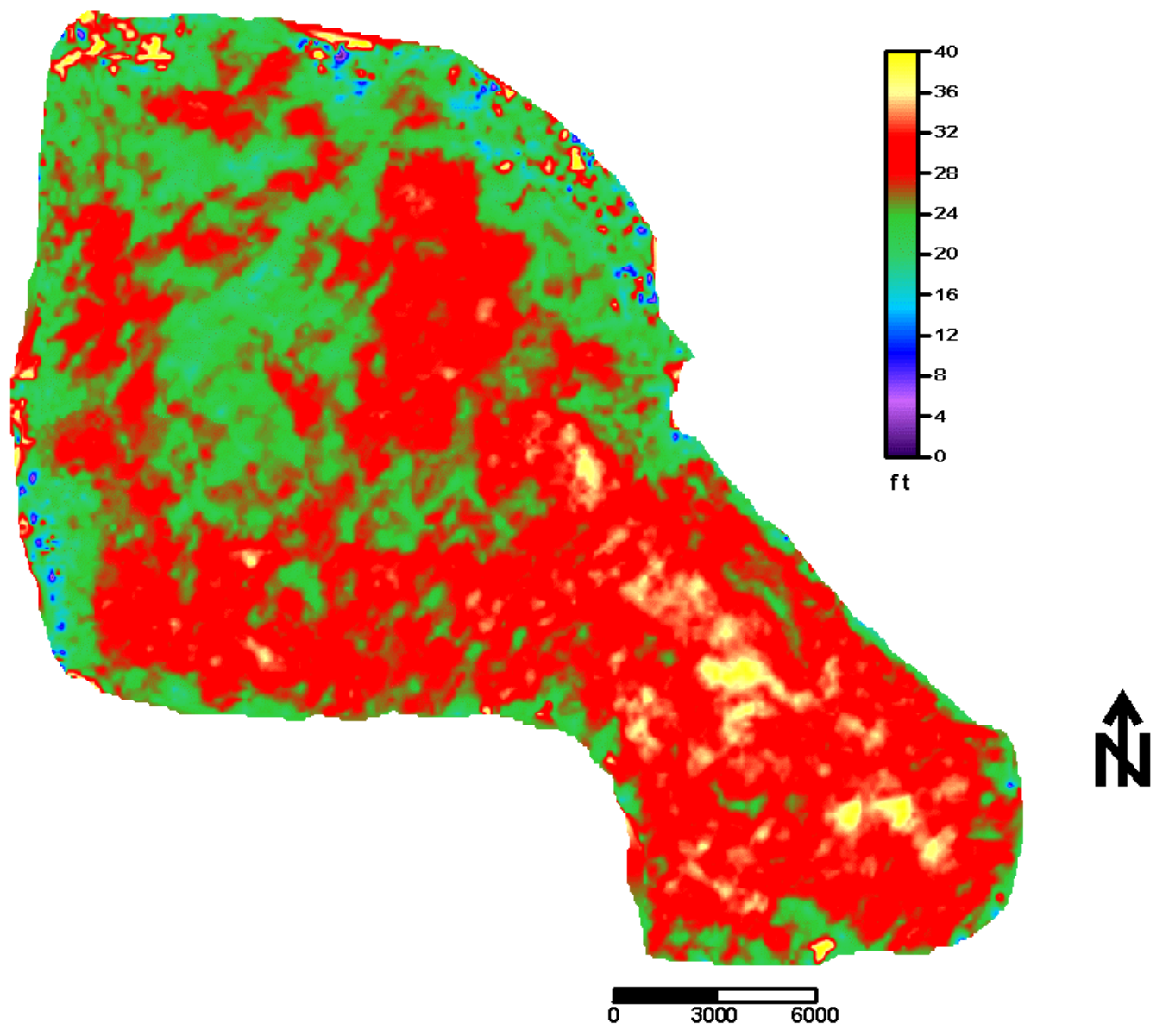

Figure 2.19. Seismic attribute-based prediction of coal thickness (in feet). 


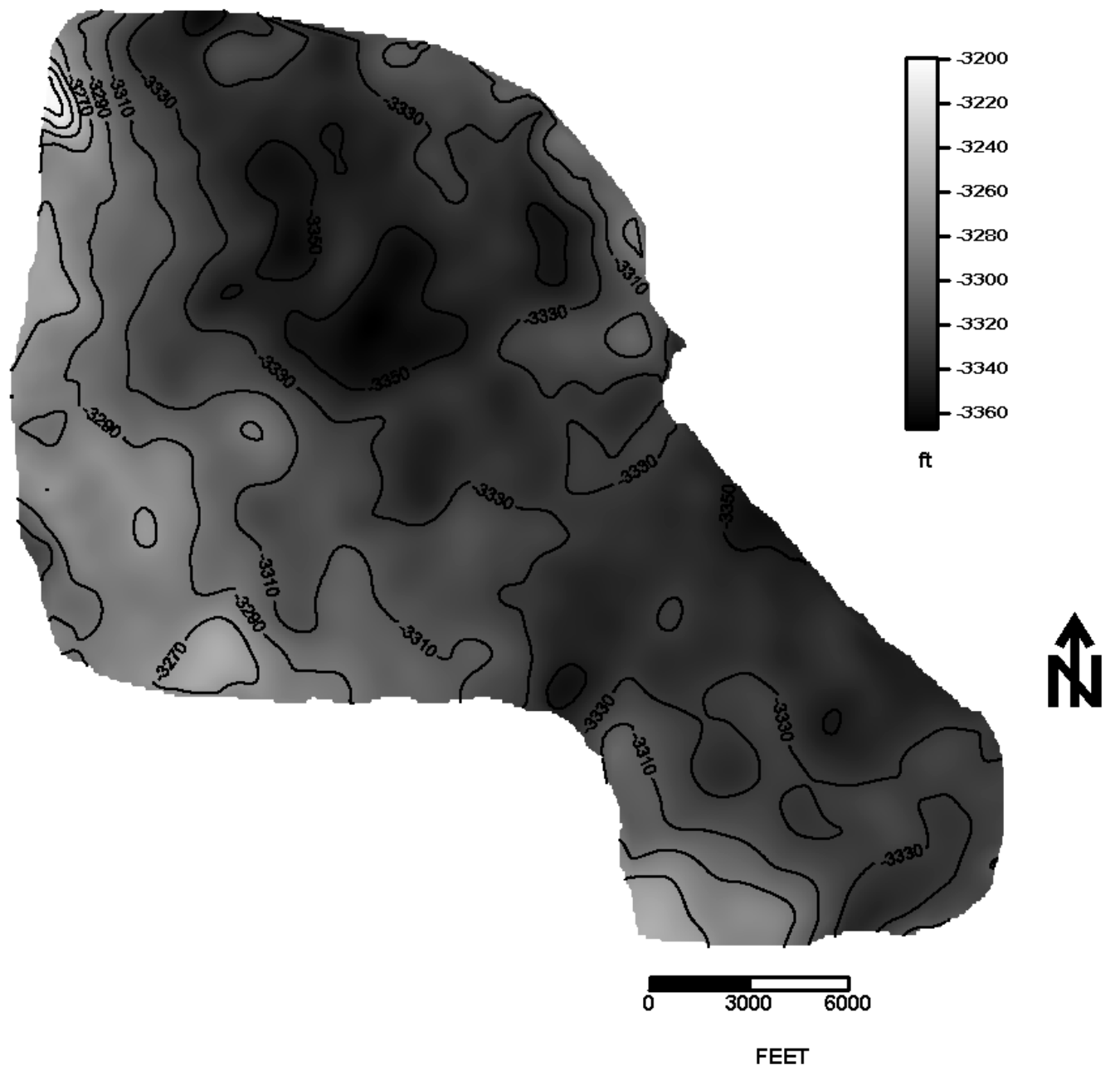

Figure 2.20. Depth-converted structure map of the top of the thick coal layer (TopTC seismic horizon). 


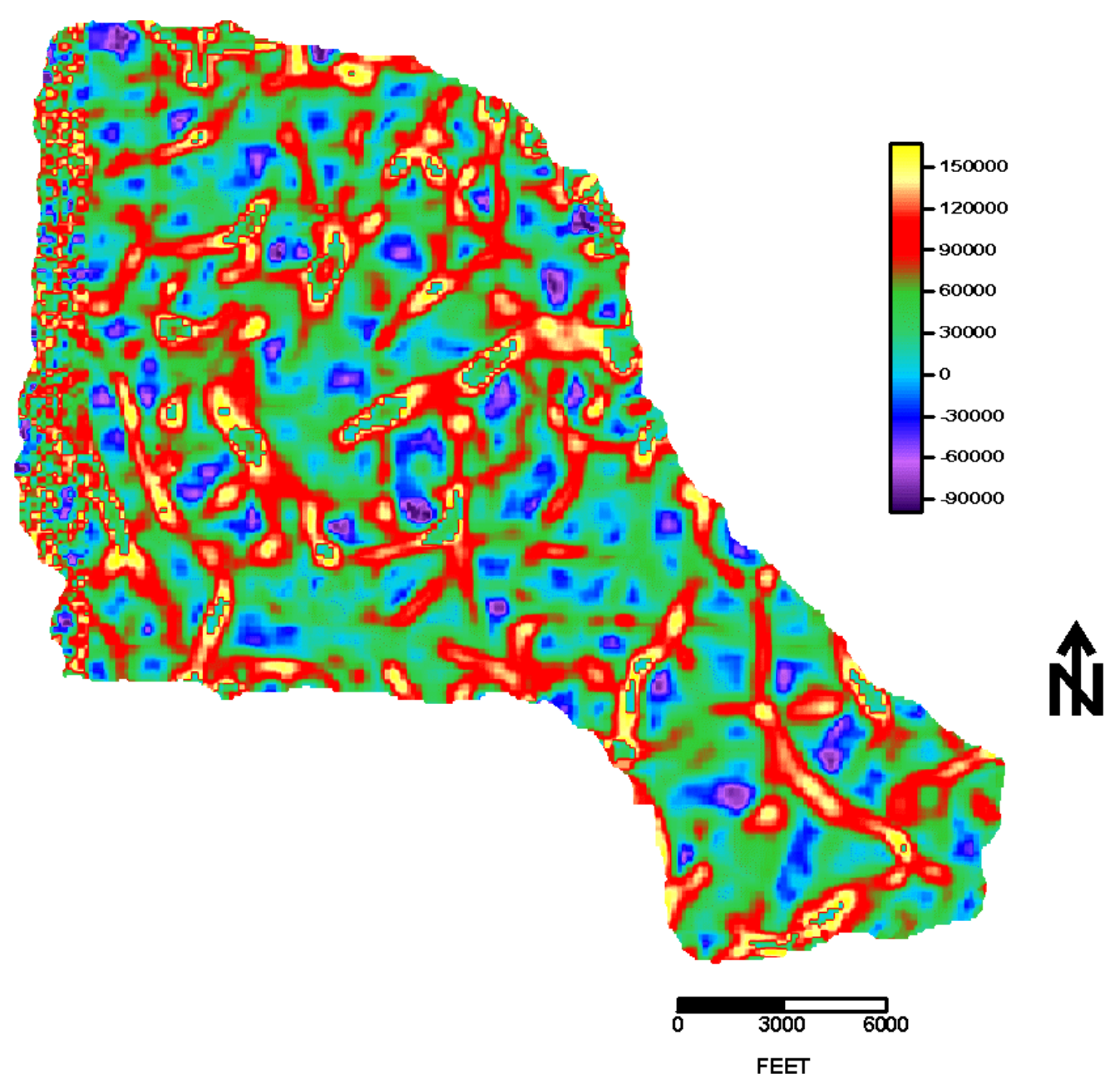

Figure 2.21. Maximum curvature map of the TopTC seismic pick. 


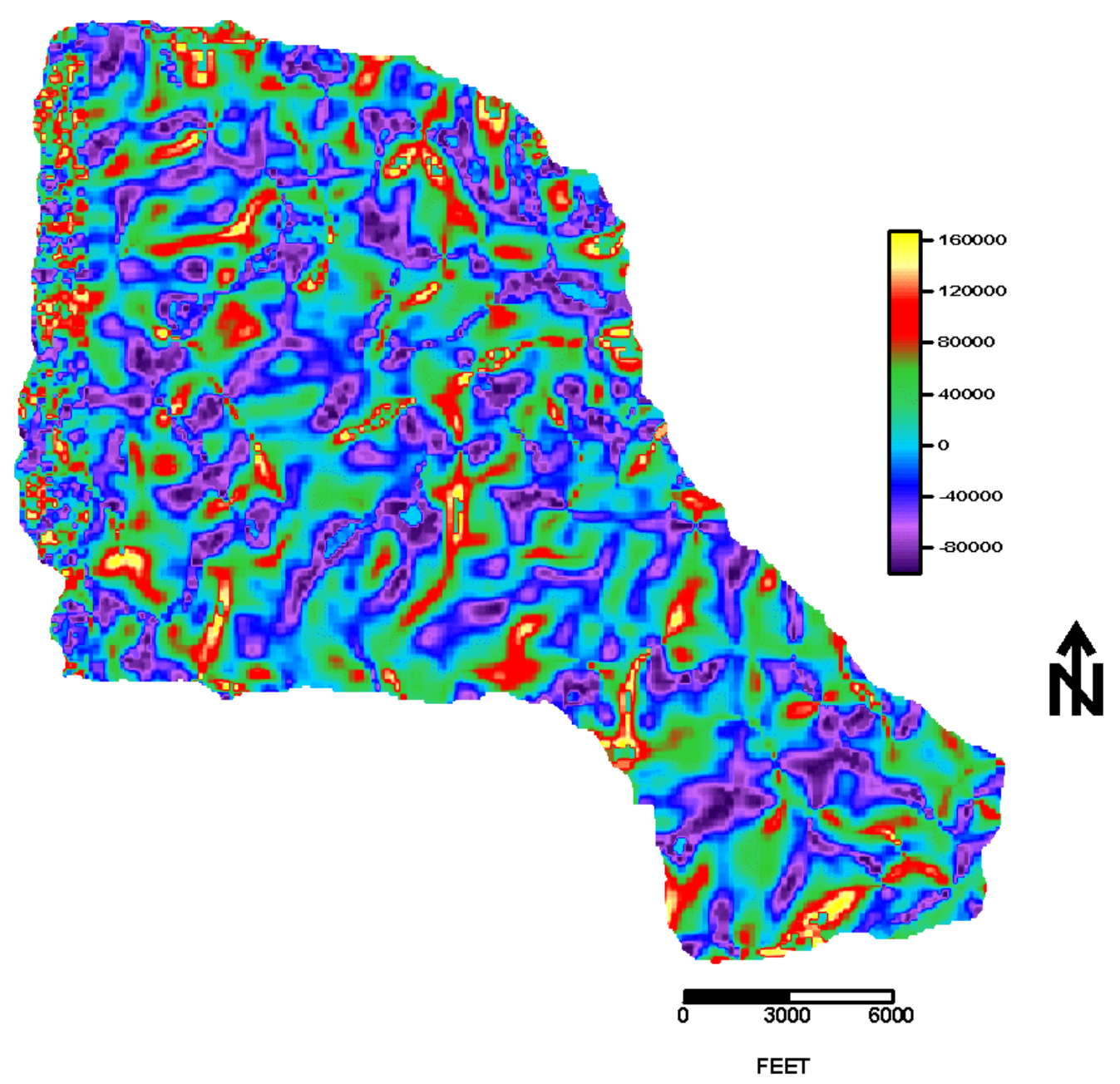

Figure 2.22. Strike curvature map of the TopTC seismic horizon. 


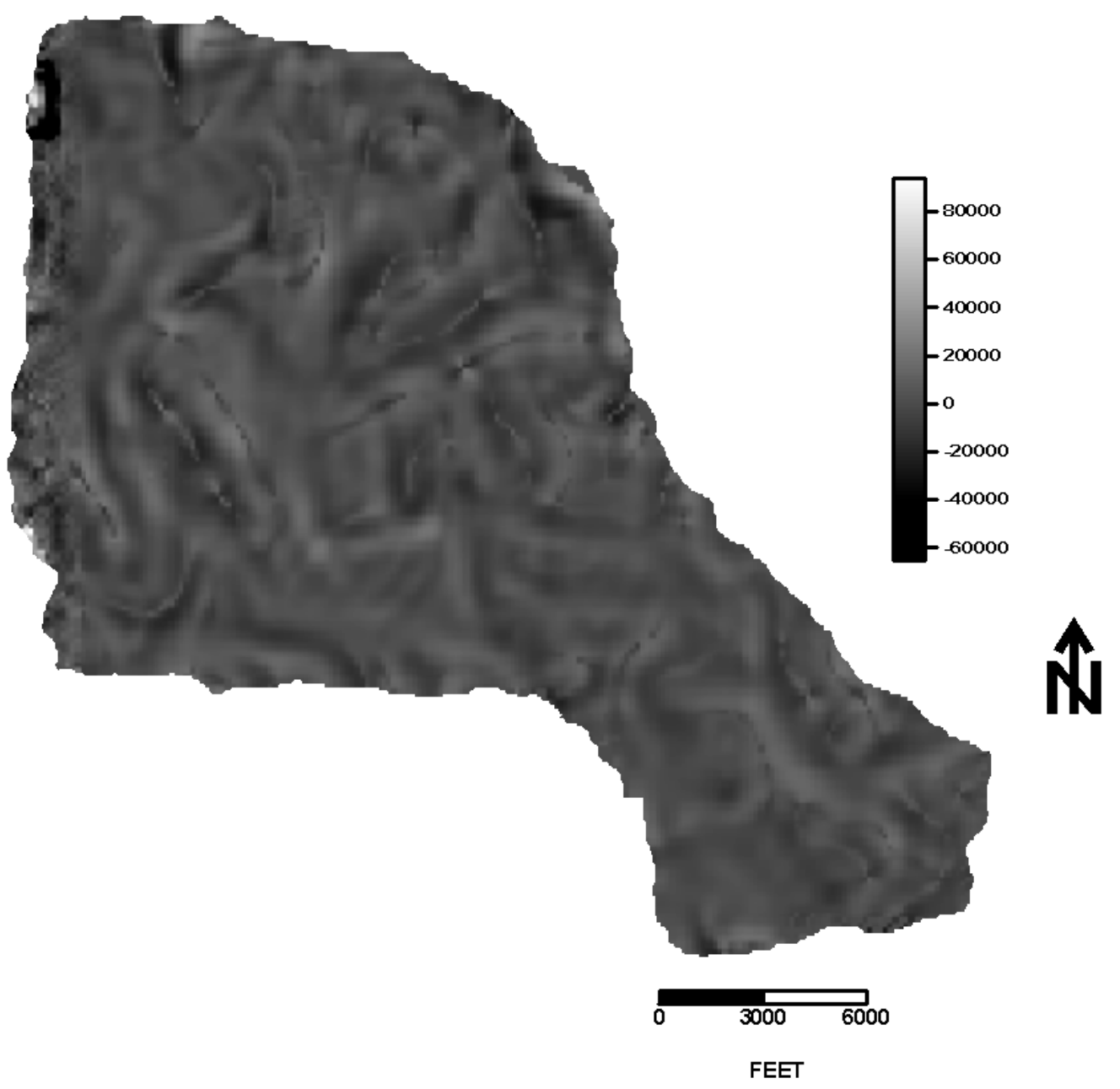

Figure 2.23. Dip curvature map of the TopTC seismic horizon. 


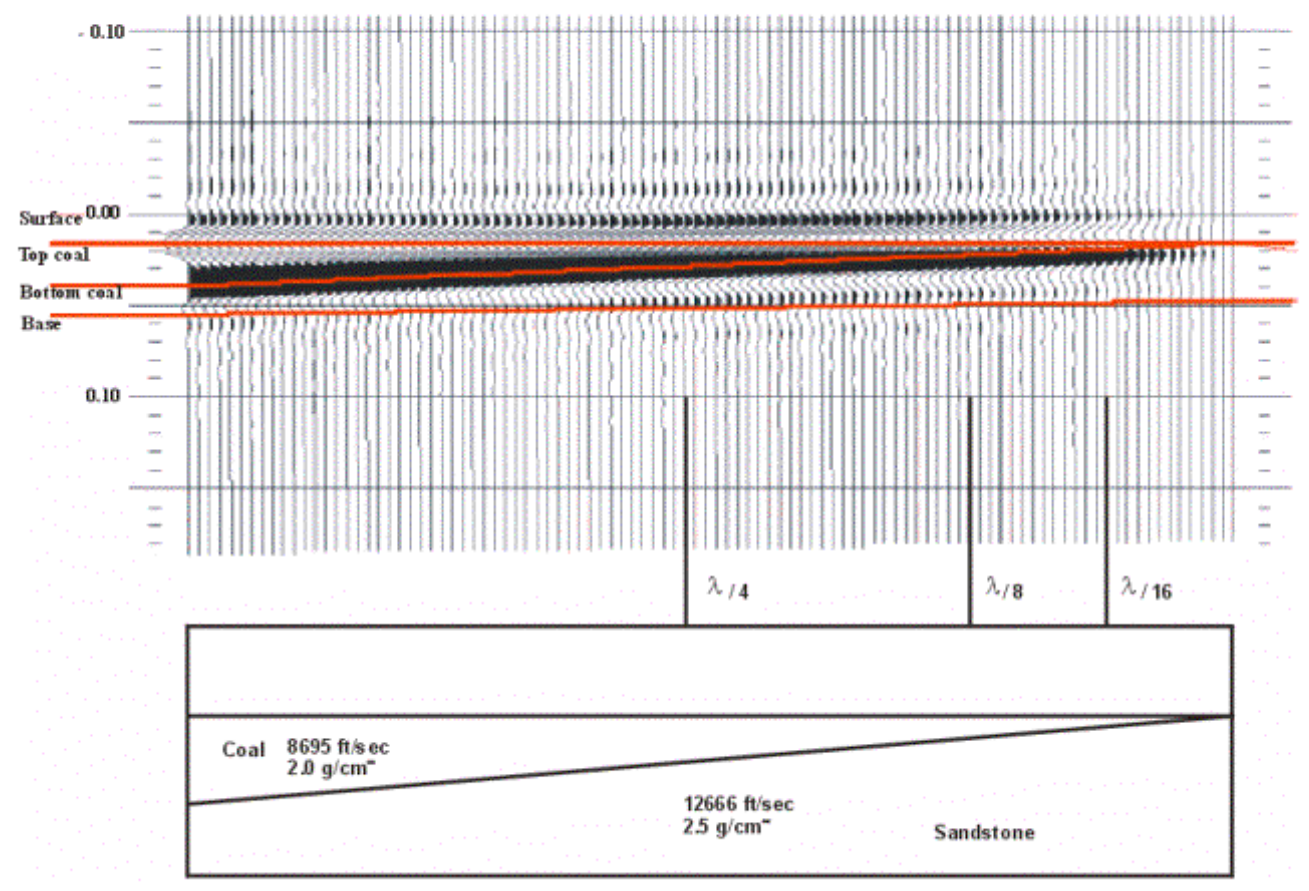

Figure 2.24. Synthetic traces and corresponding wedge model. 
a)

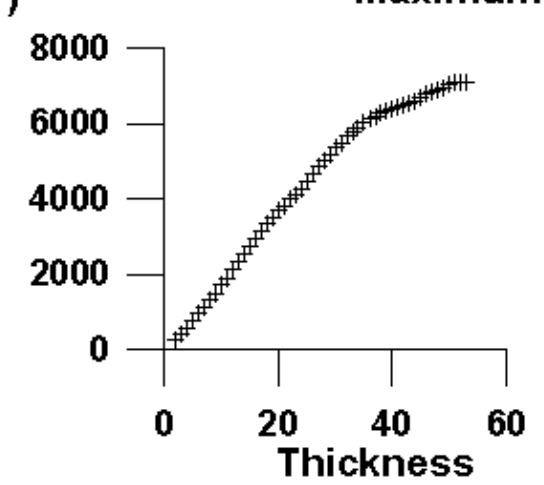

Maximum absolute amplitude

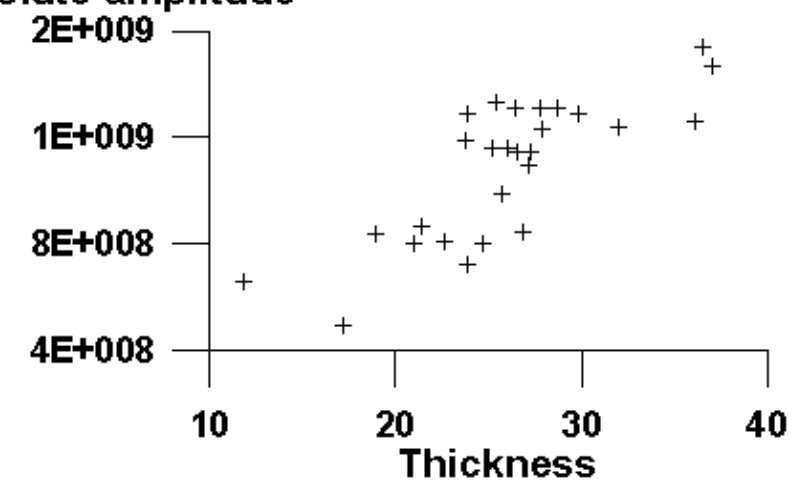

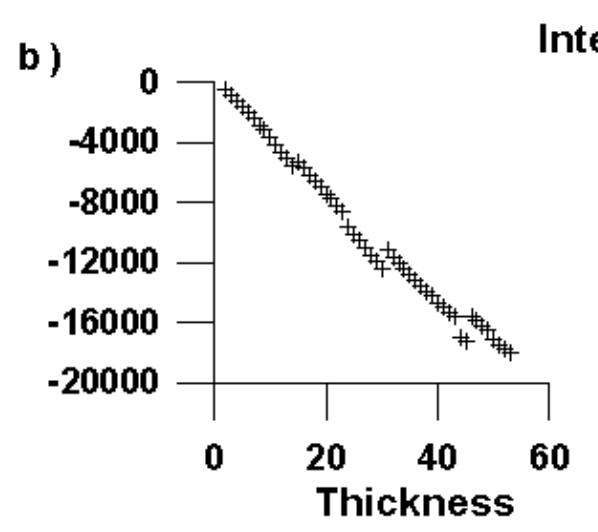

Integrated trace

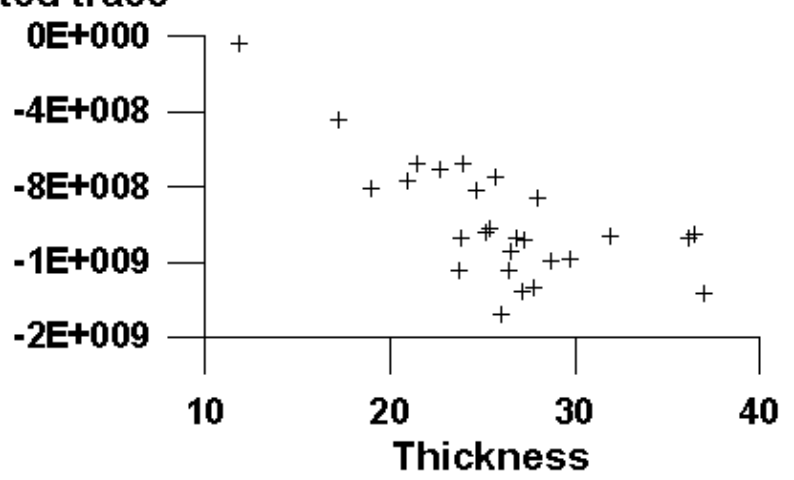

c)

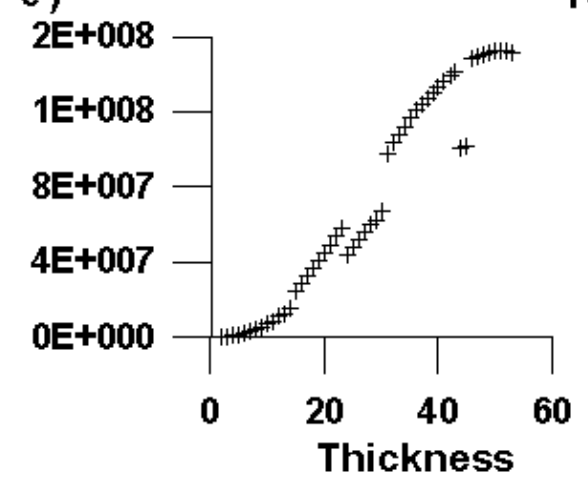

Total energy

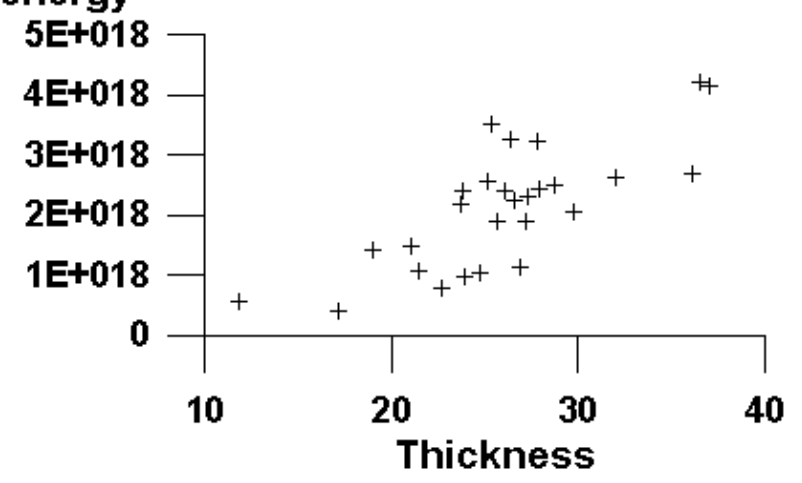

Figure 2.25. Crossplots of the (a) maximum absolute amplitude, (b) integrated trace, and (c) total energy against wedge thickness or coal seam thickness. Attributes extracted from the wedge model are in the left column, and attributes extracted from the seismic data are in the right column. Note the similarity in trends between model results and data. 

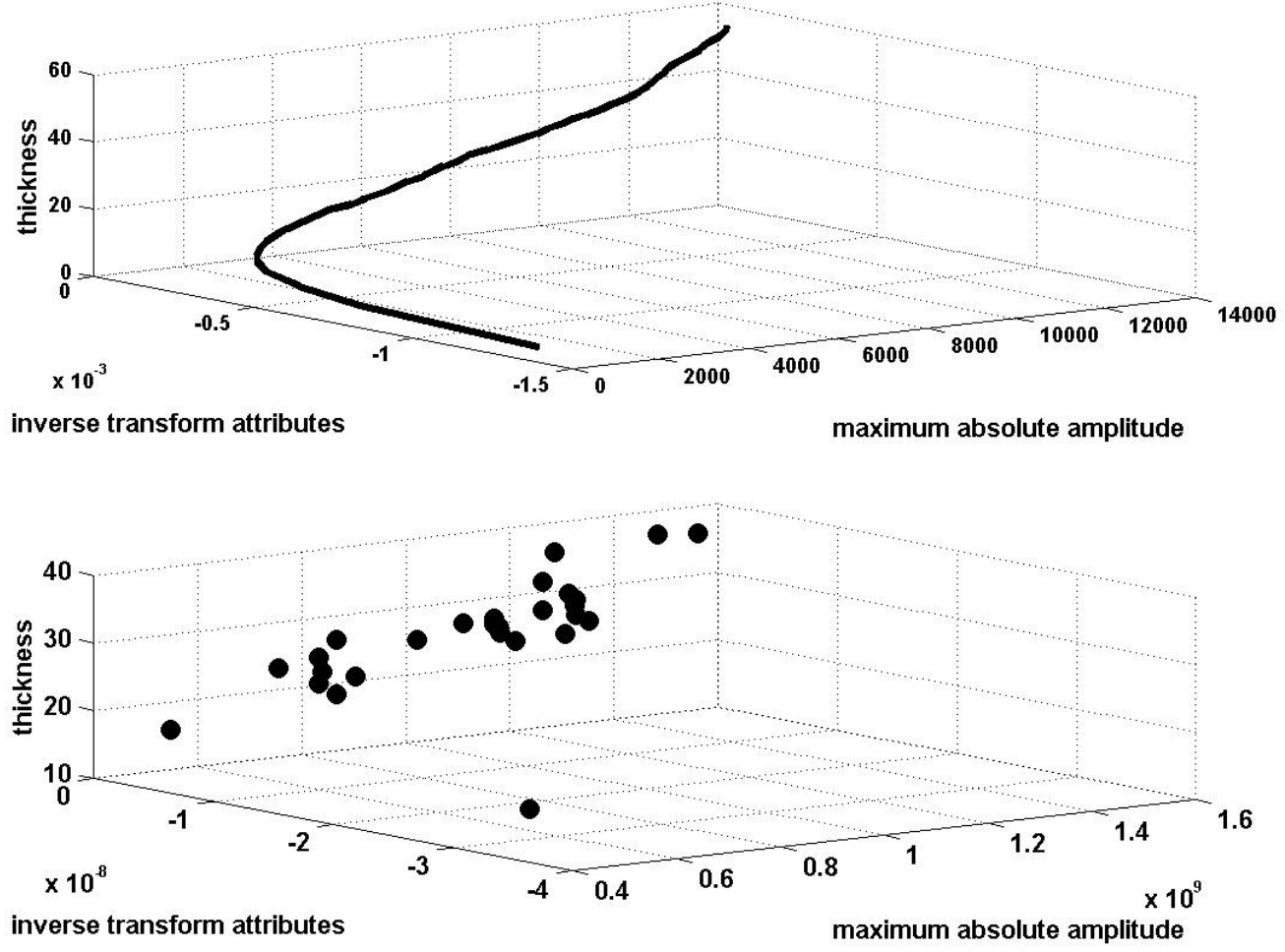

Figure 2.26. 3-D crossplots of thickness versus maximum absolute amplitude and combination of inverse transform attributes, (a) wedge model, and (b) seismic data. 


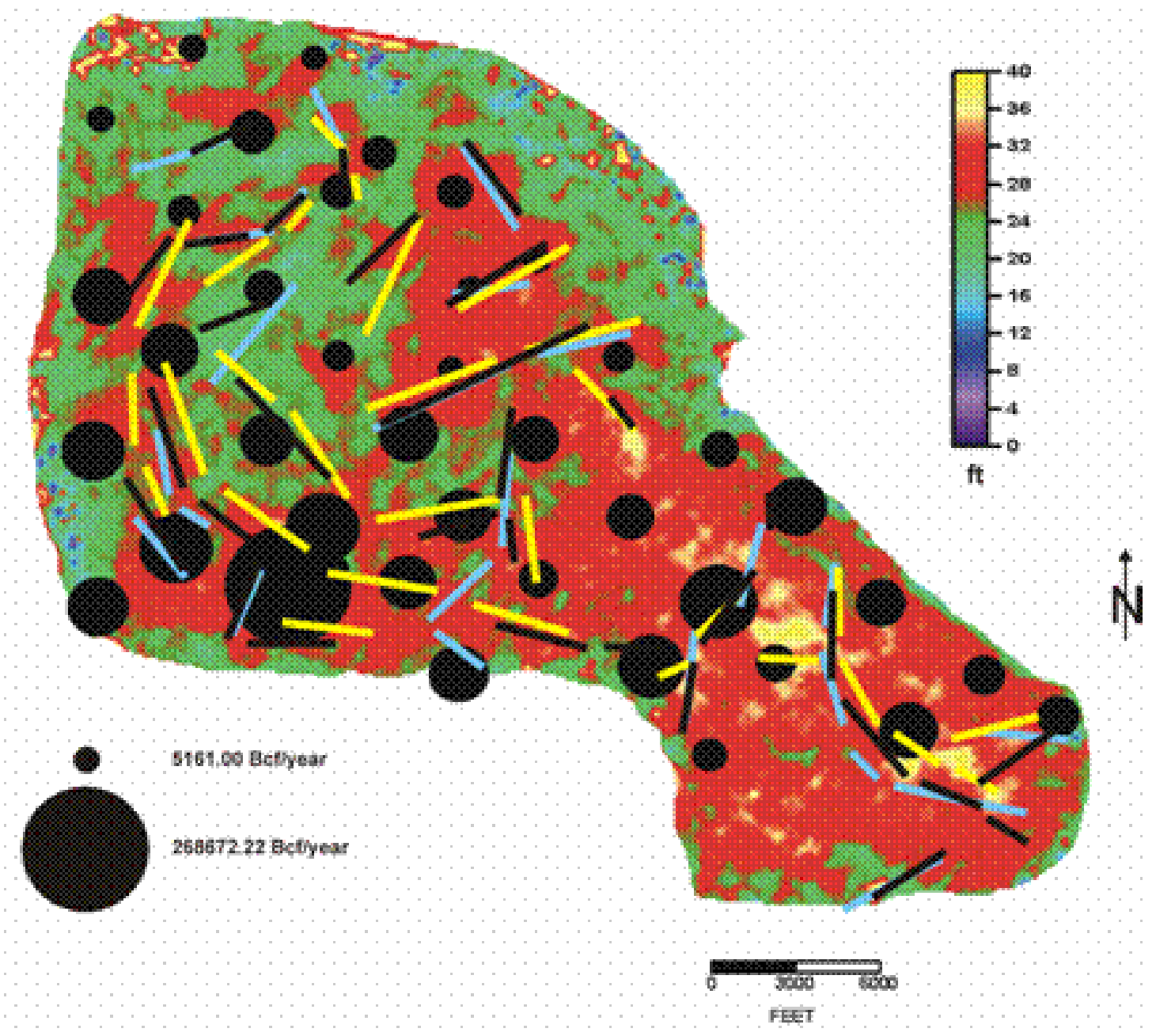

Figure 2.27. Bubble plot of cumulative production normalized by number of years of production and curvature lineaments superimposed over predicted thickness map. Note the strong association between coal thickness, curvature lineaments, and high productivity. Maximum-curvature lineaments show up in black, strike-curvature lineaments show up in light blue, and dip-curvature lineaments show up in yellow. 


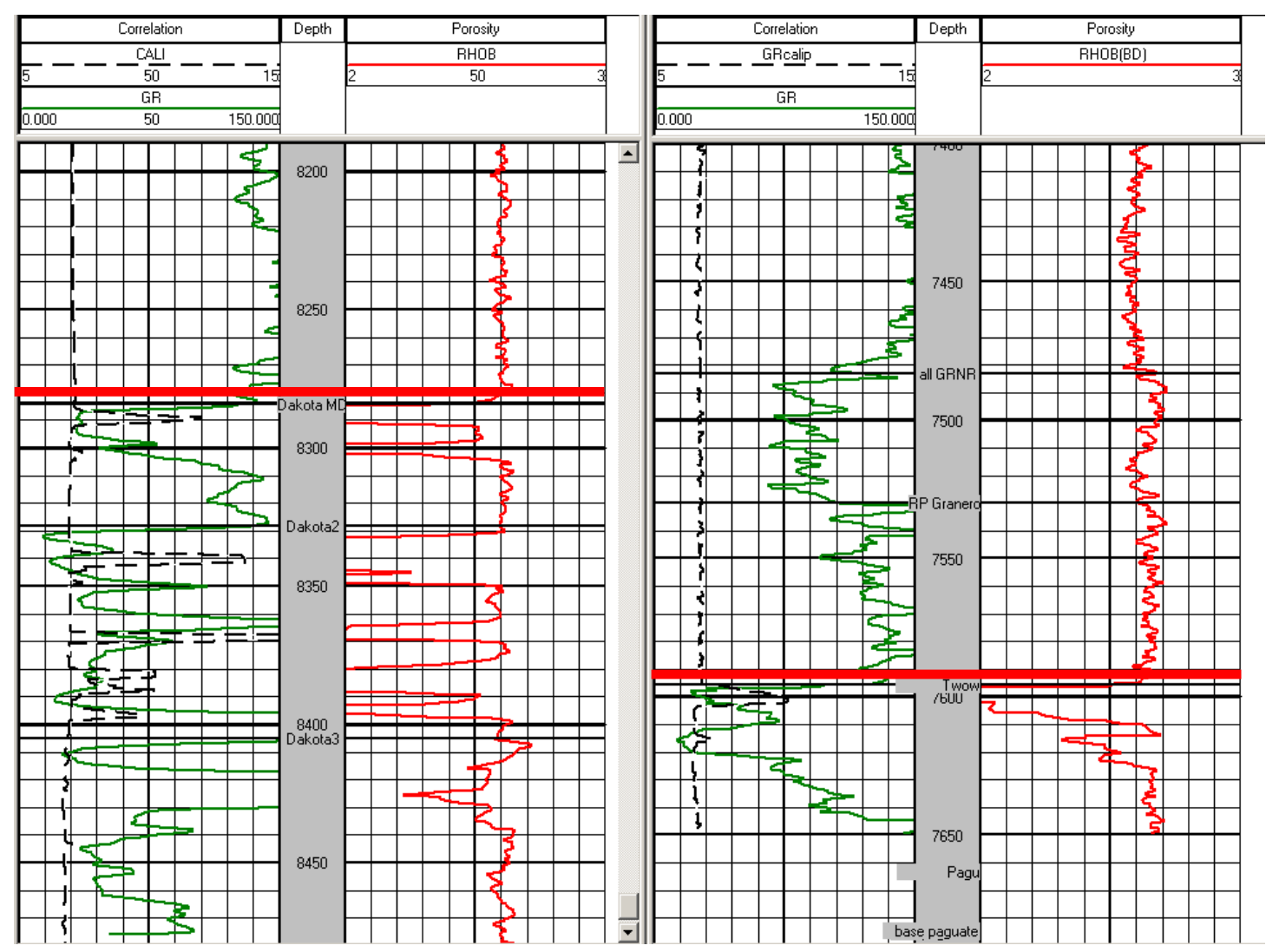

Figure 2.28. Sample logs (gamma ray and caliper on left, density on right) through parts of the Dakota Formation from the Phase I (right) and Phase II (left) study areas. Top of Dakota indicated by horizontal red line in both cases. Note tendency for borehole enlargement and anomalous density readings (both indirect fracture indicators) in cleaner sandstones. 


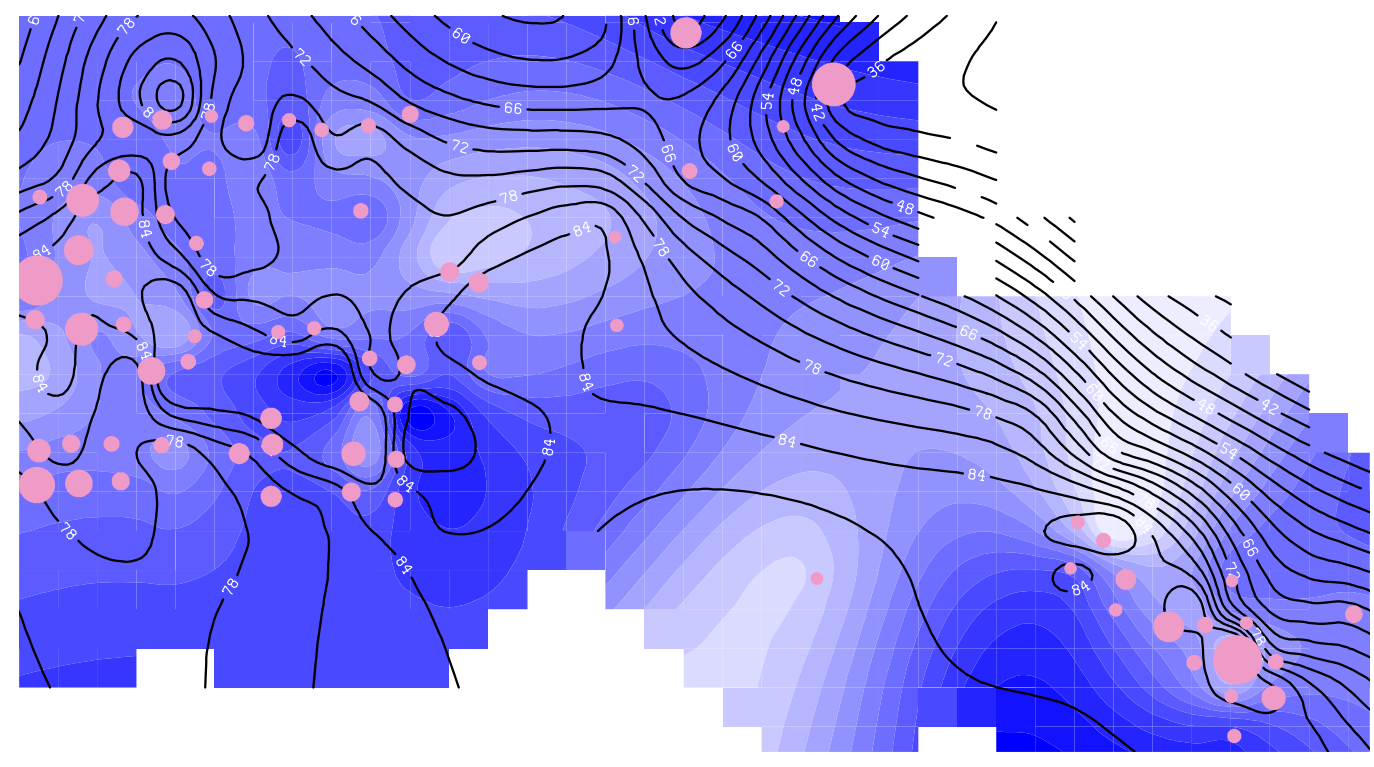

Figure 2.29. Two wells net (colors) and gross (contours) thickness and cumulative gas production (bubbles). The best production is from thick areas of high net sand. Area is approximately 20 miles wide. From Hart and Pearson (2000). 

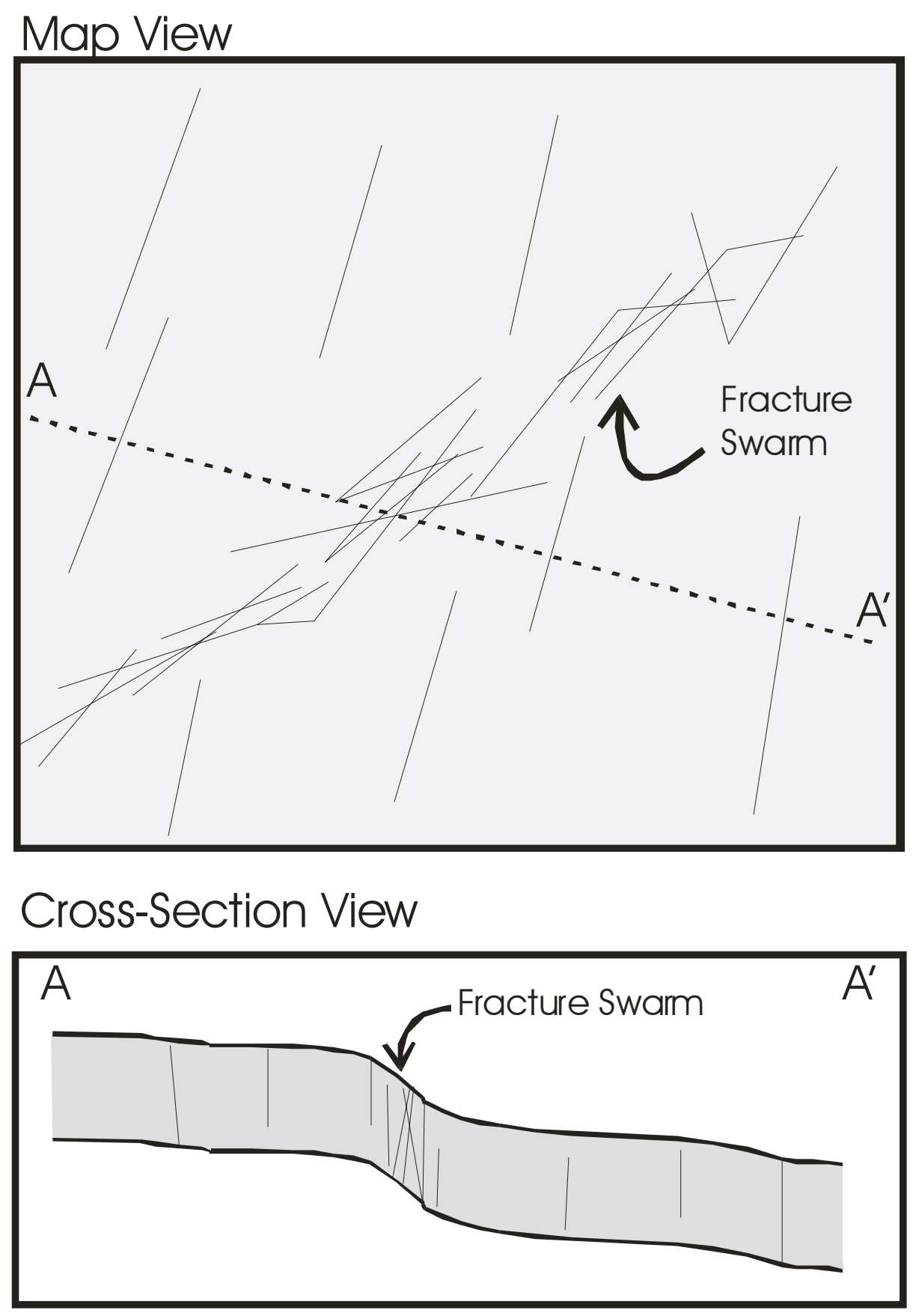

Figure 2.30. Schematic illustration of fracture swarms associated with subtle structural features, in this case a flexure. From Hart et al. (2002). 


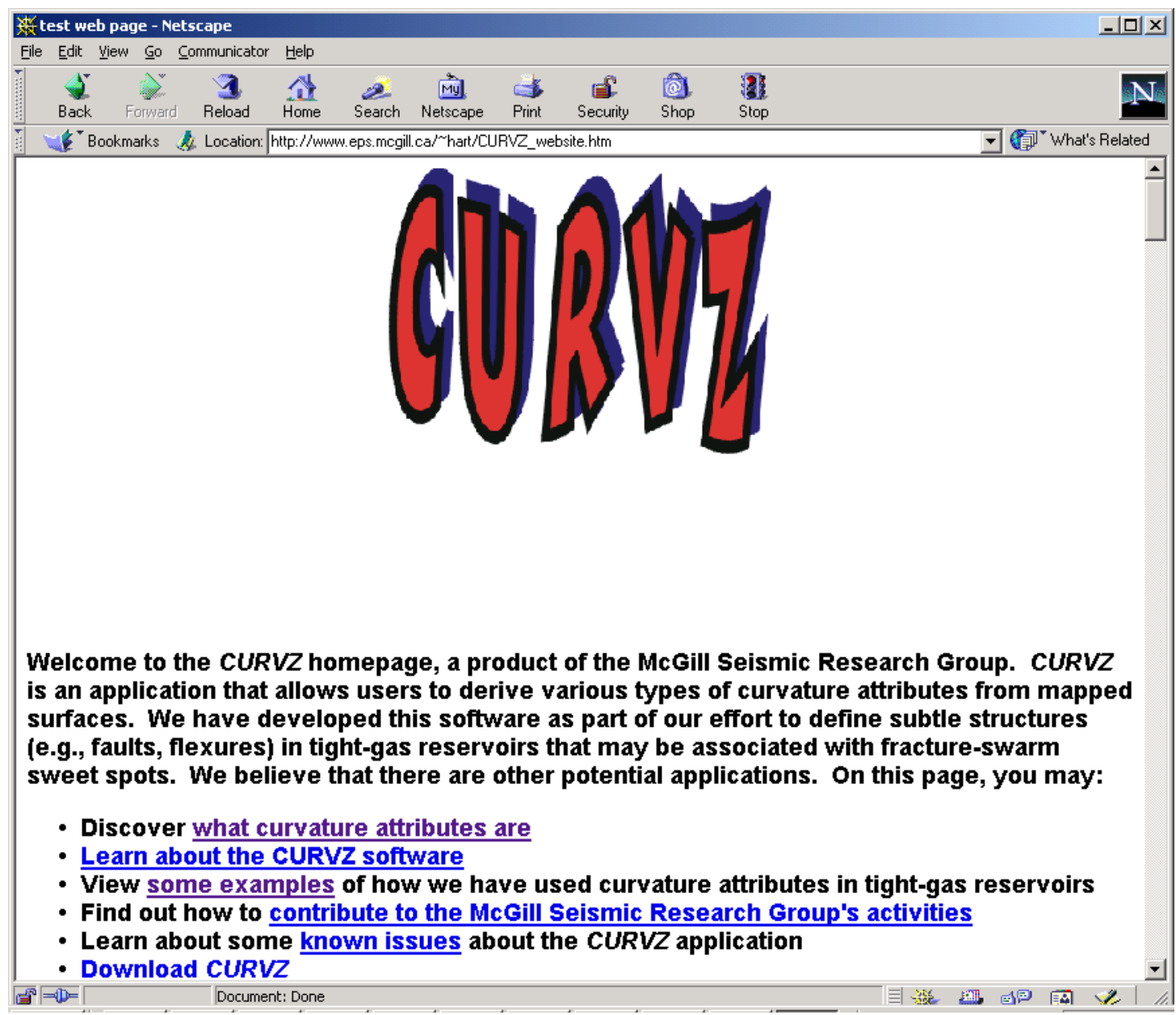

Figure 2.31. Part of the Curvz website (http://eps.mcgill.ca/ hart/CURVZ website.htm). More than 50 requests for copies of the software have been received. 


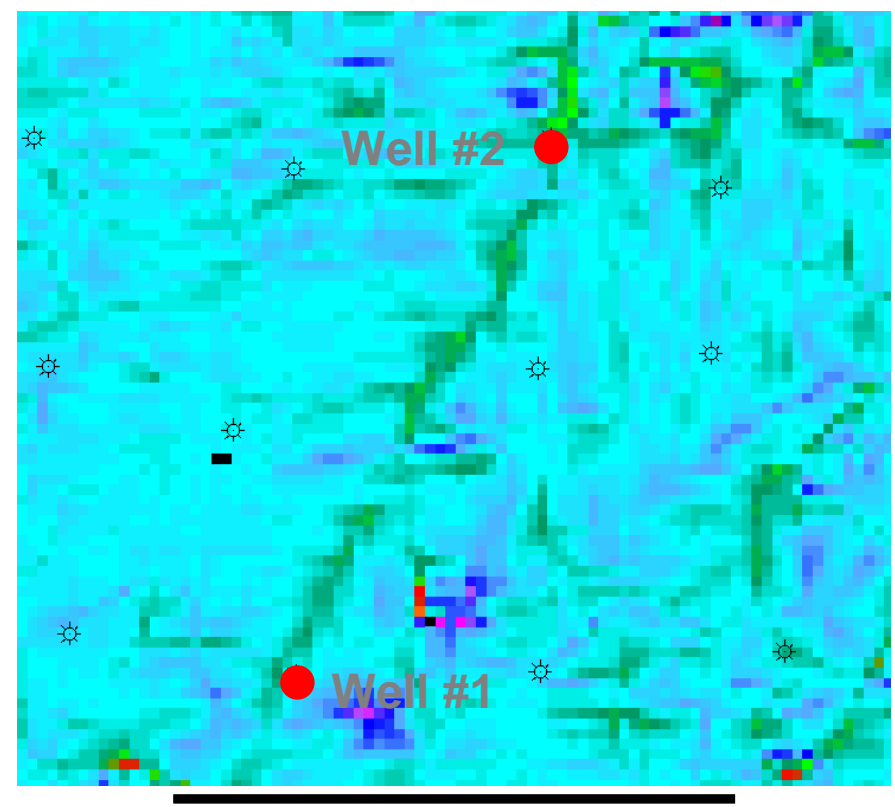

$\sim 1.5$ miles

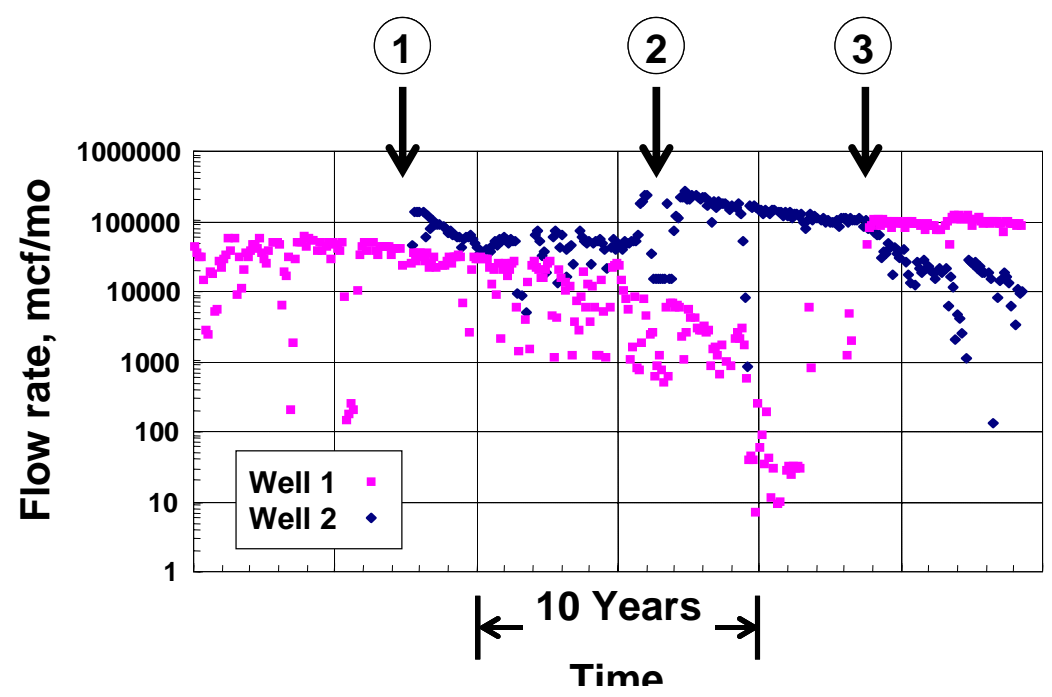

Figure 2.32. Location of two "sweet-spot" wells (i.e., cumulative production approximately $10 \mathrm{BCF}$ greater than neighboring wells) along a structural feature (small graben, green in top image) defined by strike curvature. Analysis of production from the two wells (bottom) shows that there is drainage interference between the two (Hart and Pearson, 2000; Hart et al., 2000). Further analyses showed that there is no interference between these two wells and other, closer wells (Robinson, 2001). We conclude that the structural feature identified by strike curvature is associated with an open fracture network that connects the two wells. 


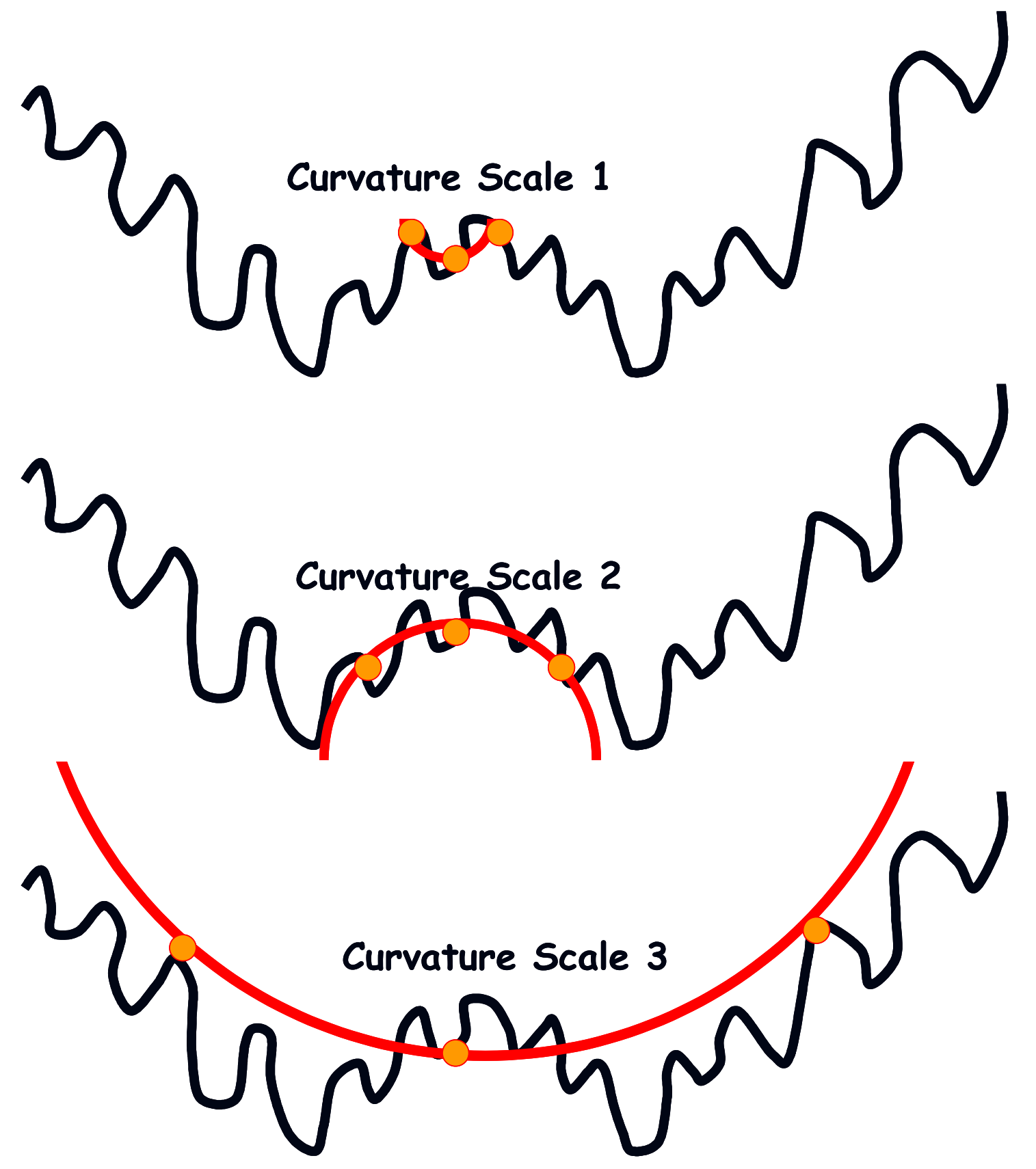

Figure 2.33. Schematic representation of the effect of changing the aperture over which curvature attributes are derived. By changing the aperture, different scales of curvature, each due to a different phenomenon, might be resolved. In the upper case, high frequency curvature might be related to noise. Opening up the aperture might reveal that an anticline is present in the center of the area (middle). Further opening up of the aperture might indicate that the anticline is situated in a syncline (bottom). Based on Stewart and Wynn (2000). 


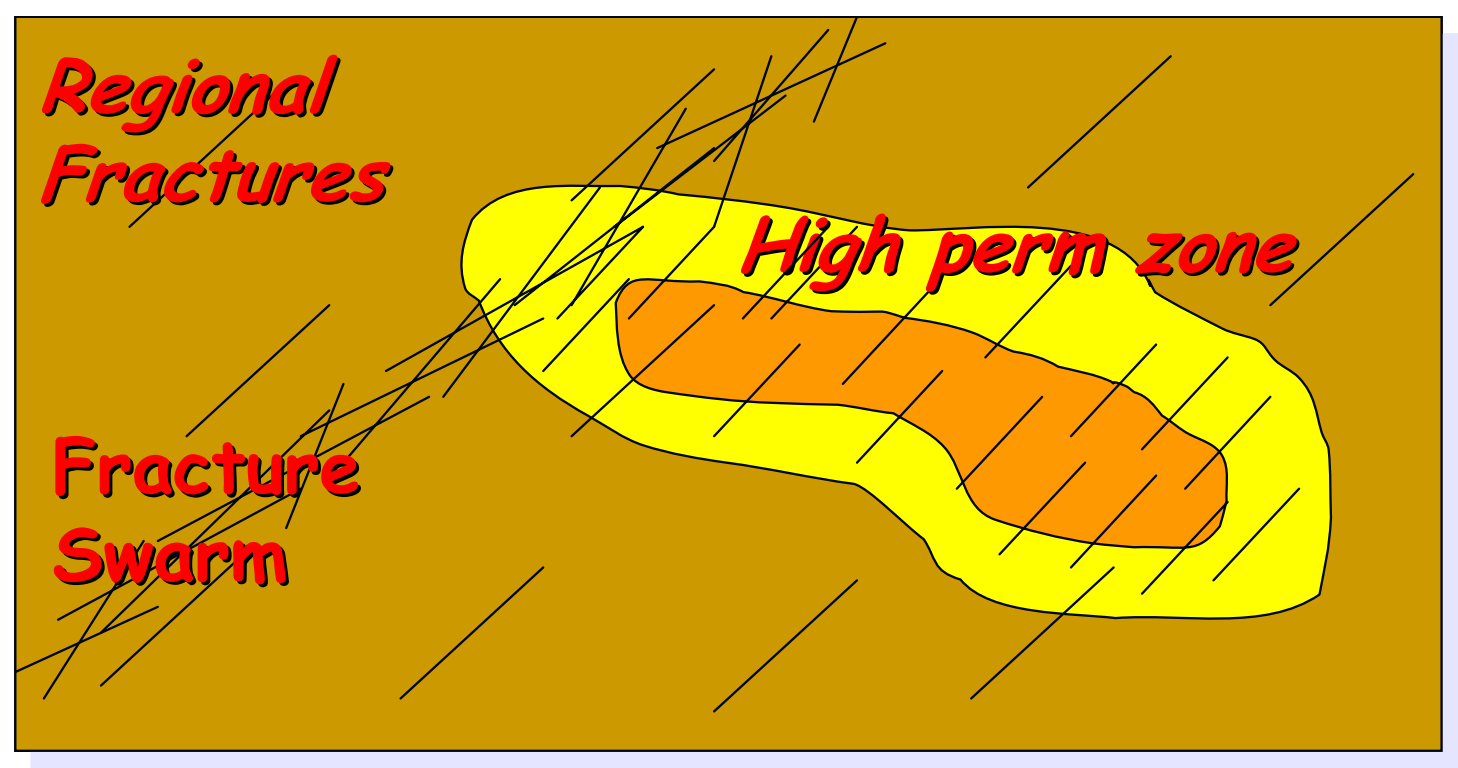

Figure 2.34. Schematic representation of map showing geological controls on fracture density. Regional fractures become more densely spaced in cleaner areas of the formation (yellow, orange) producing relatively higher permeability zone. Structural features such as folds or small-offset faults may be associated with highly-productive fracture swarms. These swarms may or may not have exactly the same orientation as the regional fracture trend. Lithology defined high perm zones and fracture swarms should be definable with good-quality conventional 3-D seismic data. 


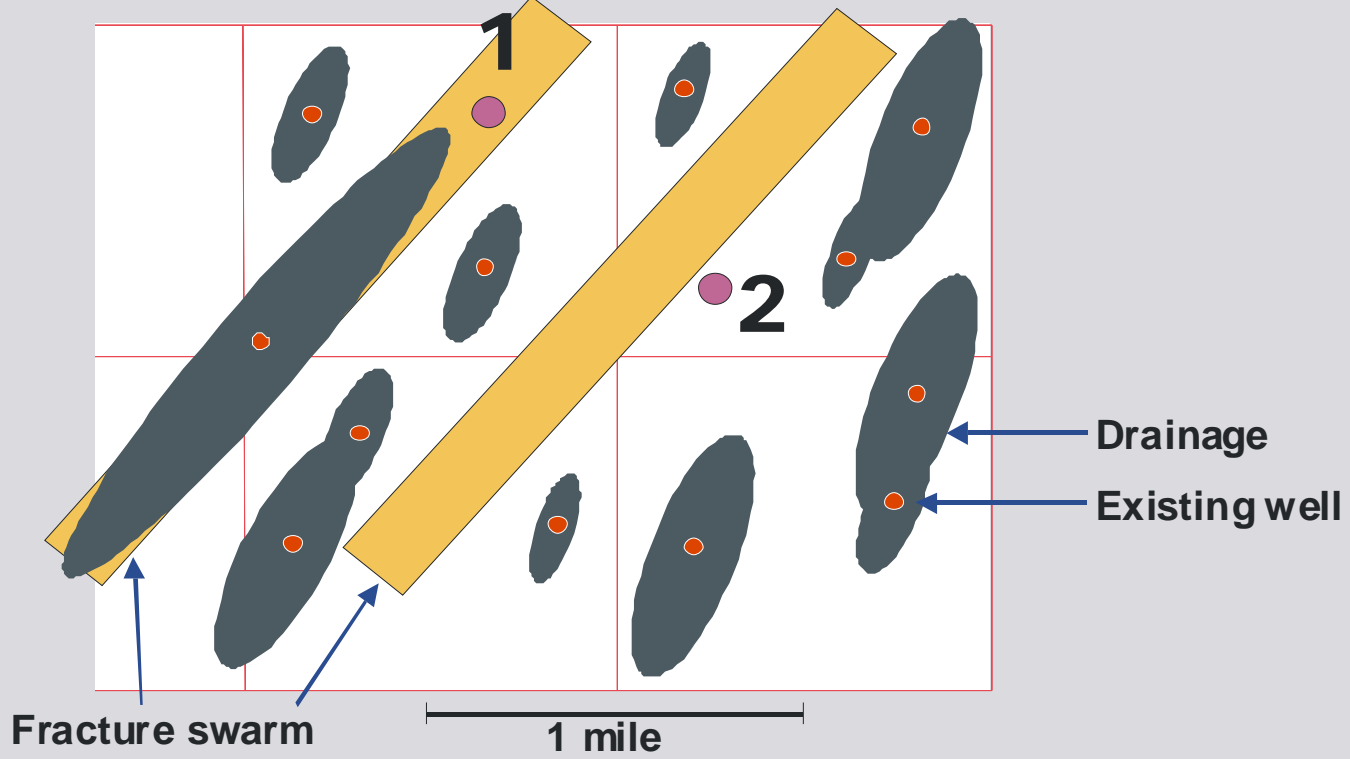

Figure 2.35. Schematic representation of an infill-drilling situation in a tight-gas reservoir. Existing wells (red) have elliptical drainage areas (grey) due to the presence of a regional natural fracture network. Yellow bars show location of fracture-swarm sweet spots identified through 3-D seismic horizon attribute analyses. Drainage areas in fracture swarms are more highly elliptical than those outside of the fracture swarms. Location 1 (magenta) shows the originally planned location of a new well. It should be moved to avoid drainage interference with the well to the SW that is already draining the fracture network. Location 2 (magenta) shows the planned location of another new well. It should be moved slightly to the left to target the undrained fracture swarm. 


\title{
CHAPTER 3
}

\section{Evaluation of the Infill Well Potential of the Blanco Mesaverde Rosa Unit in the San Juan Basin, New Mexico}

\author{
T. Engler, H-Y. Chen, L. Teufel, W. Thungsuntonkhun, \\ J. Munoz, J. Espeland, and K. Iden \\ Petroleum and Natural Gas Engineering Department \\ New Mexico Institute of Mining and Technology \\ Socorro, New Mexico
}

\subsection{Introduction}

The approach of this project is to expand and validate previously developed methodologies and tools in Phase 1 (Teufel, et al., 2000) to a different portion of the San Juan Basin. In this work, the Mesaverde Formation was the target in the Rosa Unit in the Blanco Mesaverde Pool, which is located along the northeast basin margin of the basin (Figure 3.1). This area is away from the main fairway, where the previous work in Phase I was conducted. Included in this comprehensive analysis is reservoir characterization techniques, decline curve analysis, and flow simulation. Since an 80-acre pilot program already exists, efforts were directed towards developing models to predict well performance and subsequently compare with the actual values.

As a component of the Phase II project, the Mesaverde Formation in the Rosa Unit is a prime candidate for the investigation of the response to infill drilling. To meet this objective several specific reservoir engineering tasks were investigated:

1. Petrophysical characterization was initiated in the pilot area utilizing primarily log data. Development of better estimates of cutoff values and correlations result in an improved description of the reservoir, and consequently improve flow simulation. Modeling of the reservoir will unite fluid flow with petrophysical characterization.

2. Production curve analysis is essential in evaluating the Mesaverde. Development of reservoir and well parameters from the analysis provide evidence of drainage area and useful information for the reservoir model. The method adopted was decline-curve analysis using cross type-curve matching between rate, cumulative production, and time using computer programs that were developed for tight gas reservoirs.

3. Reservoir simulation is required to predict the reservoir performance for the 80acre infill wells from reservoir simulation and compare these predictions with the actual performance of the infill wells. Comparison of the predicted results with the actual performance of infill wells provides valuable information to the 
drainage area and shape. Two methods of simulation were applied to this task: the Infill Well Locator Calculator (IWLC) and Merlin ${ }^{\mathrm{TM}}$, a 3D, multiphase, finite difference flow simulator.

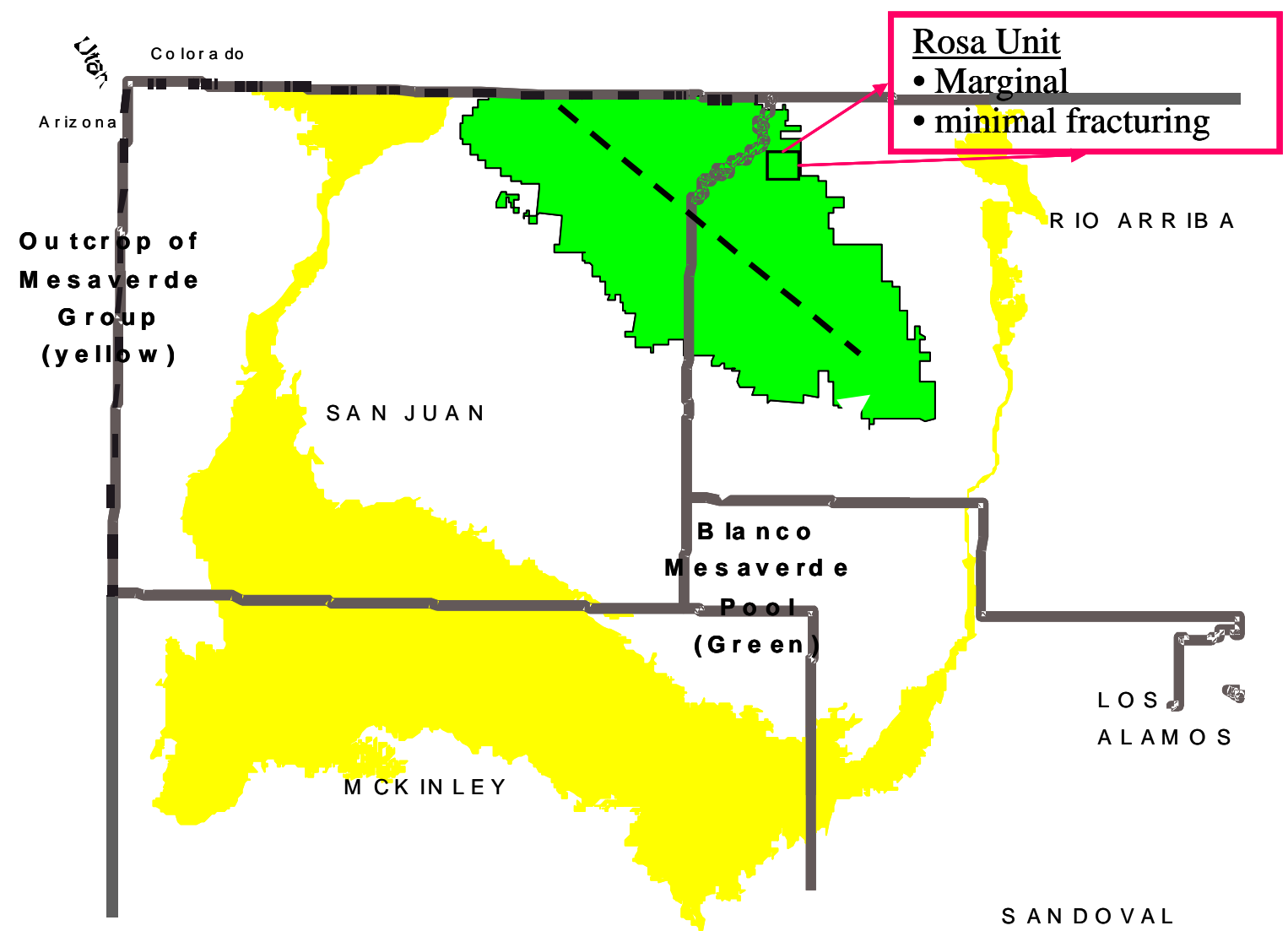

Figure 3.1. Location of Rosa Unit relative to Blanco Mesaverde Pool limits. 


\subsection{Reservoir Characterization}

The Gamma Ray log is the primary tool available to estimate shale content in a shale- sand environment. Usually, the radioactivity content tends to concentrate in the clays and shales. On the other hand, clean sand formations commonly have low levels of radioactivity; therefore, the Gamma Ray log can be used to determine the net thickness of clean sand. However, the selection of a gamma ray cutoff is highly subjective, with no rigorous standard to determine the cut off for clean sand. Subsequently, this report will present an alternative method to find the net pay by using the cumulative distribution of the gamma ray log data. Furthermore, the relationship between normalizing gamma ray distributions and geology facies will be described. This study is based on ten wells from the Rosa Unit, Mesaverde gas reservoir. Mesaverde is one of major tight gas reservoirs in San Juan Basin located in northern New Mexico. The Mesaverde is separated into three formations: Cliff house sandstone ( $\mathrm{CH})$, Menefee formation (MF), and Point Lookout sandstone (PL). Each formation will be evaluated independently for cutoff values and compared. A majority of the well log data from the Rosa unit was digitized and provided by the operator. The reservoir characterization study was conducted by W. Thungsuntonkhun and T. Engler.

\section{Procedure to Determine Clean Sand}

Normally the difference between clean sand and shaly sand can be detected by gamma ray logs, but in order to certify that this sand can be productive, other factors such as porosity and resistivity need also to be considered. It is common practice to use "ruleof-thumb" cutoffs of $6 \%$ for porosity and $20 \mathrm{ohm}-\mathrm{m}$ for resistivity. For simplicity, a constant value for gamma ray is frequently applied to estimate a clean sand cut off. For example, a widely accepted cut off for clean sand is a gamma ray reading less than 100 API. The identified clean sand intervals are then subject to porosity and resistivity cutoffs to determine the net pay for the given formation.

In this work, data from gamma ray logs are still the main parameter to detect the clean sand. However, the cut off is not set as a constant value, but the cut off will be determined from the change of slope of the plot of gamma ray vs. the cumulative distribution function (C.D.F); i.e., depth. In order to determine the inflection point, gamma ray log data recorded every half foot is sorted and plotted against the C.D.F. The graphs should show at least three different slopes, with the first slope change representing the cutoff from clean sand to silty sand. The change of the slope indicates the change of lithofacies from sandstone to silt to shale. Furthermore, porosity distribution plots were also considered in order to confirm the cut off selected by the gamma ray distribution.

\section{Results of Analysis of CDF}

As an example, the CDF plots for Cliffhouse, Menefee and Point Lookout in Well No. 9A are shown in Figure 3.2. Also, for comparison is a copy of the GR-CNL-FDC log for Well No. 9A in Figure 3.3.

Table 3.1 lists the net thickness determined for the ten wells analyzed and compares these values with the thickness determined from Williams Energy. Most of the net pays determined by the plots of gamma ray vs. C.D.F are less than net pay detected by Williams. This indicates that the gamma ray distribution method uses a cleaner sand 
cutoff point. A statistical analysis shown below includes the arithmetic average and range of the cutoffs generated for each formation. In general, the Cliffhouse and Point Lookout values are similar, while the Menefee contains more silt and thus has a slightly greater cutoff value.

Cliffhouse
Menefee
Point Lookout

\begin{tabular}{lll} 
Average & Low & High \\
\hline 83 & 77 & 95 \\
90 & 84 & 95 \\
83 & 74 & 89
\end{tabular}

As discussed in the previous section, the cut off is determined from the changing of slope therefore the gamma ray cut off is not a constant value and varies from well to well.

\section{Relationship between Normalizing Gamma Ray Distribution and Geology Facies}

To observe the relationship of gamma ray distributions between each well in the same formation, the gamma ray curves were normalized and then plotted on the same graph. The normalization technique shifts the minimum gamma ray value to the same common origin, thus allowing for better comparative analysis. Three plots of normalizing gamma ray distribution vs. C.D.F for each formation are shown in the attached figures 3.4 through 3.6. The normalizing plots show the relationship between each well that can be described as follows.

For the Cliff House formation, twelve wells were included in the analysis. From the shape of plots, two groups were identified with similar characteristics. Well 16A, 20A, and $21 \mathrm{~A}$ have similar shape, while the second group includes wells $1 \mathrm{E}, 9 \mathrm{~A}, 12 \mathrm{~A}, 16 \mathrm{~B}$, 20B, 20C, 30, 30A and 149A. The similarities may indicate the same geological facies between the wells. Furthermore, a general northeast - southwest trend is exhibited by the data. For example, 20A and 21A; and 1E, 12A, 16B, 20B, 20C, 30, 30A and 149A. Two outliers are present, 16A and 9A. The latter is on the northern fringe of the study area and therefore is postulated to be another facies similar to the others.

For the Menefee formation, the shapes of graphs for all wells are similar, subsequently differentiation into facies was not considered.

For the Point Lookout formation, the shapes of the graphs can be divided into two groups: one for well 9A, 16B, 21A, 30 and 30A and another group for wells 1E, 12A, 16A, 20A, 20B, 20C and 30A. Also, notice that 20C is transitional, between the two groups. This agrees with its areal position on the map. Subsequently, the Point Lookout formation may be separated into two geological facies that line on the northeastsouthwest direction.

\section{Porosity}

The availability and type of porosity logs is shown in Figure 3.7 and listed in Table 3.2. Of the 35 wells which have produced from the Mesaverde in this 9-section map,

11 - have density/neutron porosity logs

8 - have density only porosity logs

16 - have no useable porosity logs 
This last group includes old wells with no logs or poor-quality neutron count logs and directional wells with no openhole logs run for safety concerns.

Detailed porosity log calculations were performed on ten wells, primarily focusing on the pilot area of section 14 and also due to data limitations. The average porosity by well and formation are shown in Table 3.3. These results consider only those intervals which meet the clean sand criteria from the gamma ray CDF.

The density $\log$ porosity in column 2 of Table 3.3 is calculated from the following volume balance equation,

$$
\phi=\frac{\rho_{m a}-\rho_{b}}{\rho_{m a}-\rho_{f}}
$$

where the matrix density is taken as $2.65 \mathrm{gm} / \mathrm{cc}$ and the fluid density is assumed to be the mud filtrate density of $1.00 \mathrm{gm} / \mathrm{cc}$. The density porosity was corrected by considering the fluid density to be a weighted average of the invading fluid, in this case air, and the connate water. That is,

$$
\rho_{f}=\rho_{\text {air }}\left(1-S_{w C}\right)+\rho_{w} S_{w C}
$$

In this equation, the average fluid density is $0.46 \mathrm{gm} / \mathrm{cc}$, assuming a gas density of 0.10 $\mathrm{gm} / \mathrm{cc}$ and a connate water saturation of $40 \%$. As can be seen in the table, the result is to substantially reduce the density porosity. The neutron porosity was taken directly from the well logs, and was not corrected for gas effect. The total porosity was approximated using the root-mean-square equation for estimating effective gas-filled porosity.

$$
\phi=\sqrt{\frac{\phi_{d}^{2}+\phi_{n}^{2}}{2}}
$$

The average density porosity by zone is $7.2,8.6$, and $8.8 \%$ for the Cliffhouse, Menefee and Point Lookout, respectively.

Porosity data was plotted with the gamma ray on the CDF plots for the purpose of identifying any trends or correlations. (Refer to Figure 3.2) In general, no distinct trends were observed either with shale content or zone. For a given well the porosity trend was flat to slightly decreasing with increasing shale content. Subsequently, no definitive porosity cutoff could be identified. Moreover, limited variations were observed between the different zones.

\section{Water Saturation}

Water saturation is a severe unknown in the Mesaverde Formation for the entire San Juan Basin. This is a result of several factors: (1) limited information on $R_{w}$, (2) negligible water production, (3) no clearly identifiable water zone, and (4) the reservoirs are shaly sands. Subsequently, an approximation of between 35 to $55 \%$ is prevalent in published literature, with little to no facts supporting this percentage. Unfortunately, in this work a similar assumption was used, since no clear evidence is available to calculate a true value.

\section{Summary of Reservoir Characterization}

The results of the reservoir characterization study show: 
1. A clean sand cutoff for each member of the Mesaverde Group; i.e., Cliff House, Menefee, and Point Lookout, was established from CDF of the gamma ray curves.

2. Inflection points on these curves identified variations in the lithology of the members and were used to distinguish clean sand cutoff values.

3. Normalizing the gamma ray distributions provided a means to compare trends for a series of wells, and infer relationships and direction of geological facies between wells in the same formation.

4. Investigations into porosity variations resulted in no definitive trends with respect to shale content or location. For this reason, the shale cutoff values established were extended to net pay cutoffs. 


\begin{tabular}{|c|c|c|c|c|}
\hline Formation & \multicolumn{3}{|c|}{} \\
\hline Well Name & Vshale Cutoff & Net Thick & \multicolumn{2}{|c|}{ William's Data } \\
Rosa Unit \# & GR, API & $\mathrm{ft}$. & Gross Thick, ft & Net Thick, ft \\
\hline 1E & 84 & 7.5 & 18 & 3 \\
\cline { 5 - 5 } $12 \mathrm{~A}$ & 85 & 5.0 & 21 & 5 \\
$16 \mathrm{~A}$ & 82 & 8.0 & 18 & 15 \\
$16 \mathrm{~B}$ & 79 & 9.0 & - & - \\
$20 \mathrm{~A}$ & 95 & 5.5 & 19 & 10 \\
$20 \mathrm{~B}$ & 85 & 11.0 & - & - \\
$21 \mathrm{~A}$ & 77 & 5.0 & 22 & 2 \\
30 & 81 & 6.0 & 18 & 2 \\
$30 \mathrm{~A}$ & 82 & 7.0 & 28 & 4 \\
9A & 80 & 9.0 & 28 & 12 \\
\hline
\end{tabular}

\begin{tabular}{|c|c|r|c|c|}
\hline Formation & \multicolumn{3}{|c|}{} \\
\hline Well Name & Vshale Cutoff & Net Thick & \multicolumn{2}{|c|}{ William's Data } \\
\cline { 3 - 4 } Rosa Unit \# & GR, API & ft. & Gross Thick, ft & Net Thick, ft \\
\hline $1 \mathrm{E}$ & 93 & 12.5 & 26 & 21 \\
\cline { 5 - 5 } 12A & 90 & 8.5 & 48 & 13 \\
$16 \mathrm{~A}$ & 90 & 14.0 & 43 & 29 \\
$16 \mathrm{~B}$ & 90 & 22.0 & - & - \\
20A & 95 & 11.0 & 34 & 11 \\
$20 \mathrm{~B}$ & 91 & 15.0 & - & - \\
$21 \mathrm{~A}$ & 90 & 13.0 & 19 & 7 \\
30 & 88 & 33.0 & 46 & 29 \\
$30 \mathrm{~A}$ & 89 & 18.0 & 38 & 19 \\
$9 \mathrm{~A}$ & 84 & 15.0 & 39 & 25 \\
\hline
\end{tabular}

\begin{tabular}{|c|c|r|c|c|}
\hline Formation & \multicolumn{3}{|c|}{} \\
\hline Well Name & Vshale Cutoff & Net Thick & \multicolumn{2}{|c|}{ William's Data } \\
Rosa Unit \# & GR, API & ft. & Gross Thick, ft & Net Thick, ft \\
\hline $1 \mathrm{E}$ & 88 & 24.5 & 27 & 20 \\
$12 \mathrm{~A}$ & 81 & 6.5 & 15 & 11 \\
$16 \mathrm{~A}$ & 80 & 15.5 & 28 & 26 \\
$16 \mathrm{~B}$ & 88 & 5.0 & - & - \\
$20 \mathrm{~A}$ & 74 & 12.5 & 36 & 29 \\
$20 \mathrm{~B}$ & 75 & 11.5 & - & - \\
$21 \mathrm{~A}$ & 86 & 10.0 & 31 & 16 \\
30 & 84 & 11.0 & 32 & 19 \\
$30 \mathrm{~A}$ & 89 & 5.5 & 30 & 14 \\
9A & 82 & 10.0 & 21 & 12 \\
\hline
\end{tabular}

Note Well\#20C is a cased hole log

Table 3.1 Vshale Cut off and Net Thickness for each formation and well 


\begin{tabular}{|c|c|c|c|c|c|}
\hline \multirow[t]{2}{*}{ 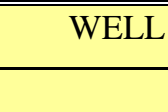 } & \multicolumn{2}{|c|}{ "POROSITY LOGS } & \multirow[t]{2}{*}{ DIGITAL } & \multirow[t]{2}{*}{ "HARD COPY } & \multirow[t]{2}{*}{$\overline{\mathrm{CDF}}$} \\
\hline & Density & Neutron & & & \\
\hline $1 \mathrm{E}$ & $\mathrm{Y}$ & $\bar{Y}$ & $\mathrm{Y}^{*}$-GR only & $\mathrm{Y}$ & $\mathrm{Y}$ \\
\hline $9 \mathrm{~A}$ & $\mathrm{Y}$ & $\mathrm{Y}$ & $\mathrm{Y}^{*}$ - missing $\phi \mathrm{n}$ & $\mathrm{Y}$ & $\mathrm{Y}$ \\
\hline 30 & $\bar{Y}$ & $\bar{Y}$ & $\bar{Y}$ & & $\mathrm{Y}$ \\
\hline $30 \mathrm{~A}$ & $\mathrm{Y}$ & $\mathrm{N}$ & $\mathrm{Y}^{*}$ - missing $\phi \mathrm{n}$ & $\mathrm{N}$ & $\mathrm{Y}$ \\
\hline 149 & $\mathrm{Y}$ & $\mathrm{Y}$ & $\mathrm{N}$ & $\mathrm{Y}$ & No \\
\hline $125 \mathrm{E}$ & $\mathrm{Y}$ & $\mathrm{Y}$ & $\mathrm{N}$ & $\mathrm{Y}$ & No \\
\hline $16 \mathrm{~A}$ & $\bar{Y}$ & $\mathrm{Y}$ & $\bar{Y}$ & $\bar{Y}$ & $\bar{Y}$ \\
\hline $16 \mathrm{~B}$ & $\mathrm{Y}$ & $\mathrm{Y}$ & $\mathrm{Y}^{*}$ - missing $\phi n$ & $\mathrm{Y}$ & $\mathrm{Y}$ \\
\hline $20 \mathrm{~A}$ & $\mathrm{Y}$ & $\mathrm{Y}$ & $\mathrm{Y}$ & $\mathrm{Y}$ & $\mathrm{Y}$ \\
\hline $20 \mathrm{~B}$ & $\mathrm{Y}$ & $\mathrm{N}$ & $\mathrm{Y}$ & $\mathrm{N}$ & $\mathrm{Y}$ \\
\hline $12 \mathrm{~A}$ & $\mathrm{Y}$ & $\mathrm{N}$ & $\mathrm{Y}$ & $\mathrm{N}$ & $\mathrm{Y}$ \\
\hline 12 & $\mathrm{~N}$ & $\mathrm{~N}$ & $\mathrm{~N}$ & Old log & No \\
\hline $18 \mathrm{~A}$ & $\bar{Y}$ & $\bar{Y}$ & $\mathrm{~N}$ & $\bar{Y}$ & No \\
\hline 79 & $\mathrm{Y}$ & $\mathrm{Y}$ & $\mathrm{N}$ & $\mathrm{Y}$ & No \\
\hline $79 \mathrm{~A}$ & $\mathrm{Y}$ & $\mathrm{Y}$ & $\mathrm{N}$ & $\mathrm{Y}$ & No \\
\hline 21 & $\mathrm{~N}$ & $\mathrm{~N}$ & $\mathrm{~N}$ & Old log & No \\
\hline $21 \mathrm{~A}$ & $\mathrm{Y}$ & $\mathrm{N}$ & $\mathrm{Y}$ & $\mathrm{N}$ & $\mathrm{Y}$ \\
\hline $14 \mathrm{~A}$ & $\mathrm{Y}$ & $\mathrm{N}$ & $\mathrm{Y}$ & $\mathrm{N}$ & No \\
\hline $101 \mathrm{M}$ & $\mathrm{Y}$ & $\mathrm{Y}$ & $\mathrm{Y}^{*}$ - missing $\phi \mathrm{n}$ & $\mathrm{Y}$ & No \\
\hline $163 \mathrm{~A}$ & $\mathrm{Y}$ & $\mathrm{N}$ & $\mathrm{Y}$ & $\mathrm{N}$ & No \\
\hline
\end{tabular}

Table 3.2. List of wells with porosity logs and type of format. 


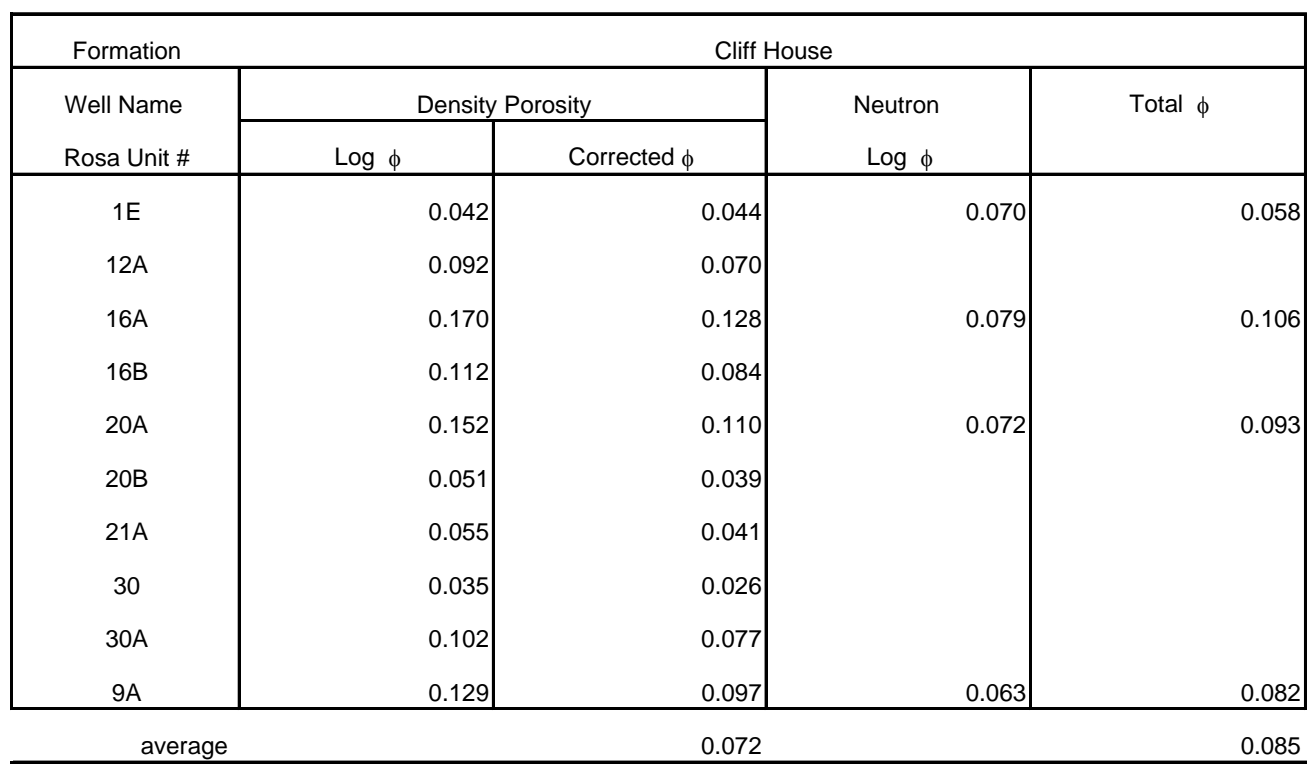

\begin{tabular}{|c|c|c|c|c|c|}
\hline \multirow{3}{*}{$\begin{array}{l}\text { Formation } \\
\text { Well Name } \\
\text { Rosa Unit \# }\end{array}$} & \multicolumn{5}{|c|}{ Menefee } \\
\hline & \multicolumn{2}{|c|}{ Density Porosity } & \multirow{2}{*}{$\begin{array}{c}\text { Neutron } \\
\text { Log } \phi \\
\end{array}$} & \multirow{2}{*}{\multicolumn{2}{|c|}{ Total $\phi$}} \\
\hline & $\log \phi$ & Corrected $\phi$ & & & \\
\hline $1 \mathrm{E}$ & 0.082 & 0.086 & 0.072 & & 0.079 \\
\hline $12 \mathrm{~A}$ & 0.108 & 0.082 & & & \\
\hline $16 \mathrm{~A}$ & 0.093 & 0.072 & 0.077 & & 0.075 \\
\hline $16 \mathrm{~B}$ & 0.129 & 0.094 & & & \\
\hline $20 \mathrm{~A}$ & 0.088 & 0.100 & 0.102 & & 0.101 \\
\hline $20 \mathrm{~B}$ & 0.112 & 0.085 & & & \\
\hline $21 \mathrm{~A}$ & 0.112 & 0.084 & & & \\
\hline 30 & 0.152 & 0.093 & & & \\
\hline $30 \mathrm{~A}$ & 0.114 & 0.080 & & & \\
\hline $9 \mathrm{~A}$ & 0.149 & 0.079 & 0.067 & & 0.073 \\
\hline
\end{tabular}

average

0.086

0.082

\begin{tabular}{|c|c|c|c|c|}
\hline \multirow{3}{*}{$\begin{array}{l}\text { Formation } \\
\text { Well Name } \\
\text { Rosa Unit \# }\end{array}$} & \multicolumn{4}{|c|}{ Point Look Out } \\
\hline & \multicolumn{2}{|c|}{ Density Porosity } & \multirow{2}{*}{$\begin{array}{l}\text { Neutron } \\
\text { Log } \phi\end{array}$} & \multirow[t]{2}{*}{ Total $\phi$} \\
\hline & $\log \phi$ & Corrected $\phi$ & & \\
\hline $1 \mathrm{E}$ & 0.107 & 0.112 & 0.045 & 0.085 \\
\hline $12 \mathrm{~A}$ & 0.136 & 0.102 & & \\
\hline $16 \mathrm{~A}$ & 0.109 & 0.083 & 0.051 & 0.069 \\
\hline $16 \mathrm{~B}$ & 0.124 & 0.093 & & \\
\hline $20 \mathrm{~A}$ & 0.103 & 0.077 & 0.038 & 0.061 \\
\hline $20 B$ & 0.132 & 0.099 & & \\
\hline $21 \mathrm{~A}$ & 0.126 & 0.095 & & \\
\hline 30 & 0.105 & 0.079 & & \\
\hline $30 \mathrm{~A}$ & 0.090 & 0.068 & & \\
\hline $9 \mathrm{~A}$ & 0.091 & 0.069 & 0.054 & 0.062 \\
\hline
\end{tabular}

Table 3.3. Log porosity values for density and neutron logs 

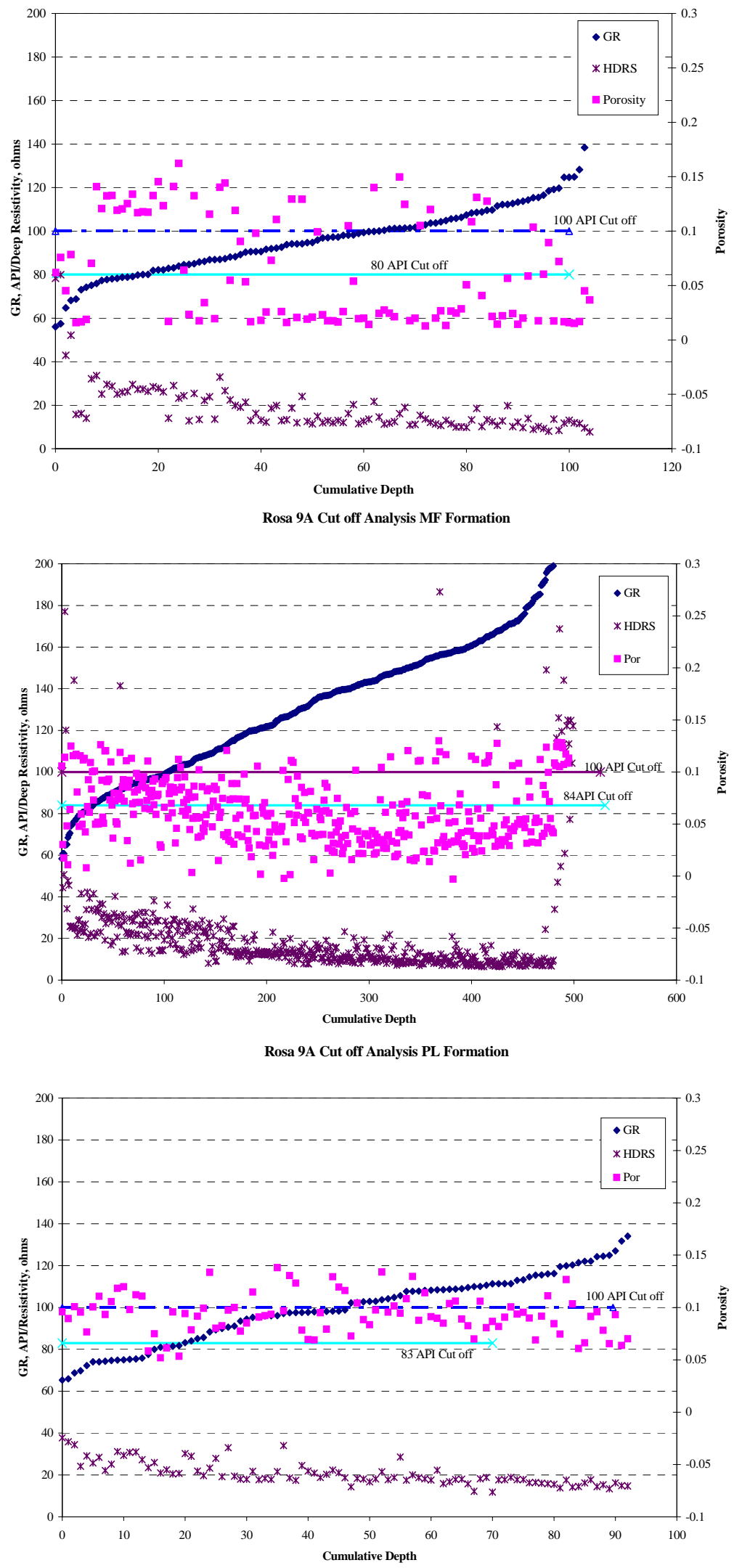

Figure 3.2. Gamma Ray, Porosity and Resistivity readings vs CDF for Cliffhouse, Menefee and Point Lookout in Well No. 9A. 




Figure 3.3. GR, Resistivity, and Porosity logs for Well 9A. 
Normalizing GR for Net Pay Cut Off Analysis CH Formation Group 1

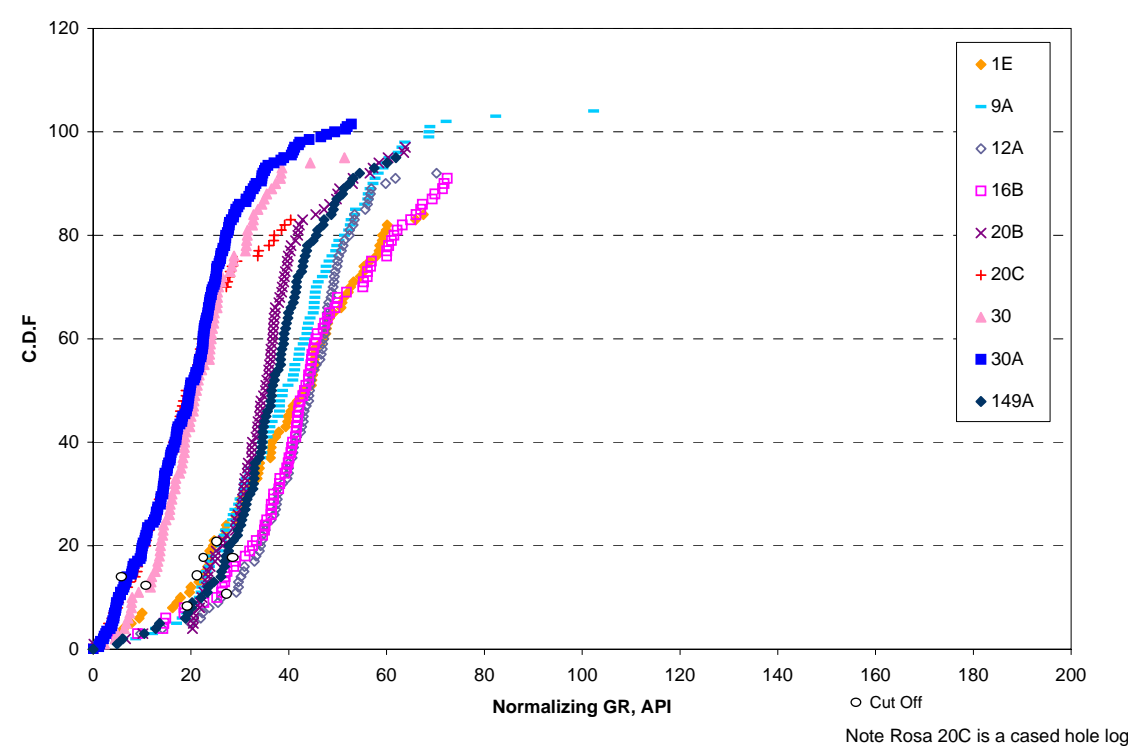

Figure 3.4a. CDF of normalized gamma ray for Cliffhouse

Normalizing GR for Net Pay Cut Off Analysis CH Formation Group 2

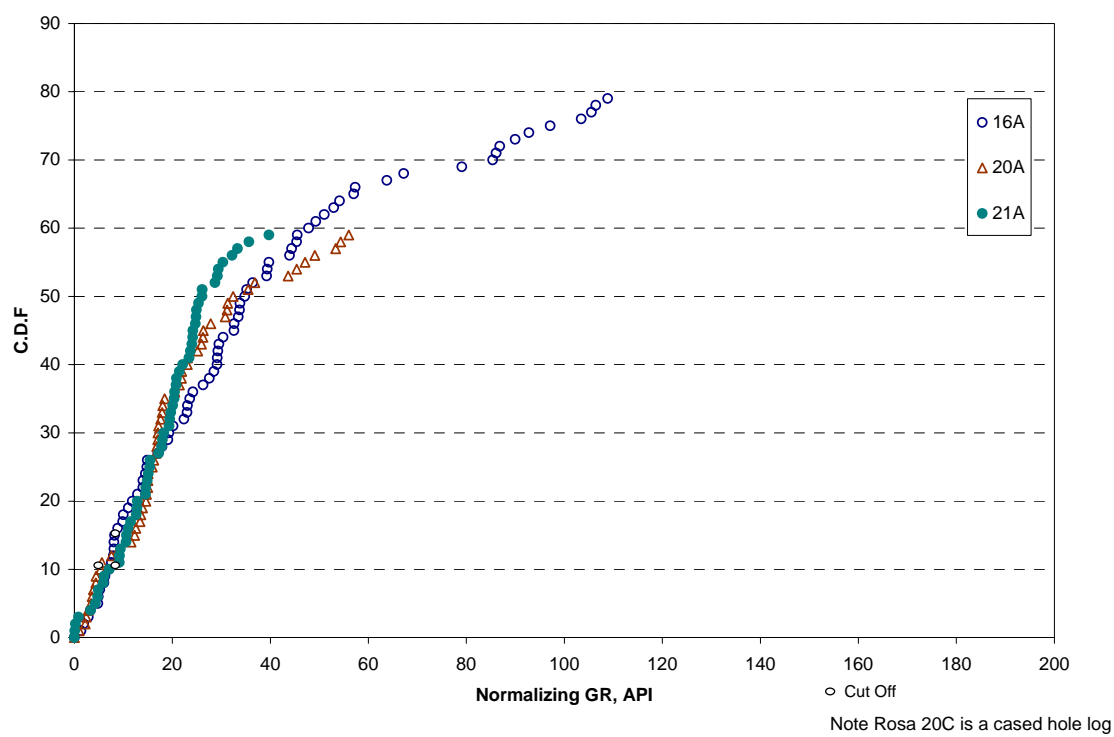

Figure 3.4b. CDF of normalized gamma ray for Cliffhouse 
Normalizing GR for Net Pay Cut Off Analysis MF Formation

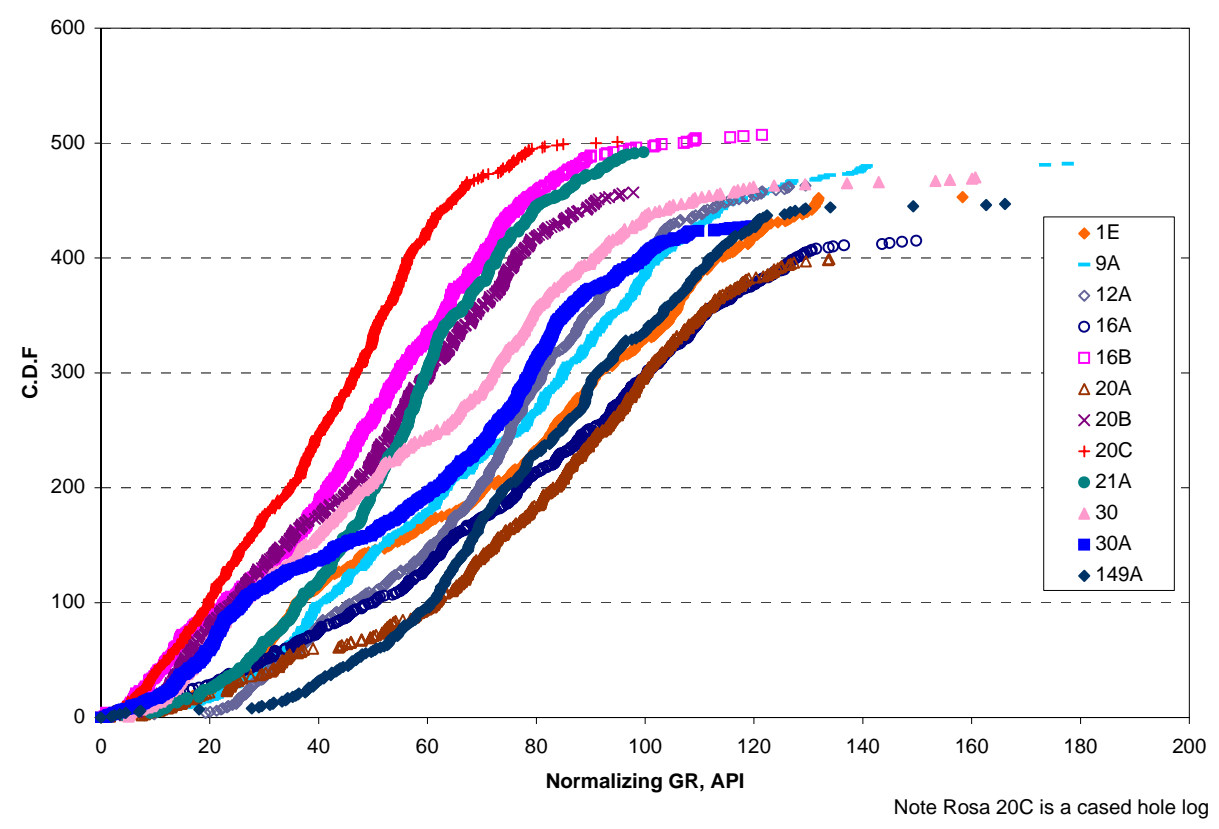

Figure 3.5. CDF of normalized gamma ray for Menefee 
Normalizing GR for Net Pay Cut Off Analysis PL Formation Group 1

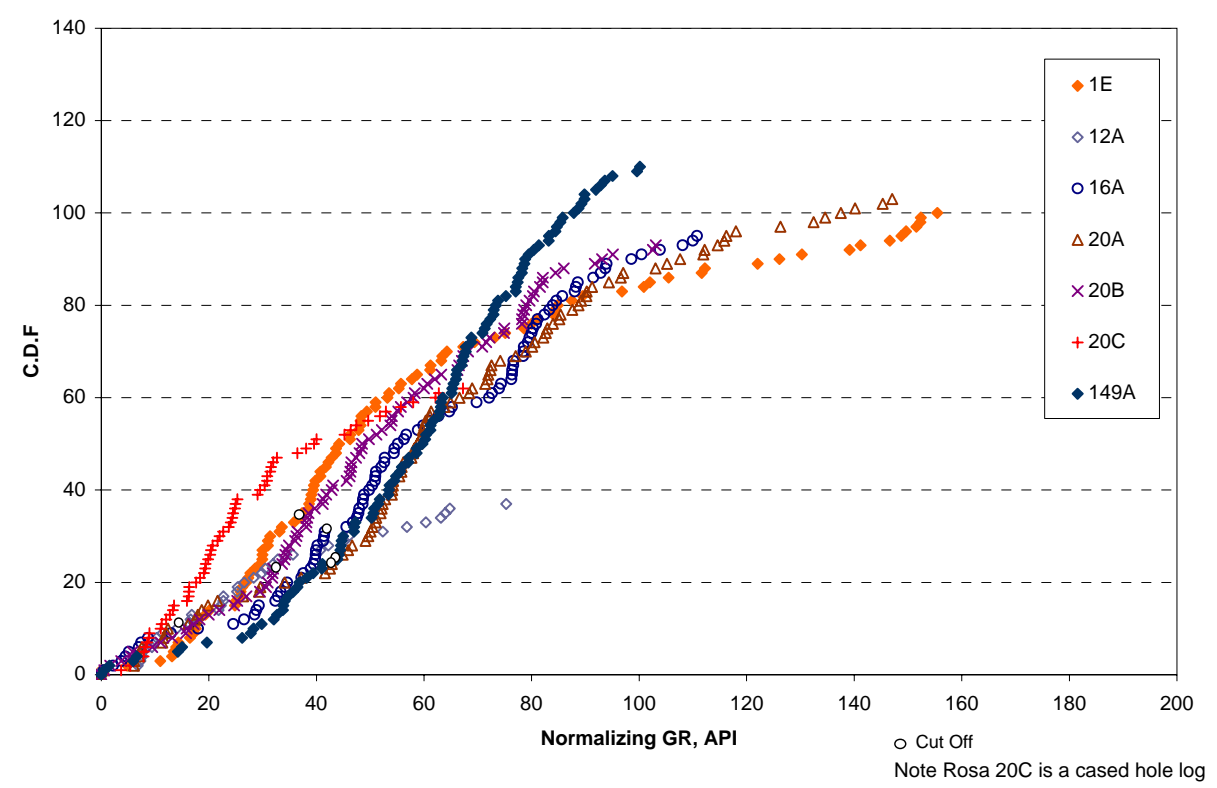

Figure 3.6a. CDF of normalized gamma ray for Point Lookout

Normalizing GR for Net Pay Cut Off Analysis PL Formation Group 2

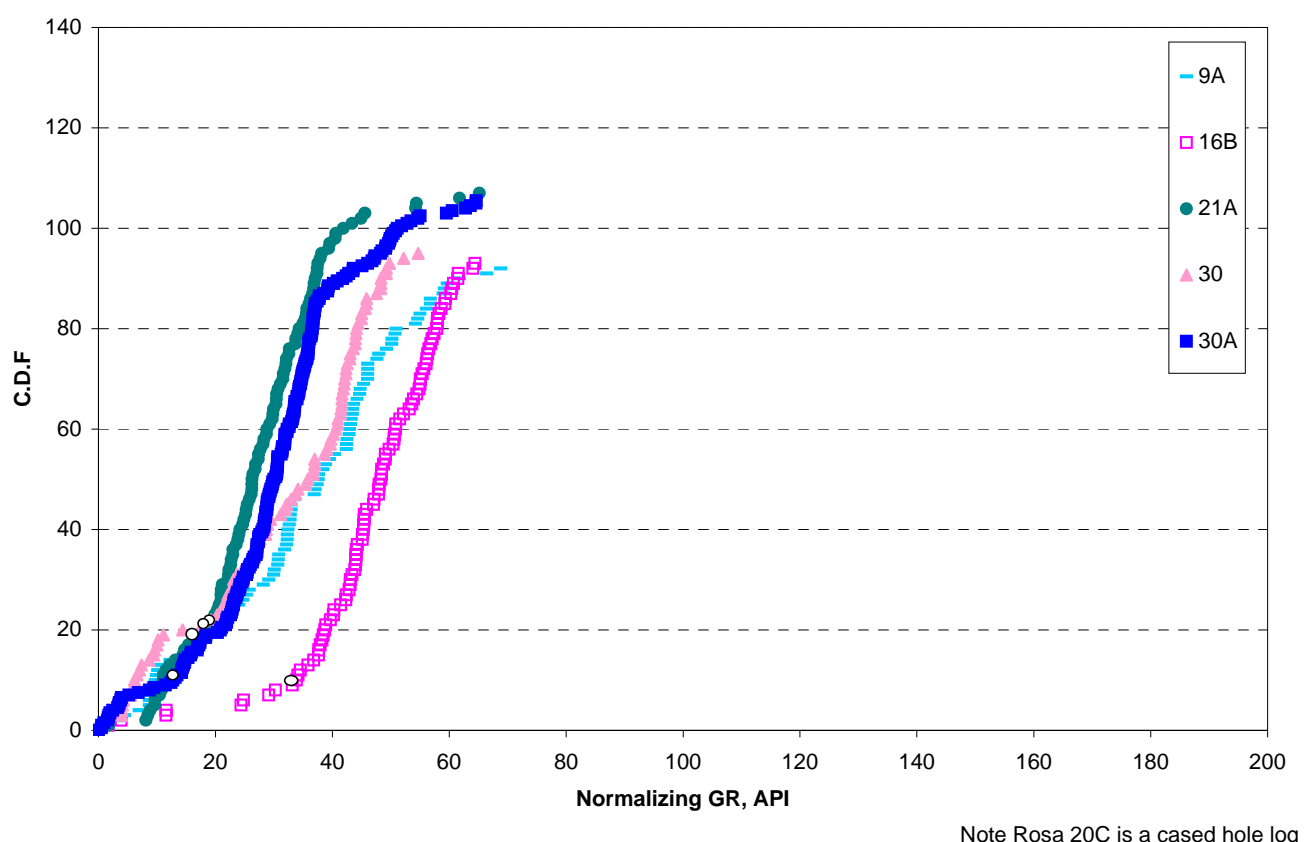

Figure 3.6b. CDF of normalized gamma ray for Point Lookout 
Well location, all wells

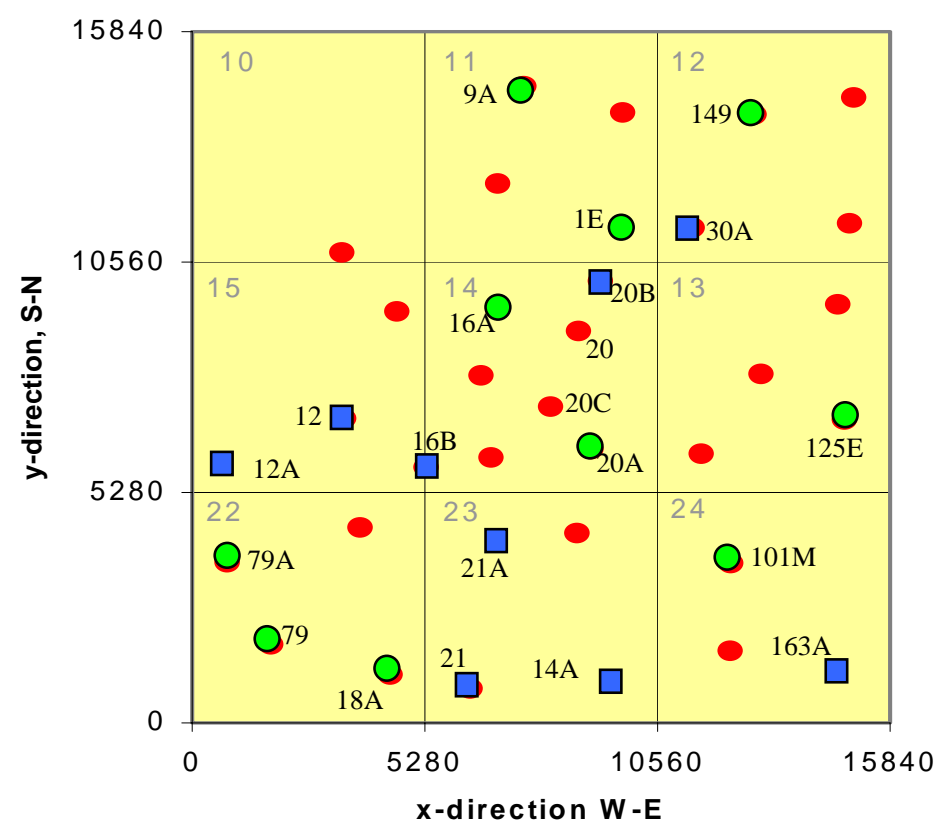

Figure 3.7. Porosity log availability in study area. (blue squares - density logs only, green circles - density/neutron logs, red circles - no porosity logs) 


\subsection{Production Analysis}

\section{Introduction}

A common source of information available for wells in the San Juan Basin is the production history, i.e., rate vs. time; therefore, it is prudent to utilize this information. In this work, 116 wells from the low-permeability Rosa Unit (Mesaverde) in San Juan Basin, New Mexico, were analyzed in order to:

(1) estimate the producing/flow characteristics,

(2) delineate the drainage volume/area, and

(3) infer the infill drilling possibilities.

This work includes (1) analysis of historical gas production trends, (2) analysis of individual well gas production data, (3) sensitivity analysis of net-to-gross thickness, and (4) analysis of infill-drilling potential. This work was conducted by J. Munoz and H-Y. Chen.

\section{Method}

The method adopted was decline-curve analysis using cross type-curve matching between rate, cumulative production, and time. Input data required is general well/ field information, well-reservoir and fluid PVT information and production data. Table 3.4 lists the input properties for the production analysis. The initial and flowing bottom-hole pressures $\left(p_{i}\right.$ and $\left.p_{w f}\right)$ are specified depending on the initial production date. Three different sets of pressures were determined as an average of the reported pressure values. Due to lack of information of net producing thickness $(h)$, sensitivity analysis was generated, based on net-to-gross thickness ratios of $1,0.75,0.50$, and 0.2 , respectively. Gross thickness for each analyzed well was assumed to be the top to bottom perforation interval. PVT properties $z$-factor $(z), \operatorname{FVF}(B)$, viscosity $(\mu)$, and total compressibility $\left(c_{t}\right)$ were calculated using the PVT program option.

In order to achieve these objectives, the following computer programs were developed: (1) type curve-based spreadsheet program for diagnosis, history matching, and forecasting of tight-gas wells, (2) programs for automation of data import, export, and plotting from commercial and private databases, and (3) plotting and scaling bubble map (circular shape) of drainage area. The approach is based on using pseudo-pressure to properly account for the pressure-dependent gas properties.

\section{Results}

\section{Decline trends}

Production for individual wells exhibited common decline trends based on the initial date of completion. Three groups were identified:

- Group 1: Initial production date from 1954 to 1962.

- Group 2: Initial production date from 1981 to 1983.

- Group 3: Initial production date from 1994 to present. 
Therefore, according to the analysis all the wells belonging to the same group have the same behavior in terms of production trend and initial time for boundary-affected flow than the others. Table 3.5 shows a representative sample from each group.

Results show the first group of wells has the largest drainage area. This reflects the thin assumed production thickness (see Table 3.5) and large calculated pore volume for this group. All the wells analyzed indicated, more or less, some transient flow; however, the duration of the transient period is longest for the first group. The existence of transient flow is to be expected (even for monthly data) because of the low permeability. During the transient flow period, Rosa Unit wells exhibit, generally speaking, very steep decline $\left(r_{e D}<10\right)$. The steep-decline behavior (low $r_{e D}$ value) is believed to be due to successful well stimulation (high negative skin).

The decline exponents $(b)$ observed during boundary-affected period range from 0 to 0.2 , with an average value of 0.02 . Therefore, exponential decline $(b=0)$ appears to be a good approximation.

\section{Comparison with other producing formations}

A comparison with other producing formations in the San Juan Basin, including the Mesaverde, is shown in Tables 3.6 and 3.7. The productivity index and flow capacity values reported for Rosa Unit by this study are similar to those reported for an average Mesaverde well. It should be emphasized that the uncertainty of producing thickness, does not change the interpretation pictures of the estimated productivity factor and flow capacity. The producing thickness does have a direct impact when the flow capacity is converted to the formation permeability.

The performance of Rosa Unit in terms of IGIP per well is poor compared to Mesaverde, Dakota, Picture Cliffs, and Fruitland Coal (See Table 3.7). In terms of drainage, pore volume the results obtained by this study for Rosa Unit are similar to these obtained from a previous study on all Mesaverde wells [Chen et al., 2001]. Finally, the drainage area and recovery factor for Rosa Unit has the same order of magnitude as the average Mesaverde, being the smallest among the formations.

The estimated drainage area is inversely proportional to the assumed producing thickness (for each well), which in turn is assumed to be the top-bottom perforation interval (for each well) in this study. Uncertainty in the "producing thickness," thus, has a direct and significant impact on the estimated drainage area. However, it should be emphasized that the uncertainty of producing thickness does not change the interpretation pictures of the estimated drainage pore-volume, IGIP, and current recovery factor. Overall, despite the issue of the producing thickness, the estimated drainage areas appear to be smaller than expected, considering the generally low flow resistance of the gas.

\section{Forecasting}

The average initial gas-in-place for the study area (98 wells) is 0.79 Bscf per well. Through 1999 the average recovery per well has been $0.34 \mathrm{Bscf}$ or $43 \%$ of the IGIP. The estimated remaining reserves per well is $0.28 \mathrm{Bscf}$ or $35 \%$ of the IGIP. These reserves were predicted from declining existing rate-time data to an abandonment rate of 10 mscfd. Combining the historical production with remaining reserves yields an estimated ultimate recovery (EUR) per well of 0.62 Bscf or a recovery factor of $78 \%$ of the IGIP. 
The total current recovery, IGIP, remaining reserves, and EUR is shown in Table 3.8. Total refers to the sum of the 98 analyzed wells. All forecasting properties were based on a $10 \mathrm{Mscf} / \mathrm{d}$-abandonment rate. The results show that the total IGIP is $92 \mathrm{Bscf}$ and the current recovery is 39 Bscf. The remaining reserves are $33 \mathrm{Bscf}$, and the EUR is projected to be 73 Bscf.

The EUR was investigated as a function of the initial producing date for each well. Four ranges were identified and selected for the analysis.

- Group 1: Initial production date from 1954 to 1962 (22 wells analyzed).

- Group 2: Initial production date from 1981 to 1983 (9 wells analyzed).

- Group 3: Initial production date from 1994 to 1998 (53 wells analyzed).

- Group 4: Initial production date from 1999 to present (12 wells analyzed).

From Figure 3.8 it is evident the EUR decreases with the initial production date from a high of $1.46 \mathrm{Bscf} /$ well for the pre-1962 wells to a low of $0.40 \mathrm{Bscf} /$ well for the newer wells. This implies that new well locations are partially drained by older, existing wells. Also shown in Figure 3.8 is a plot of PF for the groups. Notice the PI is increasing with the newer wells, suggesting better stimulation/pay prediction with time.

\section{Spatial Distributions}

The spatial distribution of the studied properties; productivity factor $(P F)$, flow capacity $(k h)$, IGIP, drainage area $(A)$ and EUR provides insight into identifying possible trends and hence potential sites for drilling. A series of bubble maps were constructed for this purpose.

\section{Productivity Factor, PF}

Figure 3.9 shows a bubble map with the relative productivity factor for the wells studied. In the figure, the northwest region of Rosa Unit (31N-6W Sections 3, 4, 8, and 9) presents the highest values for productivity factor. Moving in a southeastward direction the productivity factor progressively decreases in overall magnitude, with only minor local variations.

\section{Flow Capacity, kh}

Figure 3.10 shows a bubble map for the flow capacity of the Mesaverde wells. High flow capacity wells are concentrated in two areas: the northwest region of Rosa Unit (31N-6W Sections 3, 4, 8, and 9) and the southeast central part of unit (31N-6W Sections 25 and 31N-5W Section 30). The northwest region is expected since flow capacity is directly proportional to productivity factor. However, the southeast central region, with high flow capacity and poor productivity factor, suggests an area of poor stimulation.

\section{Initial Gas in Place, IGIP}

Figure 3.11 illustrates a bubble map with the relative IGIP for the wells analyzed. The greatest IGIP trends along a northeast to southwest diagonal in the center of the unit. This region would represent the greatest pore volume of storage capacity in the Mesaverde unit. 


\section{Estimate Ultimate Recovery, EUR}

Figure 3.12 shows a bubble map with the relative EUR for the wells analyzed. This map reinforces the higher storage capacity area seen in IGIP in Figure 3.11, and implies the best wells are dominated more by storage capacity than flow capacity.

\section{Drainage Area, A}

Figures 3.13 and 3.14 show scaled bubble maps of drainage area, based on a netto-gross thickness ratio equal to $1.00,0.75,0.50$, and 0.25 , respectively. Drainage area bubble maps were made based upon isotropic permeability assumption. Therefore, the bubbles are circular shaped and do not suggest anything about isotropic or anisotropic behavior of drainage.

Some observations from Figures 3.13 and 3.14 are:

- When net-to-gross thickness ratio is 1.00 , drainage areas are relatively small; however, there does exist slight overlapping in drainage areas in the central part of Rosa Unit (31N-6W Sections 14 and 23). This ratio is unlikely, and results in an overestimate of producing thickness and thus a corresponding underestimate of drainage area.

- When net-to-gross thickness ratio is decreased to $0.75,0.50,0.25$, drainage areas are increased as a result of the production thickness $(h)$ reduction. Increasing the size of the drainage areas implies a higher possibility of overlapping areas.

\section{Summary}

The results of the production analysis study show:

(1) Newer wells have a shorter transient period, i.e., the onset of depletion occurs earlier. This suggests partial depletion of the reservoir.

(2) During transient flow period, Rosa Unit wells exhibit very steep decline (flow geometry match parameter, $r_{e D}<10$ ), signifying improved stimulation techniques.

(3) Exponential decline, (decline match parameter, $b=0$ ), appears to be a good approximation.

(4) The flow behavior of Rosa Unit is comparable to the average flow behavior of Mesaverde formation.

(5) Rosa Unit has less storage capacity than the average storage capacity of Mesaverde formation.

(6) Northwest part of Rosa Unit shows the highest productivity factor $(P F)$ and flow capacity $(k h)$ values, central part of Rosa Unit shows the highest drainage area $(A)$, and estimated ultimate recovery (EUR) and, northeast part of Rosa Unit shows the highest initial gas-in-place (IGIP). 


\begin{tabular}{|c|c|c|c|c|}
\hline \multicolumn{2}{|l|}{ Values } & \multicolumn{3}{|c|}{ Initial Production Year } \\
\hline Properties & Units & $\begin{array}{c}\text { Before } \\
1970\end{array}$ & $\begin{array}{c}\text { Between } \\
1970 \text { - } \\
1998\end{array}$ & $\begin{array}{c}\text { After } \\
1998\end{array}$ \\
\hline Initial Reservoir Pressure, $p_{i}$ & Psi & 1300 & 800 & 500 \\
\hline Flowing BHP, $p_{w f}$ & Psi & 500 & 350 & 120 \\
\hline Initial $z$-Factor, $z_{i}$ & - & 0.9003 & 0.9322 & 0.9557 \\
\hline Initial FVF, $B_{i}$ & rb/Mscf & 2.1599 & 3.6342 & 5.9608 \\
\hline Initial Viscosity, $\mu_{i}$ & $\mathrm{Cp}$ & 0.0141 & 0.01321 & 0.0126 \\
\hline Initial Total Compressibility, $c_{t i}$ & $\mathrm{psi}^{-1}$ & $4.19 \times 10^{-4}$ & $6.69 \times 10^{-4}$ & $1.05 \times 10^{-3}$ \\
\hline Porosity, $\phi$ & $\%$ & & 9 & \\
\hline Initial Water Saturation, $\mathrm{S}_{\mathrm{wi}}$ & $\%$ & & 50 & \\
\hline Wellbore Radius, $\mathrm{r}_{\mathrm{w}}$ & $\mathrm{Ft}$ & & 0.2 & \\
\hline Reservoir Temperature, $T$ & ${ }^{\circ} \mathrm{F}$ & & 160 & \\
\hline Specific Gravity, $\gamma$ & - & & 0.6 & \\
\hline Water Compressibility, $c_{w}$ & $\mathrm{Psia}^{-1}$ & & $6 \times 10^{-6}$ & \\
\hline Formation Compressibility, $c_{f}$ & Psia $^{-1}$ & & $3 \times 10^{-6}$ & \\
\hline Mole Fraction of $N_{2}$ & fraction & & 0 & \\
\hline Mole Fraction of $\mathrm{CO}_{2}$ & fraction & & 0 & \\
\hline Mole Fraction of $\mathrm{H}_{2} \mathrm{~S}$ & fraction & & 0 & \\
\hline Frac. of $360^{\circ}$ Open to Flow, $\sigma$ & fraction & & 1 & \\
\hline Abandonment Rate, $q_{a b d}$ & Mscf/d & & 10 & \\
\hline
\end{tabular}

Table 3.4. Input data for analysis of individual well gas production data. 


\begin{tabular}{||l||c||c||c|c||}
\hline Properties & Units & Well Group 1 & Well Group 2 & Well Group 3 \\
\hline \hline Well ID & - & $\begin{array}{c}\text { ROSA UNIT } \\
\# 41\end{array}$ & $\begin{array}{c}\text { ROSA UNIT } \\
\# 45\end{array}$ & $\begin{array}{c}\text { ROSA UNIT } \\
\text { \#64M }\end{array}$ \\
\hline $\begin{array}{l}\text { Location } \\
\begin{array}{l}\text { Initial Production } \\
\text { Date }\end{array}\end{array}$ & - & $31 \mathrm{~N}-5 \mathrm{~W}-5 \mathrm{~K}$ & $31 \mathrm{~N}-5 \mathrm{~W}-9 \mathrm{M}$ & $31 \mathrm{~N}-5 \mathrm{~W}-29 \mathrm{~F}$ \\
\hline $\begin{array}{l}\text { Cumulative } \\
\text { production* }\end{array}$ & Mscf & 766641 & 57090 & 187750 \\
\hline $\begin{array}{l}\text { Last Production } \\
\text { Rate* }\end{array}$ & Mscf/d & 75 & 8.09 & 129.12 \\
\hline $\begin{array}{l}\text { Gross Thickness } \\
\text { Production Time* }\end{array}$ & $\mathrm{ft}$ & 118 & $5 \mathrm{Jun}-83$ & Sep-96 \\
\hline $\begin{array}{l}\text { Initial Time } \\
\text { Boundary Affected } \\
\text { Flow }\end{array}$ & Days & $\sim 4000$ & $\sim 1200$ & 889 \\
\hline
\end{tabular}

*Through May 1999

Table 3.5 Main properties from example wells

\begin{tabular}{||l|c|c||}
\hline \hline & $\begin{array}{c}\text { Productivity Factor } \\
\text { (Mscf/d/psi) }\end{array}$ & $\begin{array}{c}\text { Flow Capacity } \\
\text { (md-ft) }\end{array}$ \\
\hline Fruitland Sand* & 0.142 & 1.47 \\
\hline Fruitland Coal* & 1.362 & 18.92 \\
\hline Pictured Cliffs* & 0.287 & 2.54 \\
\hline Rosa Unit** & $\mathbf{0 . 9 1 0}$ & $\mathbf{6 . 3 7}$ \\
\hline Mesaverde* & 0.907 & 6.71 \\
\hline Dakota* & 0.389 & 2.42 \\
\hline \multicolumn{2}{|c|}{ *Chen et al. 2001 } & ** Present study results
\end{tabular}

Table 3.6 Average productivity and flow per-well characteristics, San Juan Basin, New Mexico 


\begin{tabular}{||l|c|c|c|c||}
\hline & $\begin{array}{c}\text { Drainage } \\
\text { Pore Volume } \\
\text { (MMscf) }\end{array}$ & $\begin{array}{c}\text { Initial Gas in } \\
\text { Place, IGIP } \\
\text { (BSCF) }\end{array}$ & $\begin{array}{c}\text { Recovery } \\
\text { Factor } \\
\text { (\% IGIP) }\end{array}$ & $\begin{array}{c}\text { Drainage } \\
\text { Area } \\
\text { (Acres) }\end{array}$ \\
\hline \hline Fruitland Sand* & 18.7 & 0.621 & 40 & 138 \\
\hline Fruitland Coal* & 35.9 & 3.540 & 55 & 58 \\
\hline Pictured Cliffs* & 16.4 & 1.574 & 23 & 104 \\
\hline Rosa unit** & $\mathbf{3 2 . 9}$ & $\mathbf{0 . 7 9 0}$ & $\mathbf{4 3}$ & $\mathbf{2 0}$ \\
\hline Mesaverde* & 31.1 & 1.971 & 51 & 26 \\
\hline Dakota* & 25.0 & 1.558 & 50 & 102 \\
\hline
\end{tabular}

\#2 Through May 1999.

* $\quad$ Chen et al. 2001. ** Present study results.

Table 3.7. Average drainage per-well characteristics, San Juan Basin, New Mexico

\begin{tabular}{||c||c||c||}
\hline Properties & Units & $\begin{array}{c}\text { Total } \\
\text { Properties }^{1}\end{array}$ \\
\hline \hline Current Recovery & Bscf & 39.08 \\
\hline Initial Gas in Place, IGIP & Bscf & 91.59 \\
\hline Remaining Reserves & Bscf & 32.67 \\
\hline $\begin{array}{c}\text { Estimate Ultimate } \\
\text { Recovery, EUR }\end{array}$ & Bscf & 73.02 \\
\hline
\end{tabular}

${ }^{1}$ Sum of individual values for 98 analyzed wells

Table 3.8. Total values, Rosa Unit, San Juan Basin, New Mexico 


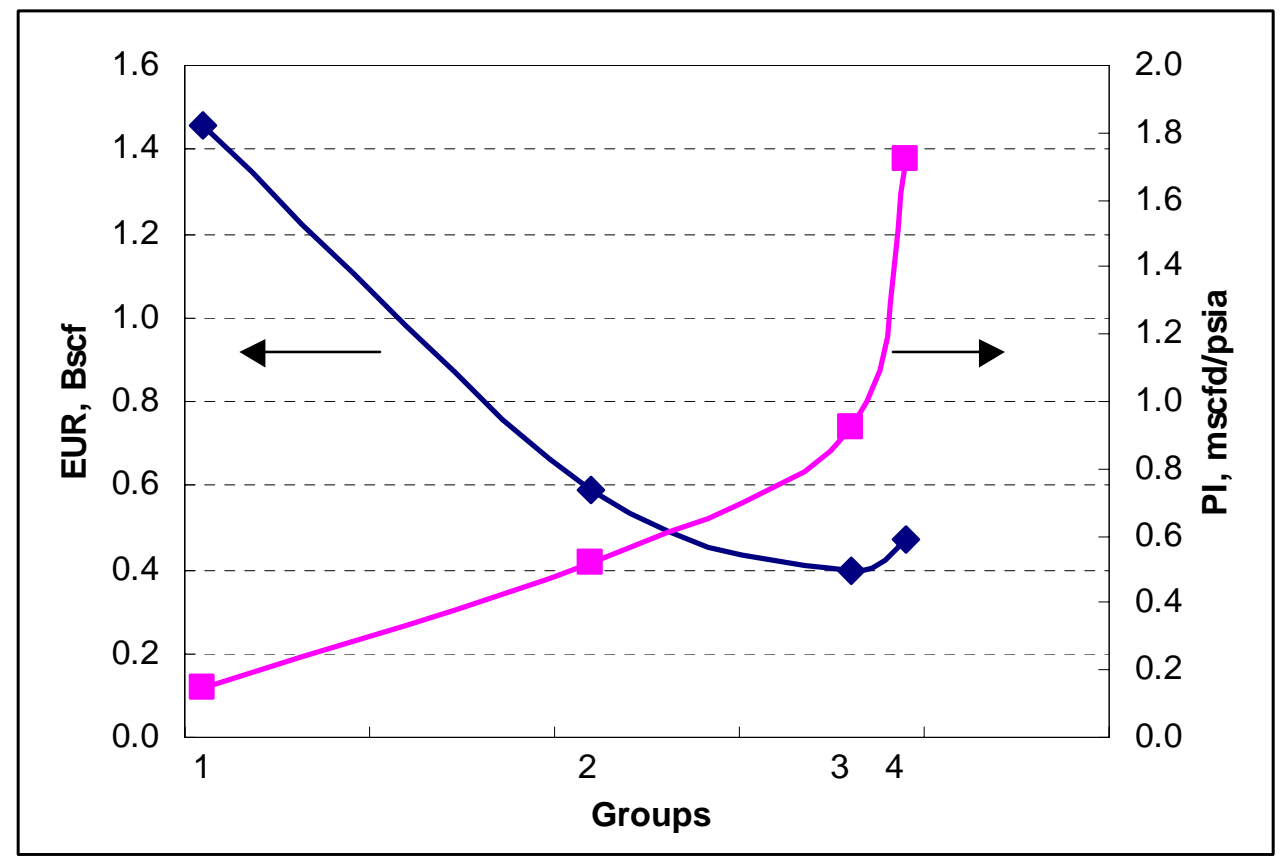

Figure 3.8. EUR and PF trends for the four groups identified. 


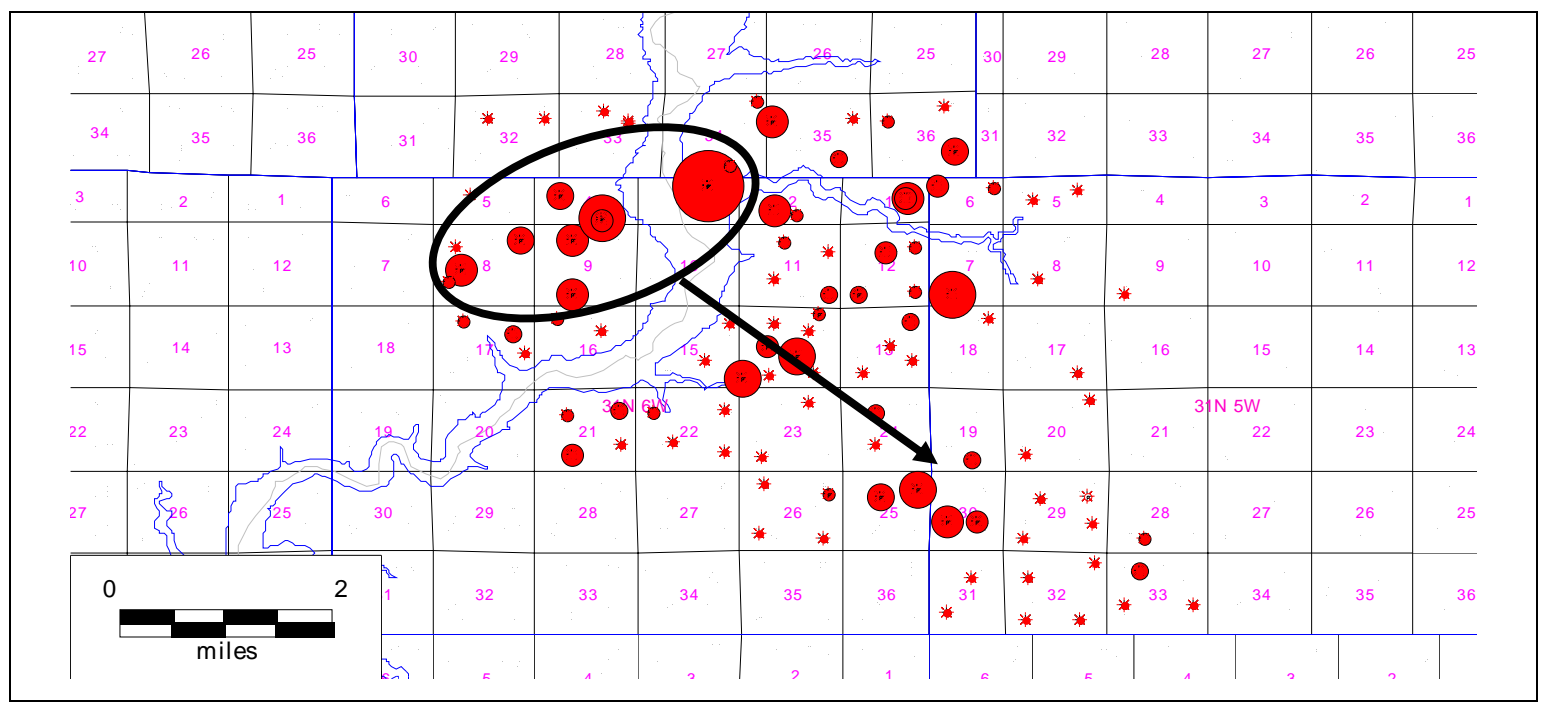

Figure 3.9. Relative bubble map of productivity factor, $P F$

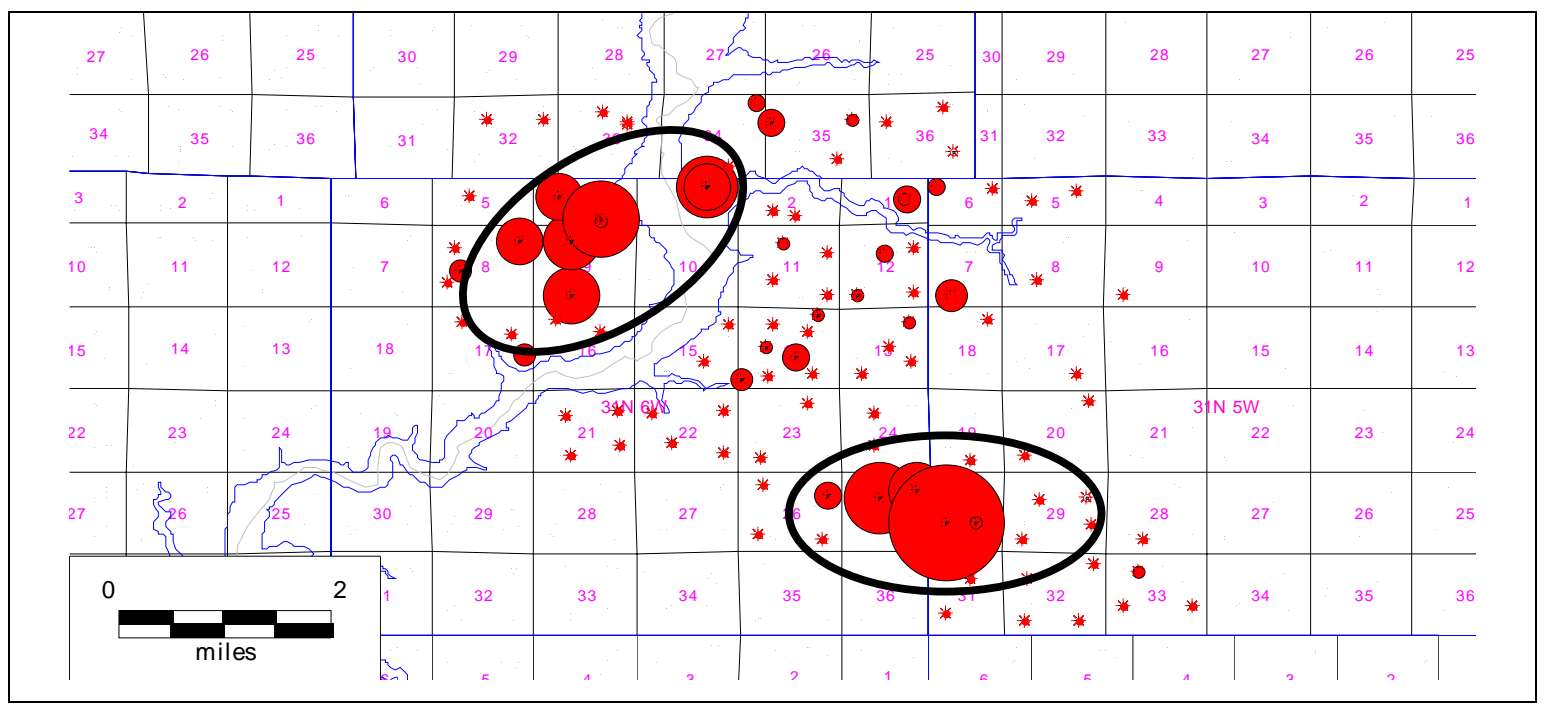

Figure 3.10. Relative bubble map of flow capacity, $k h$ 


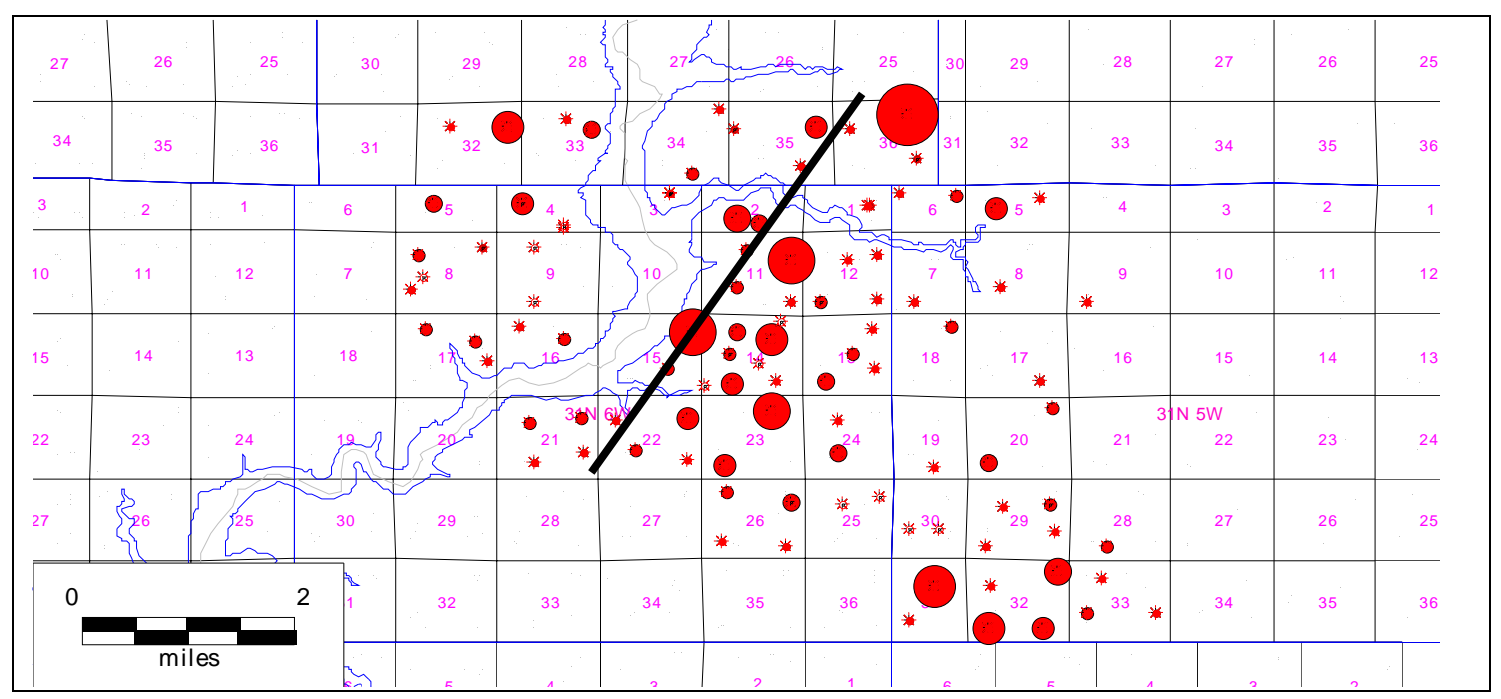

Figure 3.11. Relative bubble map of initial gas in place, IGIP

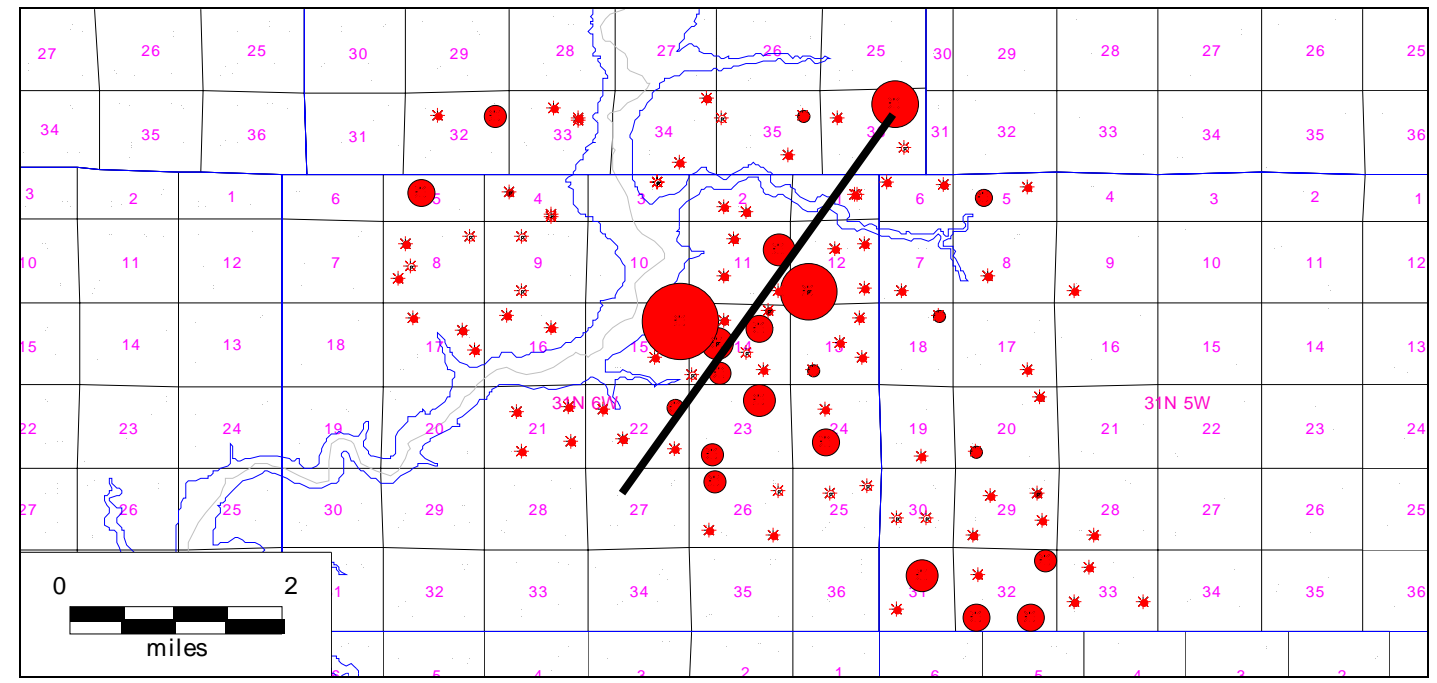

Figure 3.12. Relative bubble map of estimate ultimate recovery, EUR 
A) Drainage Area Net-to-Gross thickness ratio = 1

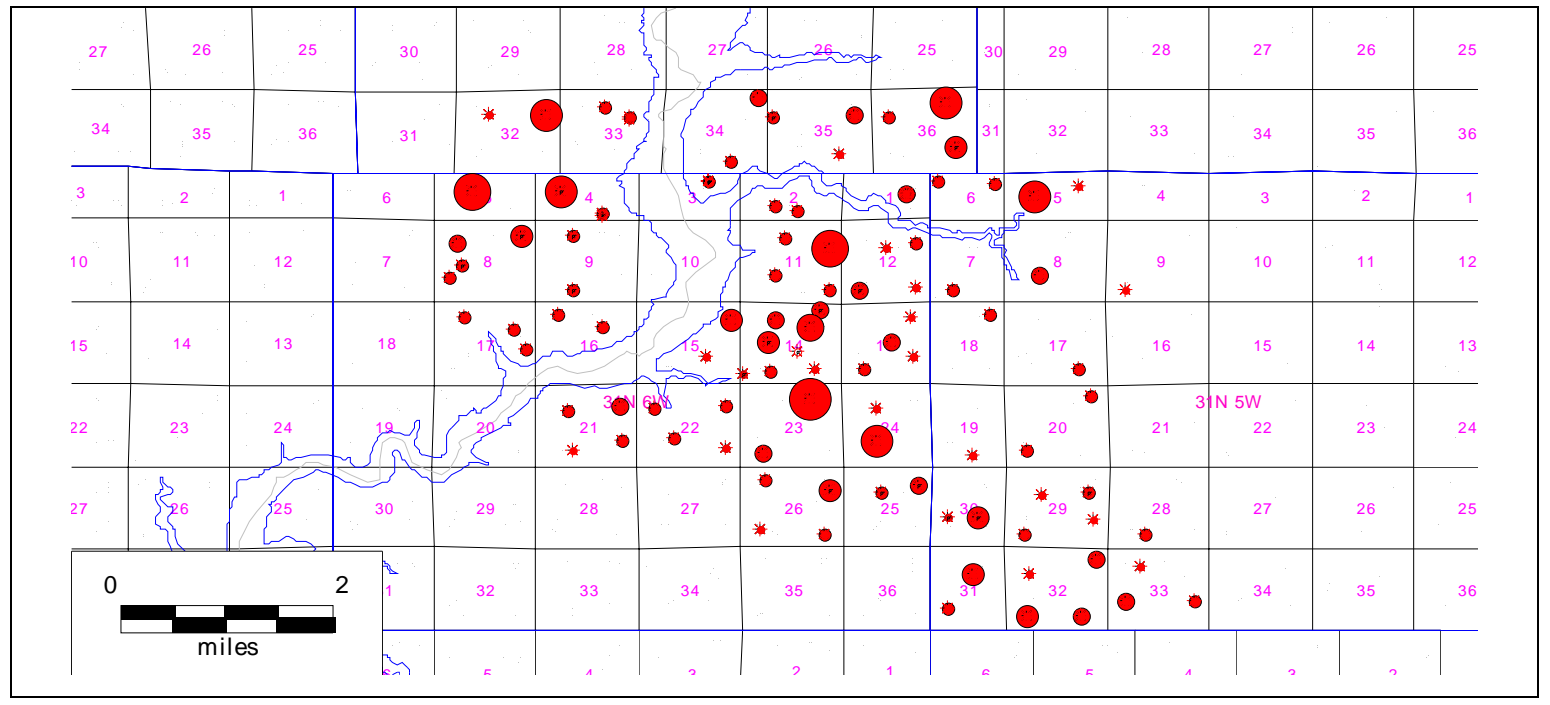

B) Drainage Area Net-to-Gross thickness ratio $=0.75$

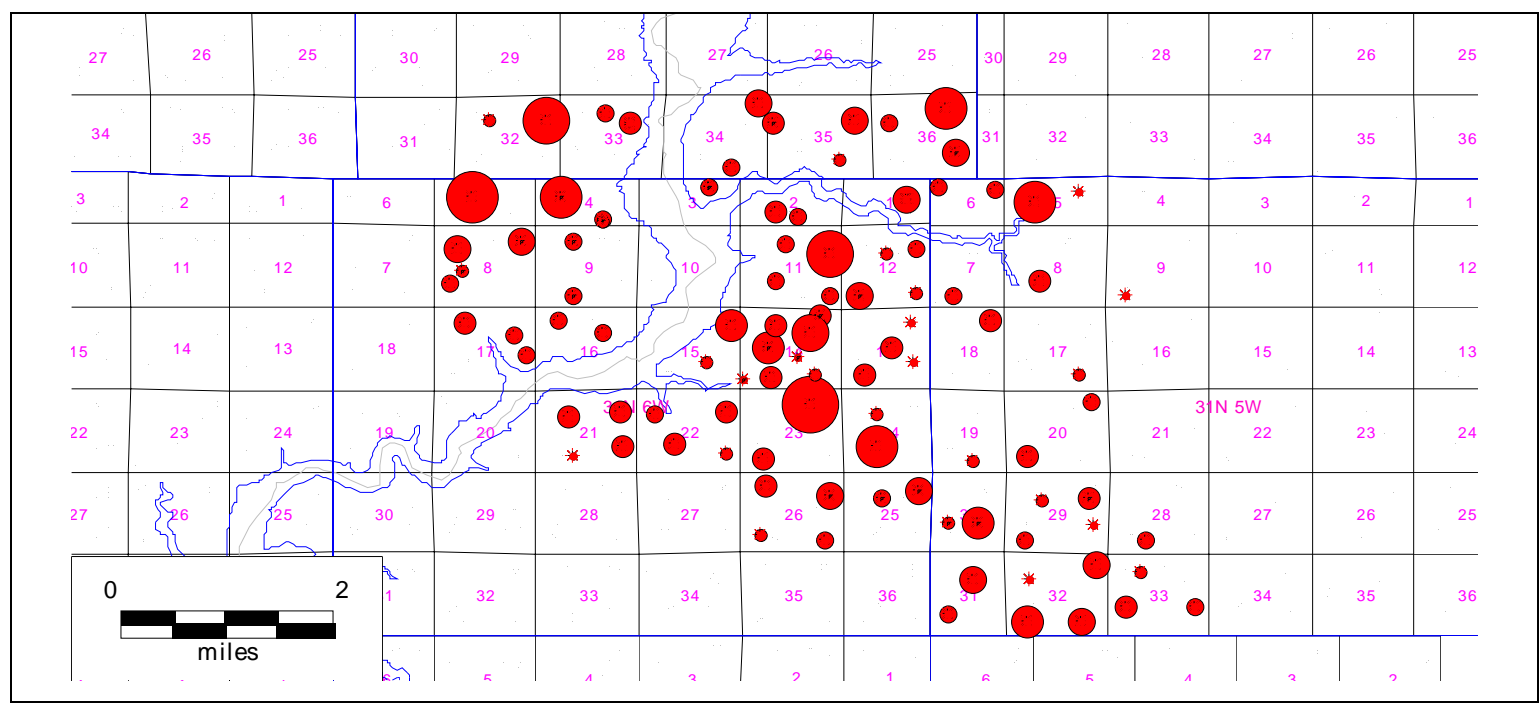

Figure 3.13. Relative bubble map of drainage area, A) net-to-gross thickness ratio $=1$, B) net-to-gross thickness ratio $=0.75$ 
A) Drainage area net-to-gross thickness ratio $=0.50$

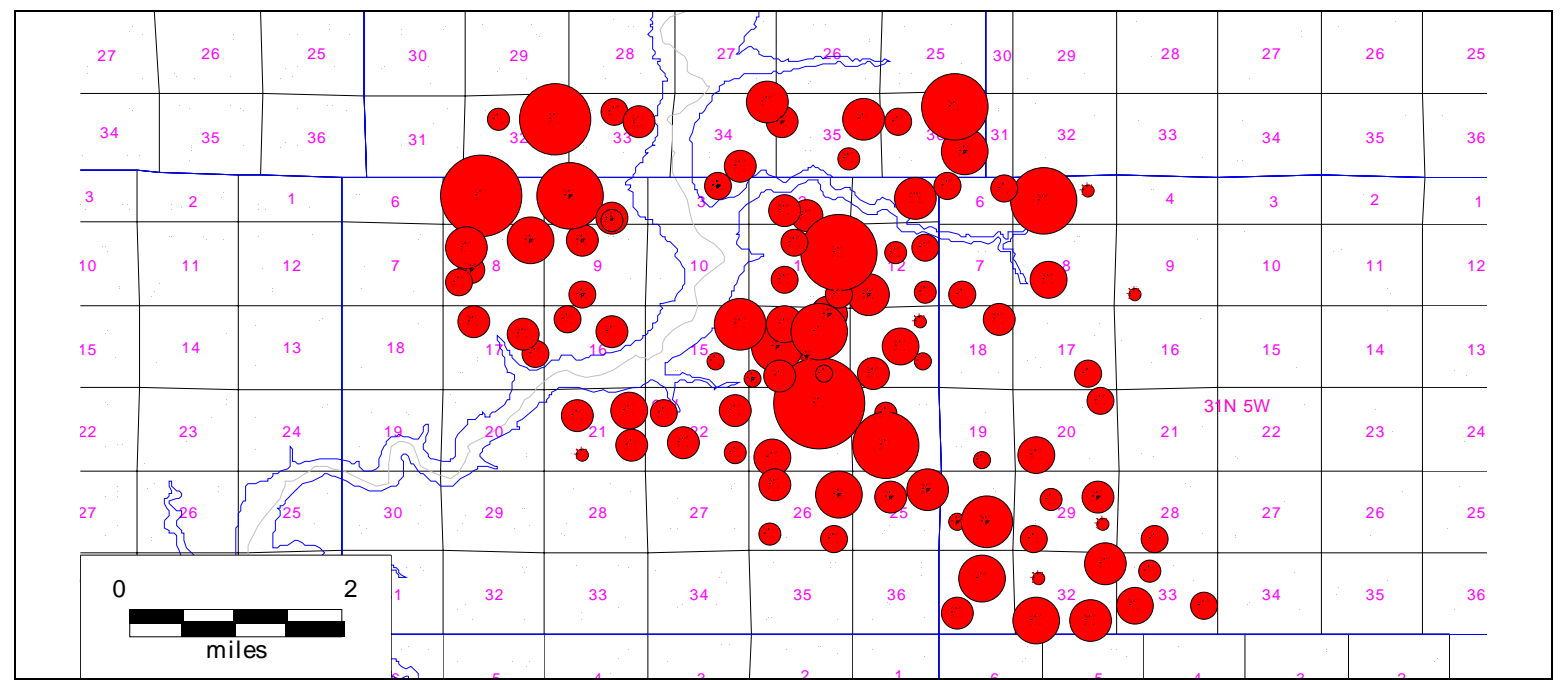

B) Drainage area net-to-gross thickness ratio $=0.25$

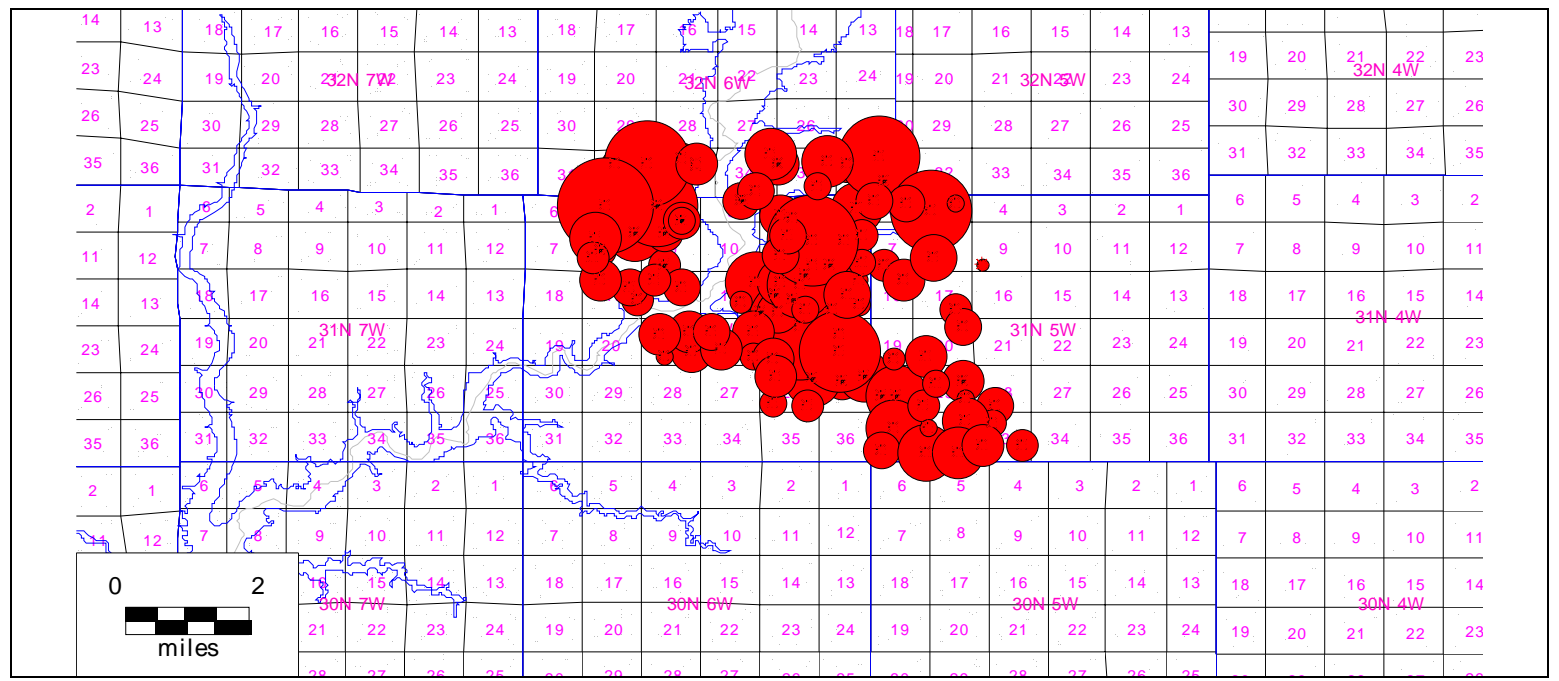

Figure 3.14. Relative bubble map of drainage area, A) net-to-gross thickness ratio $=0.50$, B) net-to-gross thickness ratio $=0.25$ 


\subsection{Reservoir Simulation}

\section{Introduction}

The approach was to predict the reservoir performance for the 80-acre infill wells from reservoir simulation and compare these predictions with the actual performance of the infill wells. Two methods of simulation were applied to this task: the Infill Well Locator Calculator (IWLC) and Merlin ${ }^{\mathrm{TM}}$, a 3D, multiphase, finite difference flow simulator.

The IWLC (Kelly, 2000) was developed as a simple tool to assist field companies in the drilling of infill-wells in low-permeability gas reservoirs. It was applied to four infill wells that were drilled on 80-acre spacing in a pilot area of the Mesaverde Blanco Rosa Unit (See Figure 3.15). The simulator uses porosity, water saturation, formation thickness, and maximum and minimum permeability data from adjacent wells, which surround an infill well. The advantage of this simulator is it will predict recovery for all gridblocks bounded by the existing wells. Consequently, a qualitative evaluation of the optimal infill location can be determined and this location compared with the actual well performance. Furthermore, the simulator is versatile in that changes in the magnitude and orientation of permeability anisotropy can readily be accomplished and the resulting effect on the location of infill wells evaluated. This work was conducted by J. Espeland , K. Iden and L. Teufel.

The limitation of the IWLC simulator is its simplified approach of modeling reservoir properties, e.g., averaged over the entire Mesaverde section at each well location and then distributed over the bounded area. This approach ignores heterogeneity within the test area and maybe the cause of some of the errors discussed later. For this reason, a second approach was to model the 80 -acre infill pilot area using a traditional reservoir flow simulator. In this way, the heterogeneity of the Mesaverde can be included in the analysis. However, as will be shown later, the caveat is the quality and quantity of input data available to capture the heterogeneity effect. Furthermore, the gridblocks must be orthogonal to the maximum and minimum permeability orientation. Thus any change in permeability orientation would require rotating the entire grid system and recalculating all gridblock values, a time consuming and tedious task.

The second approach was to apply a 3D, finite difference flow simulator to the Mesaverde Group in the Rosa Unit. Even though the potential for 80-acre infill wells in only Section 14 was to be analyzed, surrounding sections were also integrated in the model to include interference between wells. Therefore, the total area evaluated consists of 9 square miles. Geologic data provided by Williams and collected from various sources was integrated to develop a geologic model of the area. Petrophysical information, primarily from openhole well logs, detailed in Chapter 3.2 was combined with flow and wellbore properties from production analysis in Chapter 3.3, and subsequently formed the foundation for the flow simulation. 
The study area was divided into a 48x48x3 grid system. In the horizontal (x-y) plane, each gridblock has dimensions of 330 by $330 \mathrm{ft}$. Figure 3.18 illustrates the grid system. In the vertical direction, the three layers were divided to match the Cliffhouse, Menefee, and Point Lookout, respectively. Geostatistics were applied to the geological data to generate distributions within the study area.

\section{Results from IWLC}

A test of the quality and therefore reliability of the simulation results of the IWLC program was determined by comparing the measured and predicted reservoir pressure at the location of the actual drilled infill well. Results were mixed, with half of the study areas within good agreement and the other half not.

In the first study area, infill well No. 20C (see Fig. 3.15 for location), the objective was to investigate the effect of permeability orientation on the pressure response and gas recovery. Although there is no direct field evidence for natural fracture enhancement of reservoir permeability, permeability anisotropy, or productivity in the Rosa Unit, simulations were conducted to test the effect of permeability anisotropy and change in the orientation of permeability anisotropy on the location of infill wells determined by the IWLC program. Previous work in the basin suggests a maximum horizontal permeability direction of N-S to NNE-SSW and permeability anisotropy ratio of 10:1.

Five cases were generated: isotropic and four anisotropic at directions of north-south, eastwest, $\mathrm{N} 30^{\circ} \mathrm{E}$ and $\mathrm{N} 60^{\circ} \mathrm{E}$. Table 3.9 and Figure 3.16 summarize the orientations investigated and the resulting anisotropy ratios generated by the simulator. The input permeability anisotropy ratio for all areas was 10:1, however, the calculated output permeability anisotropy were quite variable, from 1.1 (nearly isotropic) to 122:1 (extremely anisotropic).

Good agreement was obtained between the predicted and measured reservoir pressure for a majority of the permeability orientations. Table 3.10 and Figure 3.17 summarize the results. The difference in pressures is less than $5 \%$ for four of the directions, suggesting limited interference effects between wells. Subsequently, since each of these directions matches the actual pressure, permeability orientation cannot be discerned from this information. The exception is the N30E anisotropy direction, which exhibits significant pressure depletion within the simulation and consequently interference effects between wells. This behavior does not match the actual behavior of the well and is therefore incorrect. In addition, the extremely high permeability anisotropy ratio would indicate a high intensity fracture area. Production evidence of the two existing wells along the N30E trend (production of approximately 1 Bcf over 44 years) does not clearly reflect wells with natural fracture productivity.

Comparison of gas recovery and optimum well location revealed close agreement between predicted and measured data. Optimal well location determined by the IWLC for the first study area (\#20C well) was two blocks (400x400 ft) northwest of the actual drilled location for the isotropic case and one block west for the N-S anisotropic case. The cumulative production forecast for the five well $(16,16 \mathrm{~A}, 20,20 \mathrm{~A}$, and 20C) area is 
nearly the same for both cases and is 12-14 MMCF $(<1 \%)$ greater than the production forecast of the actual drilled infill location. The $\mathrm{N} 30^{\circ} \mathrm{E}$ simulation run has a significantly different calculated infill well location than the drilled location due to the severe interference effects reducing the pressure in the given direction.

A second study area for infill well location $\# 16 \mathrm{~B}$, was similarly successful, with the difference between the predicted and measured pressure of 25 psi (2.3 percent) for the isotropic run and 24 psi (2.2 percent) for the N-S anisotropic run. Optimal well location determined by the IWLC was one block $(450 \times 450 \mathrm{ft})$ south of the actual drilled location for both isotropic and N-S anisotropic cases. The production forecast for the four (12A, $16,16 \mathrm{~B}$, and 18$)$ well area was essentially the same for both cases and is $1-2$ MMCF $(0.1$ $-0.2 \%$ ) greater than the production forecast of the actual drilled infill location.

In the remaining study areas, for both isotropic and N-S anisotropic reservoir permeability simulations, there was poor agreement between the predicted pressure and measured pressure at the actual location of the infill well. For example, as shown in Table 3.11, errors ranged from 14 to $25 \%$ depending on the orientation and anisotropy.

Furthermore, the predicted optimal well locations determined by the IWLC for these two are three to four grid blocks from the actual drilled infill well locations. Although gas production forecasted by the IWLC is significantly greater $(5-13 \%)$ for the calculated optimal well location than the actual drilled infill well locations, the large difference between the predicted and measured reservoir pressure raises concerns about the quality of the simulations. These concerns are related to (1) how the IWLC calculates and distributes average porosity and net thickness for the Mesaverde formations and (2) how the IWLC calculates the best match output data from the input data for permeability and well control factors of individual wells.

The lower calculated reservoir pressure may be related to the calculated effective reservoir volume, which is a function of the porosity and net thickness. As input into the IWLC program, these parameters are an average over the entire Mesaverde section at each well location and then distributed by the calculator for the local three or four well area of the model. This procedure is an over-simplification and be may responsible for the poor match in these two field cases.

Another limitation of the IWLC is that permeability and permeability anisotropy are Input as an average value over the entire three or four well area, and therefore do not take account any local variations due to natural fractures intersecting the wellbore. Accordingly, the calculated location for these two field cases may not be reliable and any forecasts of production using the calculator must be considered suspect. Although tests with four wells is a small test example and may be insufficient for a complete test of the Infill Well Location Calculator, the results of this study indicate important limitations in the general application of the IWLC program. 


\section{Conclusions/Remarks/Observations for IWLC}

1. Good agreement was found between the calculated and measured reservoir pressure at the actual location drilled for the infill well in 50\% of the selected areas tested. However, multiple permeability orientations gave reasonable agreements, therefore no permeability direction could be discerned from this work.

2. The optimal location and total cumulative gas production in each of these two field cases are essentially the same as the drilled locations.

3. Changes in the input parameters of average porosity and permeability did not change the calculated infill well location, but did reduce the predicted future production as expected.

4. It is important to note that although the input permeability anisotropy ratio for these two N-S anisotropic field cases was 10:1, the calculated output permeability anisotropy ratios for the best fit was less than 3:1, suggesting that isotropic permeability is probably a good assumption for these cases. Moreover, the well production history and lack of any reported measured pressure interference between wells indicates little or no influence of natural fractures on reservoir permeability or permeability anisotropy.

5. For those cases where predicted and measured pressures did not match, the underlying limitations of the IWLC are believed to be the culprit.

\section{Results from Flow Simulation}

A reservoir model was developed from a commercial reservoir simulator to capture the variations in net pay thickness and permeability. After successfully matching historical production data with this reservoir model, forecasting was performed 10 years into the future with the actual drilled locations and as an alternative, with proposed new infill well locations. A total of 40 wells were simulated in a nine-section area, to evaluate infill well locations in the 80 acre-pilot area of section 14 (See Figure 3.19). Both isotropic and anisotropic reservoir permeability cases were conducted in these simulations.

After history matching the production data in the nine-section area, a ten-year forecast was generated. Within the pilot area (Section 14), the incremental gas recovery was $38 \%$ of the OGIP. An attempt was made to improve this recovery by selecting areas appearing less drained (higher pressure) on the pressure map from the simulation. Figure 3.20 shows the changes in well locations. The ten-year forecast showed no significant improvement, also recovering 38\% of OGIP. Only well 20C increased its cumulative production by 21\%, from 321 to 390 mmscf; however, this gain was offset by losses in adjacent wells during the forecast period. Figure 3.21 shows the cumulative gas recovery for all Mesaverde wells in Section 14. 
A similar approach was applied considering north-south permeability anisotropy. Again, results were comparable to the isotropic cases discussed above. The incremental gas recovery was 38\% of the OGIP, both for the existing well locations and the proposed locations shown in Figure 3.21. Wells 16C and 20C increased their cumulative recoveries by 13 and $8 \%$, respectively. Figure 3.22 illustrates the cumulative gas recovery for the anisotropic case; which is nearly identical to the isotropic results.

\section{Summary of Flow Simulation}

In summary, the results of this study show only small differences in total production forecasted between the actual drilled and proposed new locations for both isotropic and anisotropic permeability cases. The proposed new infill well locations were different for both cases, but there were no significant differences in overall total recovery. The difference in well locations for the isotropic case and the anisotropic case is caused by different drainage and interference patterns. Wells in the simulated area have lower production compared to wells in areas in the basin where natural fractures have been observed and anisotropic permeability has been documented. In the Rosa unit, the assumption of permeability anisotropy due to natural fractures in the Mesaverde reservoir may not be warranted for determining infill well locations. Limited knowledge of permeability and the distribution of permeability within the modeled area increase the uncertainty in the evaluation of infill well locations and the quality of the production forecasts in this simulation study. 


\begin{tabular}{|c|c|}
\hline \multicolumn{2}{|c|}{ Case 1 } \\
\hline Orientation & K Ratio \\
\hline Isotropic & 1.6 \\
\hline N-S & 2.2 \\
\hline N30E & 122.0 \\
\hline N60E & 80.0 \\
\hline E-W & 1.1 \\
\hline
\end{tabular}

Table 3.9. Output permeability ratio utilized by the IWLC for different orientations of maximum permeability

\begin{tabular}{|c|ccc|c|}
\hline \multicolumn{7}{|c}{ Case 1, Infill well 20C } \\
\hline Orientation & $\begin{array}{c}\text { Measured Predicted } \\
\text { Pressure }\end{array}$ & $\begin{array}{c}\text { Pifference } \\
\text { Psi }\end{array}$ & $\begin{array}{c}\text { Percent } \\
\text { psi }\end{array}$ & $\begin{array}{c}\text { Psi } \\
\text { difference } \\
\%\end{array}$ \\
\hline isotropic & 937 & 968 & -31 & -3.3 \\
\hline N-S & 937 & 963 & -26 & -2.8 \\
\hline N30E & 937 & 729 & 208 & 22.2 \\
\hline N60E & 937 & 918 & 19 & 2.0 \\
\hline E-W & 937 & 985 & -48 & -5.1 \\
\hline
\end{tabular}

Table 3.10. Measured shut-in pressure for the infill well at actual drilled location, and the predicted reservoir pressure by the IWLC at the same location, including the difference between these for different orientation of maximum permeability.

\begin{tabular}{|c|cc|c|c|}
\hline Orientation & \multicolumn{2}{|c|}{ Infill well 16C } & \multicolumn{2}{c|}{ Infill well 20B } \\
\hline $\begin{array}{c}\text { Difference } \\
\text { Psi }\end{array}$ & $\begin{array}{c}\text { Percent } \\
\text { Difference } \\
\%\end{array}$ & $\begin{array}{c}\text { Difference } \\
\text { Psi }\end{array}$ & $\begin{array}{c}\text { Percent } \\
\text { Difference } \\
\%\end{array}$ \\
\hline isotropic & 131 & 14.2 & 200 & 25.2 \\
\hline N-S & 194 & 20.1 & 148 & 15.7 \\
\hline
\end{tabular}

Table 3.11. Measured shut-in pressure for the infill well at actual drilled location, and the predicted reservoir pressure by the IWLC at the same location, including the difference between these for different orientation of maximum permeability. 


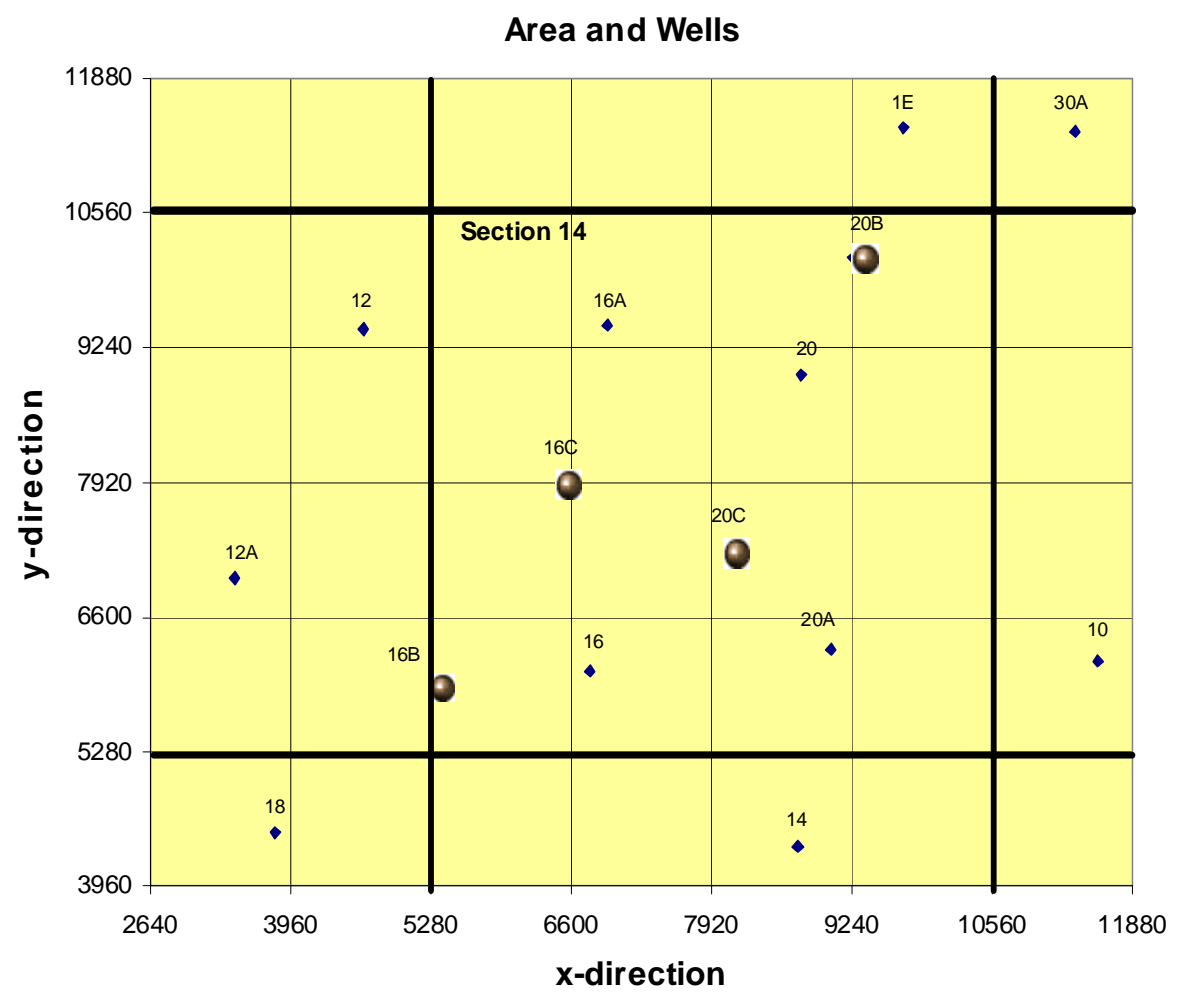

Figure 3.15. Well location map of Section 14 of the Rosa Unit. (Infill 80-acre wells are denoted by large circles). 


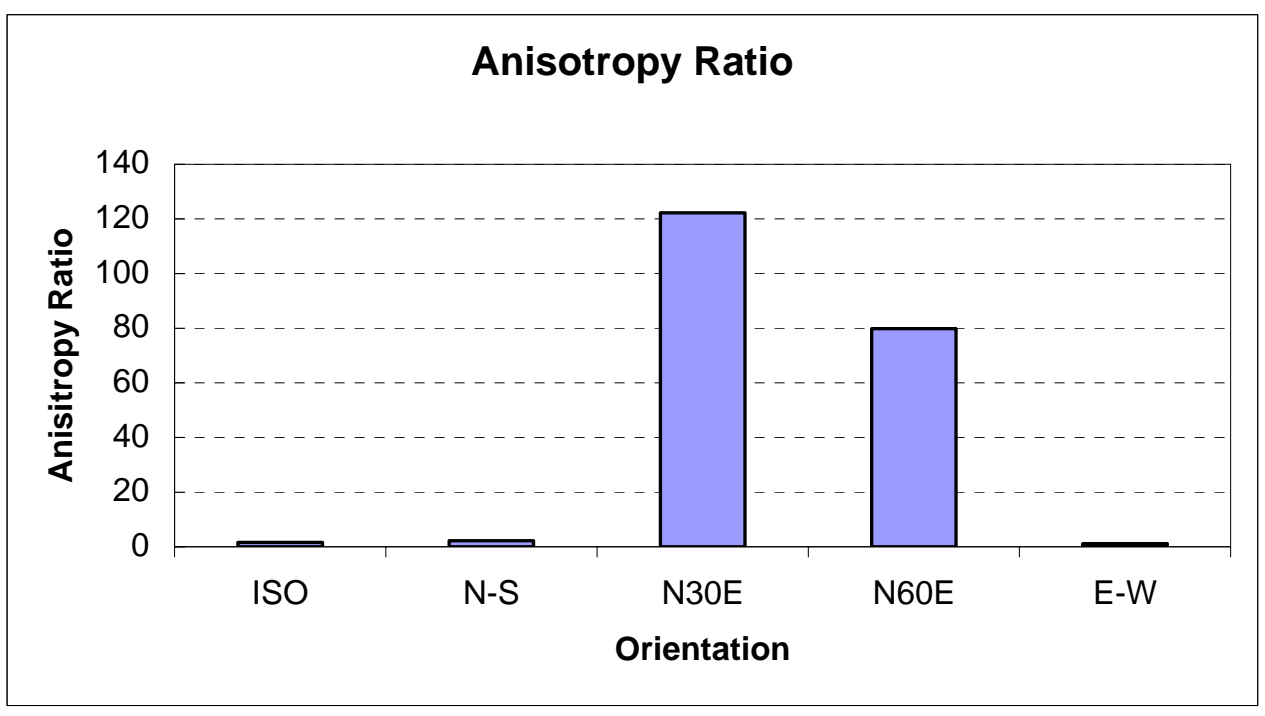

Figure 3.16. Anisotropy ratio predicted by the IWLC for different orientations of maximum permeability

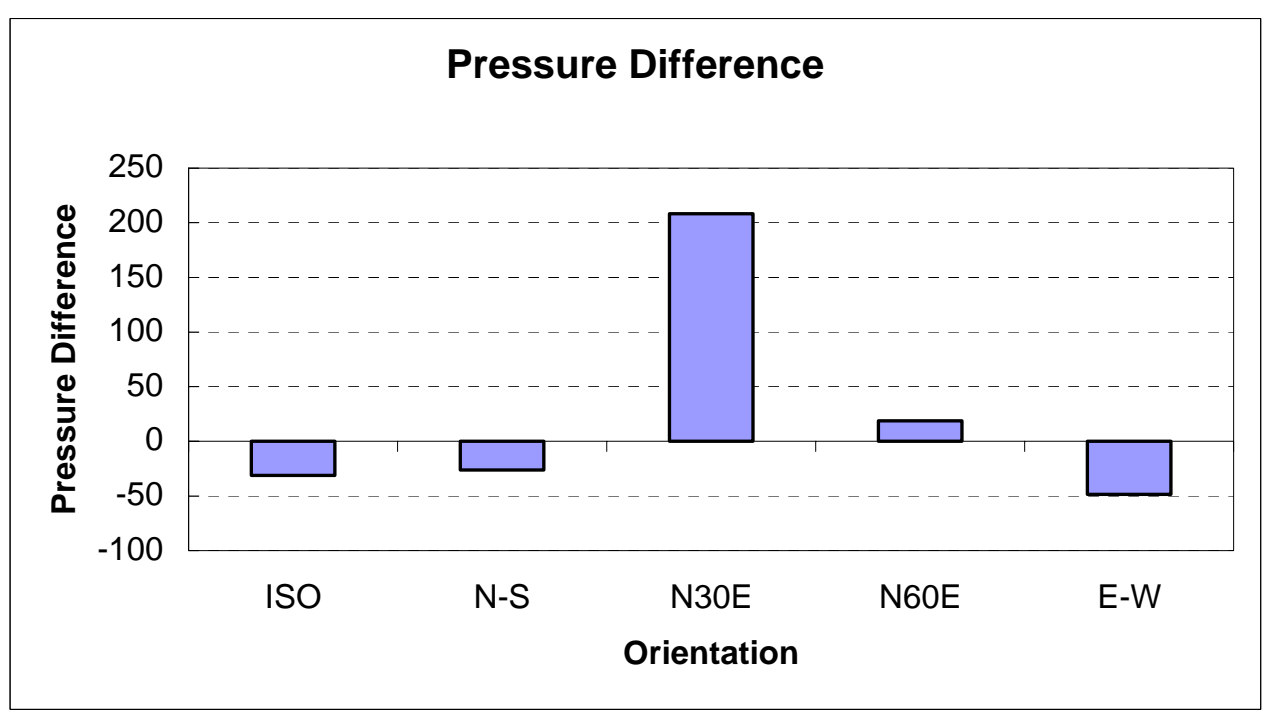

Figure 3.17. Pressure difference ( $\left.\mathrm{P}_{\text {measured }}-\mathrm{P}_{\text {predicted }}\right)$ for different orientations of permeability anisotropy. 


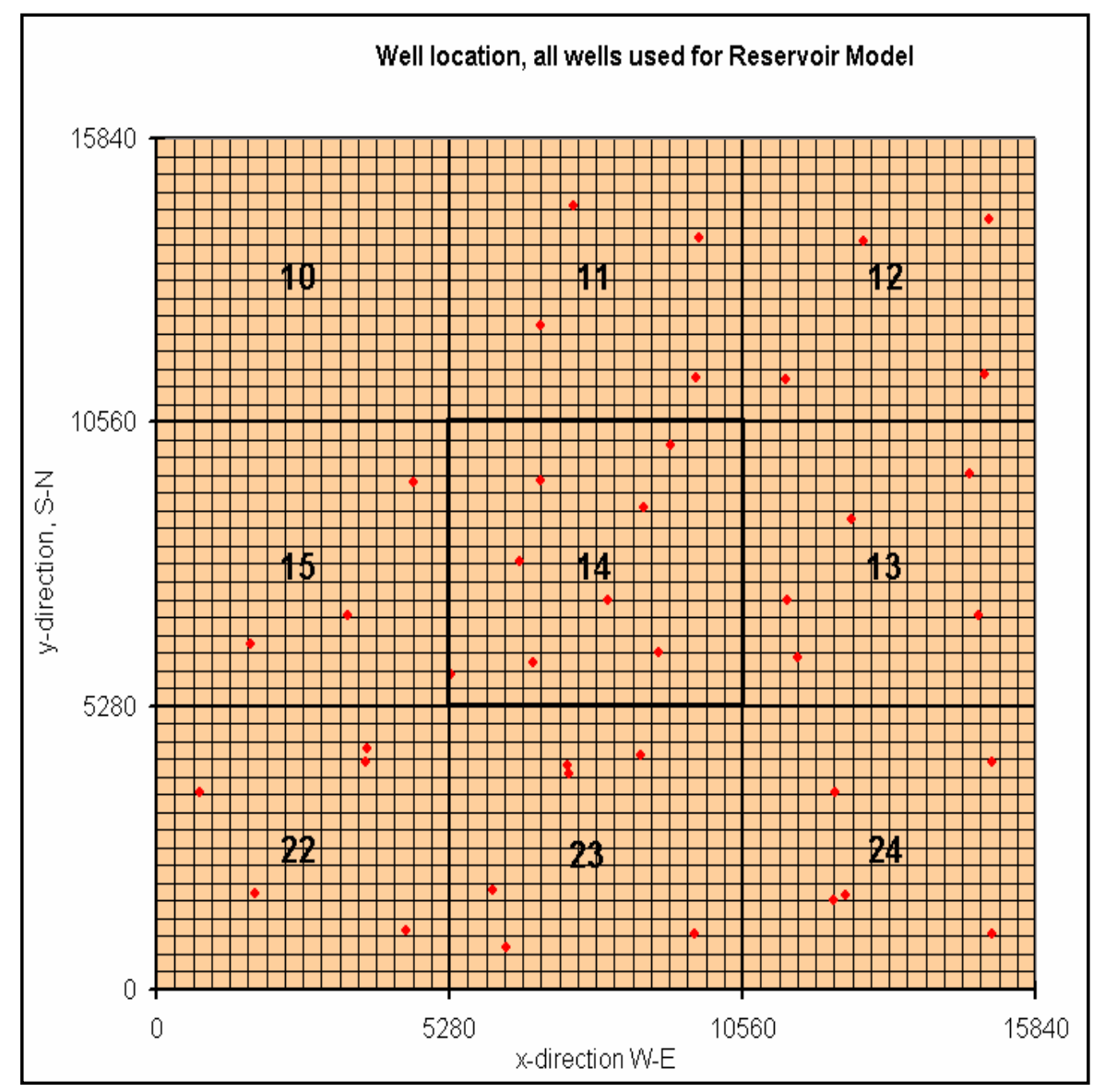

Figure 3.18. Locations of wells that were used to build the reservoir model. 


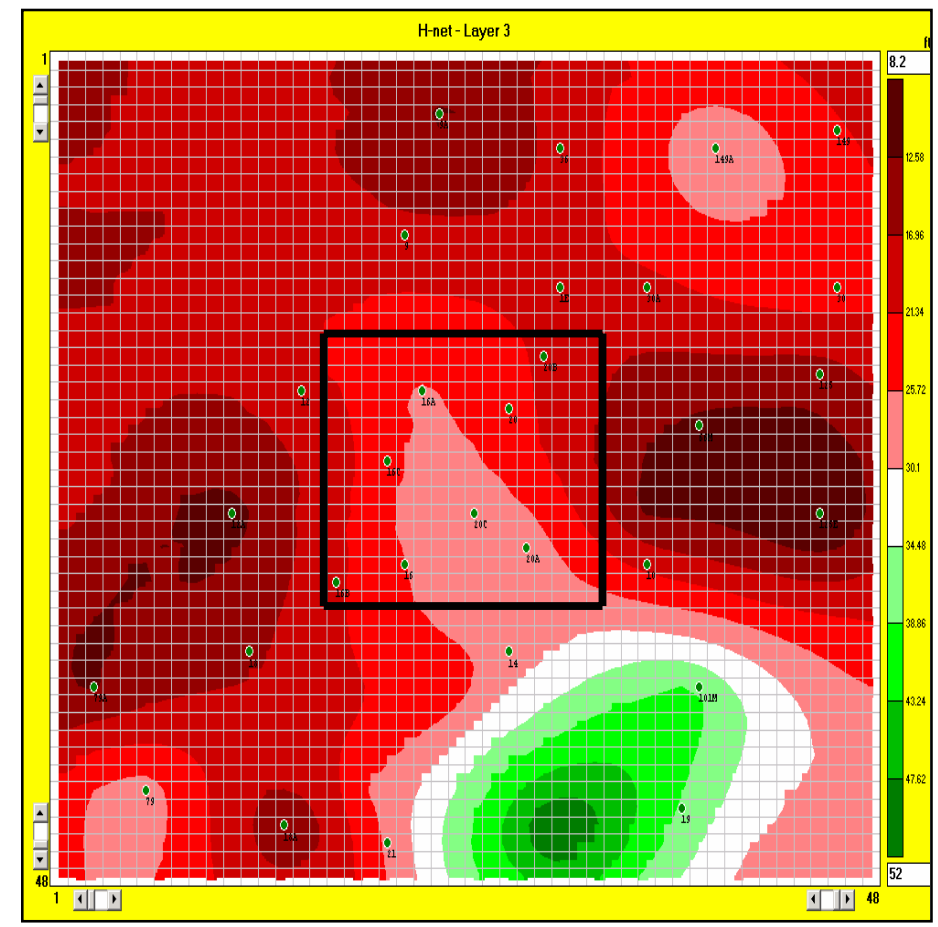

Figure 3.19. Isopach map of the Point Lookout net thickness for the 9-section simulation area .
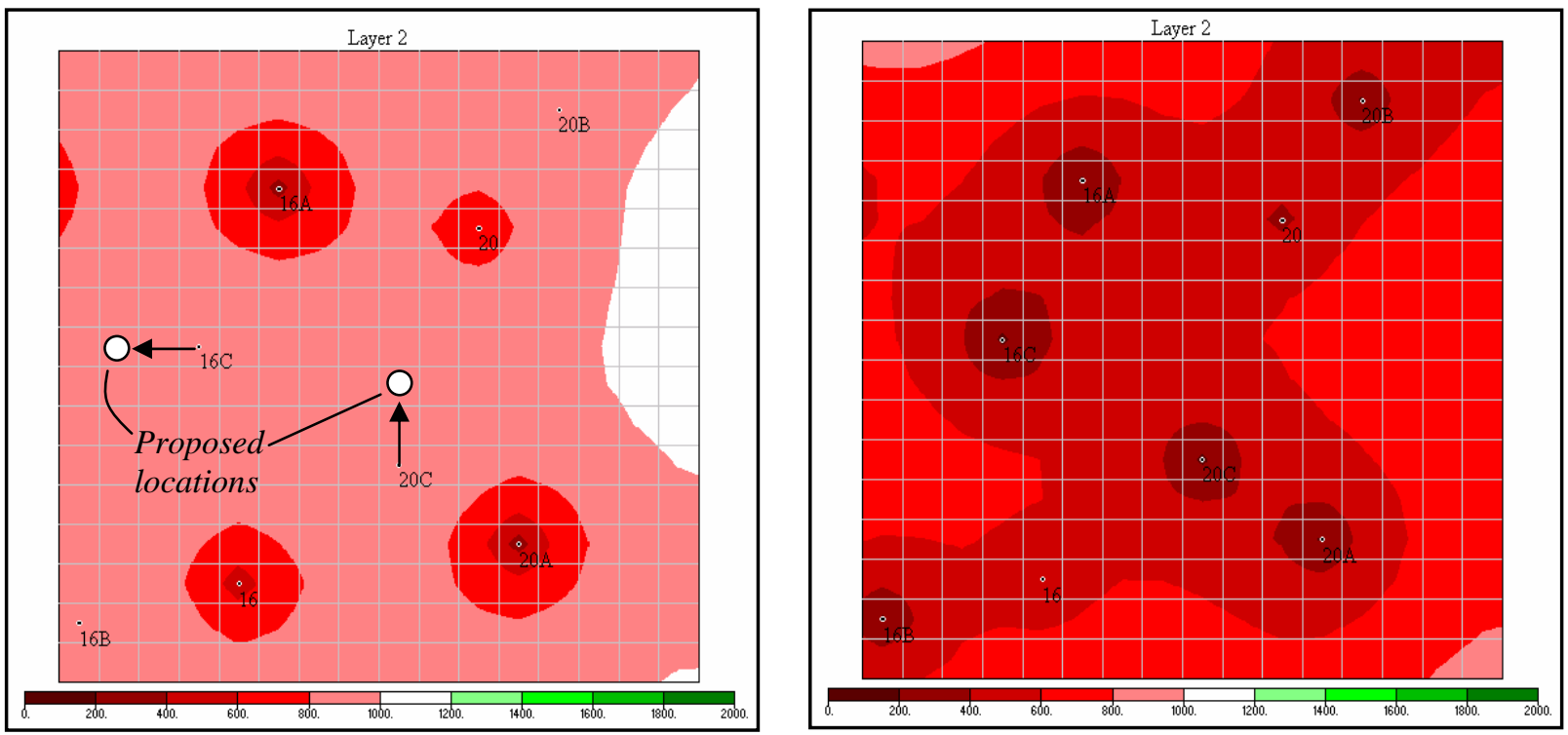

Figure 3.20. Pressure distribution map (a) prior to infill well development and (b) after 10 years of forecasting. (Isotropic case) 

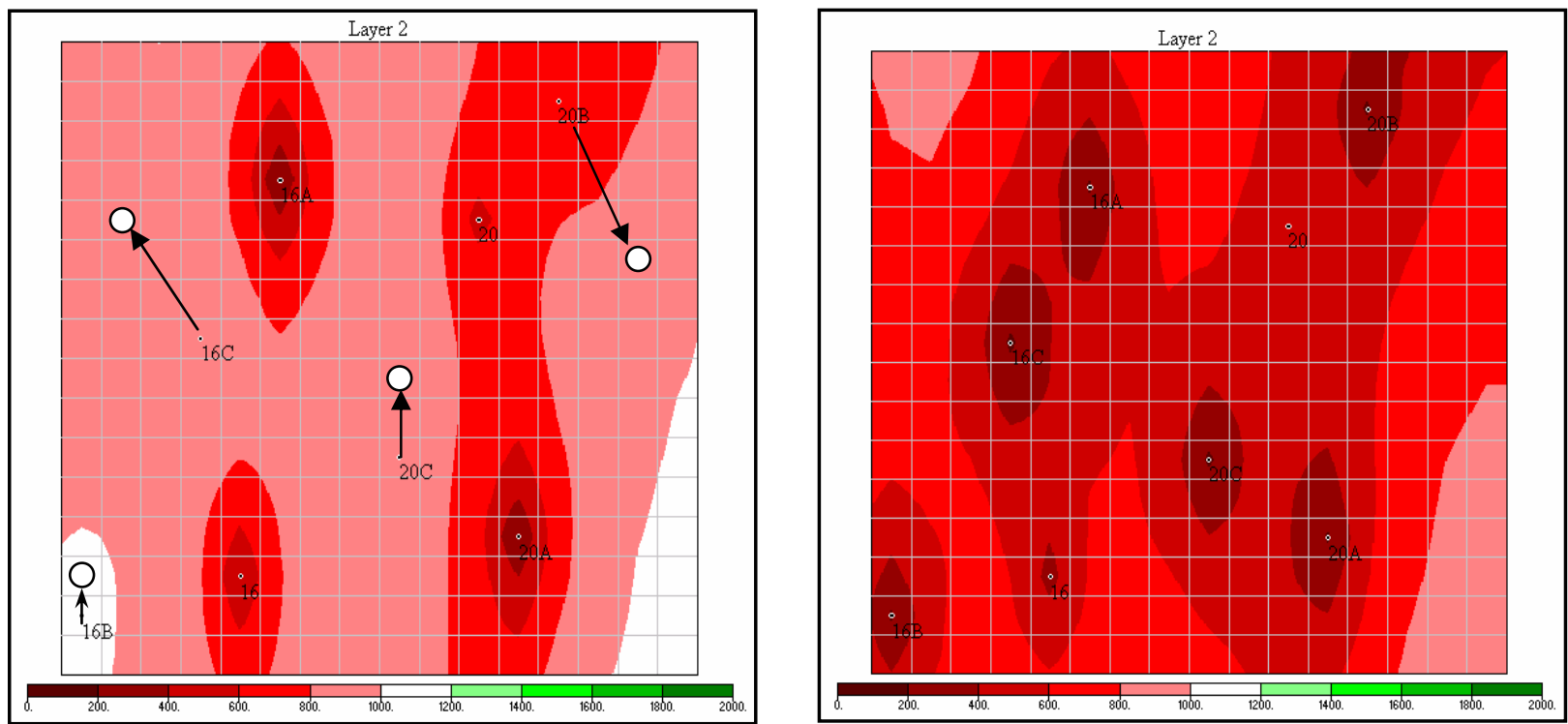

Figure 3.21. Pressure distribution map (a) prior to infill well development and (b) after 10 years of forecasting. (Anisotropic case)

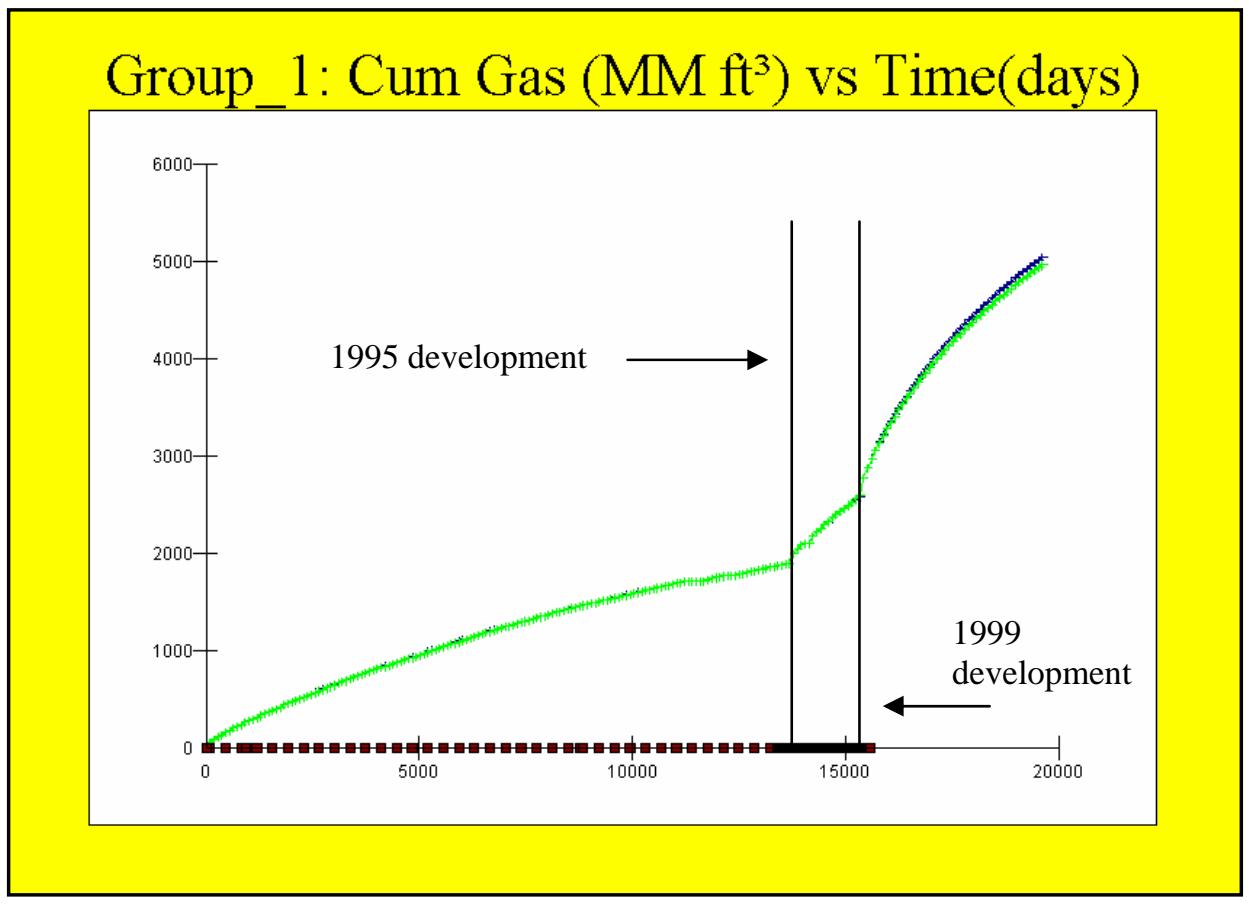

Figure 3.22. Comparison of 10-year total cumulative production forecast of all 8 wells in Section 14 between the actual drilled infill well locations and the proposed new infill well locations. 


\subsection{Conclusions}

The following conclusions are warranted by this study of the evaluation of infill well potential in the Rosa Mesaverde Unit:

1. A clean sand cutoff for each member of the Mesaverde Group; i.e., Cliff House, Menefee, and Point Lookout, was established from CDF of the gamma ray curves. Inflection points on these curves identified variations in the lithology of the members and were used to distinguish clean sand cutoff values. Investigations into porosity variations resulted in no definitive trends with respect to shale content or location. For this reason, the shale cutoff values established were extended to net pay cutoffs.

2. The production parameters from the Mesaverde in the Rosa Unit suggest an average to sub-average reservoir. This is probably due to the location being on the distal margin of the San Juan Basin where pay quality and thickness are decreased. (see Figure 1) Within the Rosa Unit, the Northwest part shows the highest productivity factor $(P F)$ and flow capacity $(k h)$ values, the central part of Rosa Unit shows the highest drainage area $(A)$, and estimated ultimate recovery (EUR) and, northeast part of Rosa Unit shows the highest initial gas-in-place (IGIP). In general, newer wells have a shorter transient period indicating the onset of depletion is occurring earlier. This suggests partial depletion of the reservoir.

3. Previous evidence in the basin suggests a fracture trend oriented northeast to southwest. With no local evidence to refute this concept in Rosa Unit, this is the likely direction as well. For the IWC, it is important to note that although the input permeability anisotropy ratio for these two N-S anisotropic field cases was $10: 1$, the calculated output permeability anisotropy ratios for the best fit was less than 3:1, suggesting that isotropic permeability is probably a good assumption for these cases. Moreover, the well production history and lack of any reported measured pressure interference between wells indicates little or no influence of natural fractures on reservoir permeability or permeability anisotropy.

4. The infill locations from the pilot project in Section 14 appear to be satisfactory. From the reservoir standpoint, a broad area is available due to the low quality rock; therefore, drainage (interference) was not observed in simulation models or production plots.

5. The Infill Well Calculator provided good agreement between the calculated and measured reservoir pressures at the actual infill location in half of the selected areas tested. However, multiple permeability orientations gave reasonable agreements, therefore no permeability direction could be discerned from this work. For those cases where predicted and measured pressures did not match, the underlying limitations of the IWLC are believed the culprit. 


\section{Bibliography}

Chen, H.Y., Munoz, J.D., Hidayati, D.T., Alzate, G., Pinzon, C., Chaianansutcharit, T., Bakken, H., and Arbelaez-L., A.: "Drainage and Flow Characteristics of the Major Gas Producing Formations in the San Juan Basin, New Mexico,” preliminary report, prepared for BLM (Bureau of Land Management), Southwest Strategy Office, NM, Feb. 2001.

Chen, H.Y. and Teufel, L.W.: "Understanding the Effects of Reservoir and Operating Parameters on Tight-Gas Production Decline," paper SPE 71066 presented at the SPE Rocky Mountain Petroleum Technology Conference, Keystone, Colorado, 21-23 May 2001.

Espeland, J.: "Evaluation of an Infill Well Location Calculator to Determine Optimal Locations of Infill Wells: Application to the Blanco Mesaverde Rosa Unit, San Juan Basin, M.S. Thesis, Petroleum Engineering (May 2001)

Iden, K: "Evaluation of Infill Drilling in Blanco Mesaverde Rosa Unit, San Juan Basin, New Mexico Using a Commercial Reservoir Simulator”, M.S. Thesis, Petroleum Engineering (August 2001)

Kelly, J.M.: "Methodology for Optimum Location of Infill Wells in Tight Gas Reservoirs”, Ph.D. Dissertation, (May 2000)

Munoz, J.: "Delineation of Drainage Area and Flow Characteristics of Rosa Unit (Mesaverde), San Juan Basin, New Mexico”, M.S. Thesis (May 2001)

Munoz, J.D., Chen, H.Y., and Teufel, L.W.: “A Type-Curve-Based Spreadsheet Program for History Matching and Forecasting Tight-Gas Production,” paper SPE 71067 presented at the SPE Rocky Mountain Petroleum Technology Conference, Keystone, Colorado, 21-23 May 2001

Teufel, L., et al.: "Optimization of Infill Drilling in Naturally Fractured Tight-Gas Reservoirs of the San Juan Basin”, Final Report sponsored by the Department of Energy, DE-FC26-98FT40486, (July 2000) 


\title{
CHAPTER 4
}

\section{Simulation Study of the Feasibility of 80-Acre Infill Well Development in the Dakota Formation, Culpepper Martin Unit}

\author{
Thomas Engler \\ Petroleum and Natural Gas Engineering Department \\ New Mexico Institute of Mining and Technology \\ Socorro, New Mexico
}

\section{Introduction}

The Culpepper Martin Unit is located in the Northeastern part of the San Juan Basin, New Mexico (T31N, R12W). It is comprised of 12 sections (numbered 1-3, 10-15, and 22-24) that include 42 producing gas wells on 160-acre spacing. The formation under study is the Dakota Sandstones, ranging in depths of 950 to $1200 \mathrm{ft}$ below sea level. To enhance the productivity of this unit, three infill well locations were drilled on 80 -acre well spacing as a pilot test to determine the feasibility to infill drill. The infill wells were drilled in sections 11, 12 and 14, increasing the total wells in the study area to 45.

The motivation to study the Culpepper Martin Unit was driven by the desire to test and expand methodologies developed in previous research on low-permeability; naturalfractured formations (see Phase I and II DOE reports for details). In this case, the Dakota Formation in the San Juan Basin was the target. The objectives are to apply the previous work to successfully model the Culpepper Martin area and thus be able to understand the impact of the infill wells and to investigate the difference in future production profiles. As a corollary, we will be able to compare and contrast our results with the industry simulation results presented at the hearing to request a reduction in spacing to 80 acres.

\section{Methodology}

To construct the simulation model, historical production data, well data, reservoir properties, PVT data, isopach maps of the various layers and the top of the Dakota Formation were collected and then analyzed. For simulation, the Eclipse ${ }^{\circledR}$ commercial simulator was chosen. Data sets are inputted in the simulator and proper history matching is done to predict future production patterns of the entire simulation area. After this is achieved, the simulation is performed with and without the infill wells. Total acreage of this block is 7,680 acres. A single porosity model was built using total grid cells of $48 \mathrm{x}$ $48 \mathrm{x} 5$ in the $\mathrm{x}, \mathrm{y}$ and $\mathrm{z}$ coordinates, respectively. After analyzing the well logs it was determined there exist three producing layers, separated by two non-producing layers in the reservoir. The thickness from top to bottom for each layer is given in Table 1 .

A representation of the multilayer model is shown in Figure 1. (Color legend is indicative of gas saturation). The thickness of each layer was determined by interpreting the well logs obtained from each well. For each producing, layer Gross, Net to Gross (NTG) and 
Net values were calculated from the logs and incorporated in the grid-building component of the simulator. These values were then distributed along the entire grid using a geostatistical tool that involves variogram selection and ordinary Kriging.

\begin{tabular}{|l|c|c|c|l|}
\hline Layer & Gross $(\mathrm{ft}) *$ & Net To Gross (NTG) * & Net $(\mathrm{ft}) *$ & Type \\
\hline Two Well & 33 & 0.61 & 20 & Producing \\
\hline Sandy Shale I & 42 & 0 & 0 & \\
\hline Paguate & 63 & 0.7 & 44 & Producing \\
\hline Sandy Shale II & 13 & 0 & 0 & \\
\hline Lower Cubero & 38 & 0.61 & 23 & Producing \\
\hline
\end{tabular}

Table 4.1. Reservoir layers thickness

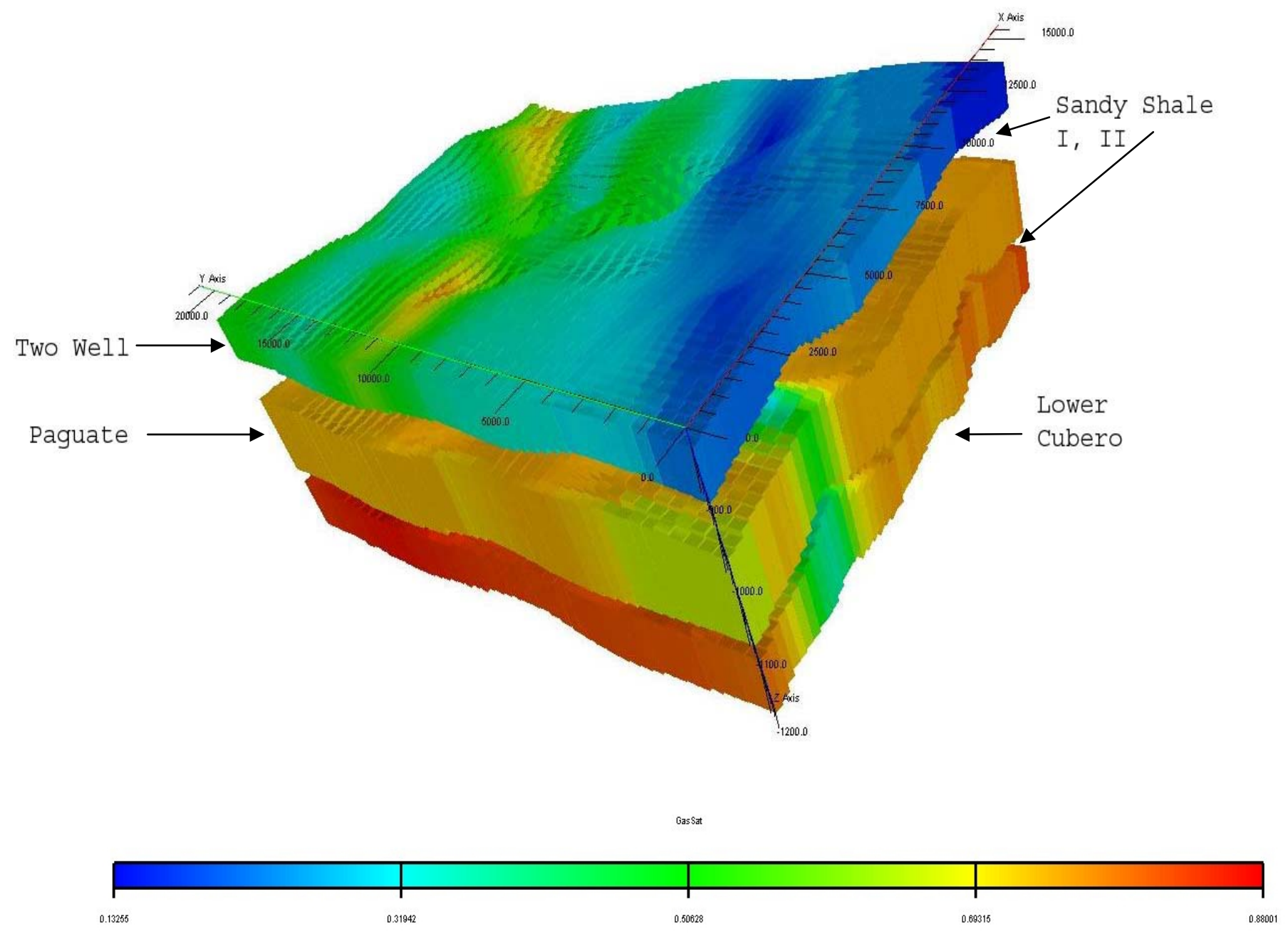

Figure 4.1. Formation Layer Grid Structure for simulation 
Similarly, reservoir properties such as porosity, permeability, and water saturations were also generated and distributed along the whole grid. Figure 2 is an example of the reference depth for the top of the Dakota in the grid.

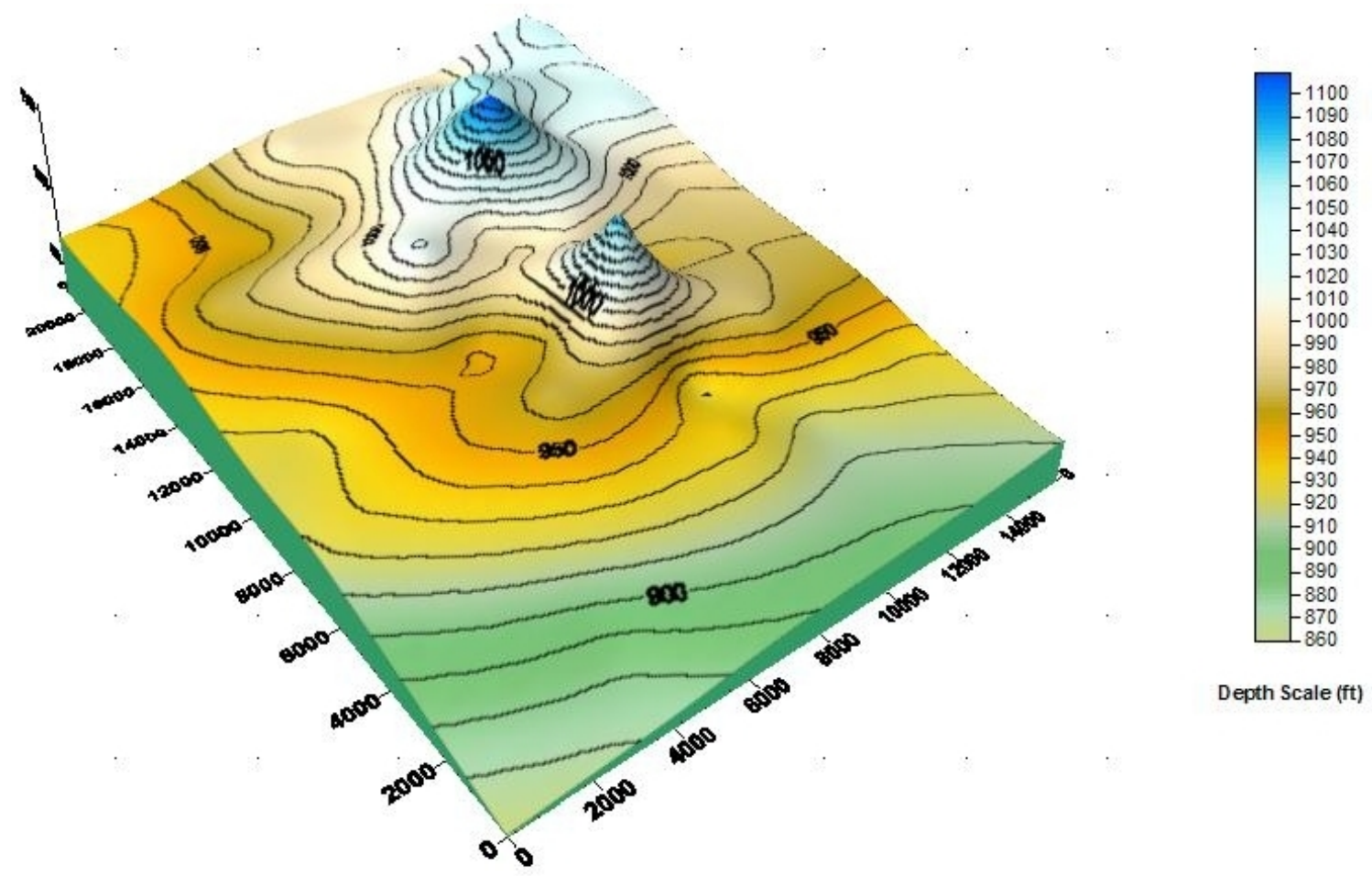

Figure 4.2. Top of Dakota Formation

In initial simulation runs, wells were rate constrained, therefore the output response function from the simulator for history matching is the flowing bottomhole pressure. This mode was chosen due to the preponderance of production data, providing better confidence in calibrating the model, and the lack of flowing pressure data to do so. As expected, production history match was obtained for the entire study area. Pressure history matches are reasonable in most wells; however, inconsistencies in several wells do exist. Multiple attempts using different reservoir property distributions, mainly permeability and skin were performed with similar results.

\section{Analysis}

Comparing this work to the industry-generated reservoir model, it was noticed that the net pay used in their model was lower than anticipated for this reservoir. From well $\log$ analysis as seen in Table 1, the average net pay for a well is $28 \mathrm{ft}$, whereas the industry data set assumes an average net pay of only $9 \mathrm{ft}$. This has significant consequences on gas-in-place (GIP) calculations. Table 2 lists the reservoir inputs for each respective model. From the industry data set, the estimate of GIP is 72 BCF while for this model data set, after permeability and porosity calibration, the GIP is estimated to 
be 306 BCF. With less gas volume, the result is increased pressure depletion in the industry study. Confirmation of their model was demonstrated through individual layer shut-in pressure history matches of the infill wells with the model. With the substantially greater gas volume in this study, the result is increased difficulty in obtaining flowing pressure matches for all wells.

\begin{tabular}{|r|c|c|}
\hline Parameter & $\begin{array}{l}\text { Industry } \\
\text { model }\end{array}$ & $\begin{array}{l}\text { This } \\
\text { work }\end{array}$ \\
\hline Average porosity,\% & 8.66 & 9.3 \\
\hline Twowells & 9 & 8.8 \\
\hline Paguate & 8 & 9.2 \\
\hline Lower Cubero & 9 & 9.8 \\
\hline Average Sw, \% & 47 & 37 \\
\hline Twowells & 63 & 62 \\
\hline Paguate & 35 & 26 \\
\hline Lower Cubero & 40 & 24 \\
\hline Average net pay, ft & 9 & 28 \\
\hline Twowells & 7 & 20 \\
\hline Paguate & 14 & 43 \\
\hline Lower Cubero & 7 & 22 \\
\hline $\begin{array}{l}\text { Initial reservoir } \\
\text { pressure, psi }\end{array}$ & 2500 & 2700 \\
\hline GIP (BCF) & 72 & 306 \\
\hline
\end{tabular}

Table 4.2. Comparison of reservoir input data for both models

To further compare the GIP issue, the net pay calculated from this work along with the respective gross thickness were used along with the reservoir input parameters of the industry model (Table 2); i.e., a single layer value of porosity and water saturation and an initial reservoir pressure of 2500 psi. Since there was no permeability or skin data known from industry work, the model values of these properties were used in this example. The results from simulation were a total GIP of 226 BCF, a significant increase of 154 BCF from the industry estimate. This difference is mainly attributed to the fact that the net pay used in this work is almost three times more than the industry model. It is also noteworthy that the original simulation run, after calibrating the reservoir input parameters results in a GIP of 306 BCF or 80 BCF greater than the modified example. This difference ( $80 \mathrm{BCF}$ ) is because the porosity values are distributed throughout the grid model. Although the average porosity is $9.3 \%$, the porosity distribution ranges from $7.5 \%-15 \%$ in the entire grid. Similarly, water saturations in the model are distributed values, which are in the range of $20 \%-80 \%$ in the entire grid. Higher porosity and lower water saturation data in most of the cells will result in higher estimation of GIP.

Another significant difference between the two models was the selection of the permeability/porosity relationships. In this work, a conventional approach was taken; i.e., single porosity and single permeability for each grid block. In the industry model, a 
dual porosity - dual permeability model was used. The simplified approach was chosen due to lack of public domain data to construct a more complex simulation model

In addition, all these wells respond favorably to the stimulation treatment. Therefore including hydraulic fracture parameters would increase the confidence of the model. With these details, it would be possible to construct a refined grid adjacent to the wellbores and subsequently include the impact on the well performance

The average permeability in this model is $0.05 \mathrm{md}$, estimated using production decline analysis. Decline analysis provides an effective permeability; i.e., inclusive of both the matrix and fracture network. Even though the magnitude of this average permeability is with the range of low-permeability, gas sands, the distribution may result in an overestimate of permeability throughout the model.

\section{Summary}

A single phase, multilayer simulation model was constructed for the Dakota Formation in the Culpepper Martin Unit of the San Juan Basin. The model was rateconstrained, using the output flowing pressures from the simulator as the matching variable to the limited, observed flowing pressure data set. Previous methodologies, such as decline curve analysis and integrated simulation proposed earlier, were utilized in this study.

Preliminary simulation cases resulted in excellent rate matches but with inconsistent flowing pressure matches. Investigations revealed significant GIP difference between various models and is suspected to be the primary reason for the difficulty in obtaining pressure matches. This conclusion emphasizes the importance of proper reservoir characterization in low-permeability, naturally-fractured reservoirs. For the storage capacity, the net pay thickness, porosity model (single vs. dual) and cutoff criteria are the key parameters. For flow capacity, the magnitude, orientation, permeability model and the net pay thickness are critical. Finally, the interaction between stimulation and the reservoir cannot be overemphasized. It is well known that these types of reservoirs require stimulation and the response is typically favorable. However, few simulation cases attempt to incorporate the complete details of stimulation and therefore fall short of accurately depicting the true reservoir behavior. 


\section{CHAPTER 5}

\section{Evaluation of Fracture Stimulation Treatments in Tight-Gas Reservoirs with Application to Infill Drilling Potential}

Vertical wells in tight gas reservoirs are always stimulated to increase production. Hydraulic fracturing is the most common stimulation treatment. In Phase II, evaluation of fracture stimulation treatments was accomplished by integrated reservoir description and fracture treatment analysis in the Pecos Slope Abo tight-gas reservoir in southeastern New Mexico and the Lewis Shale in the San Juan Basin. The primary goal of these studies was to couple reservoir characterization with hydraulic fracture analysis and subsequently, to infer infill drilling potential.

\subsection{Pecos Slope Abo Field in Southeastern New Mexico}

Sanchez, Engler and Kelly (2001) conducted two detailed case studies of the Pecos Slope Abo Field to reevaluate original hydraulic fracture treatment designs, to compare and evaluate fracture parameters, and to determine if the fracture treatments were providing sufficient reservoir stimulation. The field was originally discovered in June of 1977, but development did not escalate until the early 1980's. In May of 1981 the Abo Formation was designated a tight gas sandstone formation. Currently over 800 wells have been drilled in the field on160-acre well spacing.

Approximately 80 wells were studied in the southern part of the Pecos Slope Abo Field. Decline curve analysis was performed on all wells by a modified set of Fetkovich type curves. Analysis of this work show linear to near-linear flow in most cases with permeability values less than $0.1 \mathrm{md}$ and variations in reservoir properties as typically observed in low permeability reservoirs. These variations resulted in difficulty in evaluating infill drilling potential.

In their study, evaluation of fracture stimulation treatments was accomplished by matching recorded surface treating pressure with a fracture propagation model. Unusually high initiation pressures in the case study wells; initial stress state, vertical fracture growth, perforation restrictions, and the development of multiple fractures in a single, bounded layer were evaluated as possible causes for the high initiation pressures. Results form this work showed the multiple fractures model providing the best match. Fracture length varied from approximately $1150 \mathrm{ft}$ to $750 \mathrm{ft}$ with a single fracture model, and was reduced by approximately 10 to 30\% for additional fracture added. The fracture data was input into a fractured well performance model, which was used to match the production rate and therefore verified the process.

The integration of decline curve analysis and fracture analysis provided better descriptions of reservoir properties and more accurate designs of fracture propagation 
models. The combined approached also improved evaluation of infill drilling potential by evaluating reservoir properties and stimulation. Current infill development on 160 acres could be reduced to 80 -acre well spacing and improve drainage. However, this study indicated that about 50 to $60 \%$ of the wells were draining more than 100 acres. Therefore, some 80-acre wells could encounter drainage from offset wells and result in poor well productivity. If stimulation treatments are performed properly, infill well development at reduced spacing would not be necessary.

\subsection{Lewis Shale in the San Juan Basin}

Sande (2002) conducted an analysis of the fracture stimulation treatments of the Lewis Shale in the San Juan Basin. His work (1) summarizes relevant geological and engineering data, (2) analyzes current stimulation procedures, and (3) offers recommendations for improving the efficiency of hydraulic fractures. The following discussion of his results is taken from his MS Thesis at New Mexico Tech.

With the demand for natural gas at its current level, the Lewis Shale has become an important and economically producible source. It lies behind pipe in potentially thousands of wells producing from the Mesaverde Group and deeper reservoirs. The Lewis Shale is considered part of the Mesaverde Group statutorily, although it is geologically separate. This means, in most cases, that completing the Lewis Shale reservoir is simply a process of perforating the casing, hydraulically fracturing the Lewis, and commingling Lewis production with existing Mesaverde production. Improving the hydraulic fracture design used to complete the Lewis Shale reservoir offers significant economic benefits in terms of increased production and decreased costs.

\section{Relevant Geological and Engineering Data}

The Lewis Shale is a unique reservoir for many reasons. Although it is called a shale, it would probably be more accurate to classify it as a sandy siltstone (Dube, et al., 2000). The Lewis ranges in thickness between 1,000 and $1,500 \mathrm{ft}$ throughout the San Juan Basin (Frantz, et al., 1999). Some parts of the Lewis tend to be more sandy, while others contain primarily clay. The zones that are perforated during completion are often those with an interpreted high sand content (Dube, et al., 2000). The composition of the Lewis determined from cores is approximately $25 \%$ clay and 56\% quartz. The total porosity ranges from $2 \%$ to $8 \%$, with $1.72 \%$ average matrix porosity. The permeability ranges from 0.00001 to $0.1 \mathrm{md}$, with an average matrix gas permeability of approximately $0.0001 \mathrm{md}(1 / 10 \mu \mathrm{d})$. The average water saturation of the Lewis is $70 \%$. Due to the low matrix permeability, natural fractures are essential for economic gas production (Frantz, et al., 1999).

Another factor contributing, at least partially, to the gas production from the Lewis is desorption. Due to the organic carbon in the rock, there is a certain amount of adsorbed gas present. The TOC is estimated to be between $0.57 \%$ and $1.82 \%$ by weight (Jennings, et al., 1997). This is lower than in most producing shale reservoirs, so the desorption component may be relatively small. It is probably significant, however, due to the large net thickness of the Lewis. 


\section{Current Stimulation Procedures}

Hydraulic fracturing is the standard stimulation treatment used to complete the Lewis Shale. A number of stimulation fluids have been used in these treatments. These include slickwater, linear gel, crosslinked gel, liquid $\mathrm{CO}_{2}$, foamed ClearFRAC (trade name of Schlumberger), foamed linear gel, and foamed crosslinked gel. Fracture treatment jobs sizes of proppant range from over $400 \mathrm{k} \mathrm{lb}$ of sand and to only about $50 \mathrm{k}$ lb of sand. These jobs have been pumped in one, two, or three stages.

There have been between 800 and 1,000 Lewis pay-adds completed. A list of 626 wells representing approximately $70 \%$ of the total estimated number of Lewis completions was gathered for analysis. Out of this list, there were 313 wells that had Lewis only pay-adds and a sufficient amount of data to perform an adequate analysis. Figures 5.1 through 5.4 show some of the completion statistics for these wells.

- Figure 5.1 shows that most of the wells (280) were hydraulically fractured with foamed linear or foamed crosslinked gels. Only a few wells were fractured with slickwater, straight linear gel, $\mathrm{CO}_{2}$, or ClearFRAC, and no Lewis only wells with straight crosslinked gel. (The F. Unknown category represents foamed linear and/or foamed crosslinked gel fractures.)

- Figure 5.2 shows that approximately two-thirds of the wells were completed using one stage, and one-third were completed using two stages. Only one well was completed with three stages.

- Figure 5.3 shows that the majority of completions (65\%) were done using approximately $200 \mathrm{k}$ lb of proppant. There were a small number of wells completed with about $90 \mathrm{k}, 160 \mathrm{k}$, or $300 \mathrm{k} \mathrm{lb}$, however.

- Figure 5.4 shows that the range in gross perforation thickness is approximated by a bell curve with a low of $120 \mathrm{ft}$, a high of $1,130 \mathrm{ft}$, and a mode value of about $650 \mathrm{ft}$.

Based on these figures, a typical Lewis completion is a single-stage, 200k lb foamed linear gel, hydraulic fracture attempting to stimulate approximately half of the total Lewis thickness. Due to the data available, the best statistical analyses that can be made was comparisons of (1) foamed linear versus foamed crosslinked gel, (2) one-stage versus two-stage fractures, and (3) $200 \mathrm{k}$ lb versus $160 \mathrm{k}, 210 \mathrm{k}$, or $300 \mathrm{k}$ lb of proppant. Other observations were also made using comparisons between different fluids, proppant volumes, and number of stages, but these relationships did not have as much statistical validity, since they were not be based on as large a number of comparisons.

\section{Considerations for Hydraulic Fracture Designs for the Lewis Shale}

In many reservoirs, pumping a larger hydraulic fracture in a well increases the production from that well. Optimizing hydraulic fracture size in these reservoirs, therefore, is simply a matter of comparing the incremental cost and revenue associated 
with larger or smaller stimulations and choosing the most economic design. However, this is not necessarily the case in the Lewis Shale.

A conceptual model of the behavior of a hydraulic fracture in the Lewis was developed using known reservoir properties. These include the facts that the Lewis has a lower than average reservoir pressure, it is naturally fractured with the fractures trending northnortheast to northeast, the maximum stress direction is north-south, and the permeability is very low (Dube, et al., 2000). This model is illustrated in Figure 5.5. As shown in Figure 5.5b, a hydraulic fracture will continue to grow in length until reaching a natural fracture network. At this point, the fracturing fluid will begin leaking off into the natural fractures and the growth of the hydraulic fracture will slow or stop. Continuing to pump will merely fill the natural fractures with fluid. During the cleanup stage (Figure 5.5c), it may be relatively easy to flow back the fluid in the hydraulic fracture. Due to the low reservoir pressure and permeability, however, it may not be as easy to recover the fluid in the natural fractures. This fluid remains in the reservoir and inhibits the flow of gas to the wellbore. Therefore, pumping a larger hydraulic fracture does not necessarily stimulate greater production from the Lewis. Using these conceptual results and a statistical comparison of various stimulations performed in the Lewis, some basic design improvements have been made.

\section{Data Analysis Methods}

The primary method used to determine the optimum hydraulic fracture stimulation for the Lewis Shale was comparing and analyzing production data from Lewis wells. This required gathering both production and completion data from a large number of Lewis only pay-add wells. The data then had to be normalized to minimize effects on production differences from non-completion sources. After this was done, the production data was compared to determine which fracturing fluid, job size, number of stages, etc., that had the largest impact on the production response of wells with Lewis completions.

The data used for this research was obtained from a number of different sources. Initially, a list of wells with Lewis completions had to be compiled. Then production data and completion information was gathered. Both Burlington Resources and ConocoPhillips generously provided a list of many of their wells that had Lewis completions. The two lists were combined and added to with additional information obtained by searching scout card data for Lewis completions. Although the final list was not comprehensive and many wells had multiple pay-adds (and were therefore unusable for this analysis), there was a sufficient number of wells to make statistical comparisons between wells completed with various hydraulic fracture designs.

\section{Decline Curve Analysis}

The decline curve analysis of Lewis Shale production was a two-part process consisting of fitting decline curves to the production data and analyzing the results to determine the incremental production from the Lewis. The production data for each of the Lewis only pay-adds was plotted on semilog plots of rate (monthly production divided by the number of days of production that month) versus time. Assuming exponential decline 
for both the conventional Mesaverde and the Lewis, best-fit lines were applied to the production data. Depending on the well, there were between one and three curves fit to the data. If the production was from a well producing solely from the Lewis, only one decline curve was needed (Figure 5.6). If the production was from a well where the Lewis was commingled with the Mesaverde, two decline curves were needed in order to describe pre- and post-Lewis production (Figure 5.7). If the production was from a previously producing well, but the Lewis was isolated for a period of time before being commingled with the Mesaverde, three decline curves were needed in order to describe the Mesaverde, Lewis only, and commingled production (Figure 5.8).

\section{Calculating Incremental Lewis Shale Production}

Once the decline curves has been fit to the production data, it was a relatively simple task to compute the incremental production from the Lewis. Cumulative production is calculated by summing the area under the decline curve. Thus, the one-year incremental Lewis production from a well with commingled Lewis and Mesaverde production would be calculated using the following equation:

$$
\mathrm{P}_{\text {lew }}:=\int_{\mathrm{t}_{1}}^{\mathrm{t}_{2}} \mathrm{y}_{\text {com }} \mathrm{dx}-\int_{\mathrm{t}_{1}}^{\mathrm{t}_{2}} \mathrm{y}_{\mathrm{mv}} \mathrm{dx}
$$

where $\quad \mathrm{P}_{\text {lew }}=$ One-year incremental Lewis production

$\mathrm{t}_{1}=$ Date of stimulation

$\mathrm{t}_{2}=$ One year after stimulation date

$\mathrm{y}_{\text {com }}=\quad$ Commingled exponential decline curve

$\mathrm{y}_{\mathrm{mv}}=$ Mesaverde exponential decline curve

\section{Data Normalization}

A simple comparison of the production data from two Lewis wells can be misleading if the data is not normalized in any way. For example, a well completed in the Lewis using a foamed linear gel fracture could increase that well's production by 1,000 $\mathrm{mscf} / \mathrm{d}$, while a slickwater fracture in another well might only increase production by 150 mscf/d. The obvious conclusion is that a foamed linear gel makes a better completion fluid than slickwater. It could turn out, however, that the well completed with the linear gel was located in a very productive region of the Lewis, while the slickwater well was located on the edge of the San Juan Basin where the productivity is poor. This example illustrates that it is very important to normalize the production data to obtain meaningful results. There are a number of factors that were taken into account: (1) lithology differences between wells, (2) lithology differences between zones and (3) general well cleanup during completion.

\section{Data Comparison}

Once the production data was plotted for the Lewis Shale only pay-add wells, and a sufficient amount of completion information was gathered to normalize the data, the resulting decline curves were compared. Wells that had similar Lewis completions were analyzed first to determine what effects reservoir properties had on the production. To get 
an idea of how much the production difference will change with distance between wells, all similar wells within an increasingly larger radius were compared. Figure 5.9 shows the results of this analysis. This figure indicates, as expected, that wells within a relatively short distance do not have as great a production difference as there is when the radius is larger. For this reason, to get the most accurate results, it would be best to compare wells located within one mile or even half a mile. This limits the number of wells that can be compared, however. There are many unquantifiable factors involved, so the validity of the research depends on a statistically large number of comparisons to obtain reliable results. For this reason, a somewhat larger radius of two miles was chosen for the analysis of the quality of various fluid types, proppant volumes, and number of stages. Using this two-mile radius, wells with different completion procedures were compared to find out what methods should be used to maximize production from the Lewis.

\section{Incremental Production Range for Various Parameters}

In order to look at the overall effectiveness of various parameters, the high, low, and average incremental production values were plotted for various fluid types, proppant volumes, number of stages, and gross perforation thicknesses.

Figures 5.10a and 5.10b show the range and individual points of incremental production from wells stimulated with various fluids. It can be seen from Figure 5.10b that some of the wells have negative incremental production. This means that the one-year commingled production was less than the one-year Mesaverde production. It is not realistic to say that the incremental Lewis production was less than zero, however, so these wells were considered failed wells and were not included in the analysis. There were a total of 12 failed wells out of the 313 wells analyzed. Two other wells shown in Figure 5.10b were also not included in the analysis. These two wells had unusually high incremental production. It is desirable to get one of these wells, of course, but since they are the exception and not the norm, they were discarded to prevent skewed results. Figure 5.11 shows the incremental production distribution without the failed and unusual highly productive wells.

Figure 5.11 indicates in a very basic comparison of basinwide averages that linear gel is the best fluid, followed by slickwater, $\mathrm{CO}_{2}$, foamed linear gel, foamed crosslinked gel, and foamed ClearFRAC.

Figure 5.12 shows the range and average incremental production for wells with various proppant volumes. Looking at the values between $160 \mathrm{k} \mathrm{lb}$ and $310 \mathrm{k} \mathrm{lb}$, it appears that there may be a relative maximum somewhere around $250 \mathrm{lb}$. Because there were no completions using this volume of proppant, however, it is difficult to know for sure.

Figure 5.13 shows the range and average incremental production values for one and two stages. This figure indicates that one-stage stimulations have been more effective overall than two-stage stimulations. 
Figure 5.14 shows the incremental production ranges and averages for various gross perforation thicknesses. It appears that perforation thickness does not have a great effect on the production, but there does seem to be a slight trend (to a certain point) where incremental production increases with decreasing perforation thickness. This could indicate that attempting to stimulate a smaller zone is more effective than trying to stimulate the entire Lewis interval with one or two stages.

\section{Results}

A comparison of fluid types showed that the most consistent fluid between wells was foamed ClearFRAC followed by foamed linear gel, foamed crosslinked gel, and $\mathrm{CO}_{2}$. The quality of fluids in terms of their incremental production from best to worst was: slickwater, linear gel, $\mathrm{CO}_{2}$, foamed linear gel, foamed ClearFRAC, and foamed crosslinked gel. The amount of data available for slickwater, linear gel, and ClearFRAC was not sufficient to make a good statistical comparison, however, so the results for these fluids could change under further analysis.

A comparison of proppant volumes showed that stimulation designs using more proppant had more predictable production responses than designs using less proppant. For foamed linear and crosslinked gels, it was determined that either increasing or decreasing the volume of proppant from the typical $200 \mathrm{k}$ lb would increase the incremental production. The best proppant volume appears to be approximately 150k lb.

A comparison of the number of stages showed that incremental production from twostage stimulations was more predictable than production from one-stage stimulations. Two-stage designs did not seem to have any ability to increase production over the onestage designs, however.

The results of an economic analysis for designs using variations of these parameters showed that the best stimulation design appropriate for the Lewis Shale is a single-stage, 150k lb foamed linear gel fracture.

Based on the available data and the methods used to analyze the data for various fluid types, proppant volumes, and number of stages used to stimulate wells currently producing in the Lewis, a single-stage, $150 \mathrm{k} \mathrm{lb}$ foamed linear gel fracture is recommended as the optimum stimulation that should be used in the Lewis Shale.

More data would be required to determine the effectiveness of slickwater, unfoamed linear gel, unfoamed crosslinked gel and foamed ClearFRAC, however. The preliminary results suggested that slickwater might be a far better fluid to use in the Lewis Shale than foamed linear gel. It is recommended, therefore, that further analysis be done to determine the quality of slickwater as a fracturing fluid in the Lewis.

\section{Summary}

A variety of hydraulic fracture designs have been used to complete the Lewis in many of these wells. The production data from 313 Lewis wells was analyzed to determine what design parameters should be used to (1) maximize the fracture surface 
area, (2) minimize damage, and (3) minimize stimulation costs. This analysis was conducted by analyzing production decline curves and determining whether changing a certain parameter (e.g. fluid type) had an effect on the one-year incremental production from the Lewis. An estimate of the economic value of adding Lewis production was made using forecasted rates and gas prices for a one-year breakeven comparison. Based on the available data and the methods used, the optimum stimulation procedure for the Lewis Shale, throughout the San Juan Basin, is a single-stage, 150,000 lb foamed linear gel, hydraulic fracture treatment. However, based on preliminary results from a small number of completions, it is recommended that slickwater designs be analyzed further to determine whether they would have better results.

\section{References}

Dube, H.G., Christiansen, G.E., Frantz, J.H., Jr. Fairchild, N.R., Jr, Olszewski, A.J., Sawyer, W.K., and Williamson, J.R., "The Lewis Shale, San Juan Basin: What We Know Now,” SPE Paper 63091 presented at the 2000 SPE Annual Technical Conference and Exhibition, Dallas, TX, Oct. 1-4.

Frantz, J.H., Jr., "Methodology to Evaluate Fractured Gas Shale Reservoirs", The Lewis Shale, San Juan Basin: Approaches to Rocky Mountain Tight Shale Gas Plays, Proceedings from Petroleum Technology Transfer Council Lewis Shale Workshop, February 21, 2001.

Frantz, J.H., Jr., Fairchild, N.R., Jr., Dube, H.G., Campbell, S.M., Christiansen, G.E., and Olszewski, A.J., "Evaluating Reservoir Production Mechanisms and Hydraulic Fracture Geometry in the Lewis Shale, San Juan Basin,” SPE Paper 56552 presented at the 1999 SPE Annual Technical Conference and Exhibition, Houston, TX, Oct. 3-6.

Jennings, G.L., Greaves, K.H., and Bereskin, S.R., "Natural Gas Resource Potential of the Lewis Formation, San Juan Basin, New Mexico and Colorado", International Coalbed Methane Symposium, University of Alabama, Tuscaloosa, 1997, pp. 557-564

Sande, T.D., 2002: "An Investigation into the Effectiveness of Stimulations in the Lewis Shale, San Juan Basin,” M.S. Thesis, New Mexico Institute of Mining and Technology, Socorro, NM, 2002. 


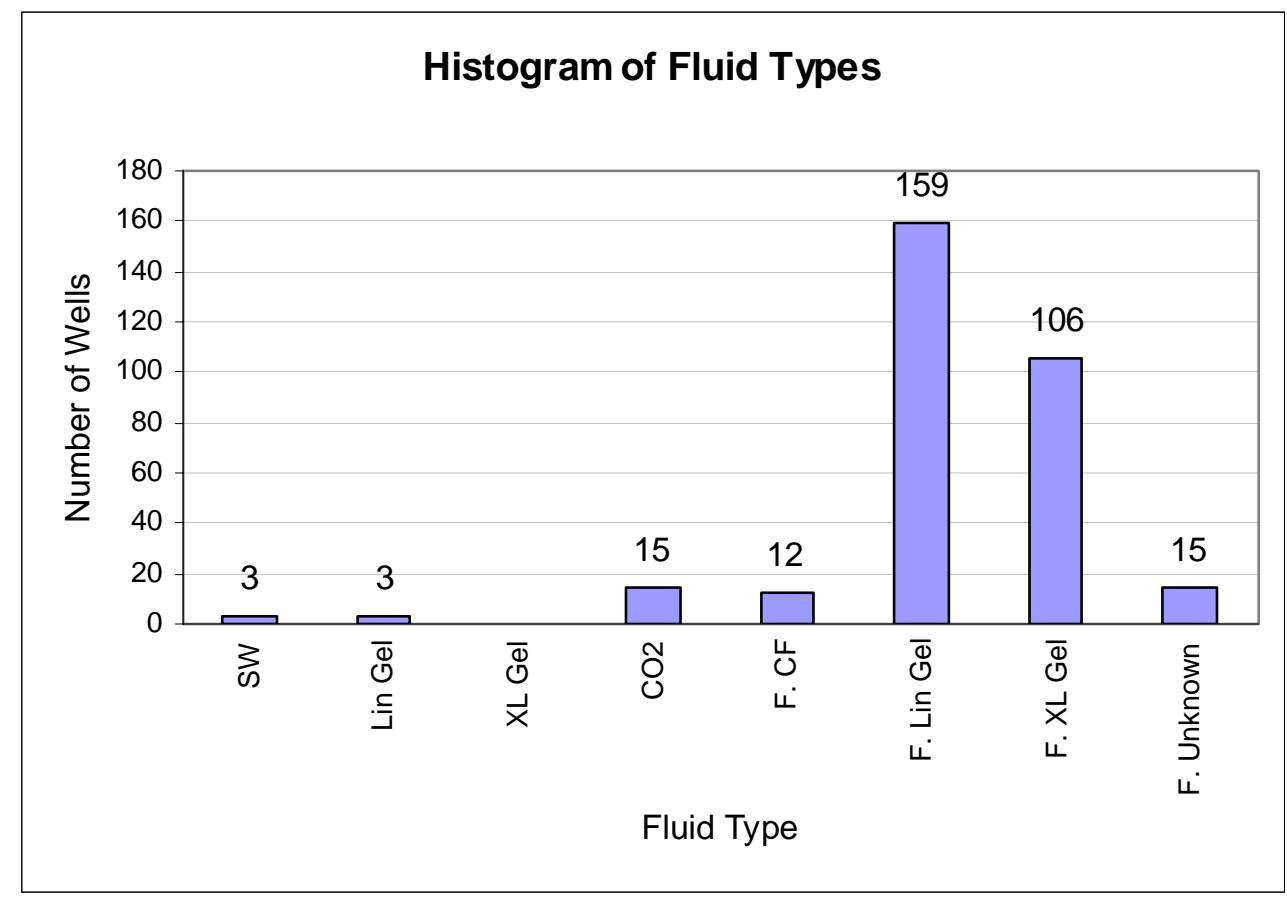

Figure 5.1. Histogram of the fluid types used for Lewis Shale only completions.

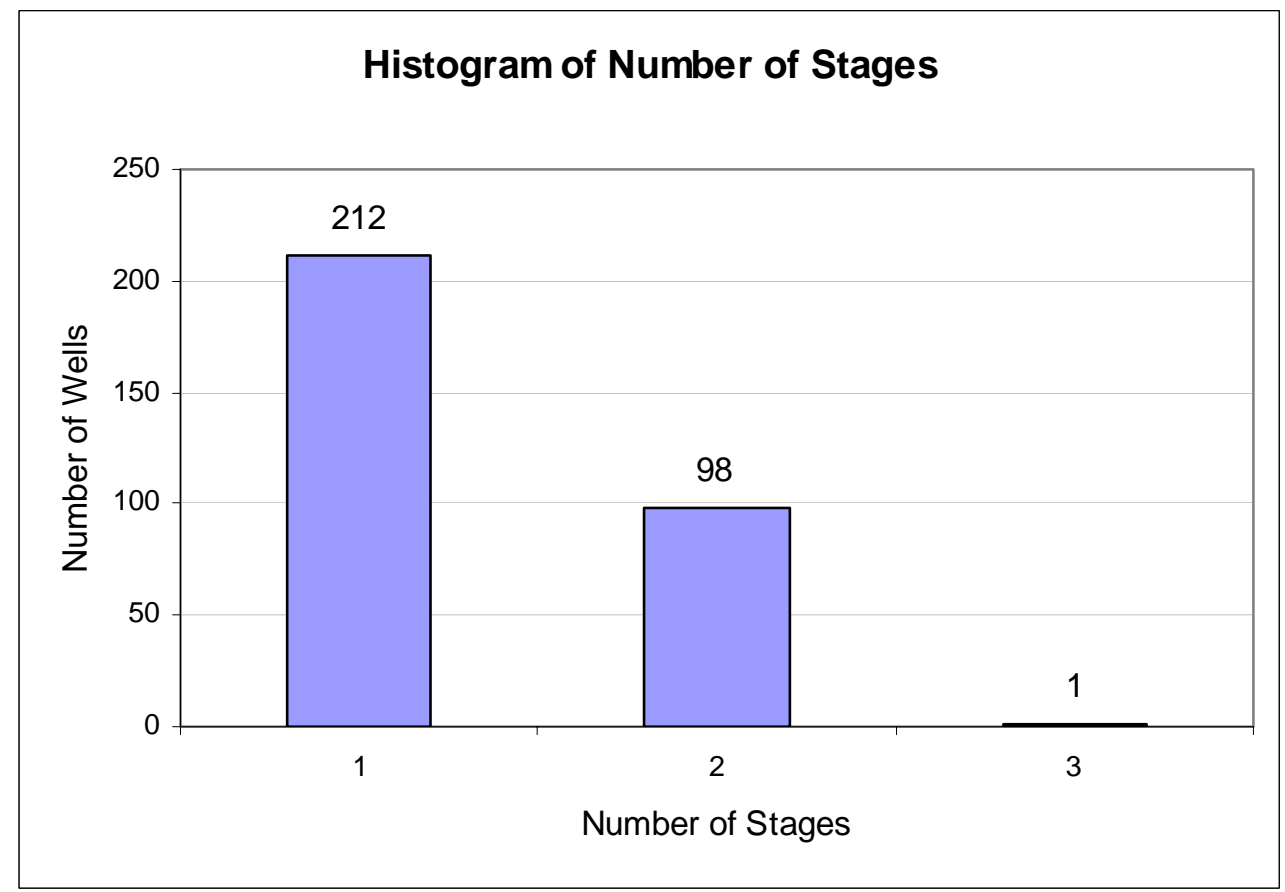

Figure 5.2. Histogram of the number of stages used for Lewis Shale only completions. 


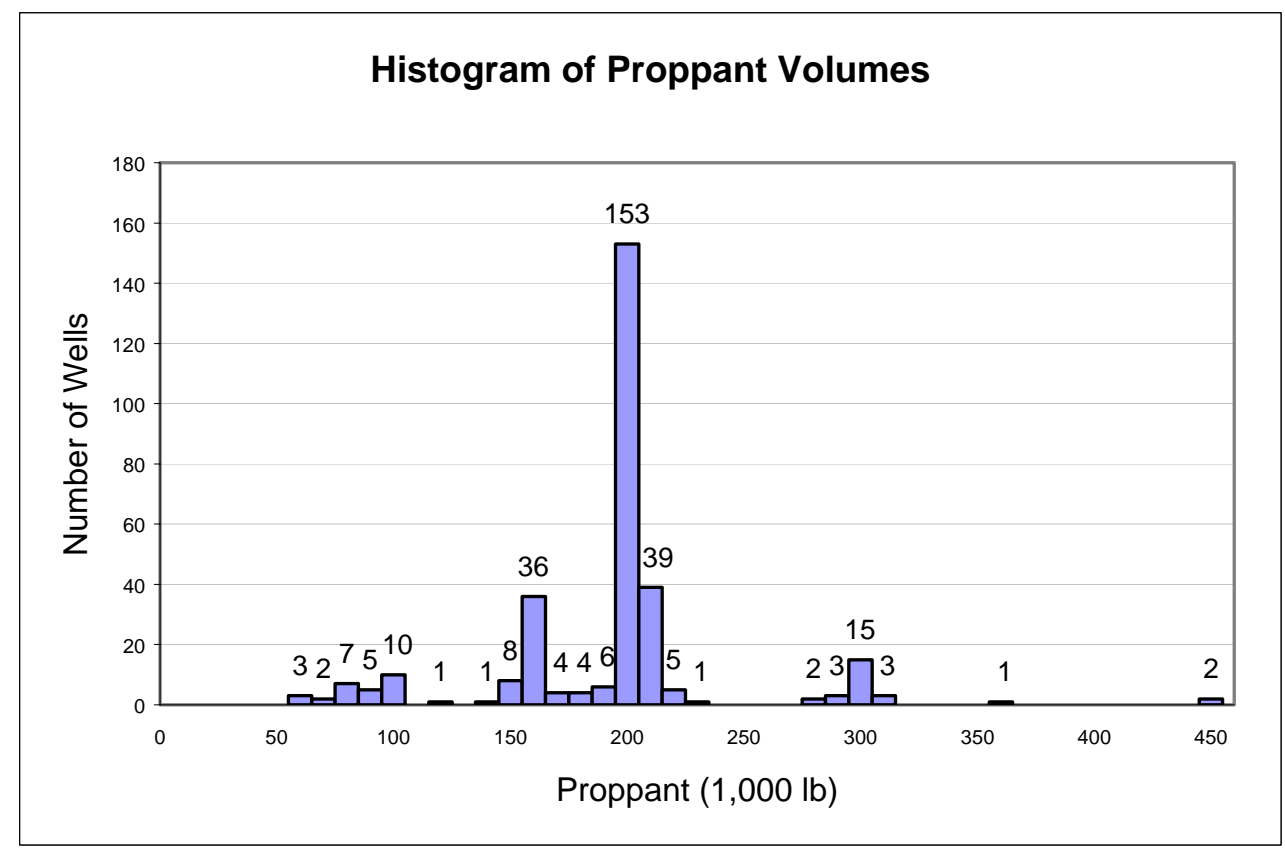

Figure 5.3. Histogram of the proppant volumes used for Lewis Shale only completions.

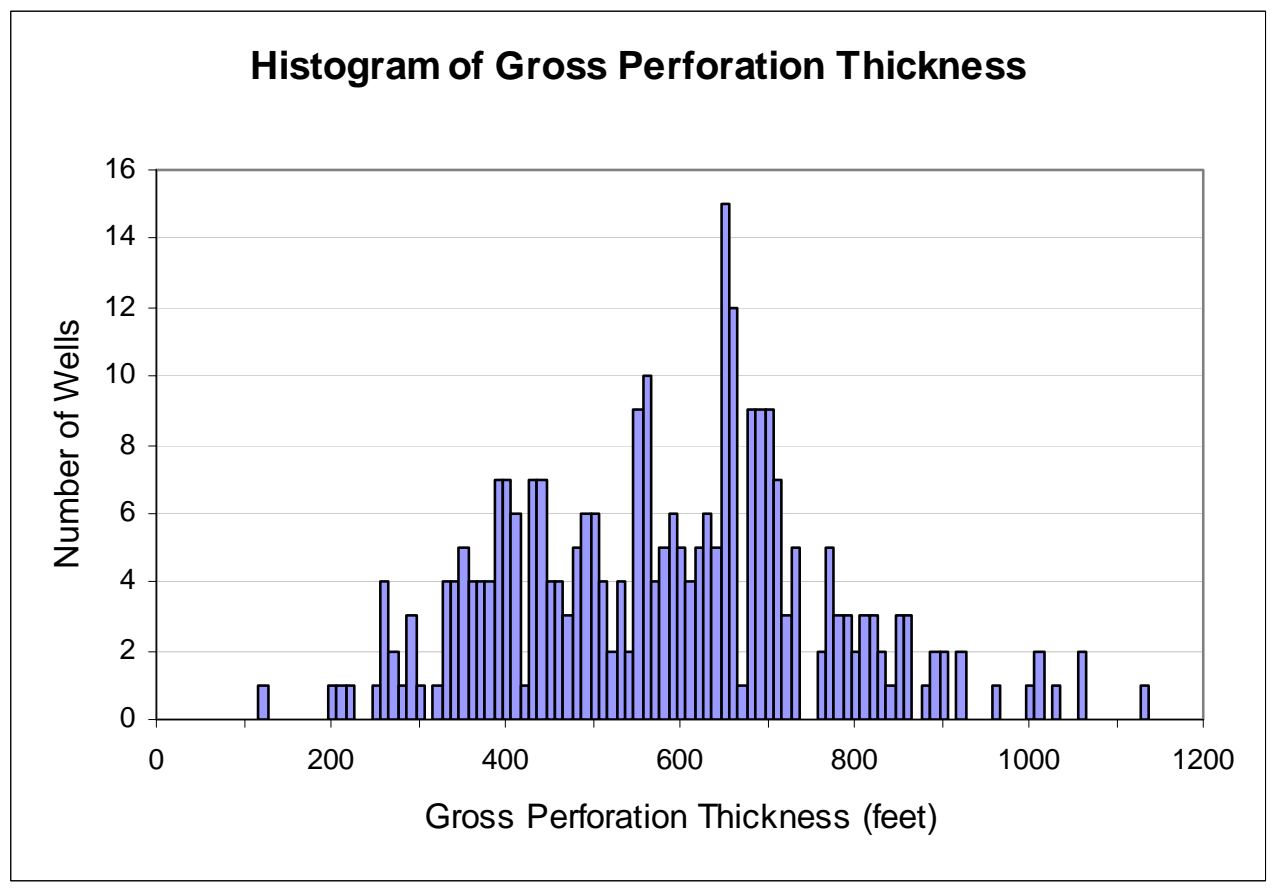

Figure 5.4. Histogram of the gross perforation thickness used for Lewis Shale only completions. 

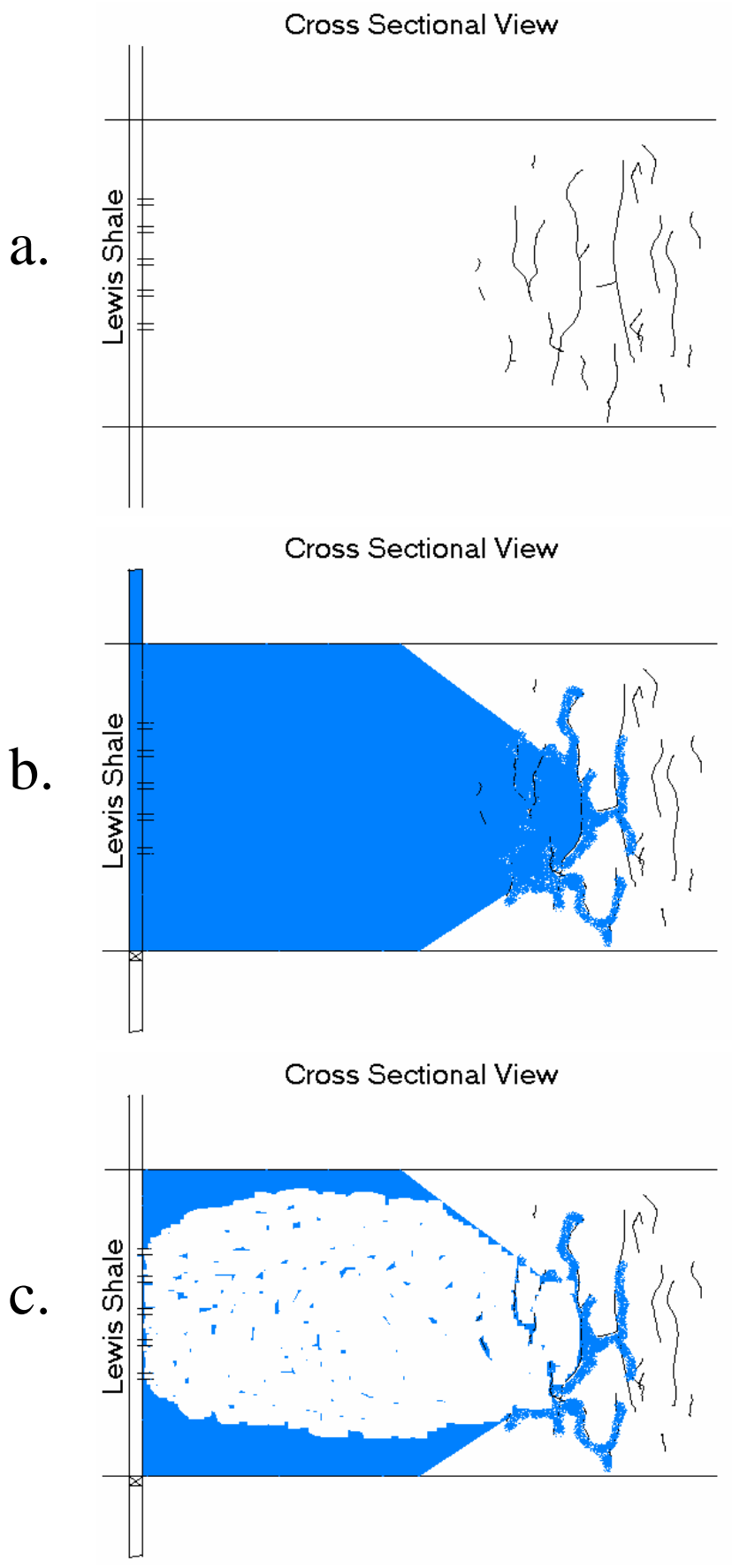

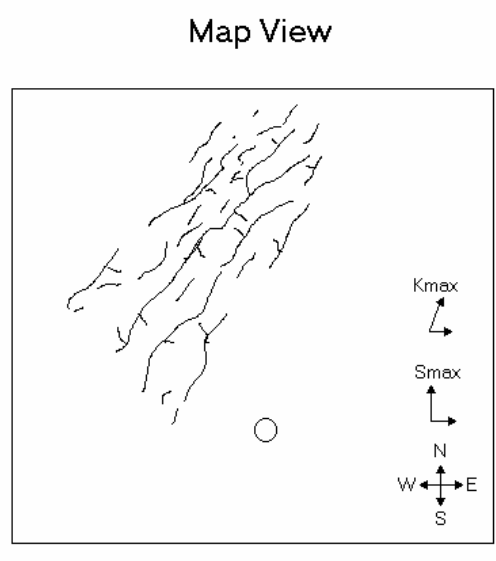

Map View

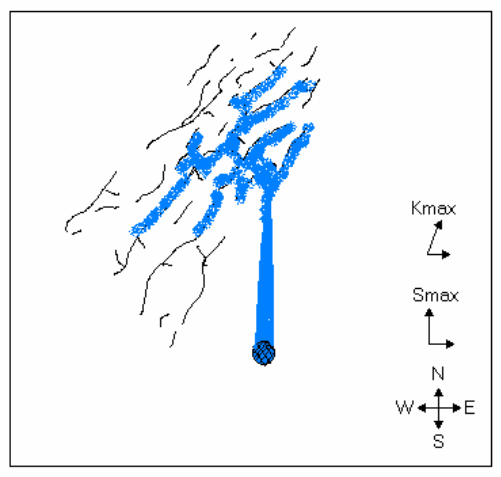

Map View

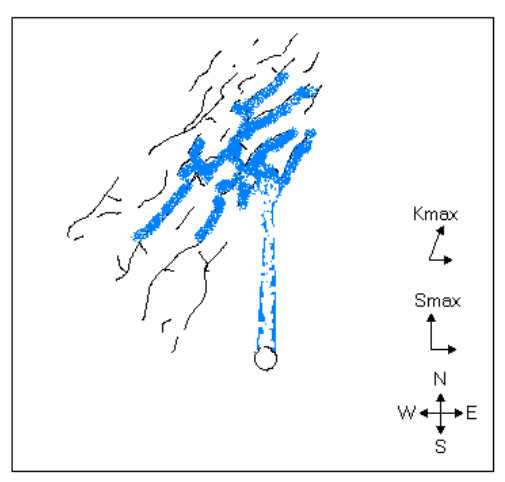

Figure 5.5. Cross-sectional and map views of a hypothetical Lewis Shale well and natural fracture network showing the reservoir (a) before stimulation, (b) after stimulation, and (c) after cleanup (maximum permeability direction, maximum stress direction and compass shown on map view). 


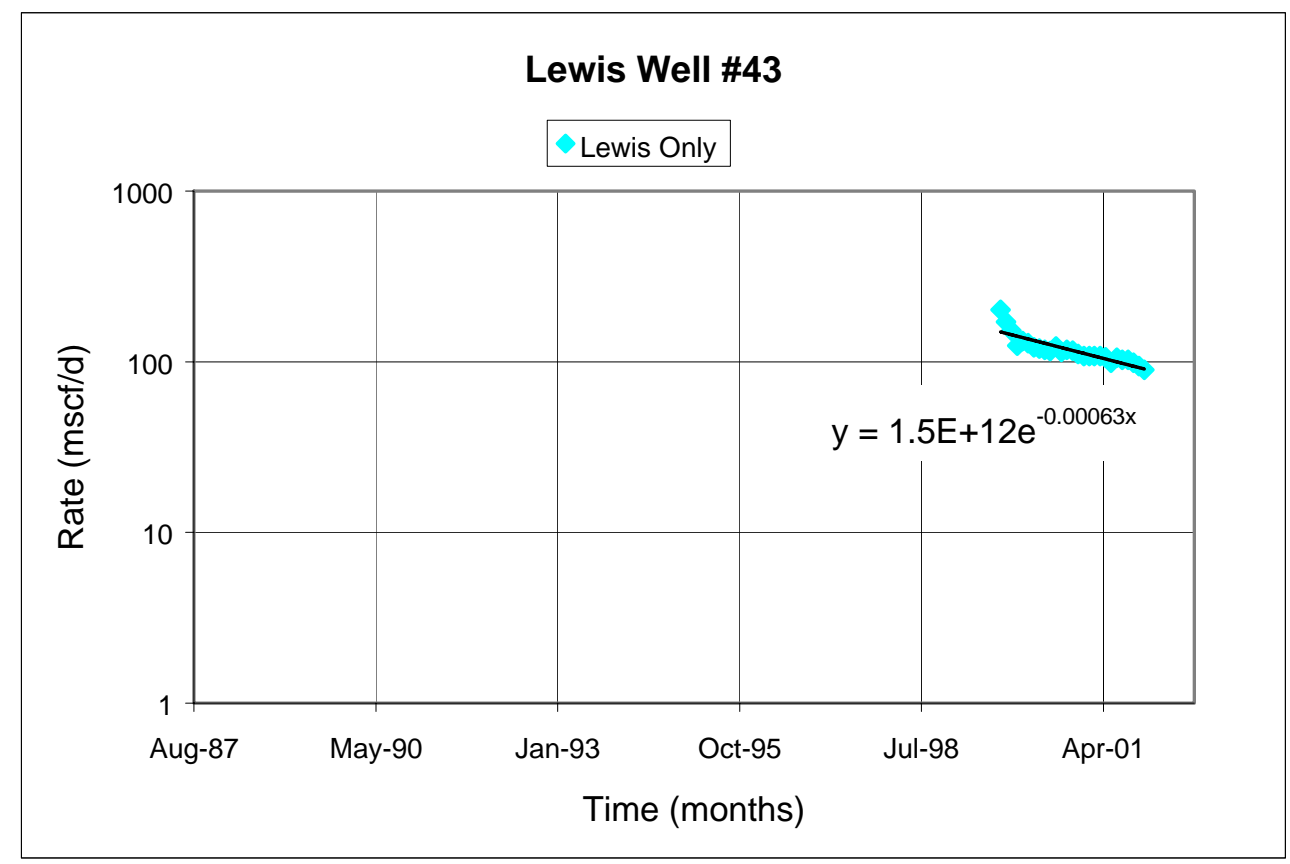

Figure 5.6. Sample well showing Lewis Shale only production.

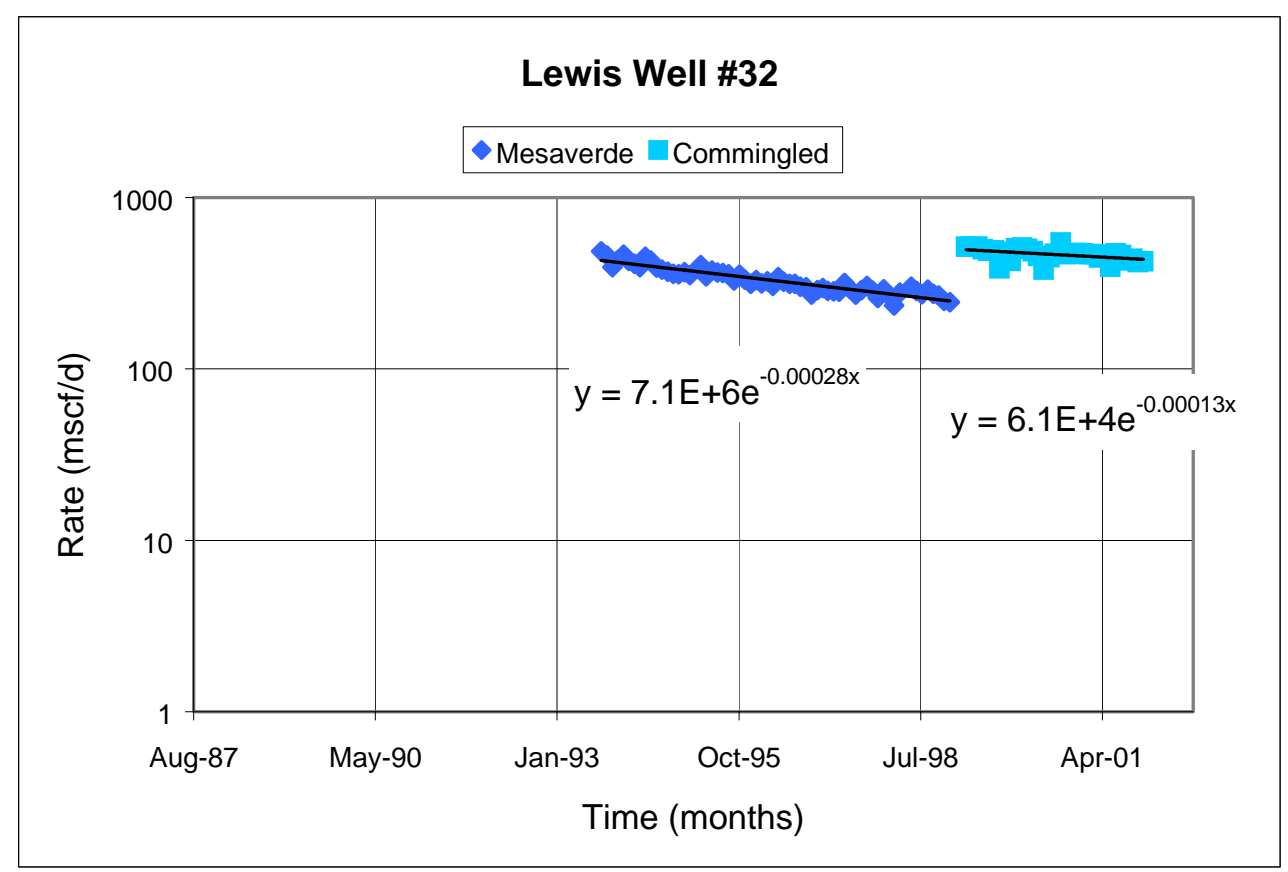

Figure 5.7. Sample well showing Mesaverde Group and commingled production. 


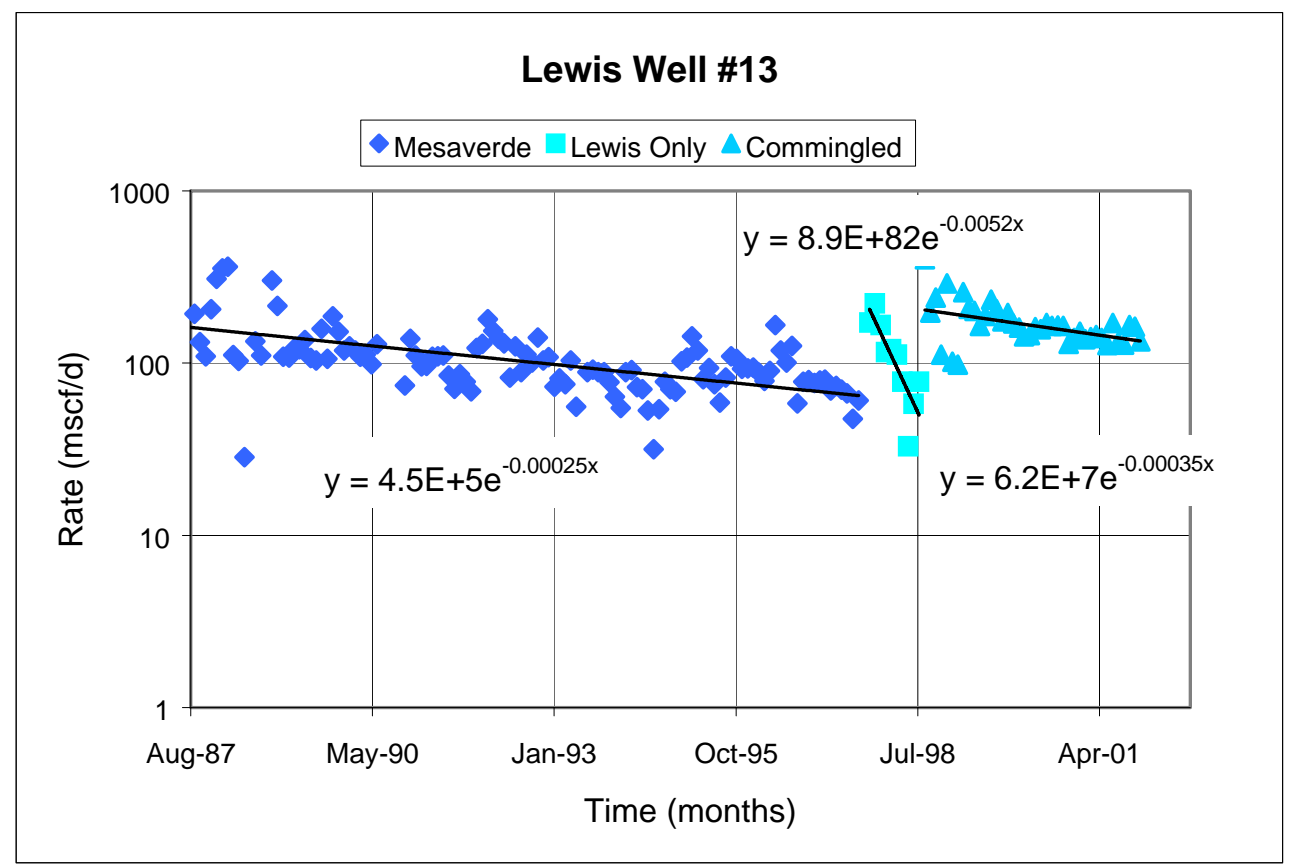

Figure 5.8. Sample well showing Mesaverde Group, Lewis Shale only, and commingled production. 


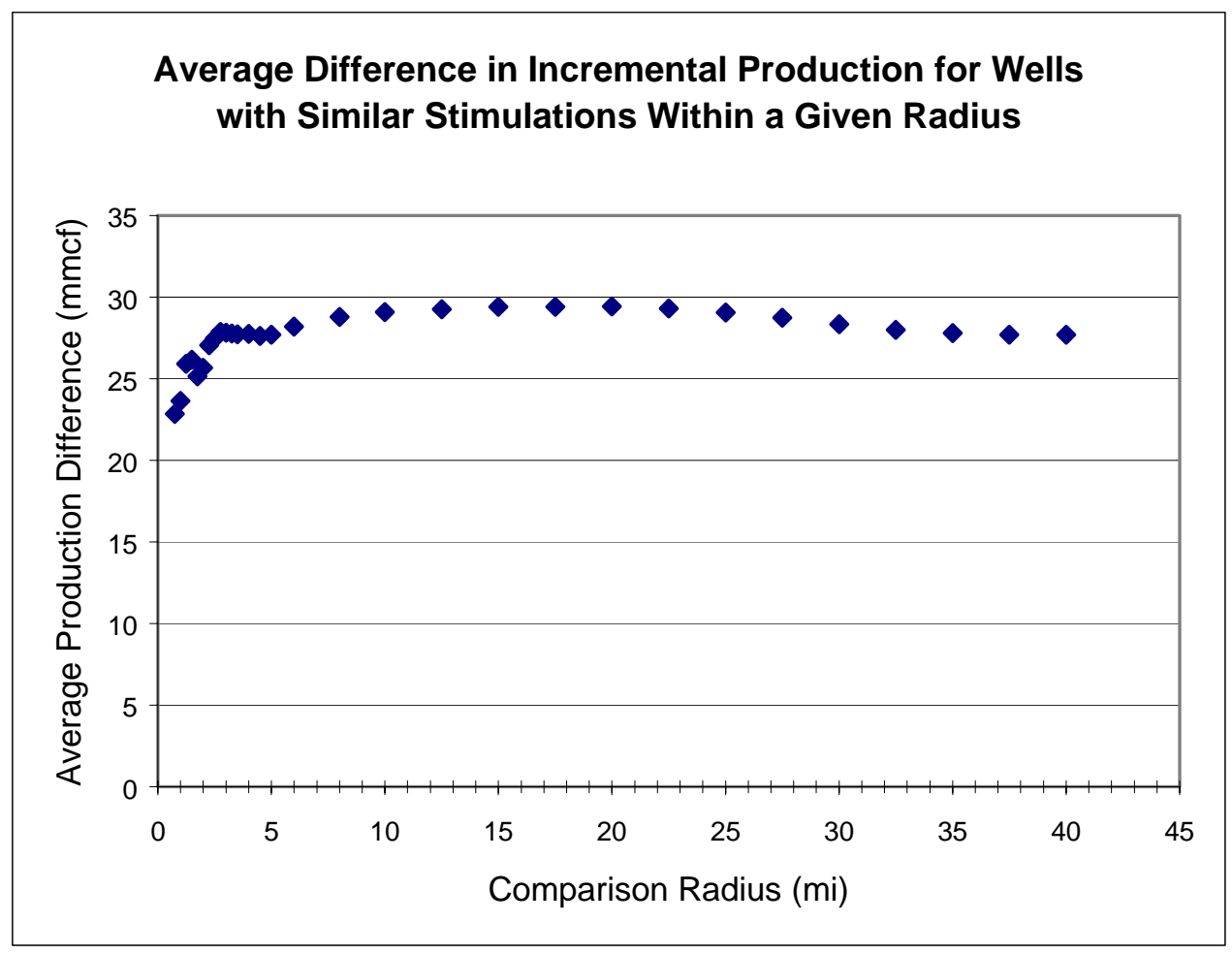

Figure 5.9. Average difference in incremental production for wells with similar stimulations within a given radius. 


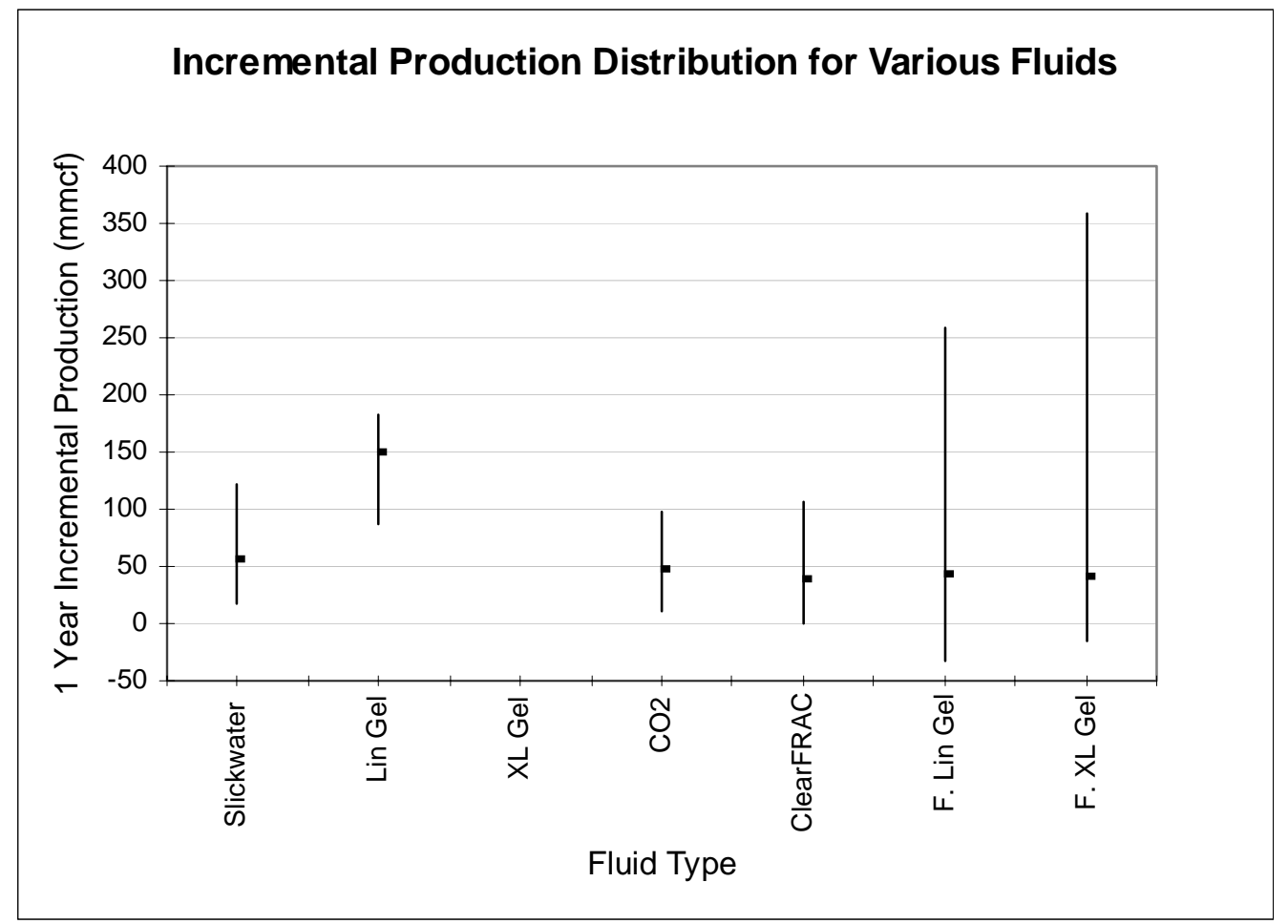

Figure 5.10a. Incremental production range for various fluids including failed and unusually productive wells (tick marks indicate mean production).

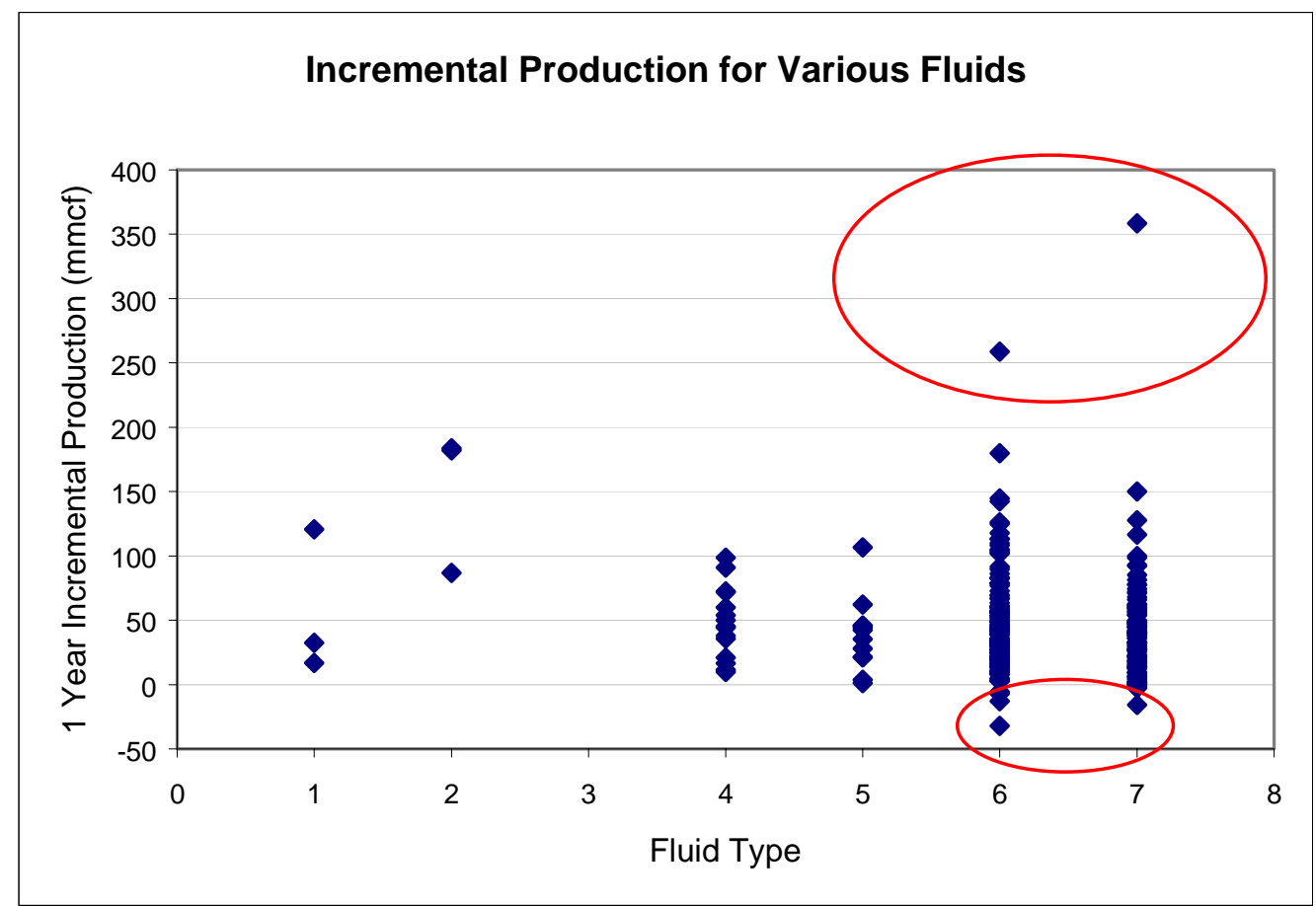

Figure 5.10b. Incremental production values for various fluids including failed and unusually productive wells (ellipses show discarded values; numbers on x-axis correspond to fluid types in figure 5.10a). 


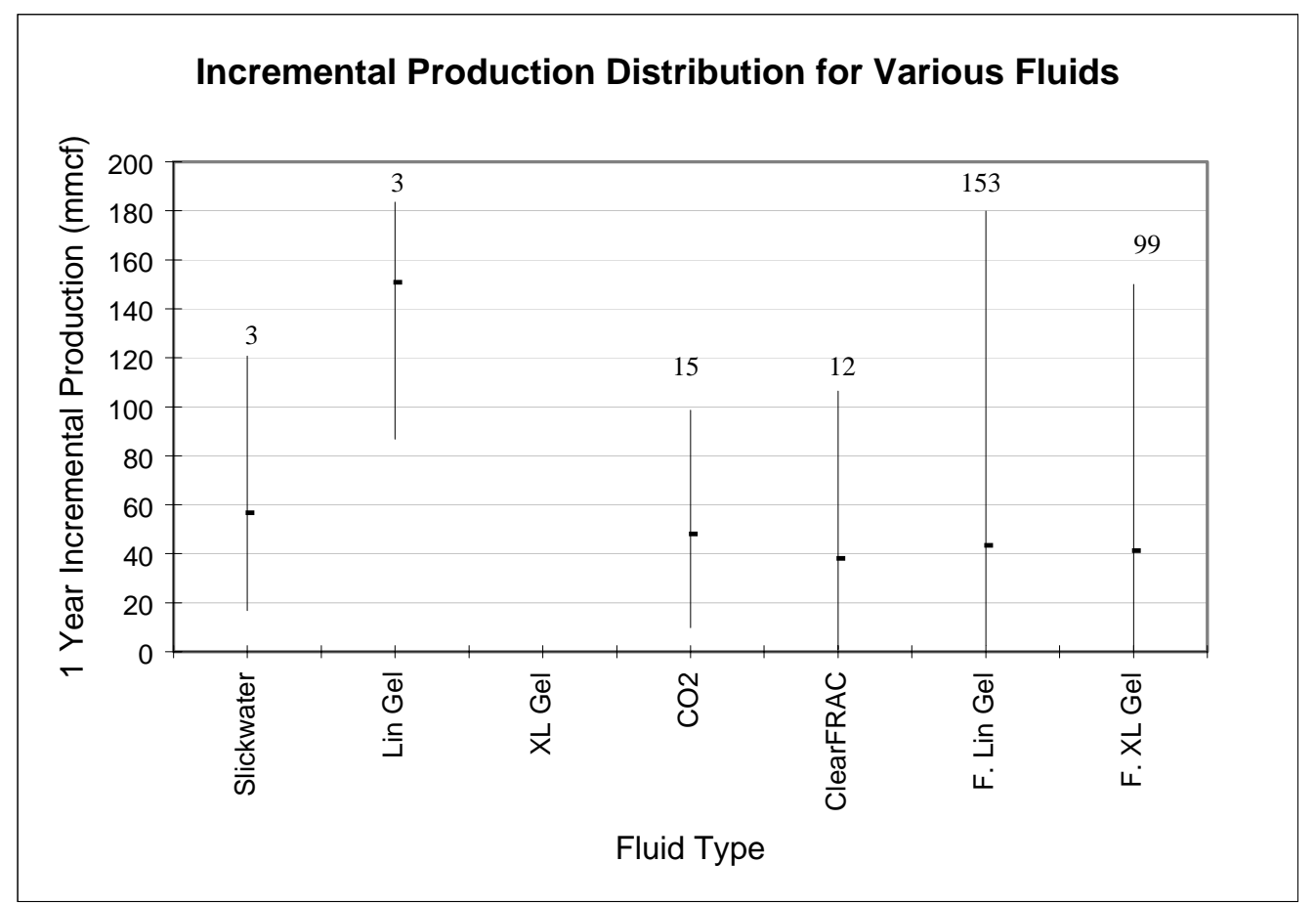

Figure 5.11. Incremental production range for various fluids excluding rejected wells (tick marks indicate mean production; values indicate number of wells).

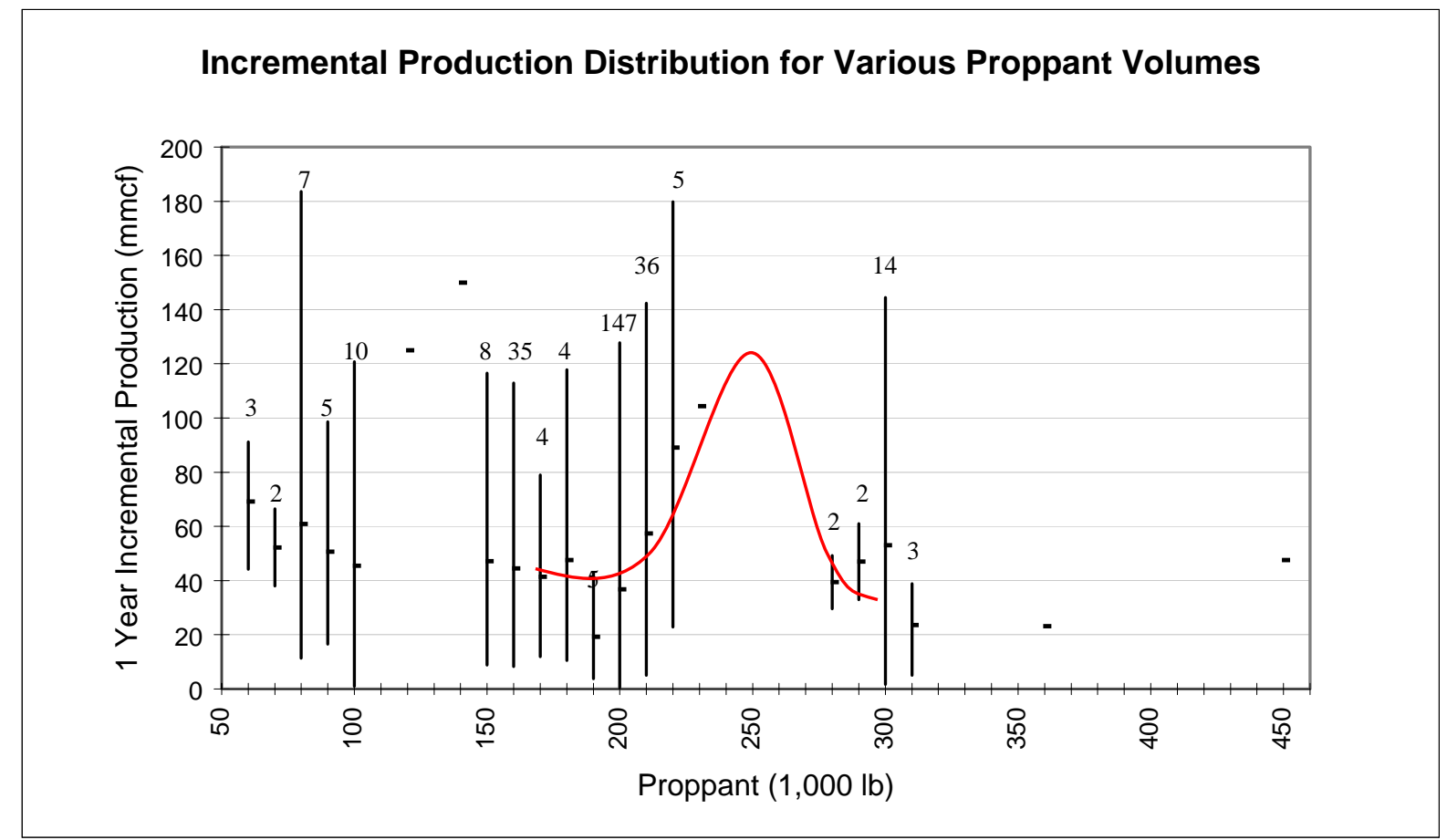

Figure 5.12. Incremental production range for various proppant volumes excluding rejected wells (tick marks indicate mean production; values indicate number of wells; curve shows apparent trend). 


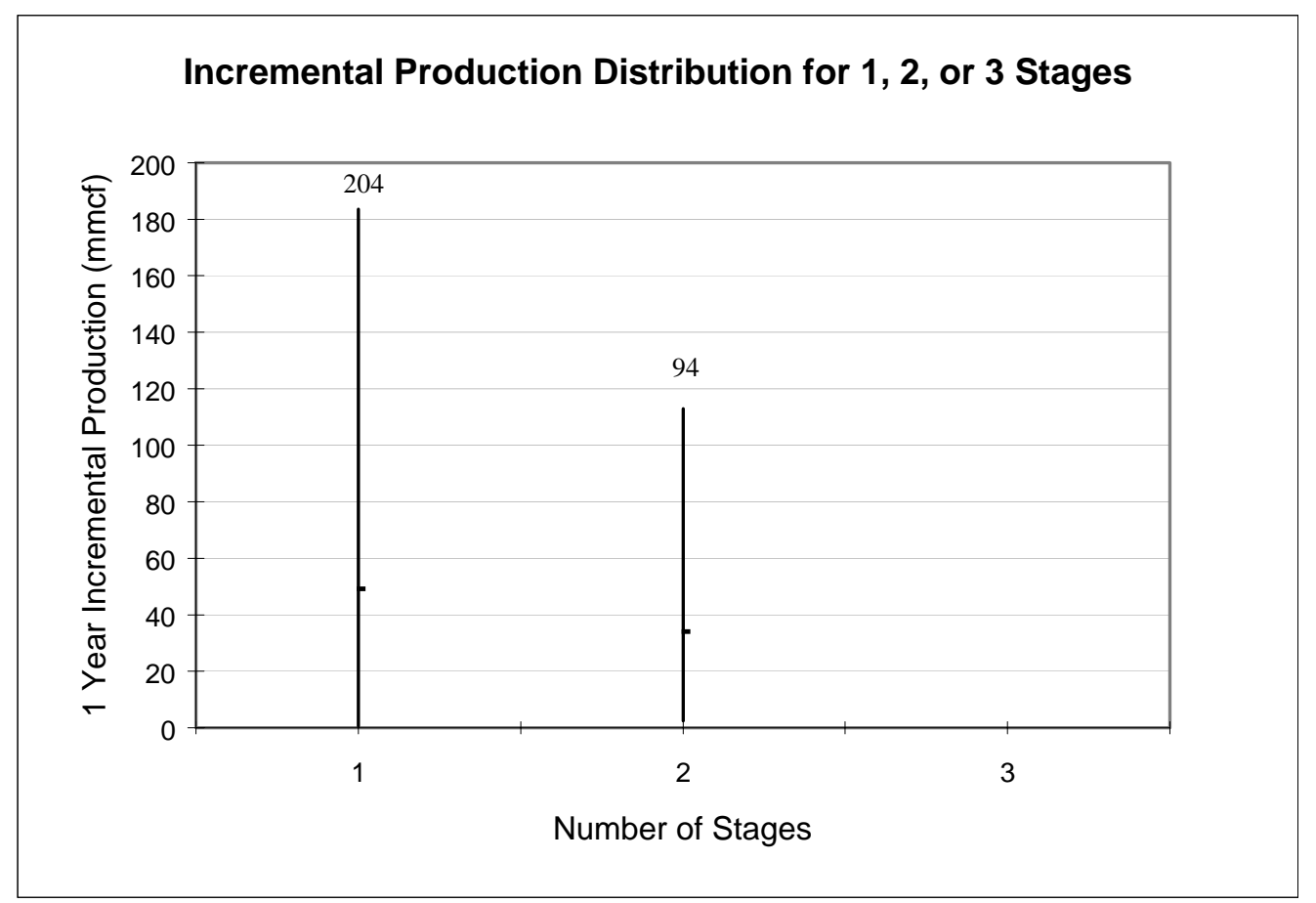

Figure 5.13. Incremental production range for various number of stages excluding rejected wells (tick marks indicate mean production; values indicate number of wells).

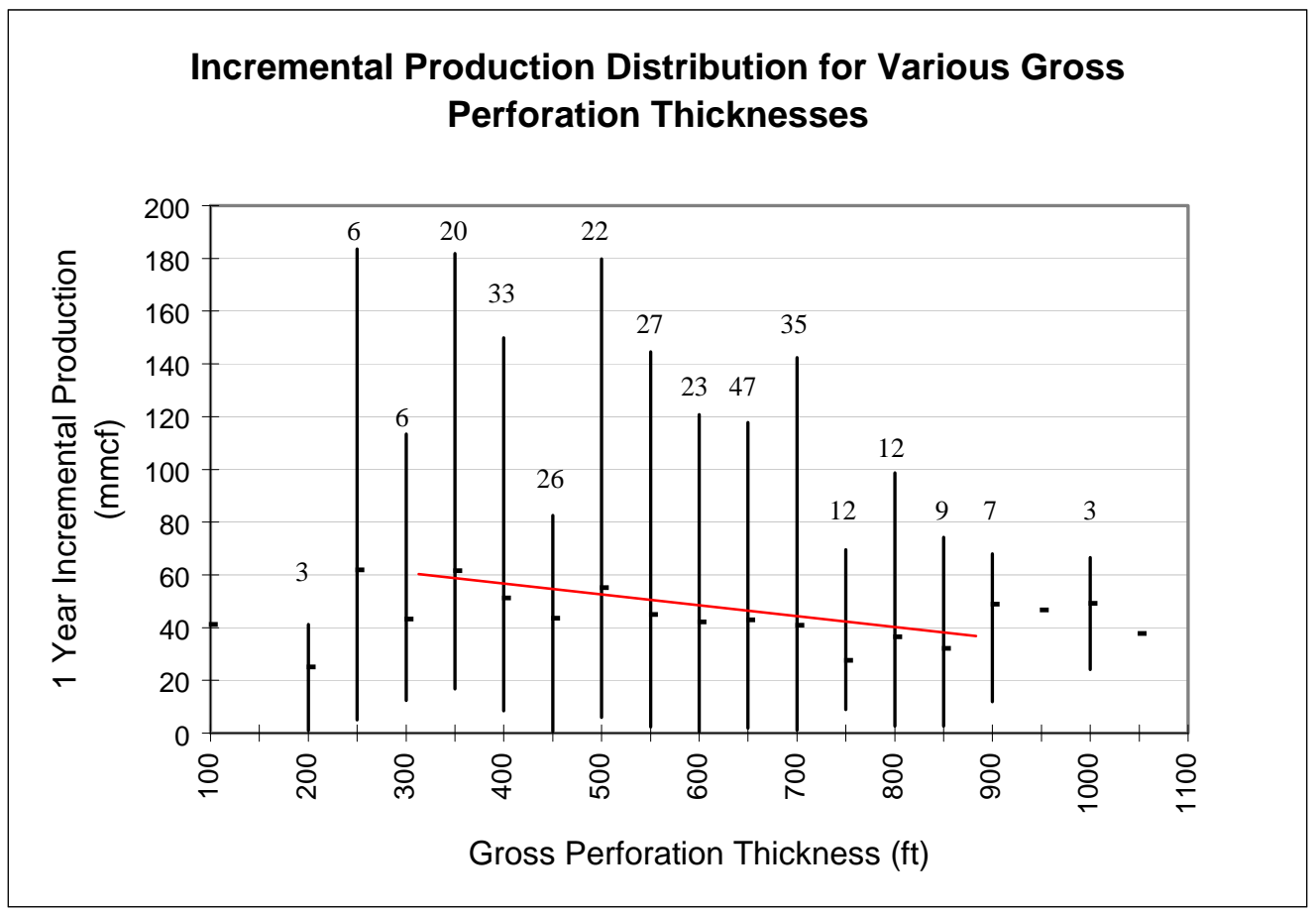

Figure 5.14. Incremental production range for various gross perforation thicknesses excluding rejected wells (tick marks indicate mean production; values indicate number of wells; line shows apparent trend). 


\section{CHAPTER 6}

\section{Analytical and Numerical Procedures and Tools Developed for Production and Well Testing Analysis of Tight-Gas Reservoirs}

In Phase II, analytical and numerical procedures and tools were developed for production and well testing analysis of tight-gas reservoirs and applied to field studies. These procedures and tools address issues related to estimation of reservoir production/flow characteristics, determination of reservoir permeability anisotropy and well interference, delineation of the drainage volume/area, and evaluation of infill well potential. A description of these procedures and tools and their applications are documented in a series of papers presented and published in proceedings of Society of Petroleum Engineers conferences. These papers are briefly summarized in this chapter.

\section{A Quick Method to Diagnose Flow Anisotropy Using Interference Data by H.Y. Chen, D.T. Hidayati, and L.W. Teufel, SPE paper 60290, presented at the SPE Rocky Mountain Regional/Low Permeability Reservoirs Symposium, Denver, Colorado, 12-15 March 2000.}

Flow/permeability anisotropy (directional variation) is common in tight gas reservoirs due to heterogeneity and natural fracturing. Optimum production strategies involving well pattern/spacing and infill drilling are highly influenced by flow anisotropy. Multiwell interference testing is the best method to determine the permeability anisotropy (magnitude and orientation) at the well-reservoir scale. This paper describes a simple method to diagnose the existence of flow/permeability anisotropy using pressure interference data. The method is based on a log-log plot of pressure-change versus time/distance. In addition, the well-pattern quadrant in which the orientation of flow/permeability anisotropy oriented can be identified within a range of 45 degrees, and the degree/contrast of anisotropy can be described qualitatively from the diagnosis plot. Examples based on simulated (analytical and numerical) and published field data are given to show the utility of the technique.

\section{A New Rate-Time Type Curve for Analysis of Tight-Gas Linear and Radial Flows by H.Y. Chen and L.W. Teufel, \\ SPE Paper 63094, presented at the SPE Annual Technical Conference and Exhibition, Dallas, Texas, 1-4 Oct. 2000.}

Tight-gas reservoirs are reservoirs with in situ gas permeability of $0.1 \mathrm{md}$ or less. Tightgas wells require hydraulic fracturing (often a massive scale) for economic production. The created long fracture coupled with the tight permeability imparts linear flow into an otherwise radial flow pattern for a significant time frame. Linear/near-linear flow has been observed at virtually all major tight-gas fields/basins in the United States. Analysis 
and modeling of such a linear/near-linear flow is extremely important, because the economic successfulness of a tight-gas well is determined primarily by the "stimulated" transient-flow phase. This paper presents a new set of Fetkovich type curves for production data analysis. The set extends early-time flow regime to include near-linear up to pure-linear flow, which are lacking in the original set. The proposed set is general but is particularly suitable for tight-gas wells due to the inclusion of the often-observed pureand near-linear flow behavior. Theory of cross type curves between rate, cumulative production, and time is presented as well as the methodology of cross type-curve matching. Examples are given to show the applicability of the type curves for tight-gas evaluation.

\section{Understanding the Effects of Reservoir and Operating Parameters on Tight-Gas Production Decline \\ by H.Y. Chen and L.W. Teufel, \\ SPE Paper 71066, presented at the SPE Rocky Mountain Petroleum Technology Conference, Keystone, Colorado, 21-23 May 2001.}

This paper presents a systematic analysis of production decline of tight-gas wells. The roles of fluid-reservoir and operating parameters on the flow rate, decline rate, decline exponent, productivity factor, ultimate recovery, and recovery factor are identified based on seven performance indicators. These seven indicators can be obtained easily by typecurve matching of production data (inverse study) or by simple computation using the presented equations (forward study). An action-reaction chart is constructed to provide a "quick-look" for the impacts (benefits or/and trade-offs) of actions (changes in reservoir/operating parameters) on the seven types of well performance (reactions). Among all the actions considered, well-stimulation and well-spacing result in the most complicated reactions. They are also the two engineering issues most pertinent to tightgas developments. Their impacts are demonstrated by numerical examples.

\section{A Type-Curve-Based Spreadsheet Program for History Matching and Forecasting Tight-Gas Production}

by J.D. Munoz, H.Y. Chen and L.W. Teufel,

SPE Paper 71067, presented at the SPE Rocky Mountain Petroleum Technology Conference, Keystone, Colorado, 21-23 May 2001.

This paper describes an Excel $^{\mathrm{TM}}$ spreadsheet program for history matching and forecasting production of tight-gas wells. The program is based on a set of recently developed type-curves. This set includes pure- and near-linear flow regimes that are lacking in the original Fetkovich type-curves, but are important for tight-gas production data analysis. The program provides constrained cross-matching between rate, cumulative production, and time to obtain a unique and consistent interpretation regardless of the type of analysis. Main features of data input, cross-type-curve matching, parameter estimations, and forecasting are described using a field example from San Juan Basin and a numerically simulated example. The spreadsheet program provides a simple 
method to quickly analyze production data when no other means is available, or when a quick-look is needed before a detailed study. The developed program is for general purposes, however, is most attractive for low-permeability, hydraulically-fractured wells because of the likely occurrence of long-transient, strongly-liner flow.

\section{Using Streamlines To Identify Drainage Volumes and Infill Locations of Tight Gas Reservoirs}

by H.Y. Chen, D.T. Hidayati, and L.W. Teufel,

SPE Paper 71086, presented at the SPE Rocky Mountain Petroleum Technology

Conference, Keystone, Colorado, 21-23 May 2001.

Three main issues arise in tight-gas infill management are: (1) How to find the size and shape of the drainage volume of each well? (2) Which well is affected by which well? (3) How to monitor the readjustment of the drainage volumes under changing field conditions (e.g., new offset wells and changing well rates)? Streamline method is ideally suited to address the above issues on a routine basis. Streamlines describe flow directions (e.g., from which region to which well) and define drainage pattern at any given time. This paper presents the fundamentals and applications of streamline interpretation with emphasis on tight-gas reservoirs. An analytical model is adopted primarily to capture the unsteady nature typical for tight-gas fields. Impacts of field boundaries (closed vs. open) and permeability anisotropy on streamlines (drainage pattern) are emphasized. A field example from San Juan Basin is provided to show the application of streamline method.

\section{Well Interference in Anisotropic Tight-Gas Reservoirs: When and Where by H.Y. Chen and L.W. Teufel, SPE Paper 75692, presented at the SPE Gas Technology Symposium, Calgary, Alberta, Canada, 30 April-2 May 2002.}

Well interference is important in determining the reservoir continuity and in optimizing well spacing/pattern of tight-gas reservoirs. Field data interpretation, however, is highly uncertain. Primary reasons may include: (1) difficulty in achieving confident reservoir characterization, especially the trend of natural fracture or permeability anisotropy, (2) the general lacking of pressure measurements due to both technical and economical reasons, and (3) lack of practical techniques to assist interpretation. The objective of this study is to develop techniques for determining the time and the point at which pressure disturbances originating from two adjacent wells begin to interact, or interfere, significantly. This type of problem had been addressed by Stevens and Thodos and Warren and Hartsock. Their work, however, did not consider permeability anisotropy. This study extends their techniques to include the effect of permeability anisotropy. The developed technique provides a method to assist the interpretation of well interference issue and the optimization of well spacing/pattern in tight-gas reservoirs.

\section{Estimating Gas Decline-Exponent before Decline-Curve Analysis}

by H.Y. Chen and L.W. Teufel, 
SPE Paper 75693, presented at the SPE Gas Technology Symposium, Calgary, Alberta, Canada, 30 April-2 May 2002.

This paper presents simple and practical equations to estimate a priori the declineexponent for decline-curve analysis of gas wells. The proposed equations are applicable for gas wells with closed boundaries and constant rock properties. Data required includes initial reservoir pressure, bottomhole flowing pressure, and fluid properties. These data are that required in a typical decline-curve analysis (i.e., no extra data is required). A field example is presented to verify the developed concept and to demonstrate the utility.

\section{Timing and Distance of Well Interference in Anisotropic Reservoirs} by H.Y.Chen, H.Y. and L.W. Teufel, SPE Paper 77455, presented at the SPE Annual Technical Conference and Exhibition, San Antonio, Texas, 29 Sept.-2 Oct. 2002.

Well interference is important in determining the reservoir continuity and in optimizing well spacing/pattern of tight-gas reservoirs. Field data interpretation, however, is highly uncertain. Primary reasons may include: (1) difficulty in achieving confident reservoir characterization, especially the trend of natural fracture or permeability anisotropy, (2) the general lacking of pressure measurements due to both technical and economical reasons, and (3) lack of practical techniques to assist interpretation. The objective of this study is to develop techniques for determining the time and the point at which pressure disturbances originating from two adjacent wells begin to interact, or interfere, significantly. This type of problem had been addressed by Stevens and Thodos, and Warren and Hartsock. Their work, however, did not consider permeability anisotropy. This study extends their techniques to include the effect of permeability anisotropy. The developed technique provides a method to assist the interpretation of well-interference issue and the optimization of well spacing/pattern in tight-gas reservoirs.

\section{A Quick Method to Determine Permeability-Anisotropy Orientation from Interference Testing}

by H.Y. Chen and L.W. Teufel, SPE Paper 84090, presented at the SPE Annual Technical Conference and Exhibition, Denver, Colorado, U.S.A, 5-8 Oct. 2003.

This paper provides a quick method to estimate the orientations of permeability/flow anisotropy from pressure interference responses only. The method can identify a 90degree range of the anisotropy orientation from two observation-well responses and a range approximately 45-degree (or less under favorable conditions) from three observation-well responses. Formal analysis (such as type-curve or simulation matching) and information of reservoir-fluid properties are not required. Significances of the developed method are: (1) It provides solution bound that contains the unique solution (if exists). (2) It may be the only solution obtainable if the adopted formal method (such as Papadopulos-Ramey procedure) fails (which is not known a priori). (3) It provides the 
most desirable information, namely, the anisotropy orientation, from a time-consuming and expensive (e.g., lost production) interference test. (4) It can be implemented for two observation wells. The validity of the developed method is demonstrated by one ideal and two field examples. We strongly recommend the developed method as part of “diagnosis” prior to any formal interference-testing analysis. 


\section{CHAPTER 7}

\section{Technology Transfer and Industry Impact}

The U. S. Bureau of Land Management (BLM) recognized the importance and impact of the project on resource development and management of oil and gas in the San Juan Basin. New Mexico Tech conducted a study and completed a report for the BLM entitled "Oil and Gas Resource Development for the San Juan Basin, New Mexico: 20 year, Reasonable Foreseeable Development (RFD) Scenario Supporting the Resource Management Plan for the Farmington Field Office, Bureau of Land Management." The report was published in July 2001. The objective of this study was to determine the subsurface development supported by geological and engineering evidence, and to further estimate the associated surface impact of this development in terms of actual wells drilled. For the major existing producing reservoirs, two approaches were used to predict development potential. The first approach was a survey of operating companies in the San Juan Basin, obtaining their perspective of future development based on current reservoir management practices. The second approach applied engineering techniques developed in this project to optimize infill drilling in naturally fractured, tight-gas reservoirs in the basin.

Burlington Resources and BP were granted permission to site new well locations based on the concept of elliptical drainage area and drainage pattern of previously drilled wells. Typically, wells are drilled on a given well spacing and pattern (usually square) that is specified by the New Mexico Oil and Gas Conservation Commission. For certain formations, gas operators have been able to convince the commission to reduce well spacing so that additional reserves could be produced. This was the first approved deviation in the Mesaverde tight gas sandstone reservoirs based on elliptical drainage patterns to prevent well interference and increase recoverable gas reserves in the San Juan Basin, and the approval was a direct result of this project.

Tight-gas sandstone reservoirs throughout the Rocky Mountain region are economically producible because of natural fracturing. Natural fractures exist in the Mesaverde and Dakota sandstones of the San Juan Basin, but their distribution, intensity and orientation varies within the basin. Thus, there are areas of high and lower gas productivity depending on the degree of fracturing. Reservoir studies conducted for this project of four pilot areas in the Mesaverde that have significantly different well/reservoir productivity demonstrate the range of importance that natural fractures and the associated reservoir permeability and permeability anisotropy have on drainage efficiency and infill well potential, and that proper evaluation methods are useful in identifying the best well locations. Evaluation techniques include: (1) Log-derived cumulative distributions to develop producing interval limits, (2) Core, log and seismic analyses to identify fractures, (3) Type-curve decline analysis to generate reservoir properties, (4) Production decline analysis for establishing inter-well relationships, (5) Geostatistical modeling to distribute reservoir characteristics, and (6) Flow simulation for verification and formation 
contribution. The result of incorporating these evaluation methods is a map that provides limits to the well drainage areas and identifies the optimal location of infill wells. Methodology can be applied to naturally-fractured tight gas reservoirs throughout the Rocky Mountain region.

The 30-year production forecast of the reservoir models predicts a total net increase in recoverable gas for 80-acre spacing for two pilot areas in the Mesaverde of 26 percent and 44 percent over the predicted gas recovery of existing wells on 160-acre spacing. Extrapolation of the results from these two pilots across the Mesaverde producing area in the San Juan Basin provides a preliminary estimate of an additional 7.8 Tscf that could be recovered by optimal infill drilling.

Analytical and numerical procedures and tools were developed for production and well testing analysis of tight-gas reservoirs and applied to field studies. These procedures and tools address issues related to estimation of reservoir production/flow characteristics, determination of reservoir permeability anisotropy and well interference, delineation of the drainage volume/area, and evaluation of infill well potential. A description of these procedures and tools and their applications are documented in a series of papers presented and published in proceedings of Society of Petroleum Engineers conferences.

Fracture swarms have been identified from 3-D seismic analysis of horizon curvature attributes and confirmed by production decline analysis. Curvature attributes are generated using Curvz; a Windows-compatible software package developed during the project and may be obtained free at http://eps.mcgill.ca/ hart/CURVZ_website.htm. More than 60 downloads have occurred at this site during 2003.

Resevoir characterization and simulation studies in three Dakota Formation pilot areas demonstrate that optimization of infill drilling in the Dakota relies upon two inter-related features: (1) the degree of natural fracturing and (2) the depositional facies.

Vertical wells in tight gas reservoirs are always stimulated to increase production. In Phase II, evaluation of fracture stimulation treatments was accomplished by integrated reservoir description and fracture treatment analysis of the Lewis Shale in the San Juan Basin. Based on the available data and the methods used, the optimum stimulation procedure for the Lewis Shale, throughout the San Juan Basin, is a single-stage, 150,000 lb foamed linear gel, hydraulic fracture treatment. However, based on preliminary results from a small number of completions, it is recommended that slickwater designs be analyzed further to determine whether they would have better results.

\section{Bibliography}

Engler, T., B. Brister, H.Y. Chen, and L.W. Teufel: "Oil and Gas Resource Development for the San Juan Basin, New Mexico: 20 year, Reasonable Foreseeable Development (RFD) Scenario Supporting the Resource Management Plan," Final Report to New Mexico U. S. Bureau of Land Management, July 2001. 


\section{NOMENCLATURE}

$$
\begin{aligned}
& A=\text { drainage area; }=w L \text { (linear); }=\sigma \pi\left(r_{e}{ }^{2}-r_{w}{ }^{2}\right)(\text { radial }), \mathrm{ft}^{2} \\
& b=\text { decline exponent, dimensionless } \\
& B=\mathrm{FVF}, \mathrm{rb} / \mathrm{stb} \text { (liquid) and rb/Mscf (gas) } \\
& B_{1}=2 \text { (linear); = } f\left(r_{e D}\right) \text { (radial) } \\
& c=\text { compressibility, } \mathrm{psi}^{-1} \\
& c_{t}=\text { saturation-weighted total compressibility, } \mathrm{psi}^{-1} \\
& \text { CUM = cumulative production } \\
& D_{i}^{*}=\text { “extrapolated” initial decline-rate, } \text { day }^{-1} \\
& \text { EUR = estimated ultimate recovery, stb (liquid) and Mscf (gas) } \\
& h=\text { net or producing thickness, } \mathrm{ft} \\
& \text { IHCIP = initial hydrocarbon-in-place, MMstb (liquid) and Bscf (gas) } \\
& \text { IGIP = initial gas-in-place, } \text { Bscf } \\
& k=\text { permeability, md } \\
& L=\text { drainage length of a linear reservoir, } \mathrm{ft} \\
& L_{f}=\text { fracture half-length, } \mathrm{ft} \\
& p=\text { pressure, } \mathrm{psi} \\
& p_{i}=\text { initial reservoir pressure, } \mathrm{psi} \\
& p_{p}(p)=\int_{p_{r e f}}^{p} \frac{\mu_{g i} B_{g i}}{\mu_{g} B_{g}} \mathrm{~d} p^{\prime}=\int_{p_{r e f}}^{p} \frac{p / \mu_{g} z}{p_{i} / \mu_{g i} z_{i}} \mathrm{~d} p^{\prime} \text {, dry-gas pseudopressure, psi } \\
& p_{w f}=\text { well flowing pressure, psi } \\
& P F=\text { productivity factor, stb/d/psi (liquid) and Mscf/d/psi (gas) } \\
& P V=\text { pore volume, MMstb (liquid) and Bscf (gas) }
\end{aligned}
$$




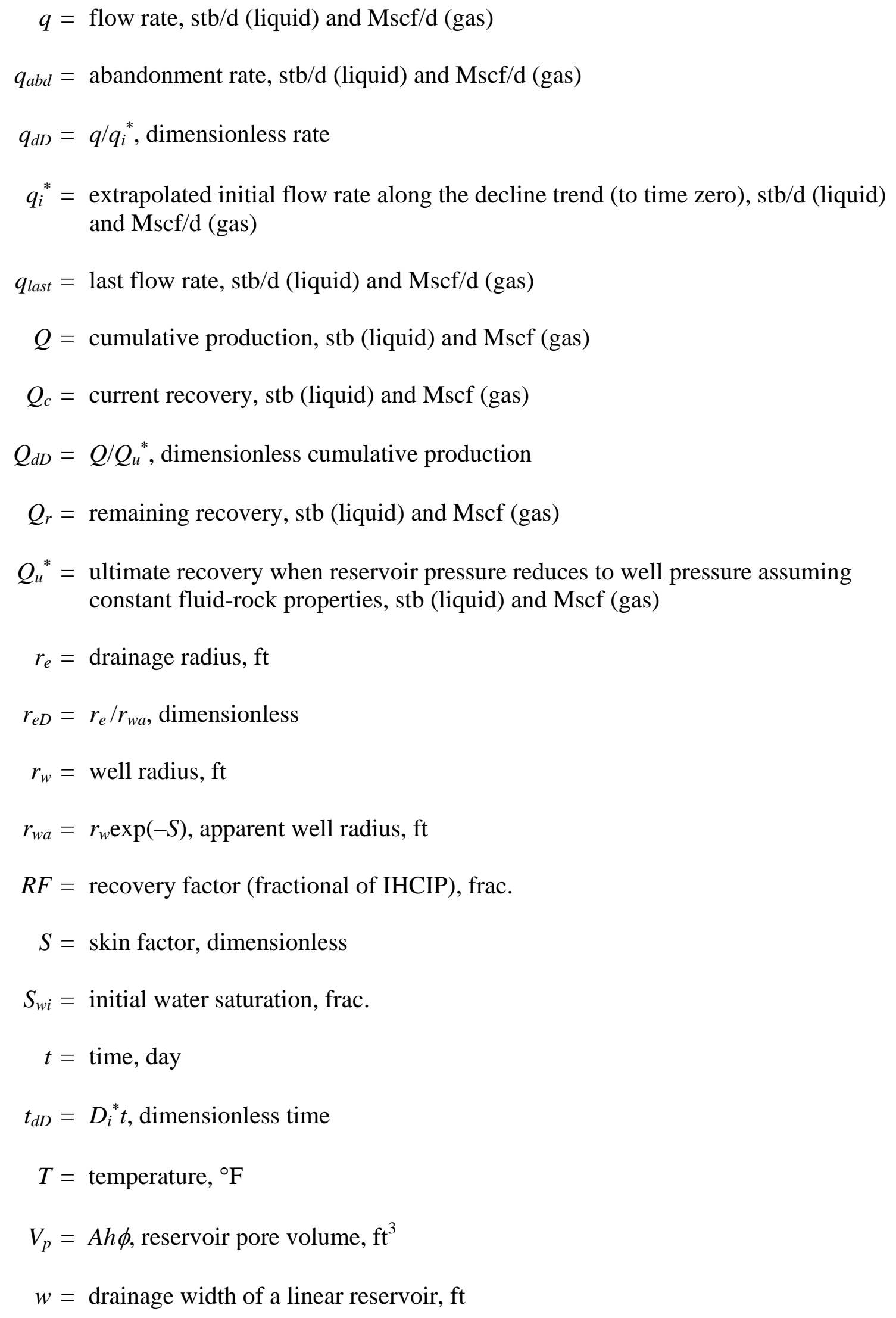




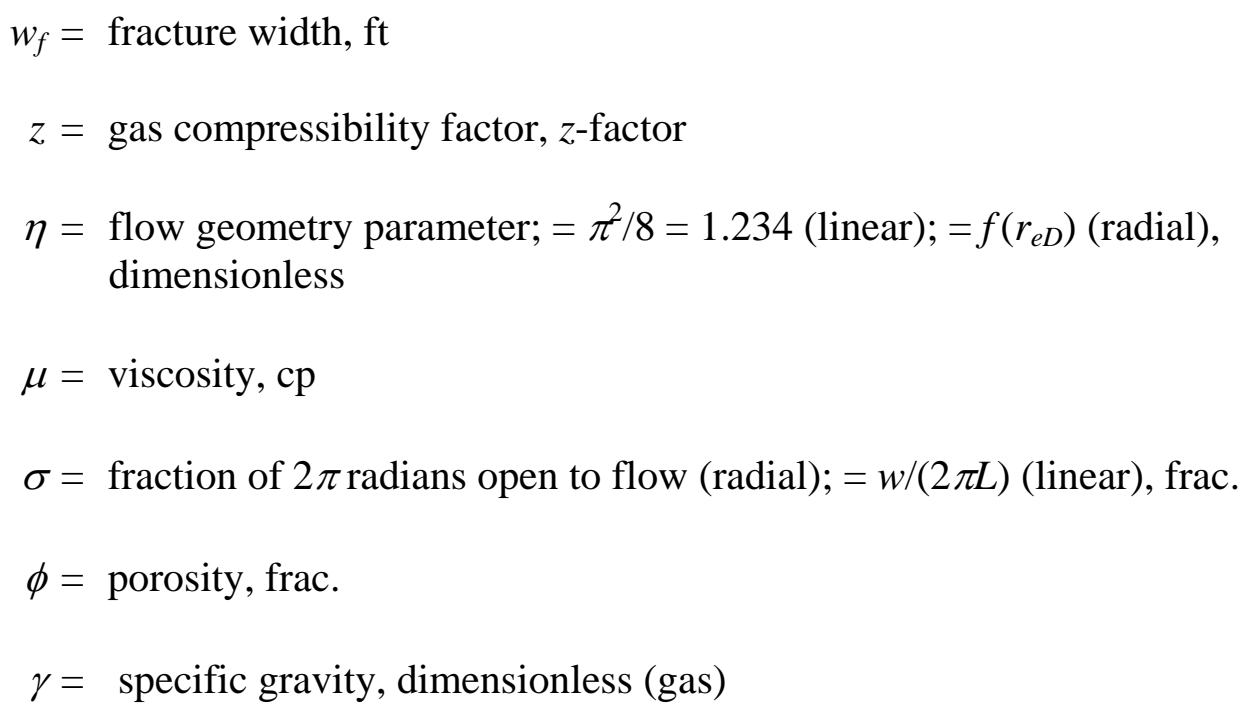

\section{Subscripts}

$$
\begin{aligned}
& c=\text { current } \\
& f=\text { formation } \\
& g=\text { gas } \\
& i=\text { initial } \\
& \mathrm{M}=\text { match point } \\
& r e f=\text { reference } \\
& u=\text { ultimate } \\
& w=\text { water }
\end{aligned}
$$

\section{Superscripts}

* = extrapolated 


\section{SI Metric Conversion Factors}

$$
\begin{aligned}
& \text { bbl } \times 1.589873 \quad \text { E-01 ....................... }=\mathrm{m}^{3} \\
& \mathrm{cp} \times 1.0^{*} \quad \mathrm{E}-03 \ldots \ldots \ldots \ldots \ldots \ldots \ldots . . . .=\mathrm{Pa} \cdot \mathrm{s} \\
& \mathrm{ft} \times 3.048 * \quad \mathrm{E}-01 \ldots \ldots \ldots \ldots \ldots \ldots \ldots \ldots . . . . . . . . . . . . . m \\
& \mathrm{ft}^{2} \times 9.290304 * \mathrm{E}-02 \ldots \ldots \ldots \ldots \ldots \ldots \ldots \ldots . . .=\mathrm{m}^{2} \\
& \mathrm{ft}^{3} \times 2.831685 \quad \mathrm{E}-02 \ldots \ldots \ldots \ldots \ldots \ldots \ldots \ldots . . .=\mathrm{m}^{3} \\
& \mathrm{md} \times 9.869233 \quad \mathrm{E}-04 \ldots \ldots \ldots \ldots \ldots \ldots \ldots . . .=\mu \mathrm{m}^{2} \\
& \mathrm{psi} \times 6.894757 \mathrm{E}+00 \ldots \ldots \ldots \ldots \ldots \ldots \ldots \ldots . . .=\mathrm{kPa}
\end{aligned}
$$

* Conversion factor is exact. 